Portland State University

PDXScholar

\title{
Reducing Seismic Risk to Highway Mobility: Assessment and Design Examples for Pile Foundations Affected by Lateral Spreading
}

\author{
Scott A. Ashford \\ Oregpn State University \\ Michael H. Scott \\ Oregon State University \\ Deepak Rayamajhi \\ Oregon State University
}

Follow this and additional works at: https://pdxscholar.library.pdx.edu/trec_reports

Part of the Structural Engineering Commons, Transportation Commons, and the Transportation Engineering Commons

Let us know how access to this document benefits you.

\section{Recommended Citation}

Ashford, S.A., Scott, M.H. and Rayamajhi, D., Reducing Seismic Risk to Highway Mobility: Assessment and Design of Pile Foundations Affected by Lateral Loading (No. OTREC-RR-13-05). Portland, OR:

Transportation Research and Education Center 2013. https://doi.org/10.15760/trec.66

This Report is brought to you for free and open access. It has been accepted for inclusion in TREC Final Reports by an authorized administrator of PDXScholar. Please contact us if we can make this document more accessible: pdxscholar@pdx.edu. 

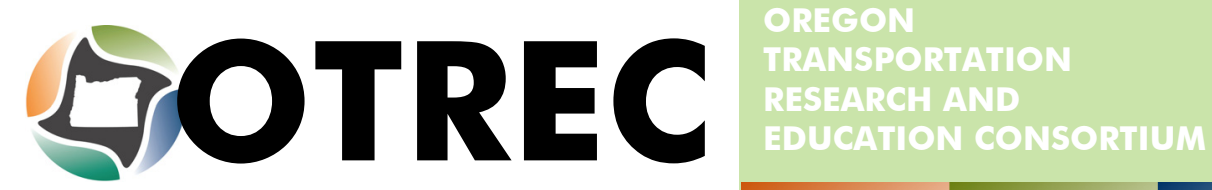

FINAL REPORT

\section{Reducing Seismic Risk to Highway Mobility: Assessment and Design Examples for Pile Foundations Affected by Lateral Spreading}

OTREC-RR-13-05

April 2013 



\title{
REDUCING SEISMIC RISK TO HIGHWAY MOBILITY: ASSESSMENT AND DESIGN EXAMPLES FOR PILE FOUNDATIONS AFFECTED BY LATERAL SPREADING
}

\author{
Final Report
}

SRS 500-300

OTREC-RR-13-05

by

\author{
Scott A. Ashford \\ Oregon State University \\ Michael H. Scott \\ Oregon State University \\ Deepak Rayamajhi \\ Oregon State University \\ for \\ Oregon Department of Transportation \\ Research Unit \\ 200 Hawthorne Ave. SE, Suite B-240 \\ Salem, Oregon 97301-5192 \\ and \\ Oregon Transportation Research \\ and Education Consortium (OTREC) \\ P.O. Box 751 \\ Portland, OR 97207
}

April 2013 



\section{Technical Report Documentation Page}

\begin{tabular}{l|l|l}
\hline $\begin{array}{l}\text { 1. Report No. } \\
\text { OTREC-RR-13-05 }\end{array}$ & 2. Government Accession No. & 3. \\
\hline
\end{tabular}

\section{Title and Subtitle}

Reducing Seismic Risk to Highway Mobility: Assessment and Design of Pile Foundations Affected by Lateral Loading

\section{Author(s)}

Scott A. Ashford, Oregon State University; Michael H. Scott, Oregon State University; and Deepak Rayamajhi, Oregon State University

9. Performing Organization Name and Address

\section{Scott A. Ashford}

Oregon State University

School of Civil and Construction Engineering

101 Kearney Hall

Corvallis, OR 97331

12. Sponsoring Agency Name and Address

Oregon Transportation Research

and Education Consortium (OTREC)

P.O. Box 751

Portland, Oregon 97207 and

Oregon Department of Transportation Research Unit

200 Hawthorne Ave. SE, Suite B-240

Salem, Oregon 97301-5192
3. Recipient's Catalog No.

5. Report Date

April 2013

6. Performing Organization Code

8. Performing Organization Report No.

Kiewit-2012/06

10. Work Unit No. (TRAIS)

11. Contract or Grant No.

15. Supplementary Notes

\section{Abstract}

Damage in pile supported structures due to liquefaction and liquefaction induced deformation were reported in past earthquakes around the world (e.g., Ansal et al. 1999; Seed et al. 1990; EERI 2010, EERI 2011; GEER 2010a, GEER 2010b, GEER 2011). For example, a reconnaissance report from a recent subduction zone event, the 2010 Chile earthquake $(\mathrm{Mw}=8.8)$, showed the pervasive nature of liquefaction and liquefaction-induced lateral spreading damage to bridge foundations (GEER 2010a, Yen et al. 2011). In terms of seismic hazard, the Pacific Northwest shares similar conditions from a Cascadia Subduction Zone (CSZ) earthquake source with the expected earthquake magnitude of 9.0 (Mw) and return period of 300 years (Atwater et al. 1995, Atwater and Hemphill-Halley 1997). The risk and damage from a CSZ earthquake event is widely recognized by the Oregon Department of Transportation (ODOT) as presented in a report by ODOT (2009). A large number of bridges were found to be vulnerable to a CSZ event, and repair and replacement costs of Oregon bridges have been estimated at more than 1 billion USD (ODOT 2009). Moreover, thousands of bridges require some kind of modification and/or seismic retrofitting to the foundation in order to improve seismic performance under liquefaction induced lateral spreading.

To evaluate the seismic performance of bridge foundations and liquefaction mitigation alternatives, ODOT/OTREC funded collaborative research between Oregon State University (OSU), University of California at Davis (UCD), University of California at San Diego (UCSD), Hayward Baker Inc., and Pacific Earthquake Engineering Research Center (PEER). The main objectives of the research were to develop design charts for different liquefaction mitigation alternatives and to develop methodologies for assessing the performance of bridge pile foundations in laterally spreading ground.

The cooperative research focuses on two aspects of liquefaction and liquefaction induced lateral spreading: (1) ground improvement methods, particularly using stone columns and deep soil mixing (DSM) grids, and (2) assess the seismic performance of bridge foundations (e.g., drilled shaft, pile groups) and seismic retrofitting alternatives for the bridge foundation. Stone columns for liquefaction mitigation and pile groups foundation assessment were investigated by the OSU team, while DSM and large diameter piles/shafts alternatives were investigated by the UCD team. Research teams used OpenSees (http://opensees.berkeley.edu/), an open source computational platform for three dimensional (3D) finite element (FE) modeling and analysis. OpenSeesPL, a graphical user interface developed by the UCSD team, was used to investigate liquefaction mitigation alternatives (i.e., stone columns and DSM grids) and the performance of pile foundations in liquefaction induced laterally spreading ground.

\section{Key Words}

Liquefaction, lateral spreading, pile foundations

18. Distribution Statement No restrictions. Copies available from OTREC: www.otrec.us
19. Security Classification (of this report)

Unclassified
20. Security Classification (of this page)

21. No. of Pages
174




\section{ACKNOWLEDGEMENTS}

The authors thank the members of the Oregon Department of Transportation (ODOT) Project Technical Advisory Committee for their advice and assistance in the preparation of this report. The authors would also like to thank the Oregon Transportation Research and Education Consortium (OTREC) for funding the project and the ODOT Research Unit for managing the project.

\section{DISCLAIMER}

The contents of this report reflect the views of the authors, who are solely responsible for the facts and the accuracy of the material and information presented herein. This document is disseminated under the sponsorship of the U.S. Department of Transportation University Transportation Centers Program and the Oregon Department of Transportation in the interest of information exchange. The U.S. Government the Oregon Department of Transportation assume no liability for the contents or use thereof. The contents do not necessarily reflect the official views of the U.S. Government and the Oregon Department of Transportation. This report does not constitute a standard, specification, or regulation. 


\section{Table of Contents}

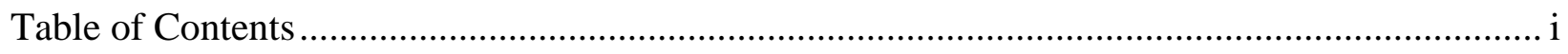

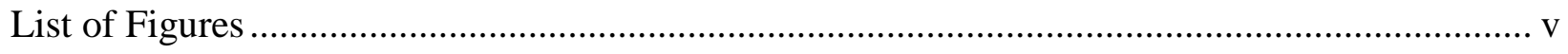

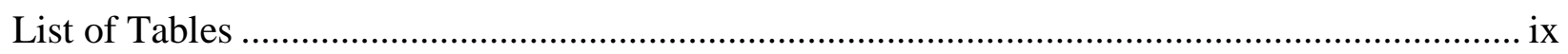

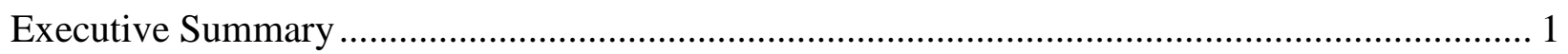

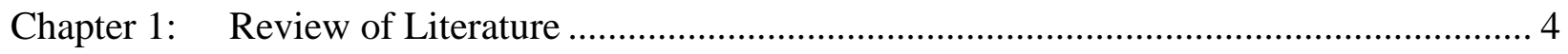

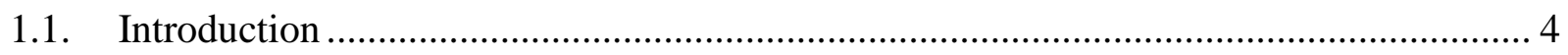

1.2. Ground Improvement Methods for Liquefaction Mitigation ...................................... 4

1.2.1. Liquefaction Mitigation using Stone Columns .................................................. 5

1.2.1.1. Densification Mechanism of Stone Columns ............................................ 9

1.2.1.2. Drainage Mechanism of Stone Columns ................................................. 12

1.2.1.3. Reinforcement Mechanism of Stone Columns ........................................... 13

1.2.1.4. Performance of Stone Columns during Earthquakes.................................. 18

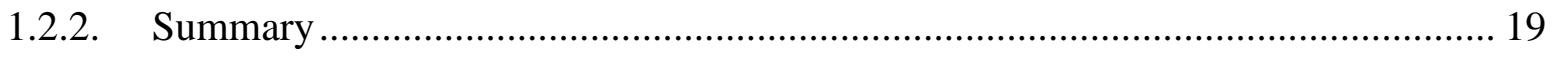

1.3. Pile Groups on Lateral Spreading Ground ........................................................ 21

1.3.1. Overview on behavior of pile groups based on experimental studies .................. 21

1.3.2. Numerical Analysis Methods for Pile Groups ............................................... 27

1.3.2.1. Limit Equilibrium Method of Analysis ................................................... 28

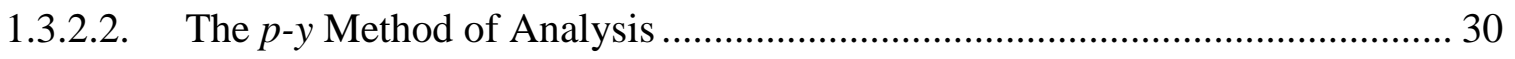

1.3.2.3. Finite Element Method of Analysis......................................................... 40

1.3.3. CALTRANS Lateral Spreading Design Guidelines ......................................... 41

1.3.3.1. Unrestrained Ground Displacement Design Case ...................................... 42

1.3.3.2. Restrained Ground Displacement Design Case......................................... 48 


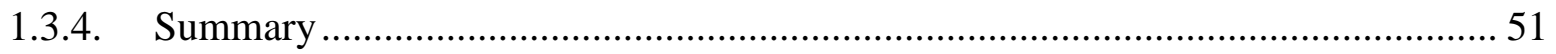

Chapter 2: Example Bridge and Liquefaction Assessment ………………………………….... 53

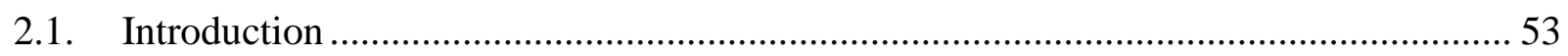

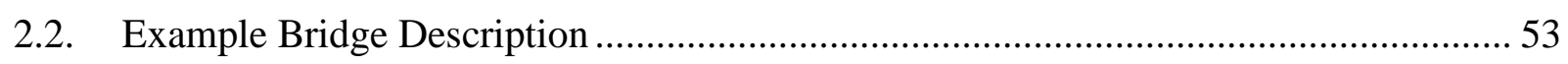

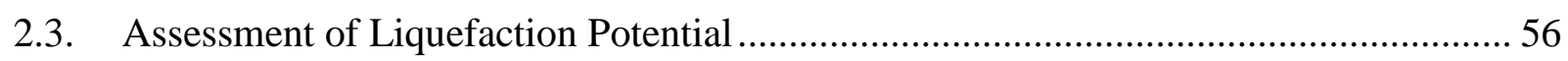

2.4. Estimation of Residual Strengths …………………................................................. 58

2.5. Estimating Lateral Spreading Displacement at Interior Bent.......................................... 60

Chapter 3: Design Example for Foundation at Bridge Interior Bent............................................ 61

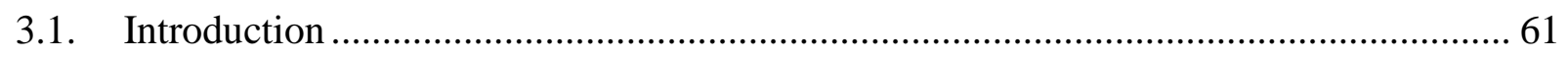

3.2. Numerical Analysis for Drilled Shaft Foundation ....................................................... 61

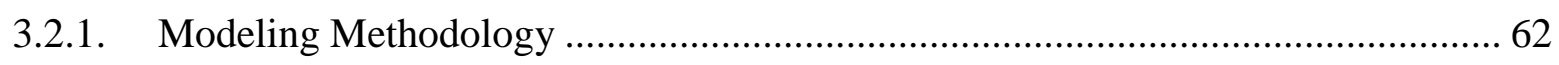

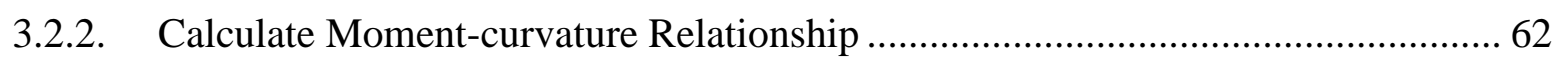

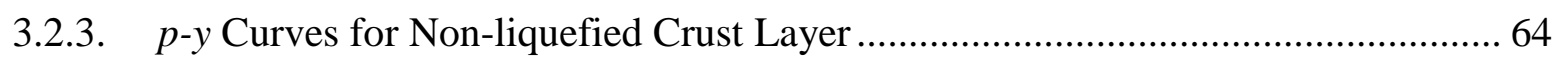

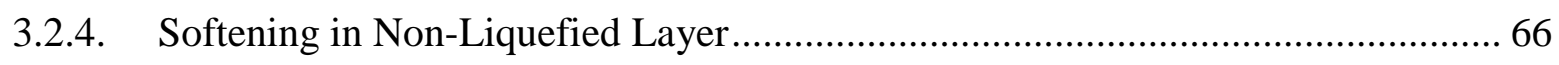

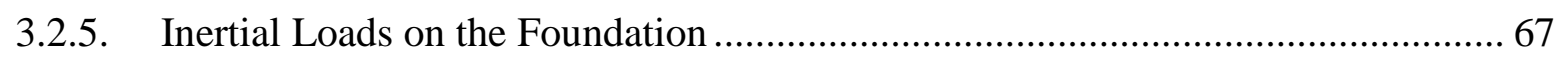

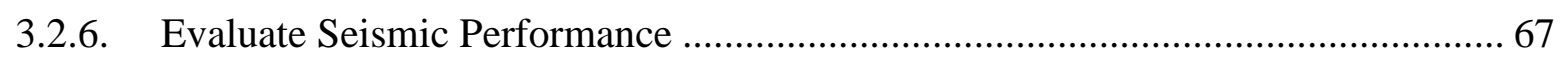

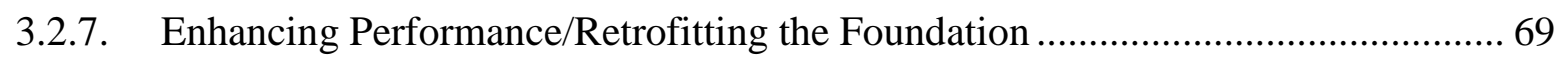

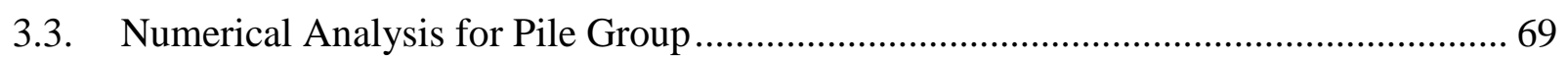

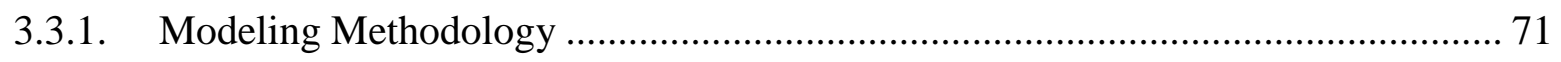

3.3.2. Calculate Moment Curvature Relationship.......................................................... 73

3.3.3. p-y Curves for Non-liquefied Crust Layer.................................................................. 74

3.3.4. Softening in Non- liquefied Layer ......................................................................... 77

3.3.5. $\quad$-y Curve Scaling Factors .................................................................................. 78

3.3.6. Rotational Stiffness for Pile Cap............................................................................ 79

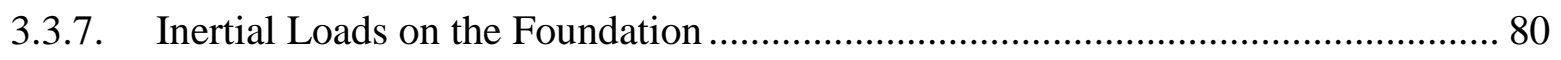




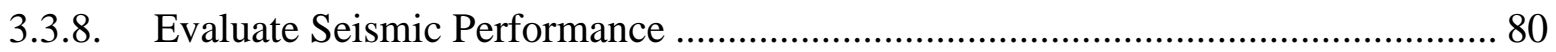

3.3.9. Enhancing Performance/Retrofitting the Pile Group Foundation............................. 82

3.3.10. Performance Enhancement by Increasing Number of Piles................................ 83

3.3.11. Performance Enhancement by Using Larger Pile ……………………............... 84

3.3.11.1. Performance Enhancement by Connecting with Additional Drilled Shafts.... 87

Chapter 4: Design Example for Foundation at Bridge Abutment ............................................... 91

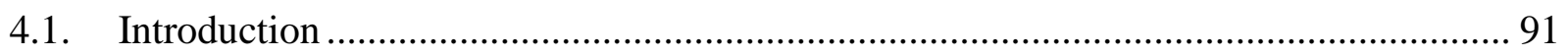

4.2. Numerical Analysis for Pile Group Foundation at Bridge Abutment ............................. 91

4.2.1. Modeling Methodology ........................................................................................... 93

4.2.2. Calculate Moment-curvature Relationship ............................................................. 93

4.2.3. p-y Curves for Non-liquefied Crust Layer.................................................................... 93

4.2.4. Softening in Non- liquefied Layer .......................................................................... 98

4.2.5. $\quad p-y$ Curve Scaling Factors ...................................................................................... 99

4.2.6. Rotational Stiffness for Pile Cap........................................................................ 99

4.2.7. Inertial Loads on the Foundation ............................................................................... 99

4.2.8. Lateral Spreading Displacement and Shear Stress in the Foundation .................. 100

4.3. Estimating Lateral Spreading displacements …………………………………......... 102

4.4. Evaluate results against foundation performance criteria .............................................. 104

4.5. Enhancing Performance/Retrofitting the Foundation ................................................... 105

4.5.1. Performance Enhancement by Increasing Number of Piles .................................. 105

4.5.2. Performance Enhancement by Connecting with Additional Drilled Shafts ......... 107

Chapter 5: Design Example for Ground Improvements ........................................................... 112

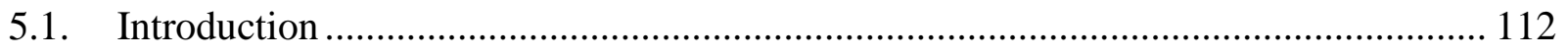

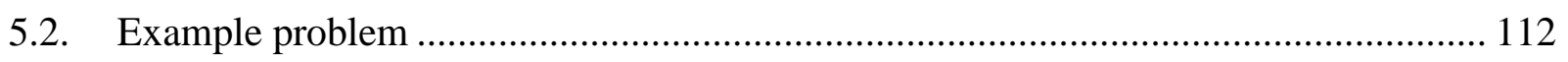

5.3. Design Calculations for Stone Column ..................................................................... 113 
5.4. Design Calculations for DSM Grids ............................................................. 116

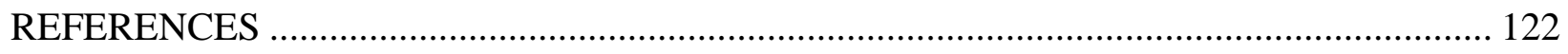

APPENDIX-A Assessing Liquefaction Potential

APPENDIX-B Residual Strength of Liquefied Soil

APPENDIX-C Estimating Lateral Spreading Displacement

APPENDIX-D Estimating p-y Curve for Pile Cap

APPENDIX-E Research Work Publications 


\section{List of Figures}

Figure number

Page

Figure 1.1: Ground improvement methods for mitigating liquefaction (Mitchell 2008) ............. 7

Figure 1.2: Stone column construction by vibro-replacement (Adalier and Elgamal 2004)........ 8

Figure 1.3: Stone columns constructed by auger-casing with internal gravel feeding compaction-rod system (after Sonu et al. 1993; Adalier and Elgamal 2004) .............. 9

Figure 1.4: Stone column arrangement and tributary area................................................... 9

Figure 1.5: Site improvement factor (n) vs normalized pre-SPT for different values Ar, for uniform fine to medium silty sands ( $<15 \%$ fine) (Baez, 1995).

Figure 1.6: Prediction of post-SPT values based on pre-SPT for different values of $A_{r}$ for uniform fine to medium silty sands (<15\% fine) (Baez, 1995) ................................ 11

Figure 1.7: Effects of area replacement ratio and shear modulus on the cyclic stress reduction factor (Baez 1995)

Figure 1.8: Shear and flexural deformation modes of a stone column (after Goughnour and Pestana 1998; Olgun and Martin 2008)................................................................ 16

Figure 1.9: Deformed shape of the soil-column system (Olgun and Martin 2008)................... 16

Figure 1.10: Percent contributions of shear and flexural modes of deformation (Green et al. 2008)

Figure 1.11: Illustration of shadowing effect (overlapping zones creating additional load on

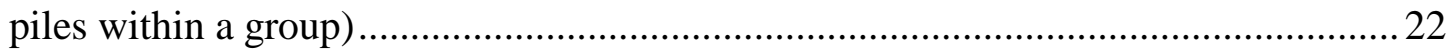

Figure 1.12: Kinematics of laterally load pile group

Figure 1.13: Illustration of kinematics of group piles in liquefaction induced lateral spreading ground (adapted from Chang et al. 2005)

Figure 1.14: Limit equilibrium method based on recommendations by (a) JRA (2002) and (b) centrifuge test results at RPI (Abdoun 1997; Dobry et al.2003)

Figure 1.15: The p-y analysis model for pile subjected to lateral spreading (adapted from Juirnarongrit and Ashford 2006) 30

Figure 1.16: The $p-y$ analysis for pile group (adapted from Juirnarongrit and Ashford 2006) ... 32

Figure 1.17: Schematic diagram for the $p-y$ analysis method for pile group (using pushover analysis). 
Figure 1.18: p-y Analysis method using displacement imposing method (a) compared with limiting pressure (b) (after from Boulanger et al. 2003)

Figure 1.19: Schematic diagram for the p-y analysis method for pile group using dynamic time history analysis (adapted from Curras et al. 2001) 35

Figure 1.20: $p$-multiplier $\left(m_{p}\right)$ versus clean sand equivalent corrected blow count, $\left(N_{1}\right)_{60 c s}$, from a variety of studies (Ashford et al. 2011) ....................................................... 37

Figure 1.21: p-y models for laterally loaded piles (adapted from Mokwa 1999) .......................38

Figure 1.22: Recommended p-multipliers for group effects (from Mokwa and Duncan, 2001b) 39

Figure 1.23: $p$-multiplier for the pile group (Juirnarongrit and Ashford 2006)..... 39

Figure 1.24: Diagrams for foundation restrained and unrestrained displacement cases (CALTRANS 2011)

Figure 1.25: Schematic diagram for the modeling of pile group bridge foundation using an equivalent pile model under lateral spreading ground deformation (CALTRANS 2011) .44

Figure 1.26: Possible failure cases for the non-liquefied crust layers (CALTRANS 2011)....... 45

Figure 1.27: Idealized $p-y$ curve for pile cap (CALTRANS 2011) .........................................45

Figure 1.28: Smeared profile correction for lateral resistance to account for the weakening effect of liquefied soil on strength of surrounding soil (Ashford et al. 2011, CALTRANS 2011)

Figure 1.29: Schematic diagram for slope stability analysis model with the application of deck resisting force, $F_{D E C K}$, and foundation resisting force, $R$ (CALTRANS 2011)..50

Figure 1.30: Determining compatible displacement ......................................................... 51

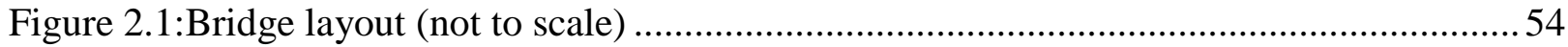

Figure 2.2: Idealized soil profile at the location of interior bend ..........................................54

Figure 2.3: Idealized soil profile at the abutment location ................................................55

Figure 3.1: Drilled shaft and bridge pier sectional properties ............................................ 62

Figure 3.2: Schematic diagrame for drilled shaft modeling in LPILE (Not to scale)..... 62

Figure 3.3: Moment curvature and stiffness moment for a) 6-feet diameter drilled shaft ; and

b) 3.5 feet diameter column section .63

Figure 3.4: Idealized p-y curve for non-liquefied crust layer 66 
Figure 3.5: Response of drilled shaft foundation to lateral spreading ...................................68

Figure 3.6: Soil profile and foundation dimension (replaced at drilled shaft location) ...............70

Figure 3.8: Description of the variables used in calculation (CALTRANS 2011)....................71

Figure 3.9: Equivalent single pile model illustrations ..................................................... 72

Figure 3.10: Boundary conditions and imposed soil displacement ....................................... 72

Figure 3.11: Section analysis: a) Moment-curvature and stiffness-moment relations for a single pile; b) moment-curvature relationship for equivalent pile .......................... 73

Figure 3.12: Idealized p-y curves for pile cap in crust layer .............................................. 77

Figure 3.13: Response of pile group foundation to lateral spreading ..................................... 81

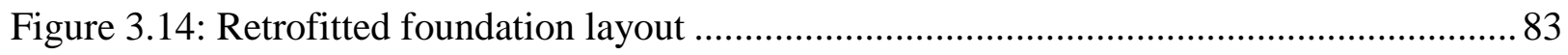

Figure 3.15: Response of pile group foundation to lateral spreading ................................... 83

Figure 3.16: Section analysis: a) Moment-curvature and stiffness-moment relations for a single pile; b) moment-curvature relationship for equivalent pile ............................ 85

Figure 3.17: Idealized p-y curve for non-liquefied crust layer ............................................. 86

Figure 3.18: Response of pile group foundation with 2-ft diameter pile ................................. 86

Figure 3.19: Size of the drilled shaft used for retrofitting ................................................... 87

Figure 3.20: Section analysis: a) Moment-curvature and stiffness-moment relations for a new drilled shaft; b) moment-curvature relationship for equivalent pile.......................... 88

Figure 3.21: Response of pile group foundation retrofitted with 3-ft diameter drilled shaft....... 89

Figure 4.1: Soil profile and abutment layout (left section) with dimensions............................92

Figure 4.2: Pile group layout with pile cap dimensions......................................................92

Figure 4.3: Idealized p-y curves for pile cap in crust layer ...............................................97

Figure 4.4: Imposed soil displacement into the analysis induced by lateral spreading ............ 101

Figure 4.5: Pushover analysis of the super pile and abutment wall from L-pile ..................... 101

Figure 4.6: Estimation of tributary width of the embankment............................................ 102

Figure 4.7: Slope stability analysis to computer $k_{y}$ for set of resisting forces. ....................... 103

Figure 4.8: Results of embankment displacement analyses for different restraining forces: (a) yield acceleration from slope stability analysis using Spencer's method and (b) embankment slide mass displacements estimated ............................................... 103

Figure 4.9: Compatibility force-displacements plot ...................................................... 104

Figure 4.10: Pushover analysis results for compatible displacement of $9.3 \mathrm{in} . . . \ldots \ldots . . . . . . . . . . . . . . .105$ 
Figure 4.11: Foundation layout for retrofitting foundation by the addition of piles................ 106

Figure 4.12: Compatibility force displacement plot for retrofitted foundation ....................... 106

Figure 4.13: Pushover analysis results for compatible displacement of 8 in......................... 107

Figure 4.14: Foundation retrofitting by additions of new drilled shaft a) Layout plan view; b) cross-section property of drilled shaft ............................................................. 108

Figure 4.15: Moment and stiffness properties of a single pile and equivalent pile: a) moment curvature and stiffness moment relationships for new drilled shaft ; b) Combined moment -curvature relationship for equivalent pile........................................... 109

Figure 4.16: Compatibility of forces and displacements for new super pile ......................... 110

Figure 4.17: Response of pile foundation to lateral spreading at 8.0-in imposed soil

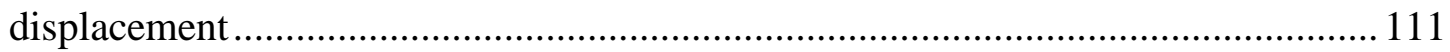

Figure 5.1: Design example soil profile for ground improvement ..................................... 113

Figure 5.2: SPT clean-sand base curve for magnitude 7.5 earthquakes with data from liquefaction case histories (Youd et al. 2001) ...................................................... 115

Figure 5.3: Approximate variation of relative density based on tributary area (Barksdale and

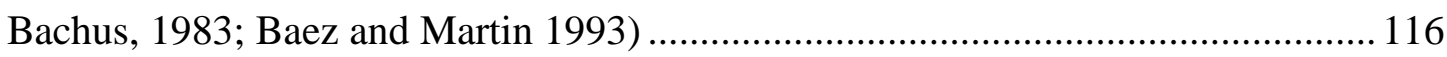

Figure 5.4: Design chart for DSM grid (Nyugen et al. 2012)............................................... 118

Figure 5.5: DSM grid unit cell and dimensions ............................................................... 119 


\section{List of Tables}

Table number

Page

Table 1.1: Liquefaction mitigation methods (after Dickenson et al. 2002; Ferritto 1997)............. 6

Table 1.2: Mechanisms of stone column for mitigating liquefaction in different soil (Baez 1995)

Table 2.1: Pile foundation performance Criteria CALTRANS (2011).......................................56

Table 3.1: Moment capacity of drilled shaft and bridge column ....................................................63

Table 3.3: Summary of bridge foundation response for drilled shaft under lateral spreading ....68

Table 3.4: Structural properties of 16" diameter PP pile .................................................................. 70

Table 3.5: Pile cap structural properties .................................................................................. 71

Table 3.6: Moment and stiffness properties of a single pile and equivalent pile..........................74

Table 3.7: Adjustment factors for softening in dense sand layer................................................... 78

Table 3.8: Summary of p-multiplier coefficient for equivalent pile ..............................................79

Table 3.9: Summary of response for pile group foundation ........................................................... 81

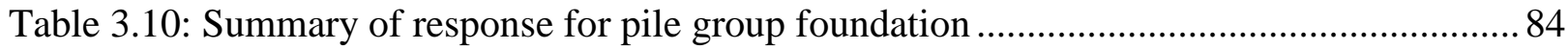

Table 3.11: Moment and stiffness properties of a single pile and equivalent pile......................... 85

Table 3.12: Summary of response of bridge foundation with 2-ft diameter piles .........................86

Table 3.13: Moment and stiffness properties of a single pile and drilled shaft .............................. 88

Table 3.14: Summary of response for retrofitted 16" PP pile.........................................................90

Table 4.1: Pile cap structural properties ......................................................................................93

Table 4.2: Moment and stiffness properties of a single pile and equivalent pile...........................93

Table 4.3: Adjustment factors for softening near the liquefaction interface .................................98

Table 4.4: Summary of p-multiplier coefficient .........................................................................99

Table 4.5: Inertia coefficients for BNWF analysis of pile foundations in liquefied ground

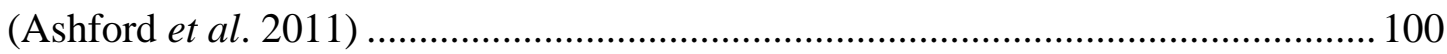

Table 4.6: Summary response for pile group foundation at abutment......................................... 105

Table 4.7: Summary response for pile group foundation at abutment......................................... 107

Table 4.8: Moment and stiffness properties of a single pile and drilled shaft ............................ 109

Table 4.9: Summary response of retrofitted bridge foundation .................................................. 111 



\section{Executive Summary}

Damage in pile supported structures due to liquefaction and liquefaction induced deformation were reported in past earthquakes around the world (e.g., Ansal et al. 1999; Seed et al. 1990; EERI 2010, EERI 2011; GEER 2010a, GEER 2010b, GEER 2011). For example, a reconnaissance report from a recent subduction zone event, the 2010 Chile earthquake $\left(M_{w}=8.8\right)$, showed the pervasive nature of liquefaction and liquefaction-induced lateral spreading damage to bridge foundations (GEER 2010a, Yen et al. 2011). In terms of seismic hazard, the Pacific Northwest shares similar conditions from a Cascadia Subduction Zone (CSZ) earthquake source with the expected earthquake magnitude of $9.0\left(\mathrm{M}_{\mathrm{w}}\right)$ and return period of 300 years (Atwater et al. 1995, Atwater and Hemphill-Halley 1997). The risk and damage from a CSZ earthquake event is widely recognized by the Oregon Department of Transportation (ODOT) as presented in a report by ODOT (2009). A large number of bridges were found to be vulnerable to a CSZ event, and repair and replacement costs of Oregon bridges have been estimated at more than 1 billion USD (ODOT 2009). Moreover, thousands of bridges require some kind of modification and/or seismic retrofitting to the foundation in order to improve seismic performance under liquefaction induced lateral spreading.

To evaluate the seismic performance of bridge foundations and liquefaction mitigation alternatives, ODOT funded collaborative research between Oregon State University (OSU), University of California at Davis (UCD), University of California at San Diego (UCSD), Hayward Baker Inc., and Pacific Earthquake Engineering Research Center (PEER). The main objectives of the research were to develop design charts for different liquefaction mitigation alternatives and to develop methodologies for assessing the performance of bridge pile foundations in laterally spreading ground.

The cooperative research focuses on two aspects of liquefaction and liquefaction induced lateral spreading: (1) ground improvement methods, particularly using stone columns and deep soil mixing (DSM) grids, and (2) assess the seismic performance of bridge foundations (e.g., drilled shaft, pile groups) and seismic retrofitting alternatives for the bridge foundation. Stone columns for liquefaction mitigation and pile groups foundation assessment were investigated by the OSU team, while DSM and large diameter piles/shafts alternatives were investigated by the UCD team. Research teams used OpenSees (http://opensees.berkeley.edu/), an open source 
computational platform for three dimensional (3D) finite element (FE) modeling and analysis. OpenSeesPL, a graphical user interface developed by the UCSD team, was used to investigate liquefaction mitigation alternatives (i.e., stone columns and DSM grids) and the performance of pile foundations in liquefaction induced laterally spreading ground.

This report presents a detailed literature review on stone columns and the behavior of pile groups under liquefaction induced lateral spreading (Chapter 1). For stone columns, literature reviews were conducted for methods of installation, working mechanisms in liquefaction mitigation, and performance during past earthquakes events. For pile groups, reviews were carried out on:

o The parameters affecting the performance/response of piles (based on published experimental results on pile groups),

o The state of practice to analyze numerically the pile group response under liquefaction induced lateral spreading, and

o Design guidelines for bridge foundations recommended by CALTRANS (2011).

The purpose of the literature review for stone columns was to identify gaps in our knowledge as a basis for research. From the literature review, no consensus was found on the contribution of the shear stress redistribution mechanism of stone columns to mitigating liquefaction. Some researchers (e.g., Baez 1995) argued that the shear redistribution mechanism is very effective to mitigate liquefaction, while others (Goughnour and Pestana 1998; Olgun and Martin 2008, Green et al. 2008) suggested not to rely on this mechanism for mitigating liquefaction. To resolve this issue, 3D FE analyses using OpenSees were carried out with different area replacement ratios of stone columns in a liquefiable soil profile. In the first phase of research, a linear elastic dry soil profile was investigated in order to gain insight on the distribution of shear stress/strain in soil. Since the current design relationship for stone columns is based on empirical relationships and linear elastic soil behavior, our linear elastic FE analysis results of this study are directly comparable to existing design relationship. Based on these results, modified design charts to account for the effect of shear stress redistribution were developed for stone columns in liquefiable soil. In the second phase, nonlinear FE analyses are being carried out, and preliminary results from the nonlinear analysis show similar trends for the 
shear stress/strain distribution between stone columns and surrounding soils. Overall, the general conclusion made from linear elastic analysis results seems to be valid for nonlinear analysis results for liquefaction mitigation using stone columns. From the linear and nonlinear analyses results, it was found that stone columns are not effective in mitigating liquefaction through the shear reinforcement mechanisms. Therefore, shear stress reduction from stone columns should not be relied on for mitigation liquefaction. For ODOT to review entire body of work performed, all the publications (conferences and journal papers) from this stone column research are included as well (Appendix-E).

In addition to the research for stone columns, as main requirement of ODOT, several step by step worked out examples are provided for:

(1) assessing liquefaction and liquefaction induced lateral spreading for bridge foundation (Chapter 2);

(2) assessing the seismic performance of drilled shaft foundations and pile group foundation for bridge interior bents along with different foundation retrofitting techniques (Chapter 3);

(3) assessing the seismic performance of pile group foundations for bridge abutments along with foundation retrofitting techniques (Chapter 4); and liquefaction mitigation using stone columns and DSM grids for bridge foundations (Chapter 5).

Parallel to the work of the OSU team, the UCD team also investigated the DSM grid on liquefiable soil using OpenSeesPL. The corresponding publications from their research are included in Appendix-E for ODOT to review. 


\section{Chapter 1: Review of Literature}

\subsection{Introduction}

To reduce the risk for loss of life as well as damage of bridges different approaches can be used to make bridge foundations more resilient to liquefiable soils. The basic approaches that have been used are ground improvement techniques and/or structural modification. Ground improvement increases the liquefaction resistance of the liquefiable soil, while structural modification strengthens the foundation (e.g., drilled shaft, pile group) of the bridges to resist the loads generated due to liquefaction (e.g. lateral spreading displacement). This chapter presents a literature review of ground improvement techniques using stone columns and pile group foundations in liquefaction induced lateral spreading ground.

\subsection{Ground Improvement Methods for Liquefaction Mitigation}

Several soil improvement methods are used to mitigate the liquefaction potential of liquefiable ground by partially/fully replacing the liquefiable soil with non-liquefiable engineered fill. Generally, the selection of ground improvement techniques depends upon acceptable limits of geotechnical/structural performance, acceptable level of risk, soil conditions, and project cost. The most common soil treatment techniques used in practice are based on soil types, ideal depth of treatment, and relative costs (Table 1.1). The state of practice for using these techniques to mitigate soil liquefaction can be found in published literature (Stewart et al. 1997, Boulanger et al. 1998, Mitchell et al. 1998, Mitchell 2008).

The most common methods for liquefaction mitigation involve densification, drainage, and cementation/reinforcing or a combination of these approaches. The utilization of the particular technique depends upon the in-situ soil type (e.g., clean sand, silty sand, no-plastic silts). Figure 1.1 shows the applicability of liquefaction mitigation techniques for different sizes of soil particles (Mitchell 2008). Though most of the techniques can be applied to most types of soil, some methods are found to be more effective when treating within a particular range of particle size. Particularly, the stone column method is suitable for a wide range of soils such as sand, silt, and clay with particle size from $4.75 \mathrm{~mm}$ to $0.0001 \mathrm{~mm}$ (shown in dotted box). The wide range applicability of stone columns in different soil conditions makes it popular for liquefaction mitigation purposes. From Table 1.1, it can be seen that stone columns are relatively moderate in terms of cost to mitigate liquefaction in a variety of soil types and is suitable for relatively high 
depth of liquefiable soil. The pros and cons of each liquefaction mitigation technique are described in Mitchell (2008).

Comprehensive information about ground improvement methods shown in Figure 1.1 can be found elsewhere (Iai et al. 1994, Yasuda et al. 1996, Boulanger and Hayden 1995, Stewart et al. 1997, Boulanger et al. 1998, Francis and Gorski 1998, Bruce 2000). In the following section, liquefaction mitigation using stone columns is reviewed in detail due to ODOT's particular interest in utilizing stone columns as a potential liquefaction mitigation method.

\subsubsection{Liquefaction Mitigation using Stone Columns}

Stone column construction involves the partial replacement of liquefiable soils with a vertical column of gravel or crushed stone or sand as backfill. The most common method of stone column installation is vibro-replacement method, while the auger-casing system method is also used in other countries such as Japan (Adalier and Elgamal 2004).

Vibro-replacement columns are generally constructed using either an electric or hydraulic actuated cylindrical shaped vibrating probe which is inserted to the desired depth by vibration. The system utilizes a water jet or air to advance the vibrator to the design penetration depth. Thereafter, gravel or crushed stone backfill is fed in increments either from the surface or from the tip of the vibrating probe. Along with vibration, which tends to push the stones out into the soil, this further densifies the surrounding soil. The extent of densification is a function of soil type, fines content, vibrator type, stone shape, area of replacement, and spacing of stone columns (Adalier and Elgamal 2004). The typical vibro-replacement construction method is shown in Figure 1.2. More information regarding the construction of stone columns by vibro-replacement methods are available in Baez (1997).

The auger-casing systems are generally constructed without the use of significant vibration to the gravel and the process does not densify the surrounding soil. In this method, a hollow auger is inserted in the ground to the design depth. A charge of gravel is placed through the stem of the hollow auger, and then the auger is withdrawn. Stone column construction by the auger casing method is popular in Japan, where the stone columns (also referred to as gravel drains) are

used primarily to dissipate excess pore water pressure. However, current Japanese practice utilizes auger casing with an internal gravel feeding and compaction-rod system shown in Figure 


\section{3, which adds an important densification effect on the surrounding soil (Adalier and Elgamal}

2004).

Table 1.1: Liquefaction mitigation methods (after Dickenson et al. 2002; Ferritto 1997)

\begin{tabular}{|c|c|c|c|c|}
\hline Method & Principle & $\begin{array}{l}\text { Ideal Soil } \\
\text { Conditions }\end{array}$ & $\begin{array}{l}\text { Suitable } \\
\text { Depth }\end{array}$ & $\begin{array}{l}\text { Relative } \\
\text { Cost }\end{array}$ \\
\hline $\begin{array}{l}\text { Excavation and/or } \\
\text { Compaction }\end{array}$ & $\begin{array}{l}\text { Excavate and dispose of liquefiable soils; Compact } \\
\text { with new fill. }\end{array}$ & All & Unlimited & High \\
\hline $\begin{array}{l}\text { Vibratory Probe } \\
\text { (e.g.,Terraprobe, } \\
\text { Virbrorods) }\end{array}$ & $\begin{array}{l}\text { Densification by vibration; liquefaction-induced } \\
\text { settlement and settlement in dry soil under } \\
\text { overburden to produce a higher density. }\end{array}$ & $\begin{array}{l}\text { Saturated or } \\
\text { dry clean sand }\end{array}$ & $20-40 m$ & Moderate \\
\hline $\begin{array}{l}\text { Vibro-compaction (e.g. } \\
\text { Vibrofloat, Vibro- } \\
\text { composer) }\end{array}$ & $\begin{array}{l}\text { Densification by vibration and compaction of } \\
\text { backfill material of sand or gravel. }\end{array}$ & $\begin{array}{l}\text { Cohesionless } \\
\text { soils with } \\
<20 \% \text { fines }\end{array}$ & $>20 \mathrm{~m}$ & $\begin{array}{l}\text { Low to } \\
\text { Moderate }\end{array}$ \\
\hline Compaction Piles & $\begin{array}{l}\text { Densification by vibration and soil displacement } \\
\text { during driving. }\end{array}$ & $\begin{array}{l}\text { Loose sandy } \\
\text { soil; partially } \\
\text { saturated } \\
\text { clayey soil }\end{array}$ & $>20 \mathrm{~m}$ & $\begin{array}{l}\text { Moderate to } \\
\text { High }\end{array}$ \\
\hline Dynamic Compaction & $\begin{array}{l}\text { Repeated application of high-intensity impacts at } \\
\text { surface. }\end{array}$ & $\begin{array}{l}\text { Cohesionless } \\
\text { soils }\end{array}$ & $30 \mathrm{~m}$ & Low \\
\hline $\begin{array}{l}\text { Displacement } \\
\text { (Compaction grout) }\end{array}$ & $\begin{array}{l}\text { Highly viscous grout pumped at high pressure to act } \\
\text { as radial hydraulic jack to displace soil. }\end{array}$ & All soils & Unlimited & $\begin{array}{l}\text { Low to } \\
\text { Moderate }\end{array}$ \\
\hline Surcharge or Buttress & $\begin{array}{l}\text { Added weight increases effective confining } \\
\text { pressures, increasing resistance. }\end{array}$ & $\begin{array}{l}\text { Any soil } \\
\text { surface }\end{array}$ & $\begin{array}{l}\text { Dependent } \\
\text { on size of } \\
\text { surcharge/bu } \\
\text { ttress }\end{array}$ & $\begin{array}{l}\text { Moderate if } \\
\text { vertical drains } \\
\text { are used }\end{array}$ \\
\hline $\begin{array}{l}\text { Drains (e.g. Gravel, } \\
\text { Sand, Wick, Wells) }\end{array}$ & Relief of excess pore water pressure. & $\begin{array}{l}\text { Sand, silt, and } \\
\text { clay }\end{array}$ & $\begin{array}{l}\text { Gravel \& } \\
\text { Sand: }>30 \mathrm{~m} \\
\text { Wick: }>45 \mathrm{~m}\end{array}$ & $\begin{array}{l}\text { Moderate to } \\
\text { High }\end{array}$ \\
\hline Particulate Grouting & $\begin{array}{l}\text { Penetration grouting to fill void space with soil, } \\
\text { cement, lime, and/or clay. }\end{array}$ & $\begin{array}{l}\text { Medium to } \\
\text { coarse sand } \\
\text { and gravel }\end{array}$ & Unlimited & $\begin{array}{l}\text { Lowest of } \\
\text { Grout } \\
\text { Methods }\end{array}$ \\
\hline Chemical Grouting & Void space filled with gel or solid precipitate & $\begin{array}{l}\text { Medium silts } \\
\text { and coarser }\end{array}$ & Unlimited & High \\
\hline Pressure injected lime & Penetration grouting- fill soil pores with lime. & $\begin{array}{l}\text { Medium to } \\
\text { coarse sand } \\
\text { and gravel. }\end{array}$ & Unlimited & Low \\
\hline Electrokinetic Injection & $\begin{array}{l}\text { Stabilizing chemical fills void space by electro- } \\
\text { osmosis or colloids through electrophoresis }\end{array}$ & $\begin{array}{l}\text { Saturated } \\
\text { sands, silts, } \\
\text { silty clays }\end{array}$ & Unknown & Expensive \\
\hline Jet Grouting & $\begin{array}{l}\text { High-speed jets excavate, inject \& mix stabilizer to } \\
\text { form columns or panels }\end{array}$ & $\begin{array}{l}\text { Sands, silts, } \\
\text { clays }\end{array}$ & Unknown & High \\
\hline $\begin{array}{l}\text { Mix-in-place piles and } \\
\text { walls }\end{array}$ & $\begin{array}{l}\text { Lime, cement or asphalt introduced through rotating } \\
\text { auger or special in-place mixer. }\end{array}$ & $\begin{array}{l}\text { Sands, silts, } \\
\text { clays, all soft } \\
\text { or loose } \\
\text { inorganic soils. }\end{array}$ & $>20 \mathrm{~m}$ & High \\
\hline $\begin{array}{l}\text { Vibro-replacement } \\
\text { Stone/Sand Columns } \\
\text { (Grouted and not } \\
\text { grouted) }\end{array}$ & $\begin{array}{l}\text { Hole jetted into fine-grained soil and backfilled with } \\
\text { densely compacted gravel }\end{array}$ & $\begin{array}{l}\text { Sands, silts, } \\
\text { clays }\end{array}$ & $\begin{array}{l}>30 \mathrm{~m} \\
\text { (limited by } \\
\text { vibratory } \\
\text { equipment }\end{array}$ & Moderate \\
\hline Root piles, soil nailing & $\begin{array}{l}\text { Small-diameter inclusions used to carry tension, } \\
\text { shear and compression. }\end{array}$ & All soils & Unknown & Low \\
\hline $\begin{array}{l}\text { Blasting (Explosive } \\
\text { Compaction) }\end{array}$ & $\begin{array}{l}\text { Shock waves and vibrations cause liquefaction, } \\
\text { displacement and settlement to higher density }\end{array}$ & $\begin{array}{l}\text { Saturated, } \\
\text { clean sand }\end{array}$ & $>40 \mathrm{~m}$ & Low \\
\hline
\end{tabular}




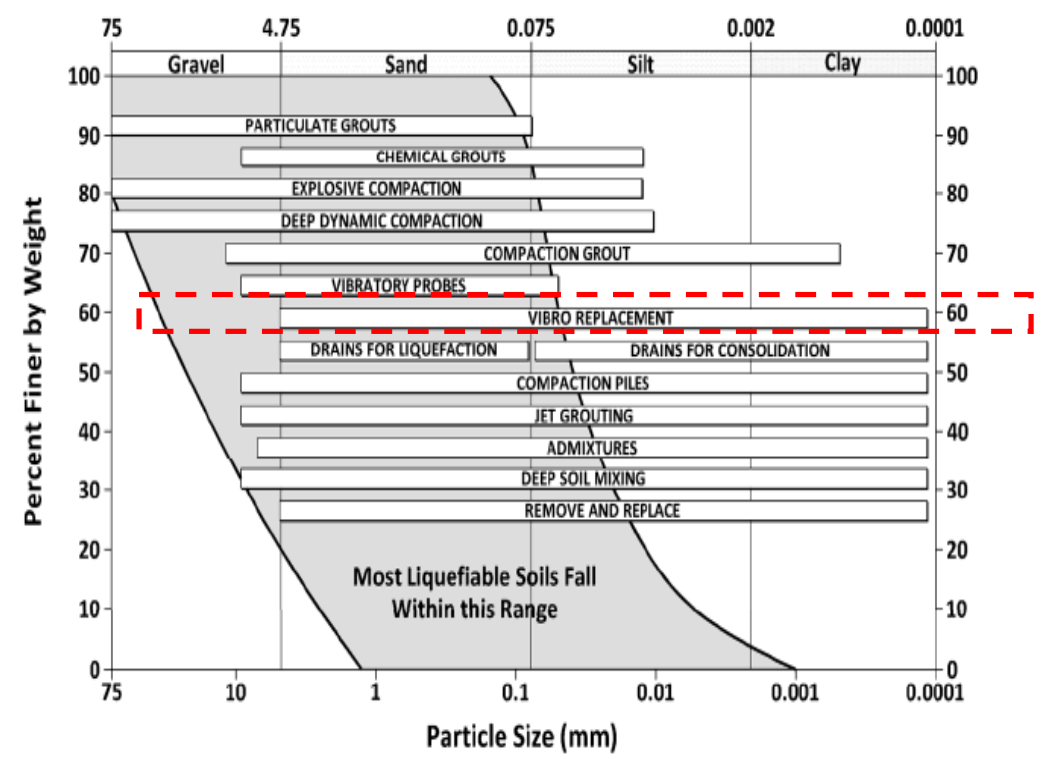

Figure 1.1: Ground improvement methods for mitigating liquefaction (Mitchell 2008)

Though there are different methods for the construction of stone column, in the United States, the vibro method is the most popular, and hereafter in this report stone column will refer to vibro-stone columns. Generally, stone columns are constructed in a grid pattern (e.g., triangular, square) where each stone column affects a tributary area as shown in Figure 1.4. The amount of soil replaced by the stone column is quantified by the area replacement ratio, $A_{r}$, which is the ratio between the cross-section area of the stone column and the tributary area of the stone column. The $A_{r}$ is the important parameter used in the design of stone columns and governs the overall cost of the stone column installation.

In terms of working mechanisms, stone columns help to mitigate liquefaction through one or more of these ways (Baez 1995; Adalier and Elgamal 2004).

1) The construction process for stone columns densifies the surrounding soil, which increases the liquefaction resistance of the soil.

2) Stone columns act as drains due to higher permeability than the liquefiable soil and allow the rapid dissipation of excess pore water pressure from the soil.

3) Stone columns act as reinforcing elements due to higher stiffness than the surrounding soil. The stone columns attract higher shear stresses and thereby reduce stresses in the liquefiable soil. 
The mechanisms of a stone column to mitigate liquefaction depend largely on the soil type. The effective mechanism and design consideration of stone columns for different soils are given by Baez (1995) are shown in Table 1.2. A detailed literature review on each mechanism is explained in the next section.

Table 1.2: Mechanisms of stone column for mitigating liquefaction in different soil (Baez 1995)

\begin{tabular}{|lcccc|}
\hline \multicolumn{1}{|c}{ Soil type/ criteria } & $\begin{array}{c}\text { Clean } \\
\text { sands }\end{array}$ & $\begin{array}{c}\text { Silty sands with } \\
<\mathbf{1 5 \%} \text { fines }\end{array}$ & $\begin{array}{c}\text { Silty sands with } \\
>=\mathbf{1 5 \%} \text { fines }\end{array}$ & Non plastic silts \\
\hline Densification & $\mathrm{XX}$ & $\mathrm{X}$ & $\mathrm{X}$ & \\
\hline Drainage & $\mathrm{XX}$ & $\mathrm{X}$ & $\mathrm{X}$ & $\mathrm{XX}$ \\
\hline Shear Stress Redistribution & $\mathrm{X}$ & $\mathrm{X}$ & $\mathrm{XX}$ & \\
\hline
\end{tabular}

Note: XX means strong contribution factor

$\mathrm{X}$ means potential contributing factor from the particular mechanism
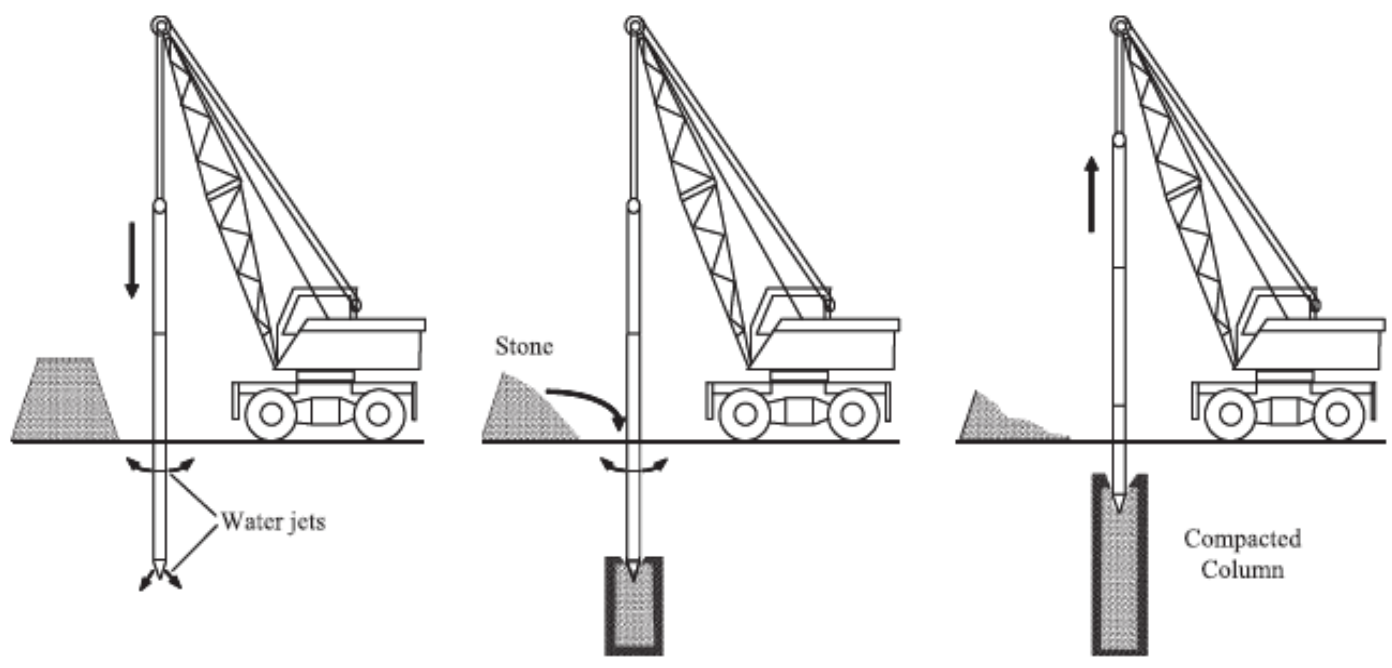

Figure 1.2: Stone column construction by vibro-replacement (Adalier and Elgamal 2004) 


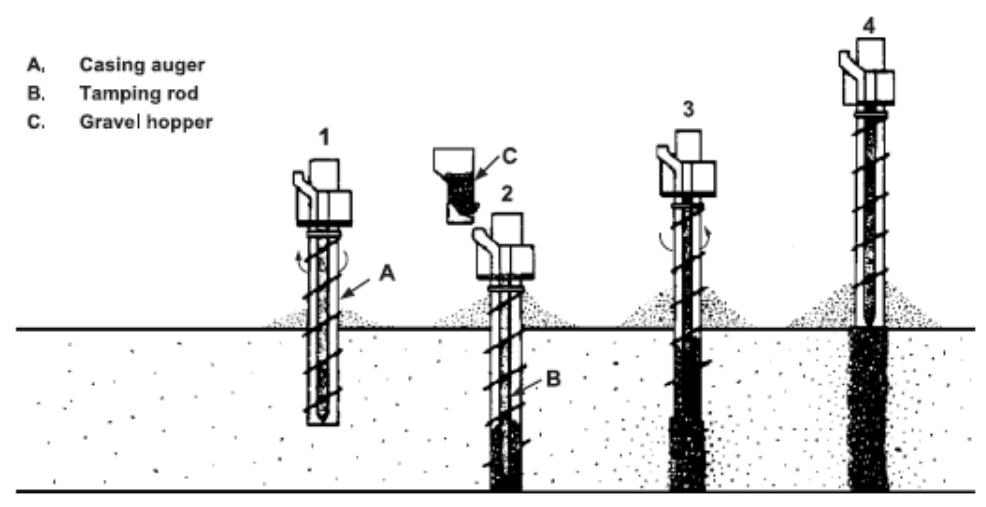

Figure 1.3: Stone columns constructed by auger-casing with internal gravel feeding compaction-rod system (after Sonu et al. 1993; Adalier and Elgamal 2004)

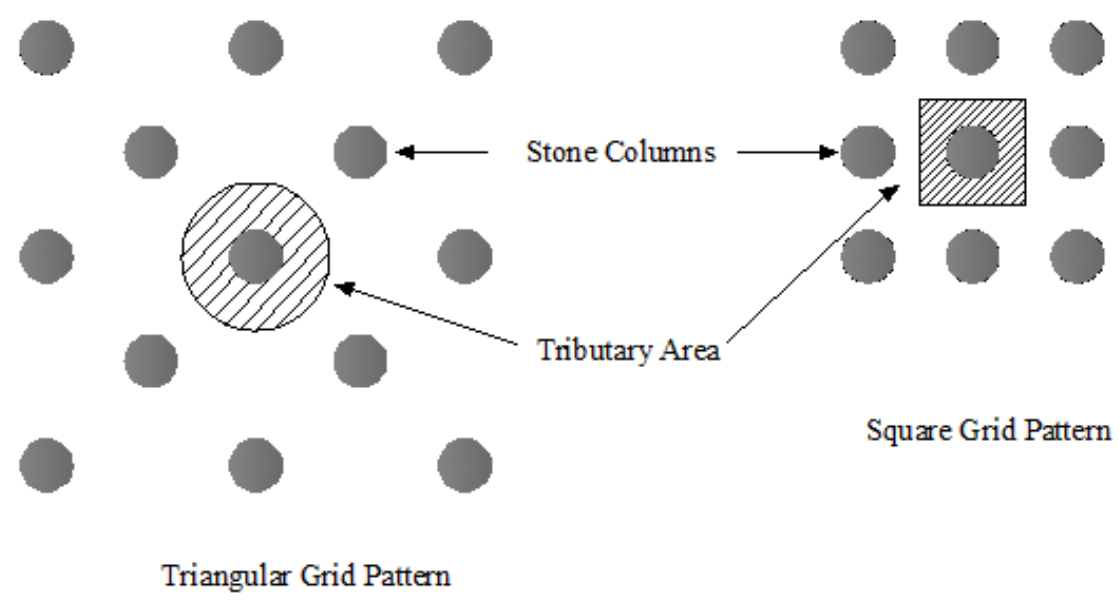

Figure 1.4: Stone column arrangement and tributary area

\subsubsection{Densification Mechanism of Stone Columns}

The stone column installation process involves insertion of a vibratory probe into the hole, then compacting stone (or gravel) and surrounding soil by vibration. Baez (1995) described the four mechanisms of densification of surrounding soil by stone columns. The first mechanism is the development of controlled vibration induced liquefaction in the surrounding soils that leads to densifying the soil due to the dissipation of excess pore water pressure. The second mechanism involves densification by the vibratory probe which tends to displace the soil even without the generation of excess pore water pressure. The third mechanism is the confining effect of 
installing columns in groups instead of installing columns as single members. The fourth mechanism is the effect of improved resistance with time. The extent of densification in the surrounding soil is a function of the distance from the point of the installed stone column, in which densification effect is inversely proportional to the distance from the center of installed columns. In the United States, densification of soil using stone columns is the most widely accepted mechanisms contributing to liquefaction mitigation (Adalier and Elgamal 2004).

Using stone columns alone to mitigate liquefaction is suitable for clean sands and sands with up to $20 \%$ fines, as the densification mechanism becomes ineffective as the percentage of fines increases in the soil (Baez 1995, Adalier et al. 2003). Silty soils are difficult to densify using stone columns because these soils are associated with a low coefficient of consolidation (or low hydraulic conductivity). The lower hydraulic conductivity of soil results in slower pore pressure dissipation during installation of stone columns, which prevents the densification of the soils (Shenthan, 2005).

Baez (1995) developed an empirical relationship based on in-situ tests [e.g. Cone Penentration Test (CPT), Standard Penentration Test (SPT)] for the design of stone columns in sand with less than 15\% fines content. Baez used pre- and post-improvement SPT data from 18 case histories to determine the relationship between pre- and post-improvement SPT blow counts. An improvement factor, $n$, measured as the normalized post-SPT blow count divided by the normalized pre-SPT blow count, was developed. The plot of $n$ versus pre-SPT blow count is shown in Figure 1.5. The relationship between pre- and post-improvement SPT blow counts for a set of area replacement ratios, $A_{r}$, of 5, 10, 15, and 20\% is shown in Figure 1.6. The trends show that the lower the pre-SPT value $(<20)$, the greater the improvement factor with higher values of $A_{r}$. However, at the higher pre-SPT values $(>20)$, there is not a significant improvement with increase in $A_{r}$.

Recent case histories show that the stone column technique may be used effectively to densify silty sands that contain fines exceeding $15 \%$ by using pre-installed supplementary wick drains. The supplementary drains help to relieve excess pore pressures developed during stone column installation (Andrews 1998, Luehring et al. 2001) and improve soil densification.

Shenthan et al. (2004a and 2004b) developed an analytical procedure to evaluate soil response during stone columns installation and to assess the effect of various construction/design 
choices and soil parameters on the degree of improvement achieved. Their analytical model simulated the pore pressure generation in the soil for the input vibrating energy during the installation, concurrent dissipation of pore pressure, and the resulting consolidation and densification of soil. Shenthan et al. (2004a and 2004b) found that area replacement ratio, hydraulic conductivity, and silt content are the important factors governing the densification of soil.

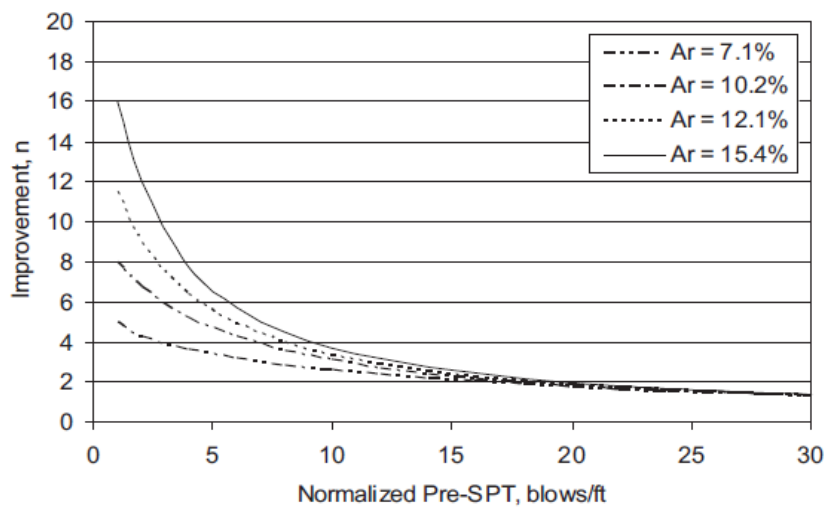

Figure 1.5: Site improvement factor (n) vs normalized pre-SPT for different values Ar, for uniform fine to medium silty sands ( $<15 \%$ fine) (Baez, 1995)

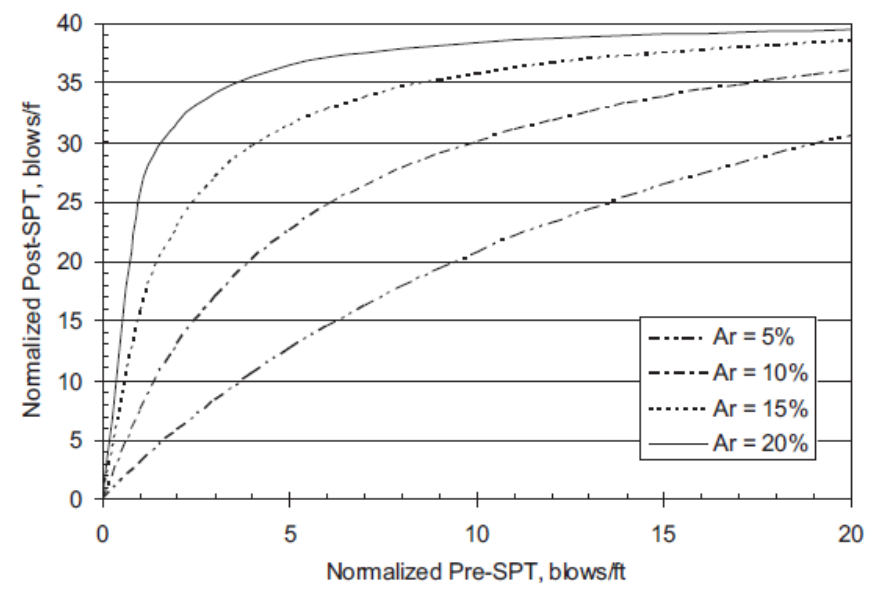

Figure 1.6: Prediction of post-SPT values based on pre-SPT for different values of $A_{r}$ for uniform fine to medium silty sands (<15\% fine) (Baez, 1995) 


\subsubsection{Drainage Mechanism of Stone Columns}

As liquefaction is attributed to generation of excess pore water pressure during an earthquake, the performance of stone columns is directly related to their capacity to dissipate excess pore water pressure. Generally, the horizontal permeability of stone columns is much higher than the permeability of the surrounding soil. The spacing of the stone columns can be less than the distance required for water to drain vertically to the soil surface, so that the drainage will essentially occur in radial directions. Hence, due to the stone columns, excess pore water pressure generated due to cyclic loading can be dissipated as soon as they are generated. Baez and Martin (1992) conducted a field study of a stone column liquefaction mitigation site where they observed that the stone column provides a drainage path even during installation.

Seed and Brooker (1977) proposed a simple radial flow analytical model to analyze pore water pressure dissipation through installed stone columns. Seed and Brooker presented a design chart, based on the stone column diameter and spacing, accounting for generation of excess pore water pressure between stone columns and earthquake parameters (e.g., number of uniform cycle representing possible earthquake records). It was suggested that the permeability of stone columns should be at least two times greater than the permeability of the native soil in order to reduce the development of high excess pore water pressure inside the stone columns. However, their model was limited by assuming infinite stone column permeability (no drain resistance), so that the excess pore water pressure in the stone columns is effectively zero and the hydraulic conductivity of the surrounding soil is constant.

Sasaki and Taniguchi (1982) performed large scale shake table tests using clean sands and demonstrated that excess pore water pressure varies spatially inside the stone columns, contrary to the assumption made by Seed and Brooker (1977) that excess pore water pressure is constant. Sasaki and Taniguchi (1982) also found that high frequency strong motion earthquakes would lead to a quick buildup of excess pore water pressure in native soils.

Millea (1990) conducted a numerical investigation using FE analysis to evaluate the effectiveness of stone columns for mitigating liquefaction with and without foundation footing. The FE model was calibrated with a centrifuge test on a saturated sand deposit. It was found that stone columns are effective in reducing pore water pressure up to a distance of one diameter (without footing) and two diameters (with footing) away from the stone columns when compared to the pore water pressure without stone columns and footing. Full scale blast-induced 
liquefaction of a site improved using stone columns in loose cohesionless soils indicate that excess pore water pressure generation can be reduced and the rate of pore pressure dissipation increases due to stone columns (Ashford et al. 2000a and 2000b).

In contrast to the work of Seed and Brooker (1977), Onoue (1988) developed design charts for stone columns by taking into consideration the finite permeability of gravel drains. Research showed that drainage resistance is important and should be considered in practical problems (Onoue 1988). On the other hand, Boulanger et al. (1998) investigated drainage effects of the stone column in layered soil conditions (with different hydraulic conductivity). They concluded that intermixing of stone column and native soil can substantially reduce the permeability of stone columns, potentially down to 0.01 times the original permeability. As a result, they recommend that the primary mechanism of liquefaction mitigation is densification without regard to drainage and any possible contribution due to drainage should be considered as a secondary effect.

\subsubsection{Reinforcement Mechanism of Stone Columns}

Installation of stone columns partially replaces the low stiffness liquefiable soil with relatively stiffer stone columns. This increases the overall stiffness of the treated ground. When the treated ground is subjected to earthquake ground motion, the stone column and surrounding soil deform

laterally, thereby distributing the stress based on their relative stiffness. The stone column acts as a reinforcing element in the soil and, being relatively stiffer than the surrounding soil, attracts greater shear stress than soil, thereby reducing the overall shear stresses in the surrounding soil (Baez 1995).

Baez (1995) developed theoretical concepts and equations to account for the distribution of shear stresses between stone column and the surrounding soil. Baez proposed that the stone column deforms in pure shear along with the surrounding soil. Shear strain compatibility is the primary assumption used to formulate the shear stress distribution between stone column and surrounding soil. Baez supported his idea of shear strain compatibility by assuming no loading from superstructure directed to the stone columns which can cause displacements in directions other than that of the ground motion. The basic equation used by Baez is

$$
\tau A=\tau_{s} A_{s}+\tau_{s c} A_{s c}
$$


where $\tau$ is total input shear stress, $A$ is total plan area, $A_{s}$ is area of soils, $A_{s c}$ is area of stone columns, $\tau_{s}$ is shear stress in soils and $\tau_{s c}$ is shear stress in stone columns. Baez introduced the concept of a cyclic stresses ratio (CSR) reduction factor, $K_{\mathrm{G}}$, to quantify the level of shear stress reduction in the native soil after installing stone columns as shown in Equation 1.2.

$$
K_{G}=\tau_{s} / \tau=C S R_{1} / C S R=\frac{1}{G_{r}\left[A_{r}+\frac{1}{G_{r}}\left(1-A_{r}\right)\right]}
$$

where $G_{r}=G_{s c} / G_{s}$ and $A_{r}=A_{s c} A ; G_{s c}$ and $G_{s}$ are the shear stiffnesses of the stone columns material and soils, respectively. The factor, $K_{G}$, is used as a shear reduction factor when liquefaction potential of the soil is evaluated. The average value of $\tau$ is computed using the simplified approach proposed by Seed and Idriss (1971). The effect of $A_{r}$ and $G_{r}$ on the CSR reduction factor, as proposed by Baez (1995), is shown in Figure 1.7. Increases in $A_{r}$ or $G_{r}$ can decrease shear stresses in the surrounding soil.

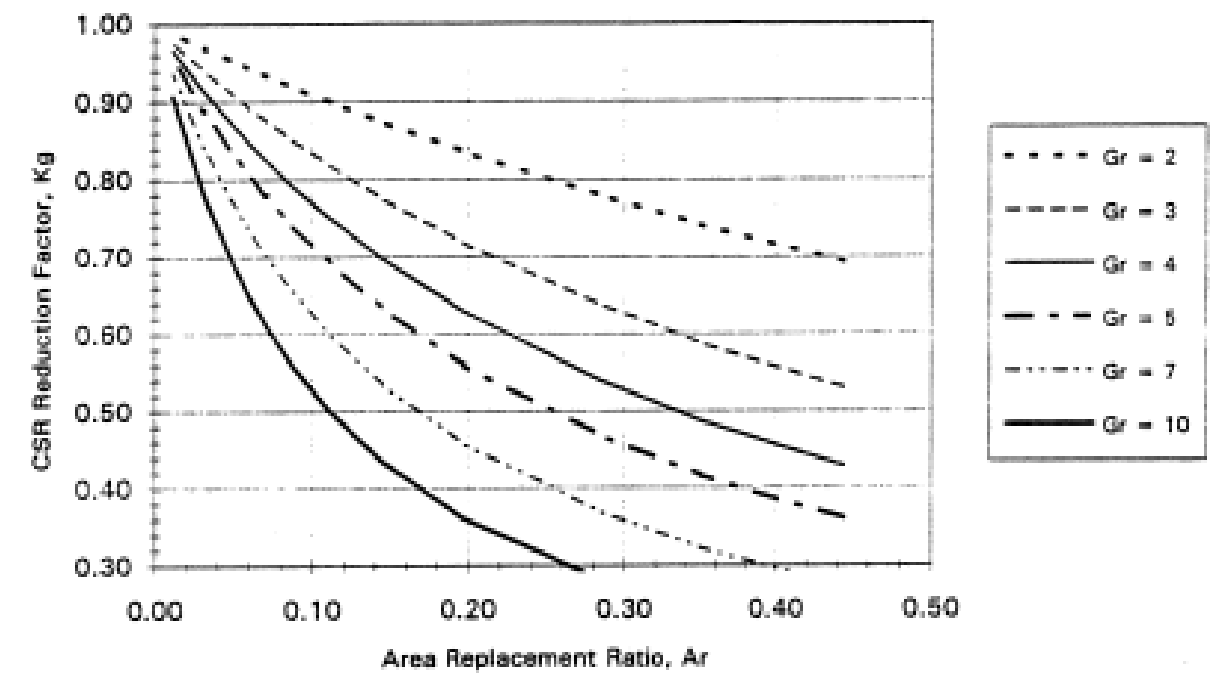

Figure 1.7: Effects of area replacement ratio and shear modulus on the cyclic stress reduction factor (Baez 1995)

Shear strain compatibility is the fundamental assumption used by Baez (1995), which is the basis for the design of stone column in current practice for mitigating liquefaction in silty soils. However, other researchers found that the shear strain compatibility assumption may not 
be applicable for shear stresses distribution. Goughnour and Pestana (1998) studied the effect of slenderness ratio of stone columns and found that stone column behavior is mostly governed by bending and the surrounding soil behaves as a shear beam as shown in Figure 1.8. Goughnour and Pestana (1998) determined the shear stress in the stone column using the flexural deformation and derived the equivalent shear modulus, $G_{s c m}$, which is defined as the shear stress divided by the shear strain experienced by the stone column as given by Equation 1.3.

$$
G_{s c m}=\frac{\tau_{s c \max }}{\gamma_{s \max }}=\frac{1}{2} \cdot\left(\frac{\pi \cdot d_{s c}}{V_{s a v g} \cdot T}\right)^{2} \cdot(1+v) \cdot G_{s c}
$$

where $d_{s c}$ is diameter of stone column, $V_{\text {savg }}$ is average shear velocity of the composite column and soil, $T$ is period of earthquake ground motion, and $v$ is Poisson's ratio. This modulus can be used to compute the shear stress reduction in the surrounding soil due to stone columns. Moreover, Goughnour and Pestana (1998) modified $K_{G}$ by incorporating the vertical stress ratio, $n$ (defined as the ratio of vertical stress within the stone column and the in-situ soil) as shown in Equation 1.4.

$$
K_{G}=\frac{1+\operatorname{Ar}(n-1)}{1+A_{r}\left(\frac{G_{s c}}{G_{s}}-1\right)}
$$

Goughnour and Pestana (1998) found that the reinforcing effect of stone columns for the mitigation of liquefaction potential of surrounding soil is very small or negligible. Based on their research, it seems that there are no significant benefits from stone columns for liquefaction mitigation, if the design only relies on shear reinforcement mechanism.

Olgun and Martin (2008) conducted 3D dynamic FE analysis using DYNAFLOW to better understand column deformation and shear stress reduction behavior. They considered a linear elastic stress strain relationship for the stone column and soil and came to the conclusion that the stone column deforms in a combination of shear and flexure during an earthquake. The deformed shape of the stone column and soil in their model is shown in Figure 1.9. The efficiency of the stone column to behave as a shear beam decreases as the stiffness of the stone column increases and thereby higher stiffness column limits the shear stress redistribution mechanism of stone column. Finally, Olgun and Martin (2008) conclude that the assumption of 
using shear compatibility in stone column design approaches may greatly overestimate the actual level of seismic improvement in terms of shear stress reduction.

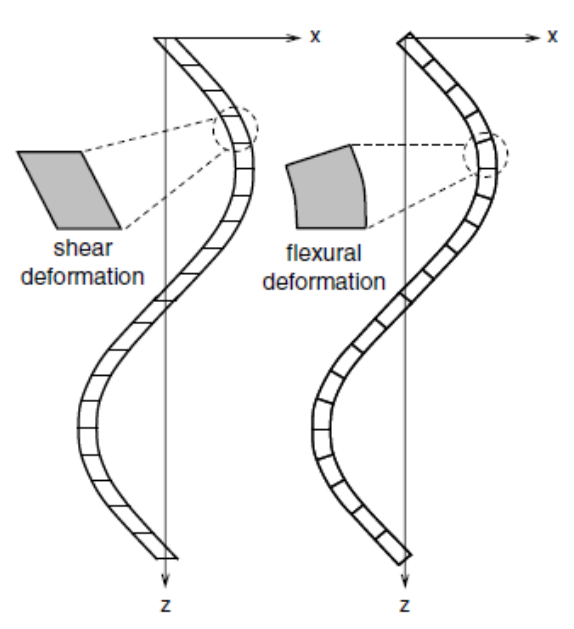

Figure 1.8: Shear and flexural deformation modes of a stone column (after Goughnour and Pestana 1998; Olgun and Martin 2008)

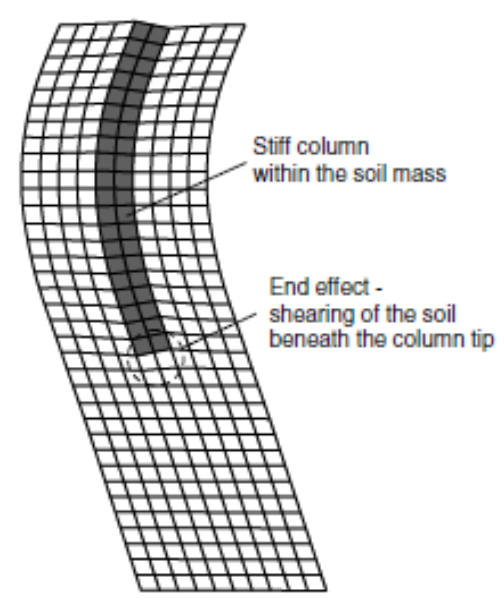

Figure 1.9: Deformed shape of the soil-column system (Olgun and Martin 2008)

Green et al. (2008) also performed 2-D finite element numerical analyses to understand seismically induced shear stresses between stone columns (e.g., Impact Rammed Aggregate Pier) and liquefiable soil. A soil profile of loose sand was considered with a stone column. They 
provided large spacing $(20 \mathrm{~m})$ in their analysis in order to achieve the free field conditions at the halfway point between the stone columns. A linear elastic stress strain relationship for the stone column and soil was assumed and the model was subjected to an artificially generated earthquake ground motion. From the numerical analysis, they calculated the cumulative shear deformations (CSD) and cumulative flexural deformations (CFD) and percentage contribution of shear strain and flexural strains as

$$
\begin{aligned}
P_{C S D} & =\frac{C S D}{C S D+C F D} \times 100 \% \\
P_{C F D} & =\frac{C F D}{C S D+C F D} \times 100 \%
\end{aligned}
$$

The relative contribution of shear and flexure deformation in the stone column along the depth is shown in Figure 1.10. Green et al. (2008) conclude that the percentage contribution of shear and flexural deformation of stone column varies with depth, with the stone column deforming predominately in flexure near the ground surface and predominately in shear at greater depths.

Green et al. (2008) derived a pseudo shear modulus of a stone column that deforms in a combination of flexure and shear $\left(G_{I P f l e x+s h e a r}\right)$ by Equation 1.6

$$
G_{I P \text { flex }+ \text { shear }}=P_{C F D} \cdot G_{I P f l e x}+P_{C S D} \cdot G_{\text {IPshear }}
$$

where $G_{I P f l e x}$ is the equivalent shear modulus of stone column deforming in flexure, derived by Goughnour and Pestana (1998); $\mathrm{G}_{I P s h e a r}$ is the shear modulus of stone column deforming in shear The modified shear modulus can be used to evaluate shear stress reduction in surrounding soil due to stone column.

Very limited experimental research has been published on the shear stress distribution behavior of stone columns. Adalier et al. (2003) conducted centrifuge tests to investigate shear stress redistribution between stone columns and non-plastic silty deposits under shallow foundations. In the free field condition (i.e. in the absence of surcharge loading), stone columns are only effective to reduce shear stress in the surrounding soil below 5-m depth from the ground surface and very ineffective near the ground surface. Moreover, they found that in order for the stone columns to work effectively by shear stress redistribution, at least $45 \mathrm{kPa}$ vertical effective 
confining stress would be required. However, no discussions were made about shear strain compatibility between stone columns and soil.

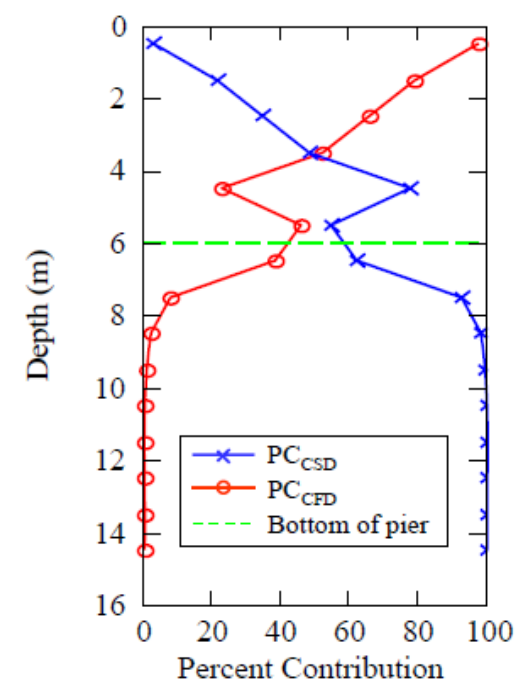

Figure 1.10: Percent contributions of shear and flexural modes of deformation (Green et al. 2008)

\subsubsection{Performance of Stone Columns during Earthquakes}

Several researchers have documented the performance of improved ground during strong earthquakes (Mitchell and Wentz 1991; Mitchell et al. 1995). Mitchell and Wentz (1991) evaluated 12 improved soil sites from San Francisco Bay to Santa Cruz following the $7.1\left(M_{w}\right)$ magnitude 1989 Loma Prieta earthquakes. The recorded peak ground accelerations ranged from $0.11 \mathrm{~g}$ to $0.45 \mathrm{~g}$ near the epicenter. The soil improvement techniques used in these sites included stone columns, dynamic compaction, compacting grouting, and chemical grouting. Out of these techniques, three sites were improved using stone columns. They reported that the improvement techniques utilized were effective in mitigating liquefaction and no damage or distress was reported in the improved site. However, untreated soil showed signs of liquefaction induced sand boils. The densification and drainage mechanisms of stone columns were considered as main contributing factors in the liquefaction mitigation and no discussion were made regarding the shear reinforcing mechanism of stone column. One example was the building site in Treasure Island (California), where construction was underway at the time of the earthquake. At this site the soil was improved using stone column technique to a depth of $22 \mathrm{ft}$. The soil profile consisted 
of 31 to $43 \mathrm{ft}$ of loose to medium dense hydraulically placed sand underlain by $30 \mathrm{ft}$ of soft bay mud. At the time of the Loma Prieta earthquake, building footings were cast partially (40\%) and two 22-ft deep elevator shafts were excavated. The footing showed no cracking during the earthquake. A portion of the elevator shaft was filled with sand and it was concluded that the soil from $22 \mathrm{ft}$ to $40 \mathrm{ft}$ had liquefied. Liquefaction sand boils and cracking were observed in the area surrounding the building footprint, where soil was not treated. The stone column treatment was thus determined to be successful in mitigating liquefaction.

Iai et al. (1994) reported on a quarry wall at Kushiro Port following the January 1993 Kushiro-Oki earthquake. The earthquake magnitude was $7.8\left(M_{w}\right)$ and the site experienced peak ground accelerations of approximately 0.47g (Iai et al., 1995). The soil profile consisted of loose to medium hydraulic sand fill underlain by dense gravelly sand deposits. Stone columns and sand compaction piles were used to prevent liquefaction. They found that no significant liquefaction at the location of where site was improved with stone column.

Baez (1995) evaluated two stone column sites following the $6.8\left(M_{w}\right)$ magnitude January 17, 1994 Northridge earthquake. One of the sites was a building located approximately 15 miles from the epicenter and experienced peak ground accelerations greater than $0.7 \mathrm{~g}$. The site consisted of inter-bedded layers of loose to medium dense sandy silt and silty sand to the depth of $40-\mathrm{ft}$ below ground surface. No ground distress or liquefaction around the building was reported. The second site was an approach to an elevated railroad track 30 miles from the epicenter. Even for this case, no signs of liquefaction were evident in the improved site following the earthquake and stone column installation was considered effective in preventing liquefaction.

\subsubsection{Summary}

A review of the literature indicates that stone columns are an effective means for mitigating liquefaction hazards as shown in past earthquake performance. In particular, stone columns are very effective in improving liquefaction resistance in clean sand to silty sand ( $<15 \%$ fine content), in which densification can be easily carried out. A large volume of research has been carried out for densification and drainage mechanisms of stone columns (e.g., Baez 1995; Andrews 1998; Luehring et al. 2001; Adalier et al. 2003; Shenthan et al. 2004a and 2004b; Seed and Brooker 1977; Sasaki and Taniguchi 1982; Millea 1990; Ashford et al. 2000a and b; Onoue 1988; Boulanger et al. 1998), but very little research has been performed on the shear stress 
distribution mechanism of stone column. In current design practice for non-plastic silts, the shear stress distribution mechanism is considered to be effective in improving liquefaction resistance.

Regarding shear stress distribution mechanisms, some researchers hypothesized that stone columns work as a pure shear beam (Baez 1995), while others argue that stone columns behave in both flexure and shear and may not be effective to reduce shear stress in the surrounding soil (Green et al. 2008; Goughnour and Pestana 1998; Olgun and Martin 2008). No clear understanding has been developed regarding the reinforcing mechanism of stone columns. In addition, the deformation mechanism and level of shear stress/strain distribution between a stone column and surrounding soil are not yet quantified. Based on the foregoing discussion, there is an essential need for research to resolve these issues. For this purpose, 3D finite element analysis would be suitable because numerical simulations cost less than experimental tests but at the same time can give in-depth information to understand stone column behaviors during earthquakes. Analysis of 3D soil profiles and stone columns would also help to understand the spatial distribution of shear stress/strain, which otherwise cannot be observed from the relationship such as used in current design practice (e.g., Baez 1995). Using numerical analyses approach, ODOT-sponsored research is currently being carried out to investigate the effectiveness of the shear stress distribution mechanism of stone columns. The initial findings from the research can be found in Rayamajhi et al. (2012). 


\subsection{Pile Groups on Lateral Spreading Ground}

The lateral resistance of pile foundations in liquefiable strata is often critical to the design of bridges and other structures. Liquefaction induced lateral spreading results in large ground deformations and has led to extensive damage to pile-supported bridges and other structures in past earthquakes (e.g. Bartlett and Youd 1992; Benuzka 1990; Chu et al. 2000; Fujii et al. 1998; Youd 1993). In the past few decades, numerous studies (case histories, physical model tests, and numerical investigation) have been conducted by several researchers to understand the complex mechanisms of soil-pile interaction in liquefiable soil and the related effects on superstructure performance.

The following sections present an overview of pile group behavior under liquefaction induced lateral spreading ground based on experimental results. In addition, the critical parameters that influence the behavior of pile groups are identified. In subsequent sections, the capabilities and limitations of analysis methods for pile groups in liquefaction-induced lateral spreading ground are presented.

\subsubsection{Overview on behavior of pile groups based on experimental studies}

Generally, the load acting on a superstructure is larger than the capacity of a single pile. In addition, due to economic reasons, piles are usually constructed in groups and embedded in a reinforced concrete cap. Piles in a closely spaced group behave differently than single isolated piles because of pile-soil-pile interactions within the group (e.g., McVay et al. 1994, 1995, 1998; Remaud et al. 1998; Rollins et al. 2005a). In a pile group, an axially or laterally loaded pile generates its own displacement field, which interferes and overlaps with those of adjacent piles resulting in inefficiencies between piles within a group.

Interference of the displacement field generated by the each pile within a group makes for complex mechanisms in determining lateral resistance of a pile group. In the case of a pile group, each pile within the group moves under lateral loading, pushing the soil in the direction of applied load. The lateral displacement/force in each pile within a group depends upon the location of the pile. Displacement of the pile located in the first (leading) row is resisted by the soil in front of the pile, whereas the piles located behind the first row (trailing rows) move the soil, which in turn moves the piles in the rows in front of them (leading row), as shown in Figure 1.11. In a closely spaced pile group, the failure zones of individual piles overlap when the pile 
group moves laterally. This overlapping of failure zones causes load and deformation of trailing rows that are lower than those for the front row. This is commonly referred to as the "shadowing” effect (e.g., McVay et al. 1994). The lateral resistance of the piles in a single row of a pile group (i.e. perpendicular to the direction of applied lateral load) is also different due to the pile interaction. This interaction is commonly called the "group" effect.

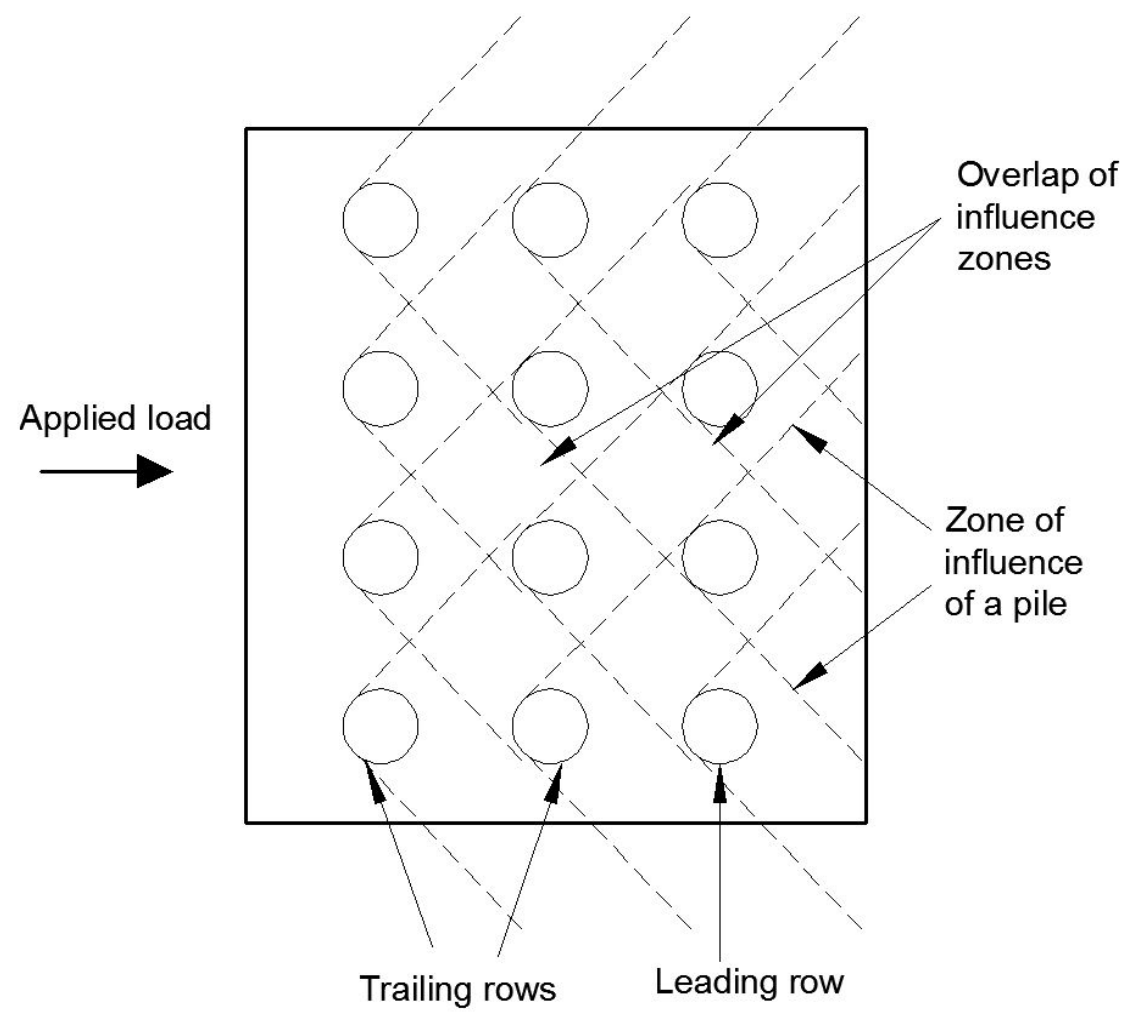

\section{Figure 1.11: Illustration of shadowing effect (overlapping zones creating additional load on piles within a group)}

The intensity of shadowing effects or interaction of the piles within the group also depends upon the liquefaction state of the surrounding soil. The lateral resistance of the piles in the leading and trailing rows in non-liquefied soil is different than that of liquefied soil. Full scale tests carried out by Brown et al. (1988) on pile groups installed on non-liquefied soil showed that the lateral resistance is greater for the front row piles than for the trailing rows and lateral resistance of piles in the trailing row within the group is remarkably lower than that for an isolated single pile. 
Rollins et al. (2005b) conducted several full scale lateral load tests on a single pile and a pile group before and after blast-induced liquefaction. They found that the lateral resistance of the isolated pile is nearly the same as that for piles in the group. In addition, the pile interaction effects are found to be relatively unimportant/negligible for pile groups in fully liquefied sand immediately following liquefaction. However, after the excess pore water pressure is dissipated from the liquefied sand, the pile interaction effects become significant.

The pile cap and its degree of fixity within the pile group also influence the behavior of piles within a group. Ashford et al. (2006) conducted full scale experiments to assess the behavior of single pile, 4-pile, and 9-pile groups subjected to blast induced lateral spreading at the Port of Tokachi, Hokkaido, Japan. Both the 4-pile and 9-pile group heads were restrained against rotation by a reinforced concrete cap. Compared to the single pile case, they found that restraining rotational movement of the pile cap led to stiffer response under loading exerted by liquefied soil resulting in smaller pile head displacement and smaller positive maximum moment in the individual piles within a group. In addition, they found that the degree of fixity of pile tips affects the moment of individual piles within a group, in that a larger degree of fixity resulted in greater bending moment in the pile.

The axial force present in the pile group also affects the lateral response of piles. Centrifuge experiments performed by Abdoun et al. (2003) on single piles and pile groups showed the axial forces in the pile group can lead to lower values of bending moments in the pile group as compared to a single pile. They postulate that the smaller moment demands in the pile group were due to the frame effect and the developed moment depended on the contribution of axial forces in the individual piles. They also found that the maximum bending moment always occurred at the boundaries between liquefied and non-liquefied soil.

Based on case histories of the 1995 Kobe earthquake, damage due to kinematic loading (i.e. from ground shaking and inertial loading) of pile groups are reported by several researchers (Tokimatsu et al. 1996, Tokimatsu and Asaka 1998, and Oh-Oka et al. 1997). In a simple soil profile and loading condition, the kinematics of a laterally loaded pile group is such that the piles in a group may have vertical movement in addition to lateral movement, rotation, and bending. The relative movement between the piles would occur under externally applied force and moment, causing the pile cap to rotate. This in turn forces the piles in the leading rows of the 
pile-cap center to undergo downward movement while the trailing rows experience uplift movement, as shown in Figure 1.12 (Salgado 2008).

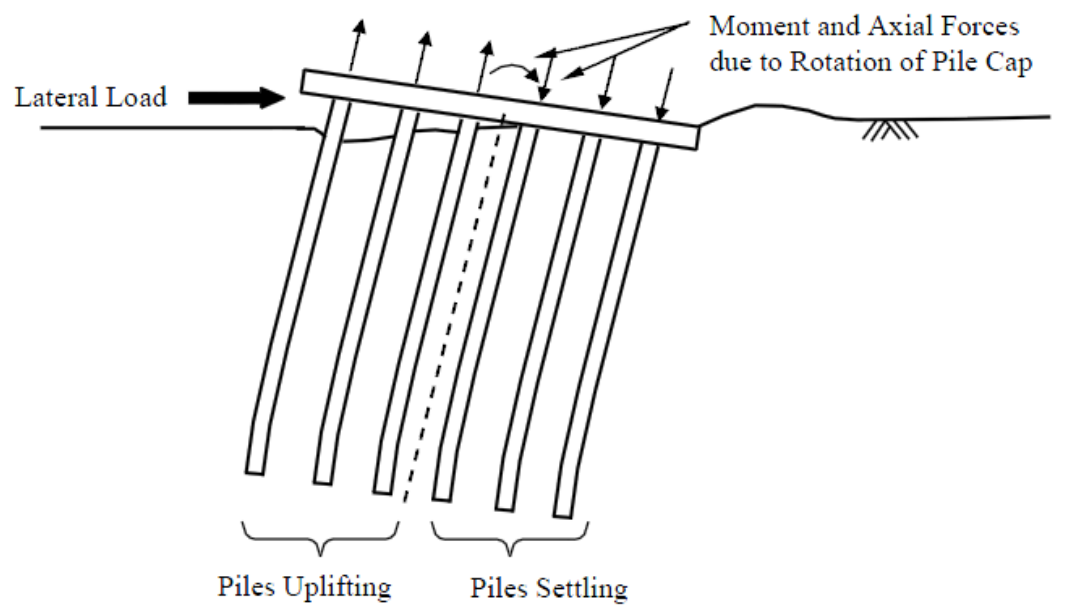

Figure 1.12: Kinematics of laterally load pile group

The kinematics of the group piles become more complicated in the presence of liquefaction induced laterally spreading ground. In addition, superstructure inertia and possibly laterally induced crustal loading increases the kinematic complexity, as shown in Figure 1.13. The crust load is generated from the movement of the crust layer in sloped ground. Due to liquefaction of the soil beneath the crust layer (Figure 1.13), the crust layer moves along the direction of lateral spreading, generating additional loads on the pile group. This additional load can further move the pile group, which again leads to increasing levels of crustal load. This is the typical pile-soil-pile interaction effect of pile groups in laterally spreading ground.

Passive pressures from the soil are often assumed to contribute the largest components of lateral loading, while friction forces along the sides and base of the pile caps are often neglected (e.g., JRA 2002). However, a number of researchers have shown that friction forces can impose significant loads on bridge components (e.g., Mokwa and Duncan 2001a, Rollins and Sparks 2002, Brandenberg et al. 2005). Friction loads from the side and base of the pile cap) can contribute significantly to the total crustal loads exerted on the pile foundation, and these friction loads can be nearly as large as passive forces exerted on the upslope faces of the pile caps 
(Brandenberg et al. 2005). The lateral loading from the liquefied soil depends upon the stiffness of the pile. If the piles are stiff relative to the soil, the liquefied soil exerts force along the direction of crust loading. For more flexible piles, the liquefiable soil may provide upslope lateral resistance on the pile, when the crust pushed the pile downslope such a way that the pile displacement is greater than that of the liquefiable soil.. Friction forces should also not be neglected when laterally spreading soils induce driving forces that increase seismic demands; but also should not be relied upon in cases where the soil provides resisting forces that reduce seismic demands on the structure (Brandenberg et al. 2005).

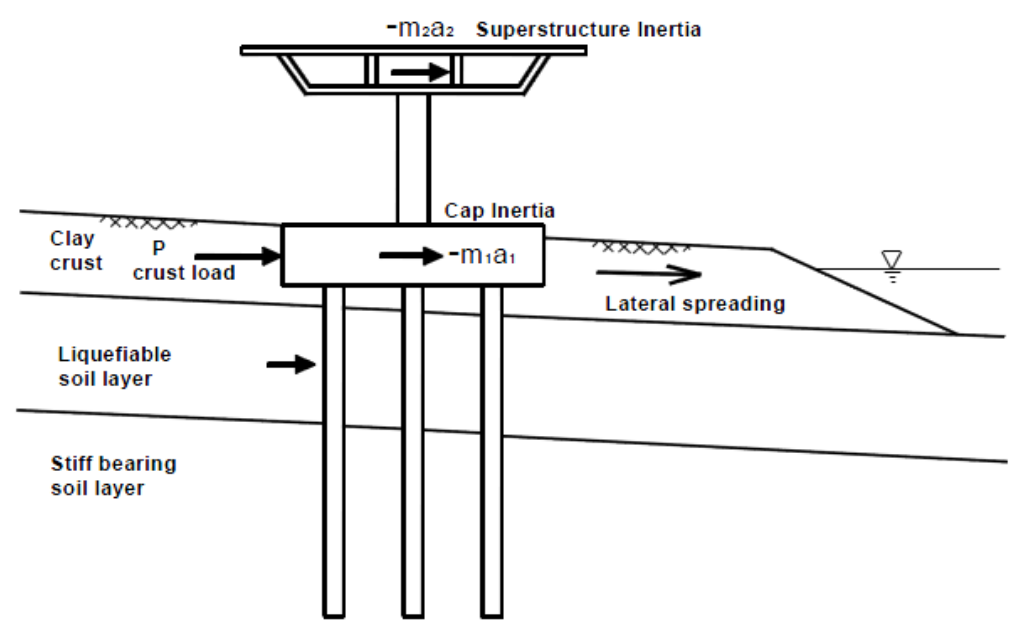

Figure 1.13: Illustration of kinematics of group piles in liquefaction induced lateral spreading
ground (adapted from Chang et al. 2005)

Dynamic centrifuge experiments by Chang et al. (2005) showed that the lateral response of pile groups and liquefaction of soil beneath the crust results in relatively low frequency crust loads relative to base shaking frequency. Crustal load/kinematic loading, cap inertia and superstructure inertia were observed in phase and in the same direction as the maximum crustal load. The maximum loading (shear force) induced on piles always occured during earthquake shaking and the peak shear force in the pile-structure can be estimated as the sum of crustal load and inertia load (Chang et al. 2005).

Tobita et al. (2006) conducted a series of centrifuge tests to study the dynamic behavior of pile foundations under lateral spreading. They conducted the experiments with different input 
accelerations and durations of shaking. It was found that the residual pile head displacement of the pile group becomes smaller as the duration of liquefaction becomes longer. The reason for this behavior was that the liquefied soils were soft enough to flow between the piles and exerts less lateral loads and longer shaking provides enough time for the piles to be unloaded.

Based on the review of past experimental studies on the performance of pile groups subjected to liquefaction induced lateral spreading, the following effects and behavior on the pile groups are found to be important.

\section{- Shadowing and Group Effects}

Shadowing effects of pile groups in non-liquefied soil is widely recognized in literature. Due to shadowing effects, piles in the leading row carry higher loads than piles in trailing rows, and the lateral resistance of piles within a group is lower than single isolated piles. Pile groups in liquefied soil show negligible shadowing effects immediately following the liquefaction (Rollins et al. 2005 b), and thus group and shadowing effects can be ignored in fully liquefied soil.

\section{- Pile Cap Rotation Restrained and Lateral Resistance}

Restraining rotation and lateral resistance of the pile cap leads to stiffer response under lateral loading applied by liquefied soil, resulting in smaller head displacement and maximum moment as compared to a single pile (Ashford et al. 2006).

\section{- Friction Force in Pile Cap}

Friction force on the pile cap (side and bottom) induces additional loading on the pile group. In addition, passive pressure and friction force should not be neglected in design calculations. Assuming lateral loads are dominated by passive forces only could be very unconservative (Brandenberg et al. 2005). 
- Kinematic Loading or Crust Load and Inertial Loading

Crustal and inertial loading (both pile cap mass and superstructure) act in phase during the peak response of soil. A suitable combination of these loads is required to predict accurately the lateral response of a pile group.

\section{- Lateral Resistance of Liquefied Soil}

The lateral resistance provided by the liquefied soil becomes lower than the nonliquefied soil, thus reduced lateral resistance for liquefied soil should be considered in the pile group analysis/design

\section{- Axial Force in Piles}

The contribution of axial force affects the maximum moment of individual piles in the group. Significant contribution of axial force from the piles in a group may result in less moment in individual piles in the group as compared to a single pile (Abdoun et al. 2003).

- Degree of Fixity at the Pile Tip

The extent of fixity of piles in a group influences the maximum moment of individual piles (Ashford et al. 2006).

\section{- Duration of Liquefaction}

The permanent lateral deformation of a pile cap depends on the earthquake shaking period and the duration of liquefaction. The longer the duration of motion, the less residual deformation of pile caps observed (Tobita et al. 2006).

\subsubsection{Numerical Analysis Methods for Pile Groups}

To design pile-supported deep foundations in liquefiable soils, a good understanding of soil-pilestructure interaction is required along with robust analysis methods. The behavior of piles under working load conditions has been the focus of numerous studies over the past few decades. The analysis methods available in the literature range from simplified methods (e.g., limit 
equilibrium method, p-y methods) to complex methods based on 3D FEM. In the following section, the procedures involved in different methods are summarized.

\subsubsection{Limit Equilibrium Method of Analysis}

The limit equilibrium (LE) method involves applying passive pressures that are independent of the free-field soil displacements. The underlying assumption for this method is that free-field soil displacement is large enough to cause laterally spreading soils to reach their ultimate passive earth pressure resistance.

The Japan Road Association (JRA 2002) provides guidelines to analyze piles subjected to liquefaction induced lateral spreading. For kinematic loading from lateral spreading, the JRA guidelines impose lateral pressures from the liquefied layer and from any overlying non-liquefied layers, as shown in Figure 1.14. Estimations of lateral movement forces are provided in JRA (2002) were based on calibrating the damages from the 1995 Kobe, Hyogo-ken Nanbu earthquake. The non-liquefied layers are assumed to impose passive earth pressures into piles located within 100-m from the waterfront and depends on liquefaction index. The liquefied layers are assumed to impose a lateral pressure equal to $30 \%$ of the total overburden stress, subject to a reduction factor for being within 50-m from water front . Lateral pressures from the non-liquefied and liquefied layers are reduced by a factor of 0.5 for distances of 50 to $100-\mathrm{m}$, and neglected for distances greater than 100-m. These modification factors for water front distance were obtained empirically based on the lessons learned from the 1995 Kobe earthquake.

Abdoun (1997) and Dobry et al. (2003) utilized the LE method to analyze piles and compared the results with series of centrifuge tests. In Abdoun analysis, the soil pressure of liquefied layers is assumed to be equivalent to a uniform pressure of $10 \mathrm{kN} / \mathrm{m}^{2}$ (Figure 1.14). The assumed uniform pressure from liquefied soil reasonably predicted the experimental centrifuge data. The LE method could reasonably predict the occurrence of maximum bending moment at the interface between liquefied and non-liquefied soil layers. Dobry et al. (2003) also used the same experimental centrifuge tests to calibrate the LE analysis results and proposed the two LE methods for evaluating the bending moments in a single pile foundation subjected to laterally spreading ground. The case study conducted by Dobry et al. (2003) using their proposed LE methods predicted well the response of end-bearing and floating piles under laterally spreading ground. 
Ashford and Juirnarongrit (2004) evaluated the LE method for the case of a single pile subjected to lateral spreading. They compared the results with full scale tests of piles subjected to blast induced lateral spreading. The displacements were computed based on structural mechanics for cantilever beam conditions using pile properties and loads acting on the pile. It was found that the LE method reasonably estimates the pile bending moments but underestimates the pile displacements. This is one of the limitations of the LE method in that the lateral displacement of piles cannot be determined accurately.

From the literature review of pile groups (Section 1.3.1), it was found that friction forces between the lateral spreading crust and the pile cap (side and below) are significant. However, JRA (2002) does not provide any guidelines to account for this effect. In fact, no specific studies have been found to account for such effects using the LE method. Furthermore, this method is limited to static analysis and cannot be utilized to predict the response of piles directly subjected to earthquake ground motion, i.e., dynamic time history analysis. Therefore, this method cannot directly simulate the dynamic loading from pile cap mass or superstructure mass, which are very critical to the behavior of pile groups as discussed in Section 1.3.1.

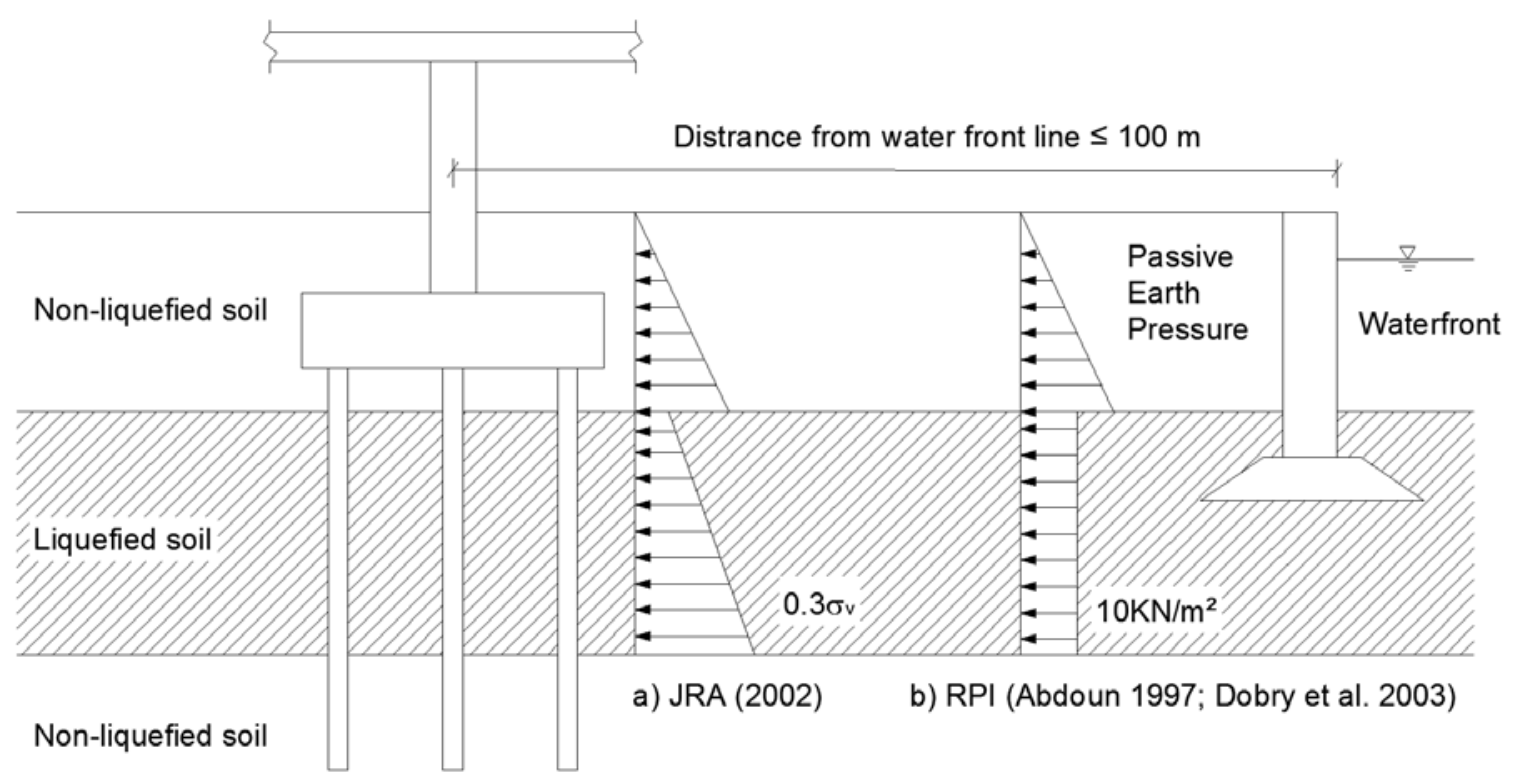

Figure 1.14: Limit equilibrium method based on recommendations by (a) JRA (2002) and (b) centrifuge test results at RPI (Abdoun 1997; Dobry et al.2003) 


\subsubsection{The $p$-y Method of Analysis}

The $p-y$ method using pushover analysis is one of the most widely accepted simplified methods to analyze the pile supported deep foundation under lateral loading. This method is based on the modification of the concept of Beam on Nonlinear Winkler Foundation (BNWF). In the $p-y$ analysis method, the soil is represented by a series of independent soil springs along the length of the pile (i.e., the soil is divided into finite intervals along the depth), and the piles are modeled using elastic beam elements. The properties of the nonlinear soil spring are represented by the relationship between the lateral soil resistance $(p)$ and relative displacement $(y)$ between the pile $\left(y_{p}\right)$ and soil $\left(y_{s}\right)$, and commonly called $p$-y curves as shown in Figure 1.15. The response of the pile foundation is estimated by imposing the lateral spreading displacement of the liquefied soil and overlying crust layer. This method is sometimes termed as displacement method of p-y analysis.

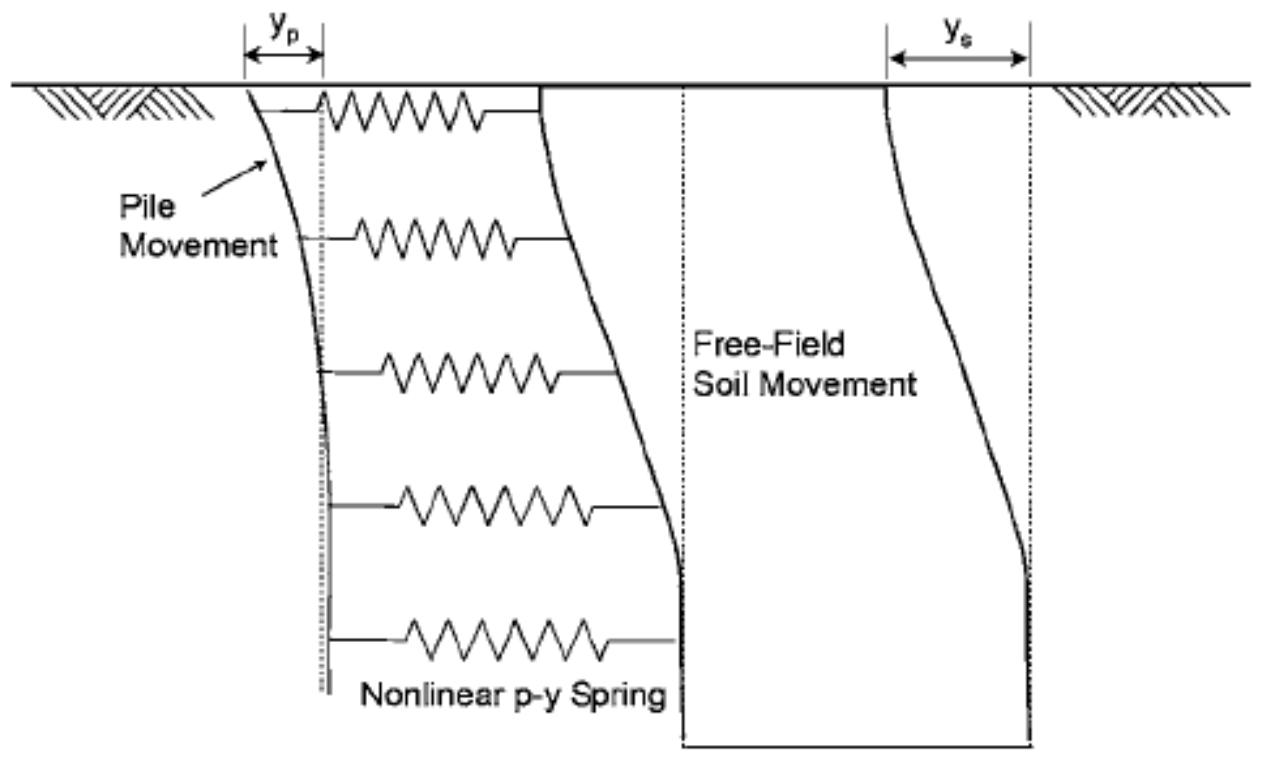

Figure 1.15: The $\mathrm{p}-\mathrm{y}$ analysis model for pile subjected to lateral spreading (adapted from Juirnarongrit and Ashford 2006) 
The modeling and analysis of single piles under laterally spreading soil is relatively simple. However, analyses of pile groups using the $p-y$ method are much more complex than single piles because of several factors that need to be considered (Section 1.3.1). During the past two decades, several researchers have proposed techniques to evaluate and design piles groups subjected to lateral spreading.

One simple approach is to model the pile group as an equivalent single pile (Mokwa 1999; Juirnarongrit and Ashford 2006). In this technique, the stiffness of the equivalent single pile is estimated by combining the stiffness of all the individual piles in a single group. To account for interaction of piles within a group, a $p$-multiplier ( $f_{m}$, described later) is applied in the $p-y$ curve of the nonlinear spring for the individual pile, and then the equivalent $p-y$ curve is estimated by combining the $p-y$ curves of all individual piles within a group.

Juirnarongrit and Ashford (2006) evaluated the response of 4-pile and 9-pile groups subjected to blast-induced lateral spreading using LPILE (http://www.ensoftinc.com) for the computational platform. The 4-pile group was modeled using the $p-y$ approach shown in Figure 1.16, where the pile cap is modeled as a pile with diameter equal to the width of the pile cap. The lateral resistance of the soil around the pile is modeled as a soil spring. Juirnarongrit and Ashford investigated the three conditions of pile cap rotation behavior; namely, free head, fixed head, and with a rotational spring. It was found that neither the free head nor fixed head conditions provided a better estimate of pile response; however, reasonable estimation of pile bending moments and pile displacement was achieved using a cap rotational spring. In terms of modeling, their study did not include the effect of pile cap inertia and friction force on the sides and below the pile cap. Experiments on pile groups show that inertia of the pile cap and friction force between the side and below the pile cap are important parameters for design (Brandenberg et al. 2005). 


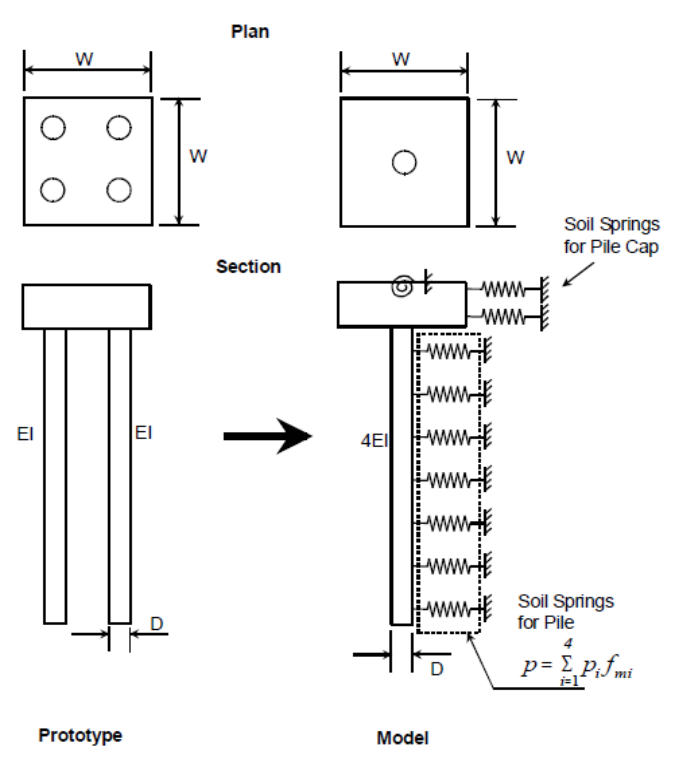

Figure 1.16: The $p$-y analysis for pile group (adapted from Juirnarongrit and Ashford 2006)

Some limitations of the simplified equivalent single pile method can be improved by adopting the method used by Brandenderg et al. (2007). Their model is an extension of the equivalent single pile but is more advanced and more detailed. They used OpenSees as a computational platform. The basic schematic of the $p$-y model used by Brandenderg et al. is shown in Figure 1.17, where the pile groups are not modeled as a single pile. Instead, the piles perpendicular to the direction of loading are combined and replaced with the equivalent size/stiffness pile. The pile cap is modeled using a beam element with equivalent size as the width of the cap. The lateral resistance of the pile is defined by using $p$-y curves. In addition, this model explicitly incorporates the skin friction resistance and tip resistance of individual piles within a group. Inertial load is directly applied at the location of pile cap combined together with the laterally spreading displacement. The detailed modeling procedure is described in Boulanger et al. (2003). Brandenderg et al. (2007) compared the response of pile groups modeled by using the above described procedure with experimental dynamic centrifuge tests results. They found that the pile group responses can be reasonably predicted using this procedure. The pile bending moments were overpredicted on average (16th and 84th percentile errors were $-8 \%$ and $+69 \%$, respectively) and pile cap displacement underpredicted on average (16th and 84th percentile errors were $-38 \%$ and $-6 \%$ ). 


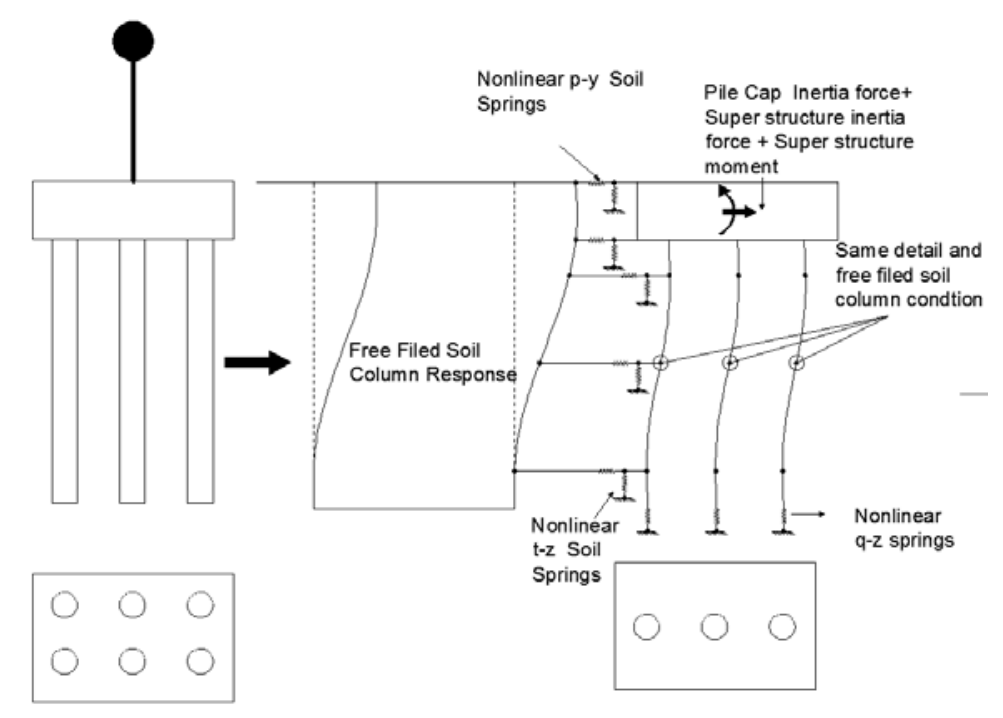

Figure 1.17: Schematic diagram for the $p$-y analysis method for pile group (using pushover analysis)

An alternative method to conduct $p-y$ analyses that accounts for the effect of liquefaction induced lateral spreading on a pile group is based on limiting pressure (sometimes termed the force-based method). In this technique, passive pressure is applied over the depth of the laterally spreading soil. The $p$-y springs of laterally spreading soil are removed including the crust layer (if any) but, $p-y$ springs are used in the underlying non-liquefied soil. The applied lateral pressures are independent of the free-field soil displacements since the soil movements are assumed to be large enough to cause lateral pressures to reach their limiting values. The schematic diagram for this method and comparison with the displacement imposing method is shown in Figure 1.18.

Brandenderg et al. (2007) conducted numerical studies using limiting pressure techniques to evaluate the response of pile groups subjected to lateral spreading. The limiting pressure method reasonably predicts bending moments for large earthquakes, but overpredicts bending moments for small and medium earthquakes because at small load the limiting pressure may not fully mobilized. On the other hand, this method underpredicts the lateral displacement of pile cap. Though Brandenderg et al. (2007) have conducted the p-y analyses using both displacement based and force based method, no specific conclusions were made regarding the superiority of one method to another in this publication. 

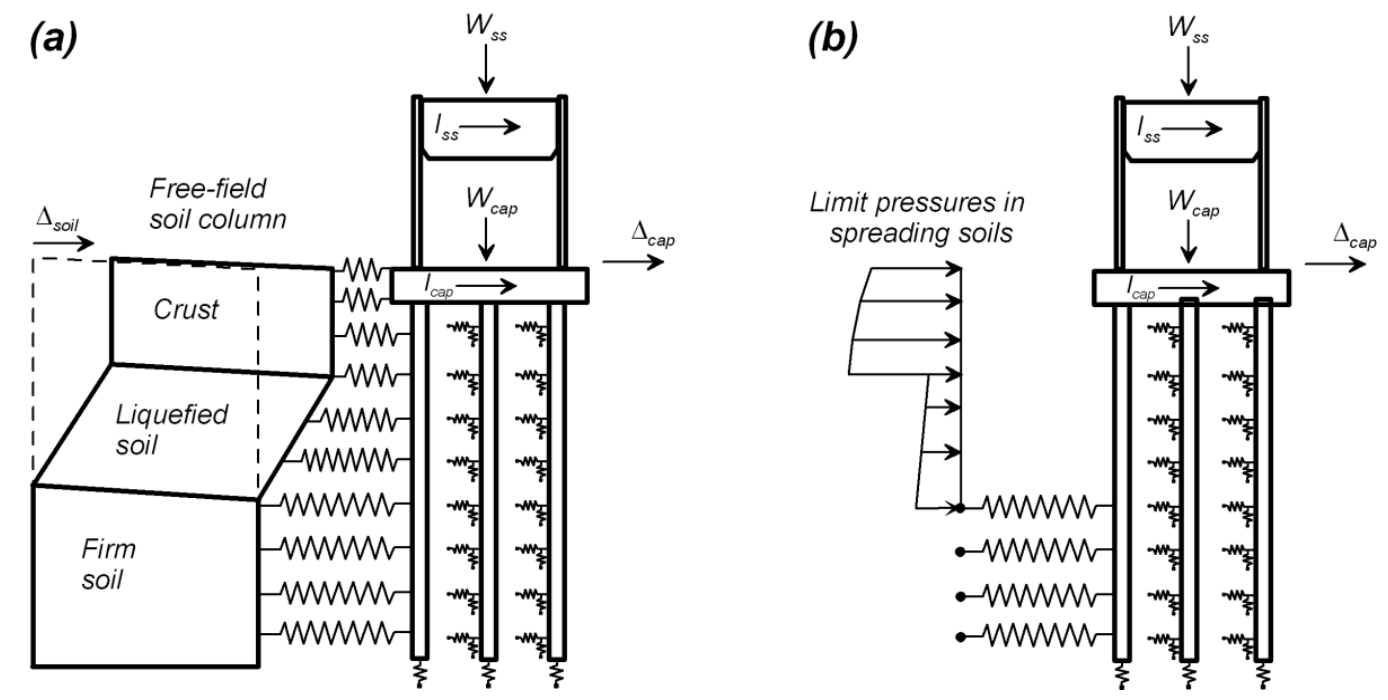

\section{Figure 1.18: p-y Analysis method using displacement imposing method (a) compared with limiting pressure (b) (after from Boulanger et al. 2003)}

Though the $p-y$ method of analysis can reasonably estimate the lateral response of the pile group, there are other limitations:

- $p$-y curves are developed empirically by back-fitting the results of numerical analysis to match the actual field pile-load test results. Thus, $p$-y curves developed for a particular site may not necessarily be applicable to other sites.

- Pushover analysis can reasonably estimate the envelope of the response; however, this method does not capture the cyclic behavior of soil (i.e. dilation and contraction) and the accumulation of permanent displacement and rotation during cyclic loading (Brandenderg et al. 2007).

- The assumption of simultaneous application of lateral spreading deformation and inertia load is valid for stiffer piles but conservative for flexible piles (Brandenderg et al. 2007). 
- This method cannot account for the dynamic behavior of pile cap and superstructure mass nor can it account for the duration of earthquake ground motion.

To account for some of the above limitations (e.g. dynamic inertial loading and earthquake duration), nonlinear dynamic time history analysis of pile groups is required. Although the modeling techniques described above are quite advanced, dynamic time history analysis is a more complicated and sophisticated modeling technique. The basic schematic diagram for pile group analysis using the $p-y$ method with dynamic time history analysis is shown in Figure 1.19. The free field response of the soil is model with more advanced soil constitutive model, which can capture behavior of soil under cyclic loading (i.e. contraction, dilation, and shear strain accumulation). In this analysis, rather than imposing any displacement or pressure load, the liquefaction induced lateral spreading load is implicitly incorporated through the far field soil modeling. This modeling and analysis technique was adopted for the evaluation of pile groups in non-liquefied soil by Curras et al. (2001). Boulanger et al. (2003) conducted numerical investigations using OpenSees, with a procedure similar to that described above, for a single pile subjected to liquefaction induced lateral spreading. They found that this method could reasonably capture the principle features of single pile behavior and liquefaction effects.

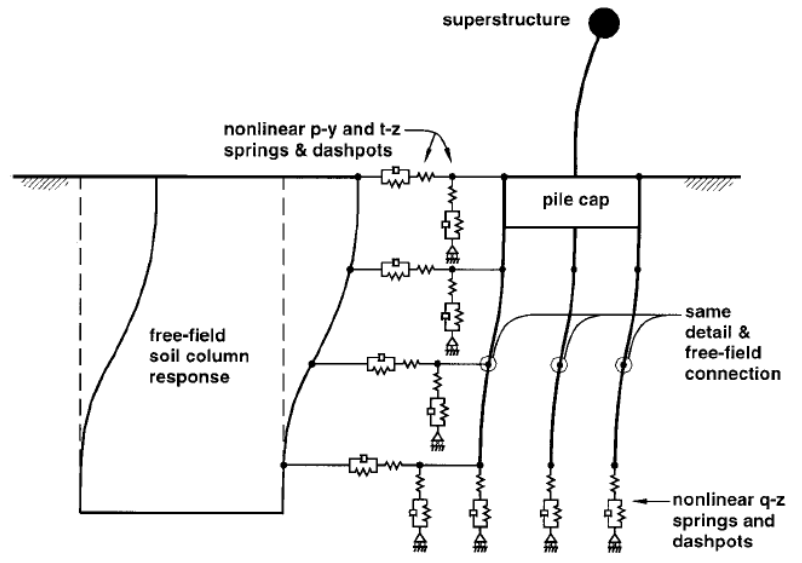

Figure 1.19: Schematic diagram for the p-y analysis method for pile group using dynamic time history analysis (adapted from Curras et al. 2001) 


\section{p-y Curves for Liquefied Soil}

It is recognized that the $p-y$ curves of soil are affected by liquefaction. Although several methods are available to develop $p-y$ curves for non-liquefied soil (Resse 1974; API 1987), limited guidelines are available to account for lateral resistance of liquefied soil. Researchers have proposed different methods to account for the effect of liquefaction on p-y curves based on full scale or centrifuge test results.

Based on their centrifuge test model, Liu and Dobry (1995) and Wilson (1998) proposed the $p$-multiplier ( $m_{p}$, a scaling factor) to incorporate liquefaction of the soil. This factor multiplies the $p-y$ curves of non-liquefied soil to obtain the equivalent $p-y$ curves for liquefied soil. The value of $\mathrm{m}_{p}$ varies from 0.3 to 0.1 , and it decreases with an increase in pore water pressure and becomes 0.1 when the excess pore water pressure becomes unity (i.e. $r_{u}=1$ ). Wilson et al. (2000) suggested that the $p$-multiplier for a fully liquefied soil also depends on the initial relative density, $D_{r}$. The values of the $p$-multiplier for liquefied sand ranged from 0.1 to 0.2 at about $35 \%$ relative density and from 0.25 to 0.35 at $55 \%$ relative density.

For the lateral resistance of liquefied soil, Wang and Reese (1998) proposed to model the properties of liquefied sand as soft clay. The $p-y$ curves were generated using the soft clay criteria and the maximum undrained shear strength was set equal to the residual strength of liquefied sand. Rollins et al. (2005b) conducted the lateral analysis of piles subjected to lateral spreading and compared the results with full-scale blast induced liquefaction tests of piles. They investigated three methods to incorporate the liquefaction effect on pile response: the Wang and Reese (1998) approach of residual strength, the Liu and Dobry (1995) and Wilson (1998) approach of $p$-multiplier, and no lateral resistance of liquefied soil. It was found that none of the approaches could predict accurately the lateral response of piles subjected to liquefaction.

The $p-y$ curves of liquefied and laterally spreading soil are much more complex than nonliquefied soil. In fact, back calculated $p-y$ curves from full scale experiments (Weaver et al. 2005; Rollins et al. 2005b) and small-scale centrifuge experiments (Wilson et al. 2000) are characterized by concave-up load displacement shape where the slope of the curve increases as the displacement increases. This nature of $p-y$ curves is due to dilative behavior during the shearing of sand and the shear strains that cause dilatancy can be imposed by the pile as it pushes through the liquefied sand or by free-field ground shaking (Ashford et al. 2011). The relationship 
proposed by Rollins et al. (2005b) can estimate the $p$ - $y$ curves for liquefied sand as a function of depth; however, the relationship was derived for soil pressure of $15 \mathrm{kN} / \mathrm{m}^{2}$ or less, deflection of 150-mm or less, liquefied sand depth of 6-m and initial relative density of sand approximately $50 \%$. Thus, the relationship is only suitable for similar type conditions of liquefied soil. Recently, Ashford et al. (2011) compiled p-multipliers for liquefied sand based on published recommendations as shown in Figure 1.20. The $p$-multipliers for liquefied sand can be obtained based on SPT blow count in equivalent clean sand.

A review of literature shows that there is not a consistent procedure for considering liquefaction resistance of liquefied soil. The prediction of strength of liquefied soil varies quite significantly between different researchers therefore cautions need to be made when selecting analysis methods for piles in liquefaction induced laterally spreading ground.

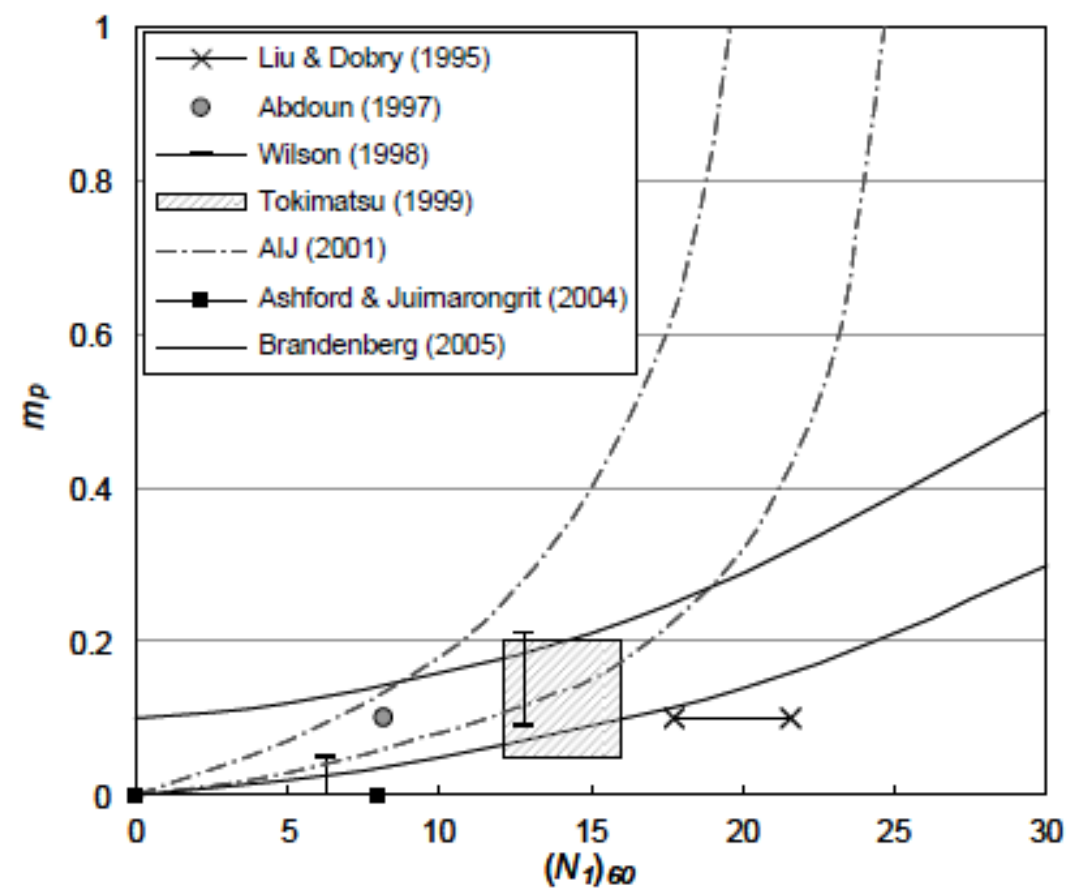

Figure 1.20: $p$-multiplier $\left(m_{p}\right)$ versus clean sand equivalent corrected blow count, $\left(N_{1}\right)_{60 c s}$, from a variety of studies (Ashford et al. 2011) 


\section{Pile Group Effects using p-multipliers}

As noted in Section 1.3.1, piles in a group carry unequal lateral loads depending on their location within the group and the spacing between piles. This unequal distribution of load is caused by "shadowing” and "group" effects that cause soil resistance to reduce within a pile group. A popular method to account for shadowing effects is to incorporate $p$-multipliers into the $p-y$ method of analysis as shown in Figure 1.21. Several $p$-multipliers are available in the literature to account for shadowing effects. An extensive literature review conducted by Mokwa (Mokwa and Duncan 2001b) compiled p-multipliers obtained from several full scale and centrifuge model tests, as shown in Figure 1.22. Their p-multipliers depend upon the diameter of the pile, spacing between the leading and trailing rows, and the location of the pile row. Juirnarongrit and Ashford (2006) compiled $p$-multipliers from previous published experimental studies on different soils (e.g., clay, sand, silty sand) and the blast-induced liquefaction experiment by Ashford and Rollins (2002). They proposed a chart for $p$-multipliers for pile group analysis, as shown in Figure 1.23. Their $p$-multipliers only depend on the spacing between the piles in terms of pile diameter and the location of rows within a pile group.
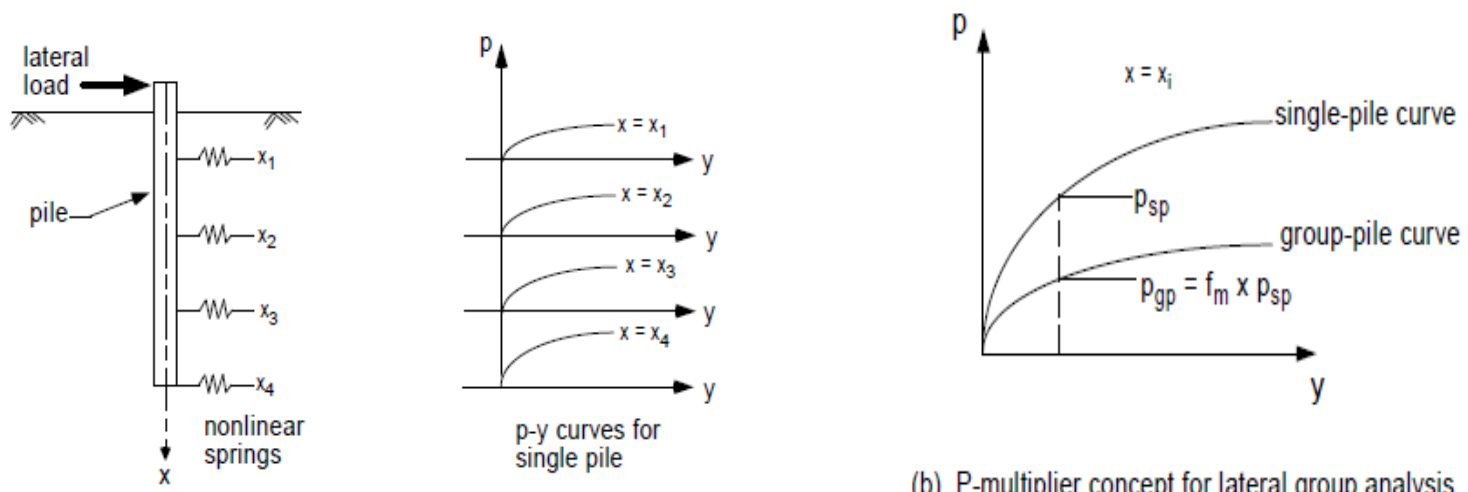

(b) P-multiplier concept for lateral group analysis.

(a) Single pile model.

Figure 1.21: p-y models for laterally loaded piles (adapted from Mokwa 1999) 


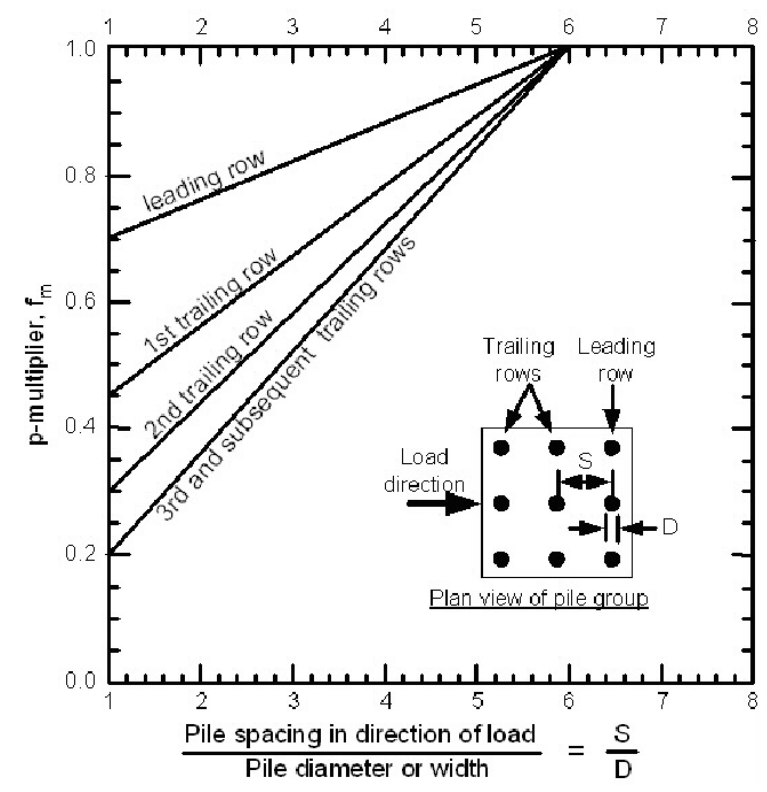

Figure 1.22: Recommended p-multipliers for group effects (from Mokwa and Duncan, 2001b)
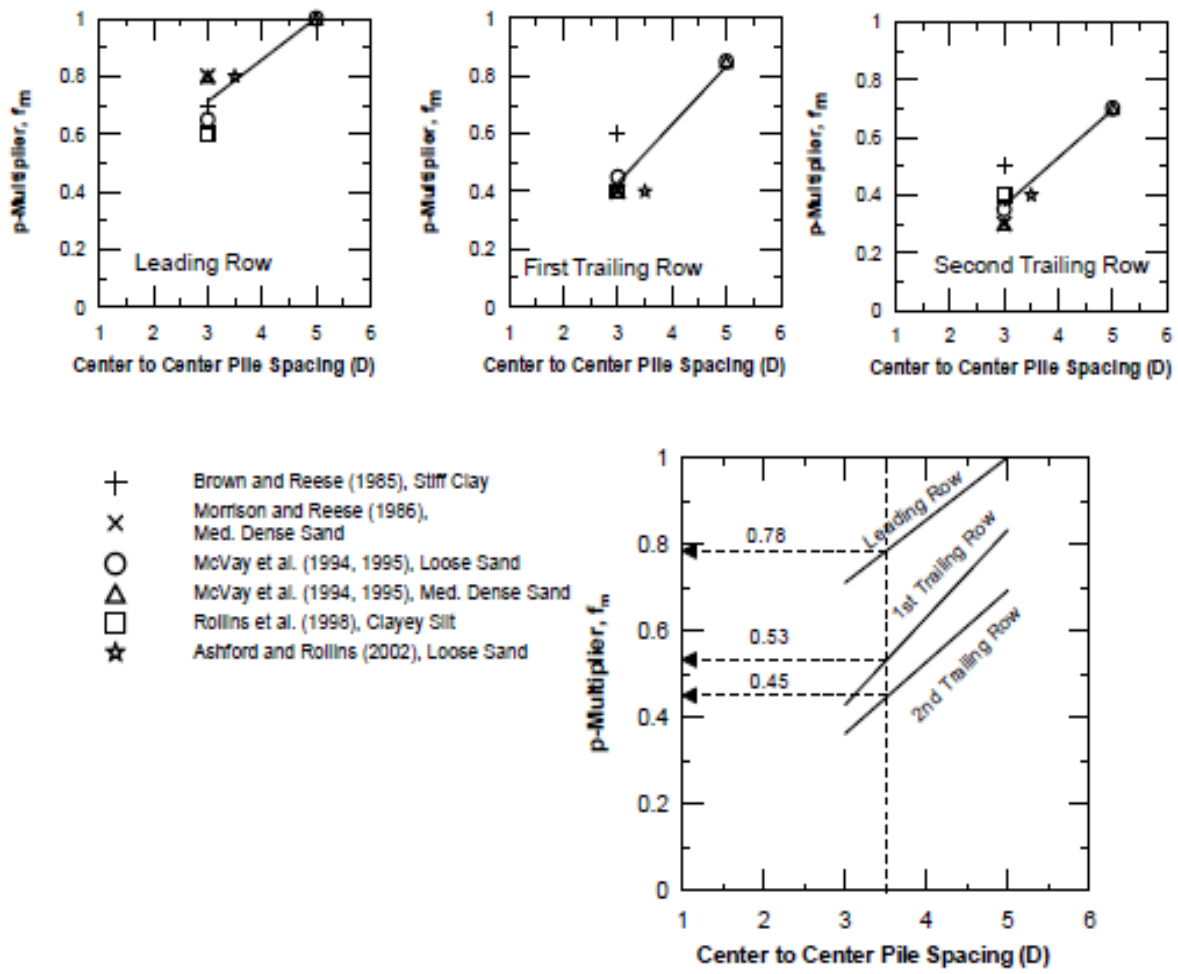

Figure 1.23: p-multiplier for the pile group (Juirnarongrit and Ashford 2006) 


\subsubsection{Finite Element Method of Analysis}

The more advanced and sophisticated method for assessing soil-pile interaction behavior in liquefaction induced laterally spreading soil is using nonlinear dynamic 2D/3D FE analysis. This method can be used with a variety of constitutive models including those for liquefiable soils (e.g., Li and Dafalias 2000; Yang et al. 2003). FE analysis has the ability to simulate contraction and dilation behavior of soil during liquefaction, in addition to capturing the interaction between the pile-soil-pile and superstructure. However, the accuracy of the results depends upon the ability to predict soil properties and selecting appropriate constitutive models to represent actual soil conditions, which depends on the calibration and validation of numerical methods with physical test data. Unfortunately, there is very limited experimental data available for calibration for liquefaction induced laterally spreading ground conditions. The major disadvantage of FE method is the high demand for computation time, input data, and interpretation of results.

In FE modeling, all components are modeled with solid elements, typically isoparametric hexahedron elements / brick elements (Brown and Shie 1990; Kimuara et al.1995; Muqtadir and Desai 1986; Trochanis 1991; Wakai et al. 1999; Elgamal et al. 2003; Yang and Jeremic 2003, 2005). Interface elements simulate interaction between the soil and structural elements, which includes behavior such as stick or no slip mode, slip or sliding mode, and separation or debonding mode (Muqtadir and Desai 1986; Elgamal et al. 2003; Yang and Jeremic 2003; Petek 2006; Lam et al. 2009). The pile-soil interface (usually a thin layer in size) is also modeled with solid elements. Each component (i.e., pile, pile cap, soil, and interface element) is modeled with their own constitutive relationship, which varies from linear elastic to non-linear elastic, and elastic-perfectly plastic behavior depending upon the simplification considered in the analysis (Pressley and Poulos 1986; Muqtadir and Desai 1986; Brown and Shie 1990; Trochanis et al. 1991).

Wakai et al. (1999) have simulated a number of models on fixed and free head pile groups by using 3D elastic-plastic FE method and found a good correlation between the experimental and analytical results. Bourgeois et al. (2010) used the 3D FE method to simulate the behavior of vertical piles under cyclic loading. Their results also showed good match between experimental and simulated results. Yang and Jeremic (2003) conducted numerical analysis of group effects for $3 \times 3$ and $4 \times 3$ pile groups in loose and dense sands using 3D FE method with elastic-plastic material. They used OpenSees (Mazzoni et al. 2007) as the 
computational platform to conduct static pushover analysis and successfully simulated centrifuge test results. In recent years, development in FEM has been quite significant. Several soil constitutive models are available to simulate the response of different soils including the earthquake-induce liquefaction and pile group response on these soils. Elgamal et al. (2009) showed computational power of OpenSees to simulate 3D pile group response in liquefaction induced laterally spreading conditions.

McGann et al. (2011) conducted several 3D FE analysis of a single pile in laterally spreading ground and evaluated the applicability of conventional $p-y$ curves in computing the pile response. They found significant difference between the results obtained from 3D FE analysis and by using conventional $p-y$ analysis. The API curves tend to have significantly higher initial stiffness than the $p-y$ curves derived from 3D FE analysis. They concluded that conventional p-y curves using API (1987) gives unreasonable results for use in design by predicting high moment demand in the pile as compared to 3D FE analysis. Therefore, recommendations were made not using such $p$ - $y$ curves without modifications for initial stiffness and ultimate resistance. Since, 3D FE analysis requires very high computational effort in terms of time and cost, FE analysis for pile group in routine engineering design practice is beyond reach.

\subsubsection{CALTRANS Lateral Spreading Design Guidelines}

Based on recommended procedures developed by Ashford et al. (2011), the California Department of Transportation (CALTRANS) established draft guidelines for the design of pile foundations in liquefaction-induced laterally spreading ground. The procedure recommended by CALTRANS (2011) is based on an equivalent nonlinear static analysis methodology (or p-y analysis method) as discussed in Section 1.3.2.2. In particular, the guidelines provide for two distinct design cases: (1) an unrestrained ground displacement case in which the foundation does not provide any support to large soil mass movement, and (2) foundation restrained ground displacement design case in which the failure soil mass is limited so that the foundation provides partial restraint to its movement. The typical schematic diagram for these two cases is shown in Figure 1.24. The following section summarizes the design of these cases recommended in CALTRANS (2011). 


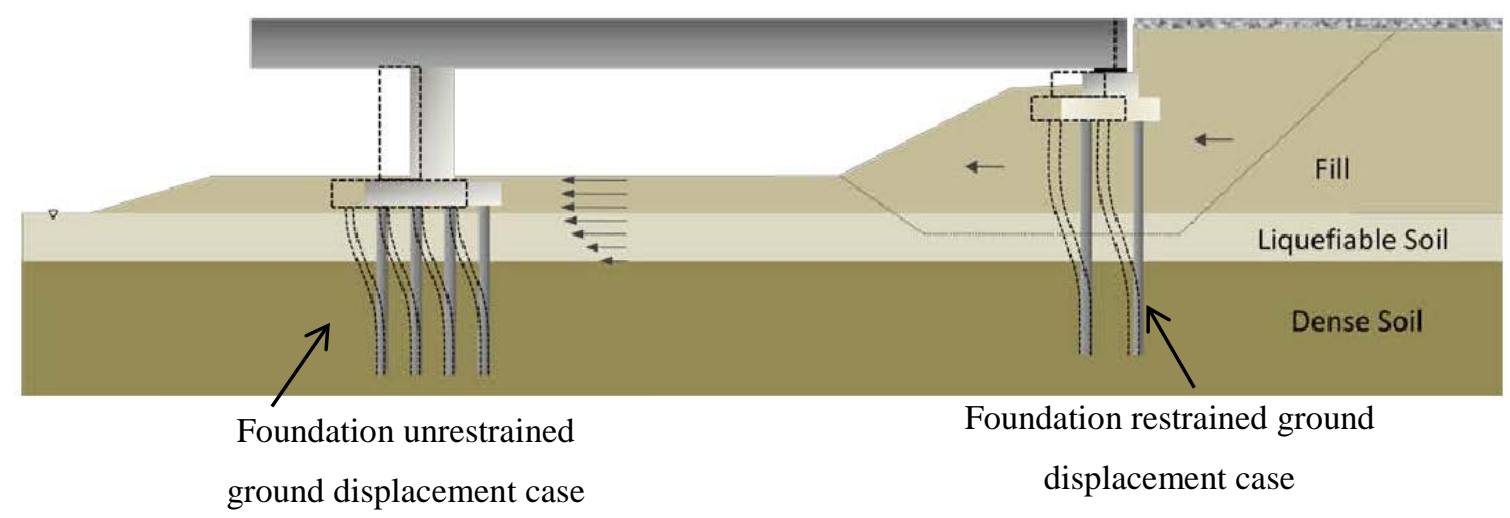

Figure 1.24: Diagrams for foundation restrained and unrestrained displacement cases (CALTRANS 2011)

\subsubsection{Unrestrained Ground Displacement Design Case}

In the unrestrained design case, it is assumed that the displacing soil mass is significantly large such that the foundation cannot provide any resistance to its flow or movement. The implication is that the lateral resistance of the foundation is relatively negligible compared to the lateral spreading loads and that the soil mass displaces the same amount regardless of the presence of the foundation. A typical case for the unrestrained ground displacement case is shown in Figure 1.24. The overall seismic evaluation procedures involve estimating crustal displacement and providing sufficient capacity to foundation to satisfy the lateral spreading load demand. The overall procedures to design the foundations for the unrestrained ground displacement case are carried out in the following steps:

\section{1) Assess Liquefaction Potential of Soils}

The liquefaction potential of the site soils are evaluated for peak ground acceleration (PGA) based on 5\% in 50 years seismic hazard at the particular site. The liquefaction assessment can be carried out using semi-empirical and field based simplified procedures (e.g., Youd et al. 2001).

\section{2) Estimate Residual Strengths of Liquefied Soils and $p$-y Curves}

Two approaches are recommended to account for the lateral resistance ( $p$ - $y$ curves) of the liquefied soil without any particular preference. The first method is based on the $p$ - 
multiplier $\left(m_{p}\right)$ approach in which the $p$-y curves for the liquefied soils are obtained by scaling the $p-y$ curves of equivalent clean sand as described in Section 1.3.2.2 (e.g., Ashford et al. 2011). The second method is based on using $p-y$ curves for soft clay (e.g. Matlock 1970) in which the undrained shear strength of the soft clay is replaced by the residual strength of the liquefied soil estimated from semi-empirical relationship (e.g., Wang 2003, Kramer 2008).

\section{3) Estimate Lateral Spreading Displacement of Slope}

First, the slope stability factor of safety (FS) is determined without taking into account any effect of foundation. If $\mathrm{FS} \leq 1.05$ then flow type failure with a very large soil displacement is assumed. When the lateral displacement is sufficiently large, ultimate passive force for the crust on the foundation is fully mobilized and analysis is considered to be insensitive to the specific displacement value. Typically, an assumption of 5-ft of crustal displacement is assumed to be sufficient to mobilize the passive earth pressure. If FS $>1.05$, the lateral spreading displacement is estimated using simplified procedures. Two methods are recommended based on the slope failure surface predictability. When the slope has a predictable failure surface, a Newmark sliding block-based approach is recommended and the deformation is estimated using the Bray and Travasarou (2007) procedure. When the slope is gentle, the failure surface is difficult to define, and displacement is the result of distributed shear, the displacement is estimated using the strain potential approach based on Faris et al. (2006) methods.

\section{4) Develop Foundation Model}

The $p-y$ method of analysis is used which is based on BNWF concept as discussed in Section 1.3.2.2. The overall procedure involves defining an equivalent pile model for a pile group foundation, defining $p-y$ curves for the pile cap (to capture pile cap-soil interaction), and defining $p-y$ curves for the piles (to capture soil-pile-soil interaction). The schematic modeling technique using an equivalent pile method is shown in Figure 1.25. The worked out examples in CALTRANS (2011) were based on the LPILE software 
Section analysis is carried out to obtain the nonlinear moment-curvature relationship for the pile in the group. The flexural stiffness and bending moment of the equivalent pile is obtained by multiplying the flexural stiffness and bending moment of a single pile by the number of piles in the group. The pile cap is modeled as an elastic section with relatively large bending stiffness (for rigid behavior) compared to the piles. A rotational restraint is provided as a boundary condition at the top of the pile, which accommodates finite rotation of pile cap (e.g., Mokwa and Duncan 2003).
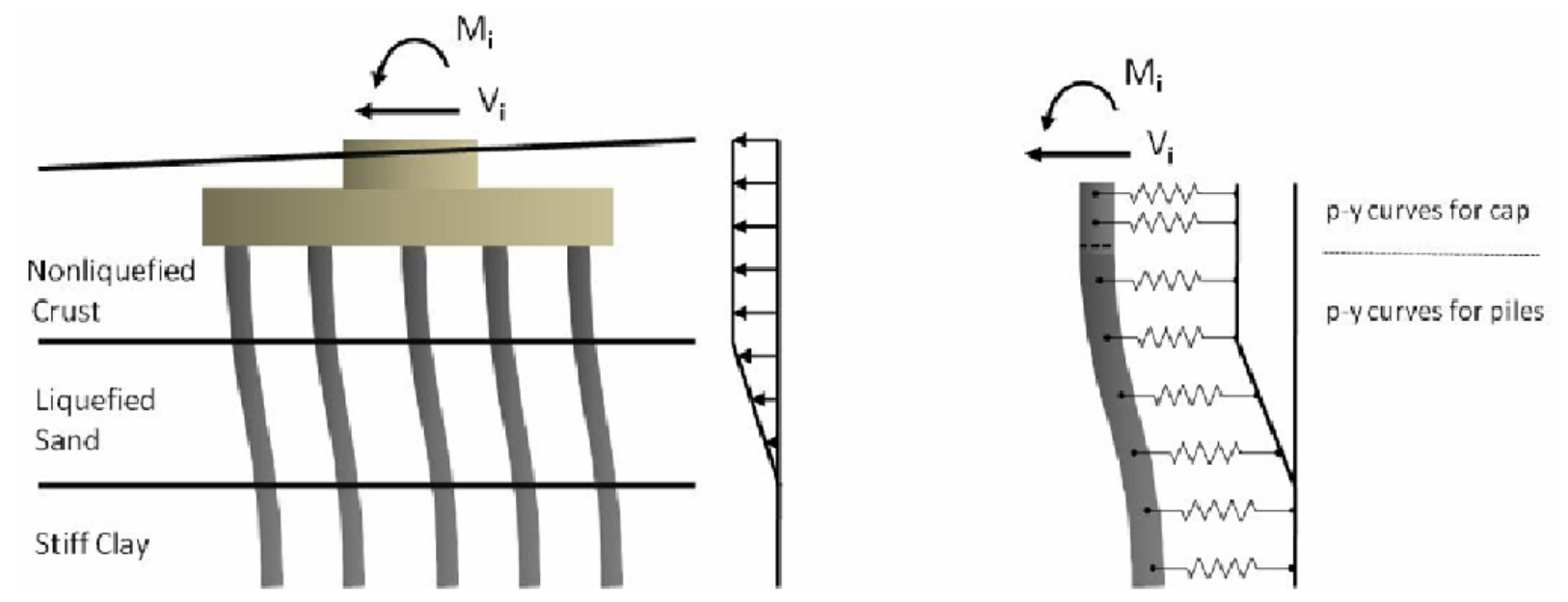

Figure 1.25: Schematic diagram for the modeling of pile group bridge foundation using an equivalent pile model under lateral spreading ground deformation (CALTRANS 2011)

The $p$ - $y$ curve for the pile cap is developed based on ultimate passive pressure force from the laterally spreading soil $\left(F_{\text {ult }}\right)$ exerted on the foundation and the maximum displacement $\left(\Delta_{\max }\right)$ required to mobilize fully the passive earth pressure force. CALTRANS (2011) considered two possible critical failure surfaces to compute $F_{\text {ult: }}$ (1) a log-spiral based failure surface on the pile cap combined with the lateral resistance provided by the portion of the pile length that extends through the crust as shown in Figure 1.26 (a), and (2) a Rankine based failure surface acting on the pile cap, soil crust beneath the pile cap, and piles within the crust assuming all these act as a composite block as shown in Figure 1.26 (b). The smallest value of $F_{\text {ult }}$ is considered to control the failure mechanism. The $\Delta_{\max }$ is estimated as $5 \%$ of the cap height with two adjustment factors which accounts for the effects of pile cap thickness and depth of the crustal layer 
(e.g., Brandenberg et al. 2007). Once $F_{\text {ult }}$ and $\Delta_{\max }$ are computed, a trilinear $p$-y curve can be developed, as shown in Figure 1.27.

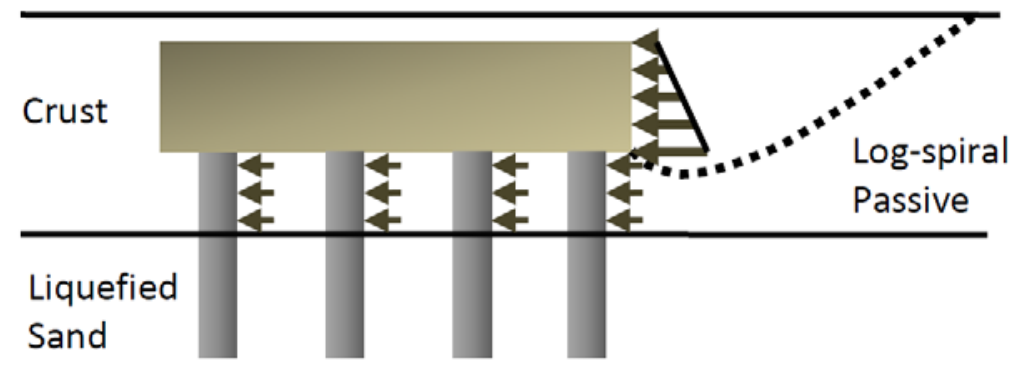

a) Case 1

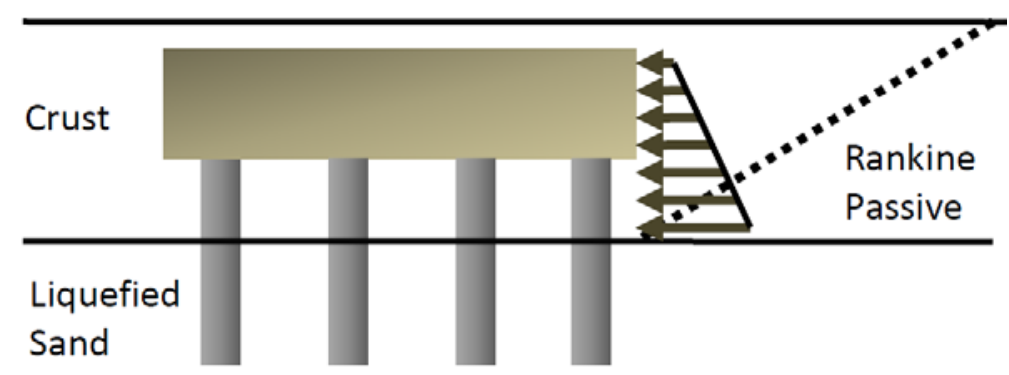

b) Case 2

Figure 1.26: Possible failure cases for the non-liquefied crust layers (CALTRANS 2011)

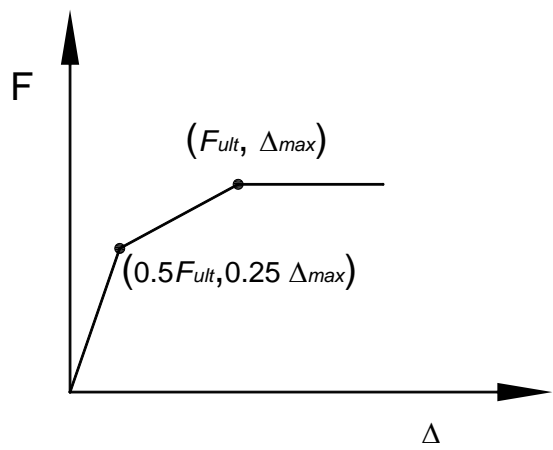

Figure 1.27: Idealized $p-y$ curve for pile cap (CALTRANS 2011) 
The $p$ - $y$ curve for the pile can be developed based on different soil materials available in LPILE. For example, sand can be modeled using the API (1993) or Reese et al. (1974) procedure, soft clay can be modeled using the Matlock (1970) procedure, and stiff clay can be modeled by the Reese and Welch (1975) procedure. The $p-y$ curve for liquefied sand is modeled as clay with its residual strength (Matlock 1970). The shadow/group effects in the pile group are considered using p-multiplier (e.g., Mokwa and Duncan 2001b) as discussed in Section 1.3.2.2. Furthermore, the effects of liquefied soil on the lateral resistance of the upper and lower non-liquefied soil layers are considered by applying a $p$-multiplier to the ultimate lateral resistance. The p-multipliers for the nonliquefied soil are calculated based on the ultimate resistance of liquefied and nonliquefied layer as

$$
m p=\frac{p_{u-L}}{p_{u-N L}}+\left(1-\frac{p_{u-L}}{p_{u-N L}}\right)\left(\frac{z}{S_{b} B}\right)
$$

where $P_{u-L}$ is the ultimate lateral resistance for liquefied layer, $P u_{-N L}$ is the ultimate lateral resistance for the non-liquefied layer, $z$ is the depth, $B$ is the diameter of the pile, and $S_{b}$ is the factor based on the zone over which the $p$-multiplier is applied due to smeared profile as shown in Figure 1.28. The $S_{b}$ factor is estimated as

$$
S_{b}= \begin{cases}2 & B<1 \\ 2-(B-1) / 2 & 1 \leq B \leq 3 \\ 1 & B>3\end{cases}
$$

where $B$ is in units of feet

Finally, all $p$-multipliers are multiplied by the number of piles in the group in order to get the $p-y$ curve for the equivalent pile. In the liquefied layer no $p$-multiplier is considered for the group effect. 


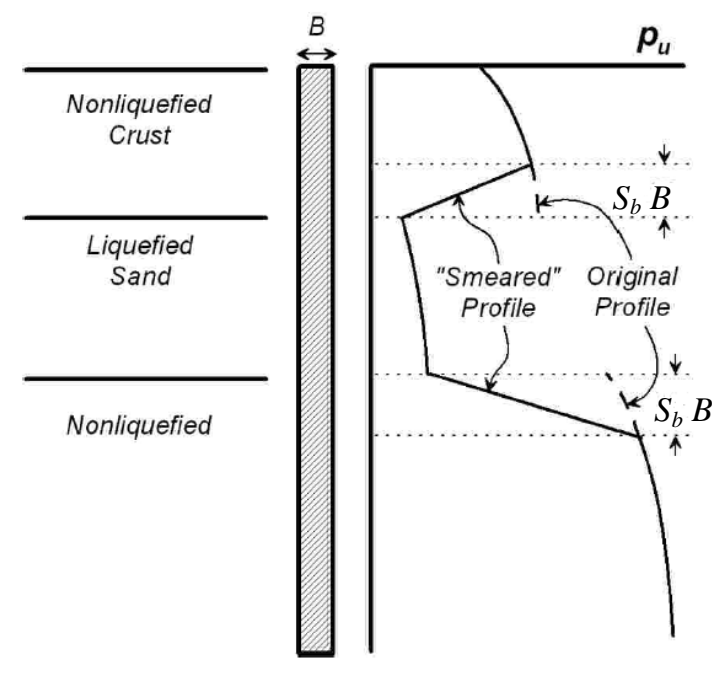

Figure 1.28: Smeared profile correction for lateral resistance to account for the weakening effect of liquefied soil on strength of surrounding soil (Ashford et al. 2011, CALTRANS 2011)

\section{5) Estimate Inertial Forces}

For a typical bridge bent, inertial effects from the superstructure are considered by applying moment and shear force at the pile head. The shear force and moment from the superstructure can be obtained from two methods.

First, if the column is expected to yield (developing plastic hinges) before the foundation, inertial moment is estimated as 1.2 times the plastic column moment and shear force is calculated based on the fixity of the columns. For free-fixed (top-bottom) column condition, the inertial force is computed by dividing the inertial moment by column height and for fixed-fixed (top-bottom) condition, inertial force is computed by dividing the inertial moment by half of the column height. Second, if the column is not expected to reach its moment capacity, then the inertial shear force is estimated as the product of the superstructure mass (tributary mass for the column) by the spectral acceleration of the bridge at its first mode natural period.

The inertial force for the pile cap is estimated by multiplying the pile cap mass with a PGA that corresponds to the non-liquefaction case. A factor of 0.65 is used, which represents a reduction in PGA resulting from the onset of liquefaction. 
In the case of seat type abutment foundations, the superstructure is supported by bearings which are free to rotate, and no moment demand is transmitted to the foundation by the superstructure. However, some amount of superstructure inertial force can be transferred to the abutment foundation through the backwall. Caltrans typical practice is to design the backwall as a weak fuse with only modest capacity to transfer force, thus it is assumed that no inertial forces are transferred to the foundation. This is not typical practice at ODOT, and this is an area where these guidelines need to be modified to adapt to ODOT's needs.

\section{6) Evaluate Seismic Performance of Foundation}

After determining all the parameters, equivalent static analysis is conducted by imposing a lateral spreading displacement estimated in step 3 and inertial forces as described in

step 5. Only $50 \%$ of inertial load is recommended to combine with the lateral spreading displacement (kinematic loading), as the peak inertial load and kinematic load occur at different times. Finally, seismic demands (e.g., pile head displacement, shear force, bending moments) obtained from the analysis are compared with the allowable foundation seismic performance criteria.

\subsubsection{Restrained Ground Displacement Design Case}

In the restrained design case, it is assumed that the displacing soil mass is limited in volume and the foundation provides restraining effects to soil flow or movement. The typical case for this type of restraining effect is an approach embankment acting on the abutment piles as shown in Figure 1.24. When the sliding mass is limited to the size of the approach embankment, it is assumed that relatively stronger and stiffer piles will provide resistance to the soil movement. The CALTRANS (2011) guidelines for the restrained ground displacement are based on NCHRP (2002) procedure for the foundation's "pinning" effect with some modification based on recent research (e.g. Ashford et al. 2011). The overall procedures for this design case are very similar to the unrestrained design case except for determining the displacement in which the laterally spreading soil is compatible with the resistance of the foundation. 


\section{1) Assess Liquefaction Potential of Soils}

Liquefaction assessment is carried out by same procedure discussed in step 1 of Section 1.3.3.1.

\section{2) Estimate Residual Strengths of Liquefied Soils}

Residual strengths are determined by the same procedure discussed in step 2 of Section 1.3.3.1.

\section{3) Develop Foundation Model}

The foundation model is created by following the same procedure discussed in step 4 of Section 1.3.3.1.

\section{4) Estimate Inertial Forces}

Inertial forces are estimated with the procedure discussed in step 5 of Section 1.3.3.1. For the abutment case, the inertial loads are assumed to be zero in the CALTRANS guidelines. This may need to be adapted to accommodate integral abutments used by ODOT.

\section{5) Perform Pushover analysis for Varying Ground Displacement}

A series of increasing soil displacements are imposed to the foundation model and pushover analyses are carried out. For each analysis, the imposed displacement is combined with inertial forces as computed in step 4. Only 50\% of the inertial load is recommended to combine with the laterally spreading displacement (kinematic loading). From the pushover analysis, pile cap displacement and shear force at the center of the liquefied soil layer are determined. Finally, running average shear forces are computed for each displacement and a foundation pushover curve is developed (shown later). The running average shear forces are computed to ensure the compatibility between the foundation sliding mass (next step) and the foundation resisting force. 


\section{6) Perform Slope Stability Analysis and Determine Lateral Spreading Displacement}

Slope stability analysis is carried out to determine yield coefficients, $k_{\mathrm{y}}$, for a range of possible foundation restraining forces, $R$. The resistance force from the bridge deck, $F_{D E C K}$, is calculated as full mobilized passive resistance, which is applied as a constant resisting force in the slope stability analysis (Figure 1.29). The failure surface is a block type surface and forced to pass through the middle of the liquefied layer and limited to extend laterally to a maximum length of four times the height of the abutment. For each $R, k_{y}$ can be determined as the horizontal yield acceleration for which the factor of safety is 1.0. Once the series of $k_{y}$ values are determined, the laterally spreading displacements are computed using the Bray and Travasarou (2007) procedure, which is based on the Newmark rigid sliding block concept. Finally, the slope stability curve is developed based on the foundation resisting force and the laterally spreading displacement as shown in Figure 1.30.

\section{7) Determine Compatibility Displacement}

The pushover curve from the foundation analysis and slope stability curve are plotted together and the intersection of the two curves yields the compatible displacement as shown in Figure 1.30. The compatibility displacement is the actual lateral displacement of the slope considering the restraining effect of the foundation system during lateral spreading.

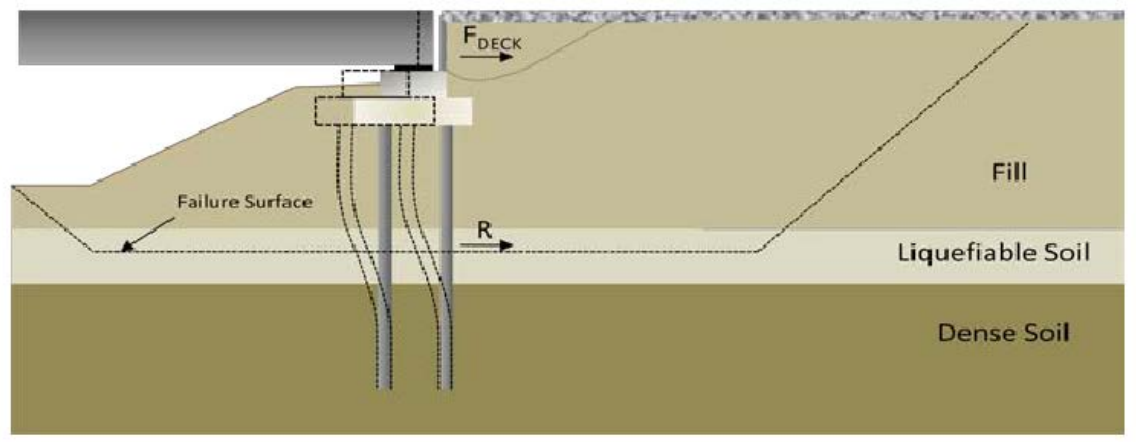

Figure 1.29: Schematic diagram for slope stability analysis model with the application of deck resisting force, $F_{D E C K}$, and foundation resisting force, $R$ (CALTRANS 2011) 


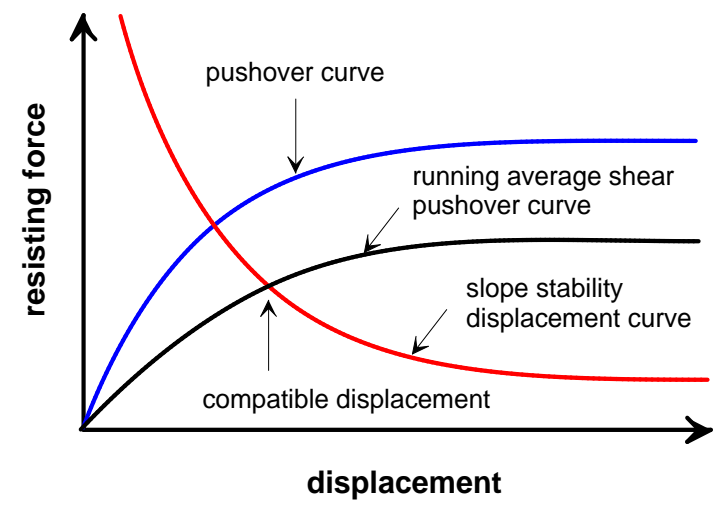

Figure 1.30: Determining compatible displacement

\section{8) Evaluate Seismic Performance of Foundation}

The lateral spreading displacement determined in step 7, is imposed to the foundation model together with the inertial forces computed in step 4. Finally, pushover analysis is carried out to determine seismic demands and compared with the allowable foundation seismic performance criteria.

\subsubsection{Summary}

Review of the literature indicates that several parameters (e.g., shadowing/group effects, pile cap friction and rotation, kinematics and crust load effect, axial load, state of soil) affect the performance of piles groups in liquefaction induced laterally spreading ground. Several techniques are available to analyze pile groups in laterally spreading ground depending on the analysis simplification to be used. Based on the reviewed literature, the simplified methods (e.g., LE method, $p-y$ methods) give reasonable estimates of performance though it cannot simulate some effects that are critical in liquefaction induced laterally spreading ground. A 3D FE analyses can account for all parameters that play an important role in pile group behavior/performance, but very limited research has been carried out in this area mainly due to computational effort and time. As a result, this method is beyond the reach of routine engineering design practice. Recently, CALTRANS provided guidelines for the seismic performance evaluation of pile foundations in lateral spreading ground based on a simplified $p-y$ 
analysis method. However, research is needed to validate the CALTRANS procedures in predicting the performance of bridge foundations in liquefaction induced laterally spreading ground. 


\section{Chapter 2: Example Bridge and Liquefaction Assessment}

\subsection{Introduction}

As a main objective of this report, several design examples are presented for seismic performance evaluation and retrofitting for a typical bridge foundation. The design example provided here, closely follows the methods described in Ashford et al. (2011) and CALTRANS (2011), with some additional assumptions (if required) as stated in subsequent chapters. In addition, design examples for ground improvement methods are also provided.

A description of the example bridge, which is a typical bridge provided by ODOT, is presented in the next section. Assessments of liquefaction are carried out for the soil profiles at the bridge foundations location. In addition, for liquefied soil the calculation of residual strength and estimation of liquefaction induced lateral spreading displacements are presented. The residual strength and lateral spreading displacement will be used in performance evaluation of pile foundations in subsequent chapters.

\subsection{Example Bridge Description}

The bridge is a 227-ft long 3-span structure with integral abutments, as shown in Figure 2.1. The length of the first and third span is 69-ft and the middle span is 89-ft. The bridge deck is resting on elastomeric bearings, and the ends of the deck terminate at abutments. The foundation system consists of a pair of 6-ft diameter drilled shafts at the interior piers and a single row of 10 steel pipe piles of size 16” x 0.5”PP (ASTM A252, Grade 3) at each abutment. Each drilled shaft supports a concrete column of 3.5-ft diameter and 25-ft length that carries an axial load of 760 kips (Figure 2.2).

\section{$\underline{\text { Geological conditions }}$}

The soil profile in the given example bridge consists of different soil materials (fill, soft clay, loose sand, dense sand, and bedrock) depending upon the location (Figure 2.1). At the interior bent locations, the soil profile consists of two potentially liquefiable layers located beneath a 10$\mathrm{ft}$ thick layer of soft clay (Figure 2.2). The thickness of each loose sand layer is 6-ft. A dense sand layer of $15-\mathrm{ft}$ thickness is below the lower liquefiable layer, underlain by bedrock. The water table is located at the ground surface. The corrected SPT values $\left[\left(N_{1}\right)_{60}\right]$ for the potentially liquefiable sand are 10 and 6 for upper layer and lower layer, respectively. The fines content 
(FC) in both loose sand layers are assumed to be 10\%. Other properties of the soils are shown in Figure 2.2. It is noted that measured field SPT values $\left(N_{m}\right)$ are corrected for several effects (e.g., effective vertical stress, drilling rod length, the presence or absence of spacers, borehole diameter, and energy ratio) in order to obtain $\left(N_{1}\right)_{60}$.

At the abutment location, the soil profile consists of 25-ft engineered fill, underlain by $15-\mathrm{ft}$ soft clay and a 12-ft potentially liquefiable layer. A 15-ft dense gravel layer is located beneath the liquefiable layer, and bedrock is located at the base. The idealized soil profile and the soil properties can be seen in Figure 2.3. . The FC for the loose sand layer is assumed to be $10 \%$. The water table is located 35-ft below the ground surface.

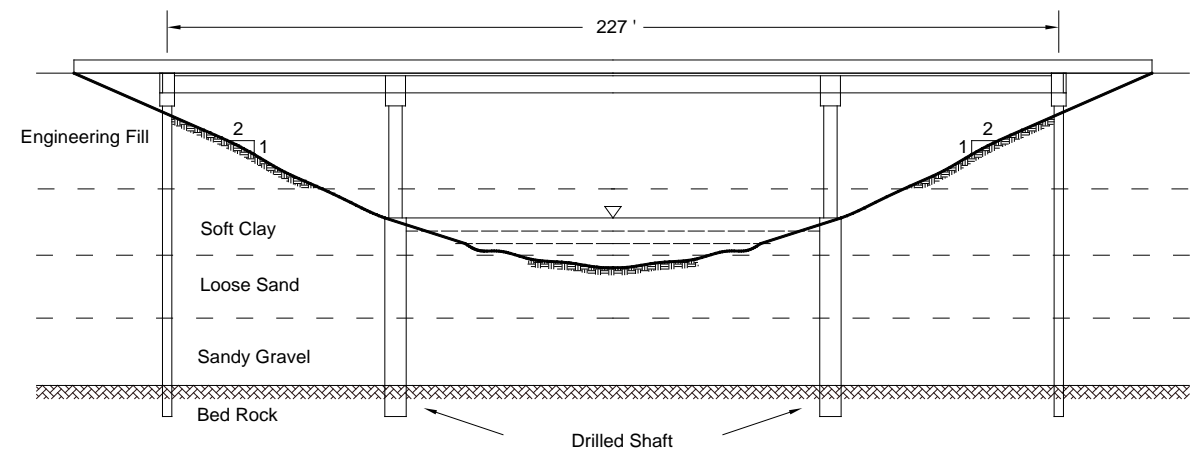

Figure 2.1:Bridge layout (not to scale)

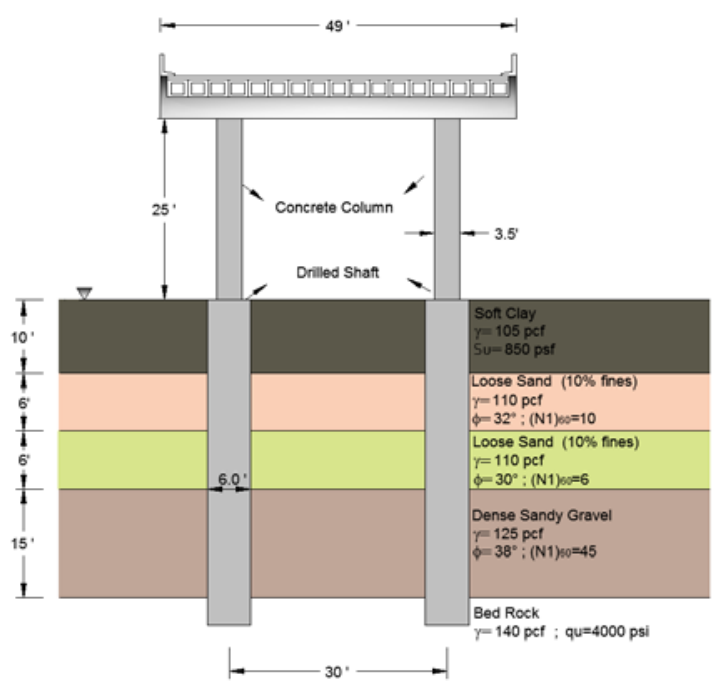

Figure 2.2: Idealized soil profile at the location of interior bend 


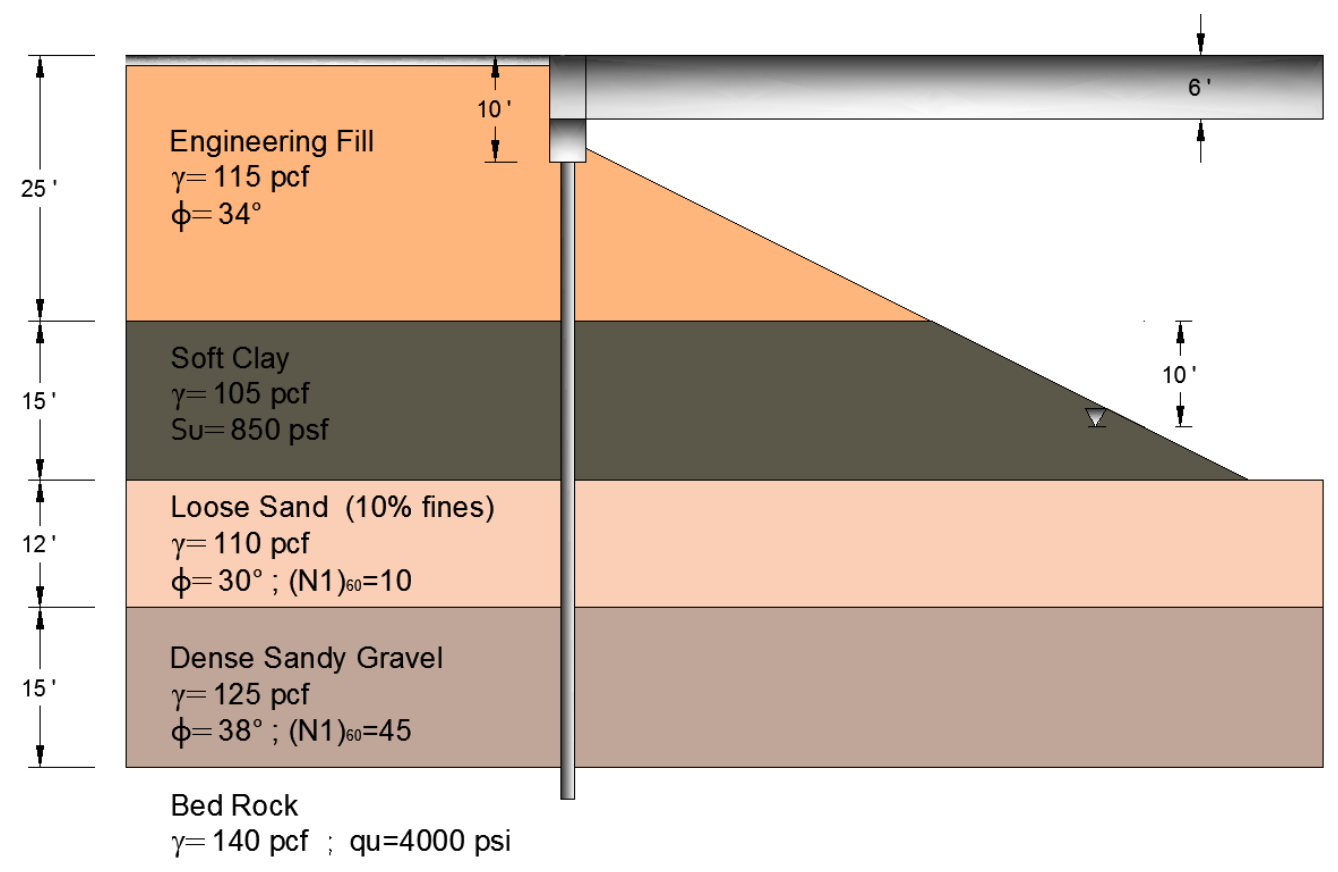

Figure 2.3: Idealized soil profile at the abutment location

\section{Design earthquake data}

Characterization of the seismic hazard should be carried out using site specific studies. For this purpose, the U.S. Geological Survey website (www.usgs.gov) provides a database to compute the seismic hazard at a particular site in the U.S. In design practice, several site specific scenarios should be considered in determining the seismic hazard depending on design requirements (i.e. by considering different return periods or probabilistic approach). Deaggregation analyses should be carried out to determine the proper design earthquake magnitude $\left(M_{w}\right)$. The U.S. Geological Survey website provides the interactive deaggregation software to compute $M_{w}$ for any site within the U.S.

In this example, ODOT provided the design earthquake scenario from the CSZ event with $M_{\mathrm{w}}=8.7$. The design peak ground acceleration (PGA) given by ODOT is $0.40 \mathrm{~g}$, which corresponds to $5 \%$ in 50 years hazard.. 


\section{$\underline{\text { Foundation performance criteria }}$}

For each component of the foundation, allowable deformation or strength is prescribed in the design process to ensure safety of the bridge during the earthquake event. Allowable foundation demands are provided in Table 2.1 based on the CALTRANS (2011) design examples. Allowing piles to yield in an earthquake event may lead to significant damage to bridge foundation and bridge itself. However, in the case of rare events like CSZ earthquake, allowing yield in piles may be a practical alternative. However, in this example, CALTRANS pile performance criteria is checked against maximum moment capacity of the pile section, and yielding is not allowed. ODOT may develop other structural performance criteria if yielding is to be allowed in some cases.

Table 2.1: Pile foundation performance Criteria CALTRANS (2011)

\begin{tabular}{cccc}
\hline Conditions & Cap Displacement & Pile Moment & Pile Shear \\
\hline Well Confined pilings & $N / A$ & $M_{u}$ & $V_{u}$ \\
Well confined abutment pilings & $N / A$ & $M_{u}$ & $V_{u}$ \\
Poorly confined pilings & $N / A$ & - & - \\
\hline
\end{tabular}

Note: $H=$ column height; $M_{u}=$ ultimate moment capacity of the pile section; $V_{u}=$ shear capacity of the pile section

\subsection{Assessment of Liquefaction Potential}

The liquefaction assessment can be carried out by the procedure described in Appendix A. Different methods are available to estimate liquefaction potential of soils. In this design example, the Youd et al. (2001) procedure is used for liquefaction assessment.

\section{$\underline{\text { At bridge interior bent location }}$}

The SPT values are corrected for fine contents as described in Youd et al. (2001). The (N1) 60 for upper and lower loose sand layers are 10 and 6, respectively. The corrected $\left(\mathrm{N}_{1}\right)_{60 \mathrm{cs}}$ for upper and lower loose sand layers are, 11 ( $\mathrm{FC}=10 \%)$ and 7 ( $\mathrm{FC}=10 \%)$, which leads to the cyclic resistance ratio (CRR) values of 0.12 and 0.09 respectively. 
For upper loose sand layer,

Depth $(z)=13 \mathrm{ft}$

Overburden stress $\left(\sigma_{v 0}\right)=10 \cdot 105+3 \cdot 110=1380 p s f$

Effective stress $\left(\sigma_{v o}^{\prime}\right)=10 \cdot 105+3 \cdot 110-13 \cdot 62.4=568.8 p s f$

Depth reduction factor $\left(r_{d}\right)=0.97$

Cyclic Stress Ratio $(C S R)=0.65 \frac{1380 p s f}{568 p s f} \cdot 0.4 \cdot 0.97=0.61$

Magnitude Scaling Factor $(M S F)=\frac{10^{2.24}}{8.7^{2.56}}=0.68$

For, $\left(N_{1}\right)_{60}=10, D_{r}=\sqrt{\frac{\left(N_{1}\right)_{60}}{46}}=47 \%$

Overburden stress correction factor $\left(K_{\sigma}\right)=(568 / 2116)^{(0.7-1)}=1.48$ use 1.0

Factor of Safety $\left(F S_{\text {liq }}\right)=\left(\frac{C R R}{C S R}\right) \cdot M S F \cdot K_{\sigma}=\frac{0.14}{0.61} \cdot 0.68 \cdot 1 \cdot 1=0.14$

For lower loose sand layer,

Depth $(z)=19 \mathrm{ft}$

Overburden stress $\left(\sigma_{v o}\right)=10 \cdot 105+6 \cdot 110+3 \cdot 110=2040 \mathrm{ps} f$

Effective stress $\left(\sigma_{v o}^{\prime}\right)=10 \cdot 105+6 \cdot 110+3 \cdot 110-19 \cdot 62.4=854.4 p s f$

Depth reduction factor $\left(r_{d}\right)=0.96$

Cyclic Stress Ratio $(C S R)=0.65 \frac{2040 p s f}{854 p s f} \cdot 0.4 \cdot 0.96=0.59$

For $\left(N_{1}\right)_{60}=6, D_{r}=\sqrt{\frac{\left(N_{1}\right)_{60}}{46}}=36 \%$ and

Overburden stress correction factor $\left(K_{\sigma}\right)=(854 / 2116)^{(0.7-1)}=1.31$ use 1.0 


$$
\text { Factor of Safety }\left(F S_{l i q}\right)=\left(\frac{C R R}{C S R}\right) \cdot M S F \cdot K_{\sigma} \cdot K_{\alpha}=\frac{0.09}{0.59} \cdot 0.68 \cdot 1 \cdot 1=0.10
$$

Since $\mathrm{FS}_{\text {liq }}<1$ for both loose sand layers, they are susceptible to liquefaction for the given earthquake loading case.

\section{Bridge abutment location}

As seen in the soil profile, the depth of the liquefiable layer can vary depending upon location (i.e., 6-ft to 46-ft). So, in this example, average depth of $26 \mathrm{ft}$ is used to assess the liquefaction potential of the loose sand layer. The corrected $\left(\mathrm{N}_{1}\right)_{60 \mathrm{cs}}$ for loose sand layers is 11 (FC=10\%), which leads to the CRR values of 0.12 .

$$
\begin{aligned}
& \text { Depth }(\mathrm{z})=26 \mathrm{ft} \\
& \text { Overburden Stress }\left(\sigma_{v o}\right)=5 \cdot 115+15 \cdot 105+6 \cdot 110=2810 \mathrm{psf} \\
& \text { Effective Stress }\left(\sigma^{\prime}{ }_{v o}\right)=5 \cdot 115+15 \cdot 105+6 \cdot 110-11 \cdot 62.4=2124 \mathrm{psf} \\
& \text { Depth reduction factor }\left(r_{d}\right)=0.94 \\
& \text { Cyclic Stress Ratio }(C S R)=0.65 \frac{2810 p s f}{2124 p s f} \cdot 0.4 \cdot 0.94=0.32 \\
& \text { FS }_{\text {liq }}=\left(\frac{C R R}{C S R}\right) \cdot M S F \cdot K_{\sigma} \cdot K_{\alpha}=\frac{0.12}{0.32} \cdot 0.68 \cdot 1 \cdot 1=0.26
\end{aligned}
$$

Since $\mathrm{FS}_{\text {liq }}<1$, the loose sand layer is susceptible to liquefaction for the design earthquake loading.

\subsection{Estimation of Residual Strengths}

The residual loading is estimated as described in Appendix B. The Kramer (2008) method is used to estimate the residual strength.

\section{At bridge interior bent location}

For upper loose sand layer, $\left(\mathrm{N}_{1}\right)_{60}=10$ 
Residual Strength $\left(S_{r}\right)=2116 \cdot \exp \left(-8.444+0.109 \cdot 10+5.379\left(\frac{568}{2116}\right)^{0.1}\right)=151 p s f$

For lower loose sand layer, $(\mathrm{N} 1)_{60}=6$

Residual Strength $\left(S_{r}\right)=2116 \cdot \exp \left(-8.444+0.109 \cdot 6+5.379\left(\frac{854}{2116}\right)^{0.1}\right)=119 p s f$

\section{Bridge abutment location}

As the depth of the liquefiable layers varies along the slope in the embankment, the effective stress also varies such that it affects the residual strength. To incorporate this, the residual strength is calculated primarily at three locations: upper, middle, and lower region along the sloping ground. Later, the residual strengths will be used for slope stability analysis of the embankment.

Upper location in slope

$$
\begin{aligned}
& Z=46 f t ; \sigma_{v o}^{\prime}=25 \cdot 115+15 \cdot 105+6 \cdot 110-11 \cdot 62.4=4423 p s f \\
& S_{r}=2116 \cdot \exp \left(-8.444+0.109 \cdot 6+5.379\left(\frac{4423}{2116}\right)^{0.1}\right)=443 p s f
\end{aligned}
$$

Mid location in slope

$$
\begin{aligned}
& Z=26 f t ; \sigma_{v o}^{\prime}=5 \cdot 115+15 \cdot 105+6 \cdot 110-11 \cdot 62.4=568 p s f \\
& S_{r}=2116 \cdot \exp \left(-8.444+0.109 \cdot 6+5.379\left(\frac{568}{2116}\right)^{0.1}\right)=294 p s f
\end{aligned}
$$

Lower location in slope

$$
\begin{aligned}
& Z=6 f t ; \sigma^{\prime}{ }_{v o}=6 \cdot 110-6 \cdot 62.4=286 p s f \\
& S_{r}=2116 \cdot \exp \left(-8.444+0.109 \cdot 6+5.379\left(\frac{286}{2116}\right)^{0.1}\right)=111 p s f
\end{aligned}
$$




\subsection{Estimating Lateral Spreading Displacement at Interior Bent}

For the bridge interior pier location, slope stability analysis was carried out using Geostudio 2012 (SLOPE/ $\mathrm{W}^{\mathrm{TM}}$ ) by assuming unrestrained crustal displacement. Using the residual strength (calculated above), the factor of safety (FS) from the slope stability analysis is found to be less than 1.05, which suggests flow type failure in the interior bent location. For flow type failure, CALTRANS (2011) recommended to use 5-ft (60-in) as a maximum lateral spreading displacement, assuming that the full passive pressure will be mobilized at this displacement. It is noted that for gentle slope, the lateral spreading displacement can be estimated using limiting shear strain potential as described in Appendix C. 


\section{Chapter 3: Design Example for Foundation at Bridge Interior Bent}

\subsection{Introduction}

In this chapter, design examples for the seismic performance evaluation of bridge foundations at interior bents are presented. As mentioned earlier, the design example closely follows the procedures recommended in Ashford et al. (2011) and CALTRANS (2011). In this design example, the interior bent is considered to be equivalent to the case of the unrestrained crustal displacement case in CALTRANS (2011) guidelines. The liquefaction assessment of the soil profile at the interior bent location shows the liquefaction potential and lateral spreading condition (Chapter 2), therefore assessment of the bridge foundation for lateral spreading condition is required.

Two cases are considered for the interior bent: the drilled shaft foundation and the pile group foundation. The pile group foundation is not presented in the original drawing provided by ODOT. However, ODOT is also interested in the evaluation of pile groups at interior bents. Therefore, an additional design example is carried out for pile group foundations by replacing the drilled shaft foundations at the same location. In addition to seismic performance evaluation, examples are also presented for different seismic retrofitting options of the bridge foundation. In this example and others (next chapter), the analyses are carried out using LPILE. The residual strength of the liquefied soil and laterally spreading displacement of the soil profile is already computed in Chapter 2, which will be used in the following section.

\subsection{Numerical Analysis for Drilled Shaft Foundation}

The cross-section dimensions and reinforcement details of the drilled shaft and column are shown in Figure 3.1. The compressive strength of the concrete is 4000 psi and the tensile strength of the reinforcement steel is 60, 000 psi. 


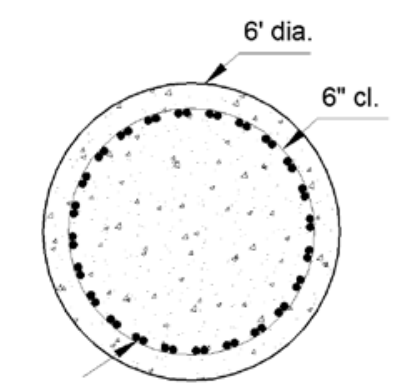

$24 \sim$ Bundles of $2 \# 11$ (total 48)

Drilled Shaft Section

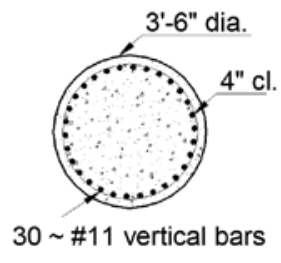

Column Section

Figure 3.1: Drilled shaft and bridge pier sectional properties

\subsubsection{Modeling Methodology}

The conceptual drawing for the drilled shaft analysis is shown in Figure 3.2. The shaft is connected to soil springs at corresponding depths and a displacement is imposed (from chapter 2). In addition, equivalent inertial forces (from the superstructure) are applied at the pile top.

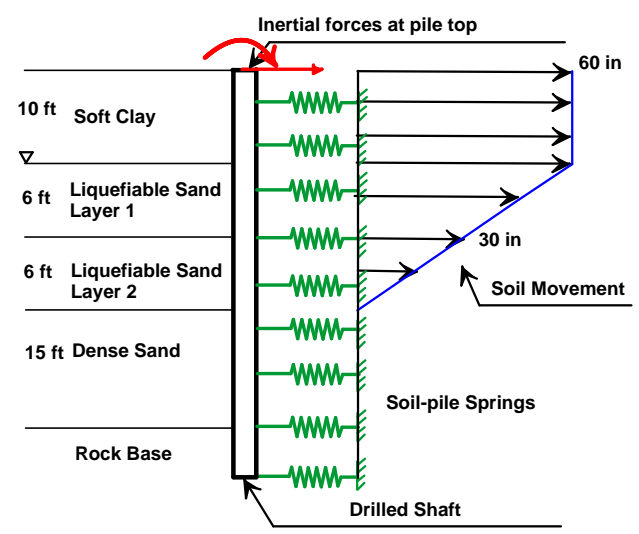

Figure 3.2: Schematic diagrame for drilled shaft modeling in LPILE (Not to scale)

\subsubsection{Calculate Moment-curvature Relationship}

The moment-curvature behavior of the shaft and pile depends on the cross-sectional dimensions and material properties of concrete and steel reinforcement. In LPILE, the cross-sectional properties can be directly provided with the unconfined compressive strength of concrete and yield strength of the reinforcement. The reinforcement is provided in a circular fashion as either single or bundle bars, and the bar size is inputted as the bar number. The moment curvature of 
the cross-section for the drilled shaft and bridge column are shown in Figure 3.3. The moment curvature relationships are determined for axial load of 0 and 760 kips.
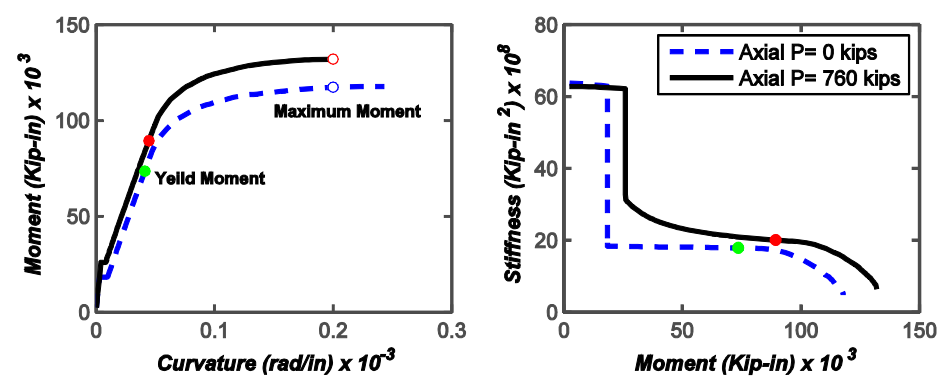

a) Drilled shaft section
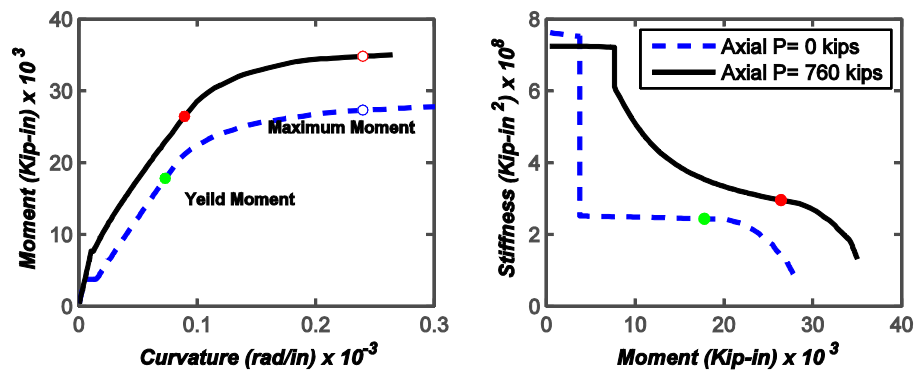

b) Bridge column section

Figure 3.3: Moment curvature and stiffness moment for a) 6-feet diameter drilled shaft ; and b) 3.5 feet diameter column section

Based on the moment-curvature analysis results, the yield and ultimate moment capacity of drilled shaft and column section were determined. The yield moment is moment at which the reinforcement bar reached it maximum tensile strength. The moment capacity of the drilled shaft and bridge column sections are shown in Table 3.1.

Table 3.1: Moment capacity of drilled shaft and bridge column

\begin{tabular}{cllll}
\hline Moment & \multicolumn{2}{l}{ Drilled Shaft } & \multicolumn{2}{l}{ Bridge Column } \\
\cline { 2 - 5 } & P=0 kip & P=760 kip & P=0 kip & P=760 kip \\
\hline Yield Moment $\left(M_{y}\right)$ (kip-in) & $7.35 \times 10^{4}$ & $8.93 \times 10^{4}$ & $1.78 \times 10^{4}$ & $2.64 \times 10^{4}$ \\
Max. Moment $\left(M_{\max }\right)($ kip-in)* & $1.16 \times 10^{5}$ & $1.30 \times 10^{5}$ & $2.75 \times 10^{4}$ & $3.40 \times 10^{4}$ \\
Ultimate Moment $\left(M_{\text {ult }}\right)$ (kip-in)** & $1.39 \times 10^{5}$ & $1.56 \times 10^{5}$ & $3.30 \times 10^{4}$ & $4.08 \times 10^{4}$ \\
\hline
\end{tabular}

Note:

* The maximum moment is moment when strain in the concrete reaches 0.003 . 
** The ultimate moment is estimated as 1.1 times the maximum moment. The unconfined compressive strength is used for the concrete material in the moment curvature analysis so, to account the confined strength the ultimate capacity is increased by 1.1.

\subsection{3. $\quad p-y$ Curves for Non-liquefied Crust Layer}

From Section 2.5, flow failure was predicted on the loose sand layer and a 5-ft displacement was considered to fully mobilize the passive pressure of the non-liquefied crust (soft clay) layer. The CALTRANS (2011) guidelines only provide the design examples for pile group foundation so, the procedure to develop p-y curves for the pile cap in non-liquefied crust layer may not be applicable for drilled shaft. Therefore, in this example the p-y curves for the drilled shaft for in crust layer are developed in different manner. The passive soil resistance in the clay layer is calculated from API (1993) method. Generally, in the smaller pile (diameter <3 ft), the contribution from side shear friction is neglected. However, drilled shafts are relatively larger in diameter, so the side friction force also contributes to the lateral resistance. Therefore, the total lateral force for the crust layer is calculated as the sum of the ultimate lateral force and side shear force.

The lateral resistance force per unit length of drilled shaft from API (1993) method in the clay is calculated as

$$
p_{\text {ult-Pile }}=\left(3 c+\gamma^{\prime} X+J c \frac{X}{B}\right) B \quad \text { for } \mathrm{X}<\mathrm{X}_{\mathrm{R}}
$$

where, $\mathrm{c}$ is the cohesion and B is the diameter of drilled shaft, $\mathrm{J}$ is empirical constant (assume 0.5), $\gamma^{\prime}$ is the effective unit weight of soil, and $X$ is the depth. The $X_{R}$ is the depth estimated as

$$
X_{R}=\frac{6 B}{\frac{\gamma^{\prime} B}{c}+J}=\frac{6 \cdot 6}{\frac{42.6 \cdot 6}{850}+0.5}=44.96 \mathrm{ft}
$$

For average depth of $\mathrm{X}=5 \mathrm{ft}$, the $p_{\text {ult-pile }}$ is calculated as 


$$
p_{\text {ult-Pile }}=\left(3 \cdot 850+42.6 \cdot 5+0.5 \cdot 850 \cdot \frac{5}{6}\right) \cdot 6=18703 \mathrm{lb} / \mathrm{ft}
$$

Thus, lateral force from drilled shaft is

$$
F_{\text {Pile }}=p_{\text {ult-Pile }} \cdot L_{c}=18703 \cdot 10 \cdot \frac{1}{1000}=187 \mathrm{kip}
$$

where $L_{c}$ is the length of the drilled shaft in clay layer.

The side shear force in the drilled shaft is calculated as

$$
F_{\text {SIDES }}=2 \alpha c L_{c} B=2 \cdot 0.5 \cdot 850 \cdot 10 \cdot 6 \cdot \frac{1}{1000}=51 \mathrm{kip}
$$

where $\alpha$ is the adhesion factor (assumed 0.5).

The total lateral force in the drilled shaft

$$
F_{p}=F_{\text {Pile }}+F_{\text {SIDES }}=187+51=238 \text { kip }
$$

The lateral resistance $p$ for the non-liquefied crustal layer then can be estimated as

$$
p=\frac{F_{p}}{H}=\frac{238}{10}=23.8 \mathrm{kip} / \mathrm{ft}=1983 \mathrm{lb} / \mathrm{in}
$$

It is generally recognized that significant amount of relative displacement is required to mobilized the lateral earth pressure of the soil. For the soft clay, Canadian Geotechnical Society (1992) suggested the relative displacement can be as large as $4 \%$ of the wall height. Based on experimental test on pile cap, Cubrinovski and Ishihara (2007) found that displacement of 2 to $8 \%$ of the wall or cap height is necessary to mobilize the earth pressure in dense sand and even higher displacement is required for the loose sand. In CALTRANS (2011), the maximum displacement to mobilize the lateral earth pressure in the crust layer is estimated using the procedure recommended by Brandenberg et al. (2007). In this example, due to the lack of guidelines in the literature to estimate the displacement to mobilize earth pressure in drilled shaft, CALTRANS (2011) procedure is adopted. 


$$
\begin{aligned}
& \Delta_{\max }=\left(0.05+0.45 f_{\text {depth }} f_{\text {width }}\right) \cdot H \\
& \text { where } f_{\text {depth }}=e^{-3\left(\frac{Z_{c}-D}{T}-1\right)}=e^{-3\left(\frac{10}{10}-1\right)}=1 \\
& f_{\text {width }}=\frac{1}{\left(\frac{10}{\frac{W_{T}}{T}+4}\right)^{4}+1}=\frac{1}{\left(\frac{10}{\frac{6}{10}+4}\right)^{4}+1}=0.0428
\end{aligned}
$$

The maximum displacement $\left(\Delta_{\max }\right)$ for the $p-y$ curve of non-liquefied crustal layer is

$$
\Delta_{\max }=(0.05+0.45 \cdot 1 \cdot 0.0428) \cdot 10=0.069 \cdot 10=0.693 \mathrm{ft}=8.3 \mathrm{in}
$$

The $p$-y curve is shown in Figure 3.4.

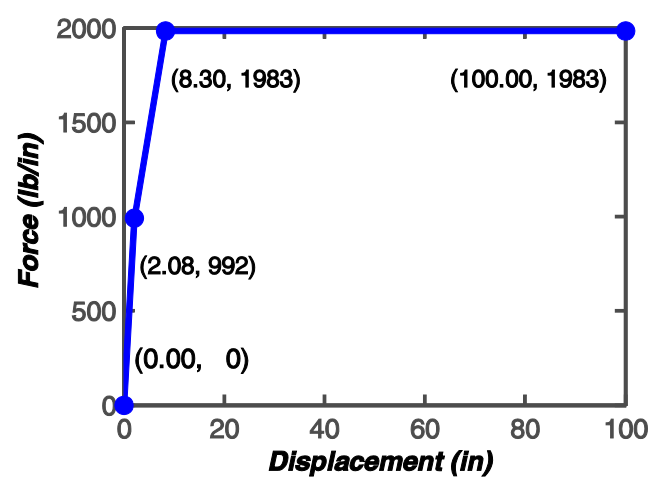

Figure 3.4: Idealized p-y curve for non-liquefied crust layer

\subsubsection{Softening in Non-Liquefied Layer}

The lateral resistance of non-liquefied layers in the vicinity of liquefiable layers is affected during liquefaction. For individual piles in a group, the region at 2 times diameter of the pile is affected by the liquefied soil. However, Ashford et al. (2011) recommended ignoring this softening behavior in non-liquefied layers for larger diameter drilled shafts because twice their diameter could exceed the thickness of the layer, and additional research is needed in this area. Therefore, in this example smeared profile due to liquefied soil is ignored in both upper and lower non-liquefied layers. 


\subsubsection{Inertial Loads on the Foundation}

The inertial load from the superstructure weight can be applied directly as the equivalent shear force acting at the top of the drilled shaft. In the case that large soil movement is expected during strong motion, inertial forces at the drilled shaft and the superstructure need to be considered with soil displacement simultaneously to provide a conservative estimate of displacement and moment demands in the piles. The shear force acting on the drilled shaft can be estimated assuming the column yielding at strong earthquake shaking.

\section{Column yielding condition}

In the case of high seismic demand, the bridge column can potentially develop a plastic hinge and may limit the maximum inertial load transferred to the foundation. Assuming this is the case, and considering a fixed-fixed condition of the column, the inertial force is computed as

The moment capacity of the bridge column $\left(M_{\max }\right)=3.40 \times 10^{4}$ kip-in

Length of the pier $(\mathrm{H})=25 \mathrm{ft}$

$$
V_{\text {SHEAR }}=\frac{2 M_{\max }}{H}=\frac{2 \cdot 3.4 \times 10^{4} \mathrm{kip}-\mathrm{in}}{25 \mathrm{ft}} \cdot \frac{1}{12}=227 \mathrm{kip}
$$

It is unlikely that the peak shear force and peak displacement demand will occur at the same time, thus $50 \%$ of the inertial load from the superstructure and column is combined with the kinematic loading.

$$
V_{i}=0.5 \cdot 227=114 \text { kips }
$$

\subsubsection{Evaluate Seismic Performance}

Using all the data, an LPILE model is developed as shown in Figure 3.2. For the non-liquefiable crustal layer, a modified $p-y$ curve is used (Section 3.2.3), the liquefiable layers are modeled as soft clay with residual strength (Section 2.4), the dense sand layer is modeled as API sand and the bed rock is modeled as strong rock (available in LPILE). A constant displacement of 60-in is imposed throughout the non-liquefiable crust with linear decreasing values to zero at the interface of the bottom liquefiable layer and the non-liquefiable dense sand layer. The inertial 
shear force (computed above), one half of yielding moment of the column, and axial force of 760 kips (given in the problem) are applied as a boundary condition at the top of the drilled shaft.

Based on the performance criteria shown in Table 3.1, the maximum allowable moment for the drilled shaft is $1.56 \times 10^{5}$ kip-in (13000 kip-ft). The displacement, bending moment demand, shear force demand, and soil loading for the drilled shaft are obtained from pushover analysis and the results are shown in Figure 3.5. A summary of the results obtained from the Figure 3.5 is presented on Table 3.2. The maximum drilled shaft displacement, bending moments, and shear force are 6.8-in, 10416 kip-ft, and 1570 kip, respectively. The bending moment demand and shear force demand are less than the allowable limits specified in foundation performance criteria (Section 2.2). Therefore, the drilled shaft foundation satisfies the targeted performance. It is noted that ODOT does not specified any displacement criteria so that no performance has been assessed in terms of pile displacement.

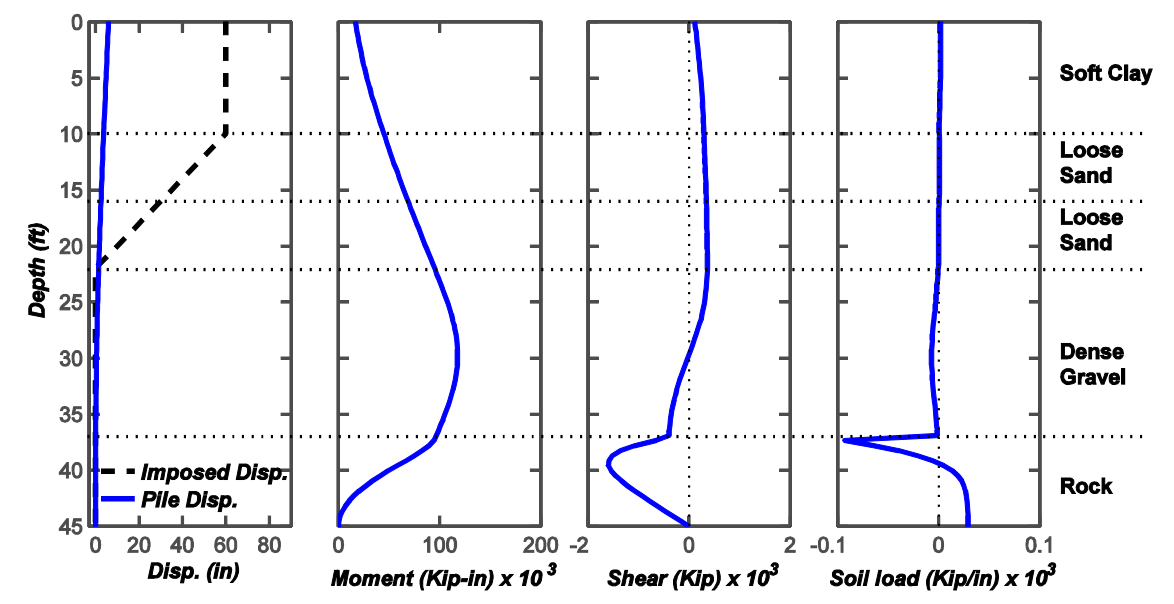

Figure 3.5: Response of drilled shaft foundation to lateral spreading

Table 3.2: Summary of bridge foundation response for drilled shaft under lateral spreading

\begin{tabular}{ccc}
\hline Parameter & $\begin{array}{c}\text { Inertia and lateral } \\
\text { spreading demand }\end{array}$ & Allowable limit \\
& 6.8 in & - \\
\hline Disp. of drilled shaft & $1570 \mathrm{kip}$ & $1877 \mathrm{kip} *$ \\
Maximum shear & $10416 \mathrm{kip}-\mathrm{ft}$ & $13000 \mathrm{kip}-\mathrm{ft}$ \\
\hline
\end{tabular}


Note: * The shear capacity of the drilled shaft was computed using ACI 318-11 code as

Shear strength from concrete

$$
V_{c}=2 \lambda \sqrt{f c^{\prime}} A=2 \cdot 0.85 \sqrt{4000} \cdot(6 \cdot 12-2 \cdot 6) \cdot 6 \cdot 12 \cdot \frac{1}{1000}=464 \mathrm{kip}
$$

where $\lambda$ is constant $(0.85), \mathrm{f}_{\mathrm{c}}$ ' is compressive strength of concrete, and $A$ is the area of section acting in shear and calculated as effective depth times diameter of the section.

Shear strength from reinforcement

$$
V_{s}=\frac{A_{v} f_{y t} d}{s}=\frac{\left(2 \cdot \pi \cdot 1^{2} / 4\right) \cdot 60000 \cdot(6 \cdot 12-2 \cdot 6)}{4} \cdot \frac{1}{1000}=1413 \mathrm{kip}
$$

where $A_{v}$ is the two times area of shear reinforcement, $f_{y t}$ is the tensile strength of reinforcement, $d$ is the effective depth of the section, and $s$ is the pitch or spacing.

Total shear capacity $V=V_{c}+V_{s}=464+1413=1877$ kip.

\subsubsection{Enhancing Performance/Retrofitting the Foundation}

In this example, the drilled shaft foundation satisfies the performance criteria (Section 3.2.6), so no seismic enhancement is required. However, if the performance criteria were not satisfied, then seismic enhancement/retrofitting would be required. For the new foundation design, the simplest way to enhance performance is to increase the diameter of the drilled shaft, longitudinal reinforcement, and shear reinforcement. For a pre-existing foundation, another drilled shaft can be designed to tie together with the existing drilled shaft and seismic performance can be evaluated again. If enough space is available, ground improvement (using stone column or deep soil mixing columns) can be carried out to mitigate liquefaction in the loose sand, altogether preventing laterally spreading displacement.

\subsection{Numerical Analysis for Pile Group}

As mentioned earlier, an additional design example is presented in order to demonstrate the procedures to analyze the pile group of the interior bent. The drilled shaft foundation at the interior bent is replaced with a 4 x 4 pile group of 16” x 0.5” PP (ASTM A252, Grade 3) piles. 
The factored axial resistance of each pile is 225 kips. The soil profile used in this example is exactly the same as in the drilled shaft foundation case (Figure 3.6). The center to center spacing of the piles is $5.0 \mathrm{ft}$, and the pile cap length, width and height are $19 \mathrm{ft} \times 19 \mathrm{ft}$ x $4 \mathrm{ft}$, respectively. The other structural properties of the pile and pile cap are shown in Table 3.3 and Table 3.4, respectively. Descriptions of the variables used for the calculation are shown in Figure 3.7 (identical to the variables used by CALTRANS 2011).

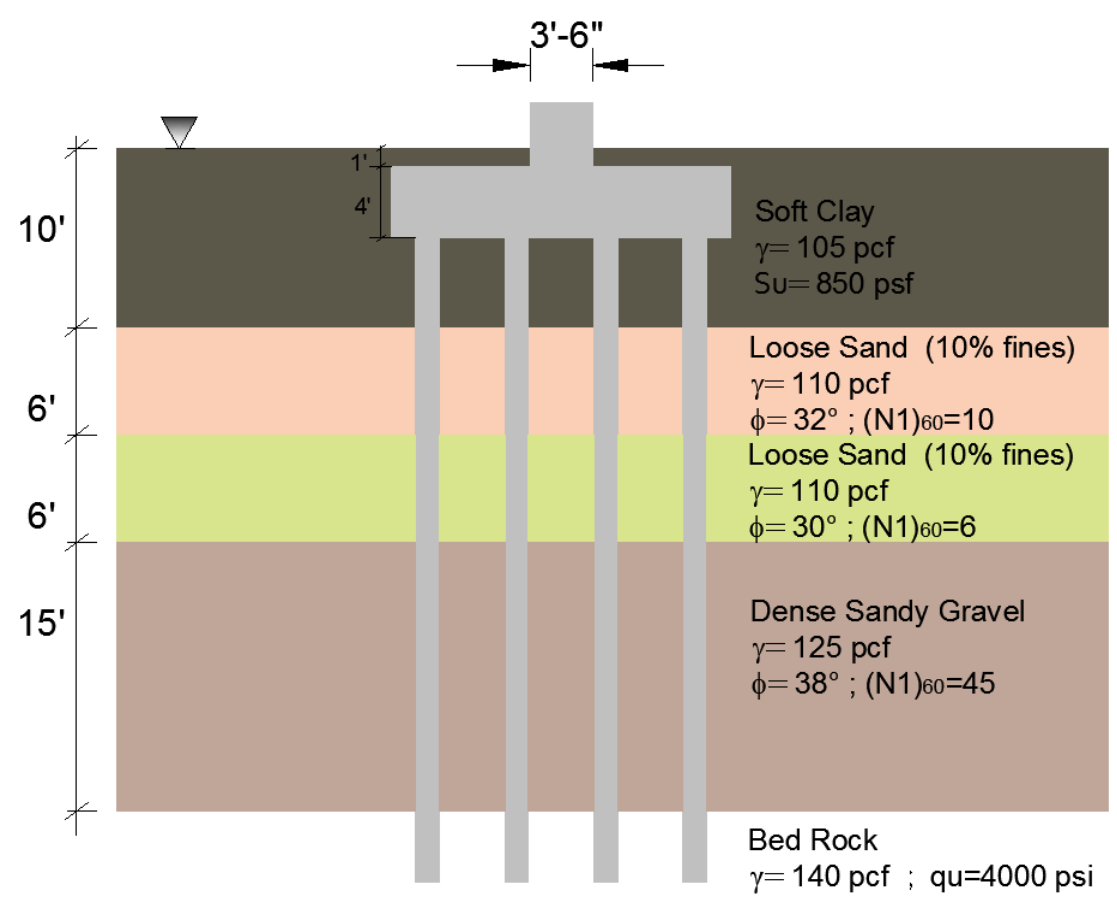

Figure 3.6: Soil profile and foundation dimension (replaced at drilled shaft location)

Table 3.3: Structural properties of 16” diameter PP pile

\begin{tabular}{cc}
\hline Description & Value \\
\hline Diameter $(B)$ & $16 \mathrm{in}$ \\
Thickness $(t)$ & 0.5 \\
Length & $38 \mathrm{ft}$ \\
Yield Stress $\left(f_{y}\right)$ & $45000 \mathrm{psi}$ \\
\hline
\end{tabular}


Table 3.4: Pile cap structural properties

\begin{tabular}{cc}
\hline Description & Value \\
\hline Width $\left(W_{T}\right)$ & $19 \mathrm{ft}$ \\
Length $\left(W_{L}\right)$ & $19 \mathrm{ft}$ \\
Thickness $(T)$ & $4 \mathrm{ft}$ \\
Moment of inertia $(I)$ & $1.1 \times 10^{4} \mathrm{ft}^{4}$ \\
Young's modulus $(E)$ & $3.61 \times 10^{3} \mathrm{ksi}$ \\
\hline
\end{tabular}

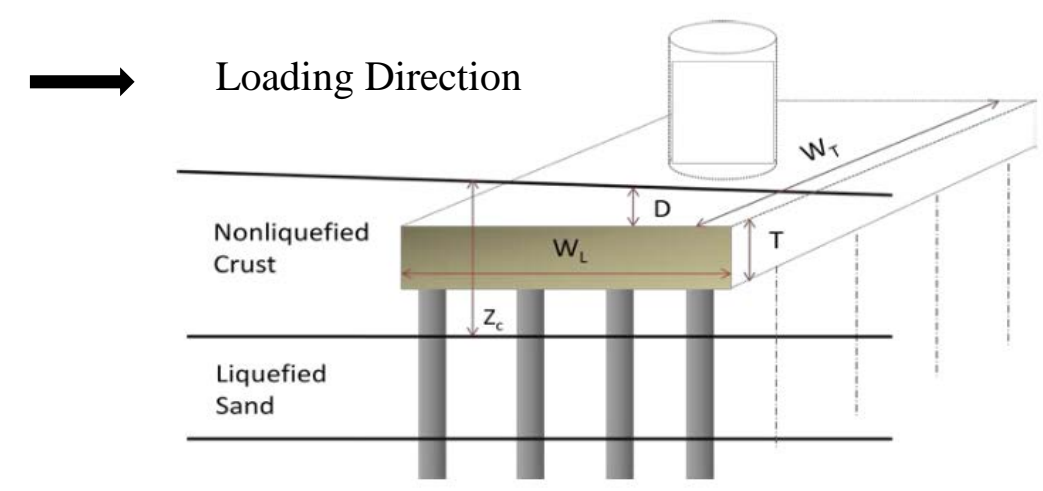

Figure 3.7: Description of the variables used in calculation (CALTRANS 2011)

\subsubsection{Modeling Methodology}

The conceptual drawing of the pile group analysis in laterally spreading ground is shown in Figure 3.8 and Figure 3.9. The piles in a group were modeled as an equivalent single pile with $n$ times the flexural stiffness and yielding moment of a single pile for the pile group composed of $n$ piles ( $n$ : number of piles). Soil springs for the equivalent piles are computed by amplifying the $p$ $y$ curves for a single pile using group p-multipliers. Separate $p-y$ curves are computed (based on passive earth pressure) for the pile cap portion and non-liquefied crustal layer. Figure 3.9 shows a schematic diagram for the LPILE model with equivalent soil-pile springs subjected to liquefaction induced lateral spreading together with equivalent inertial forces at the pile top and superstructure. For the boundary condition, a rotational spring is provided for the pile cap in order to accommodate the pile cap rotation during the earthquake loading. The application of a rotational spring gives better results than a free or fixed head boundary conditions as reported in previous research (Juirnarongrit and Ashford 2006). 


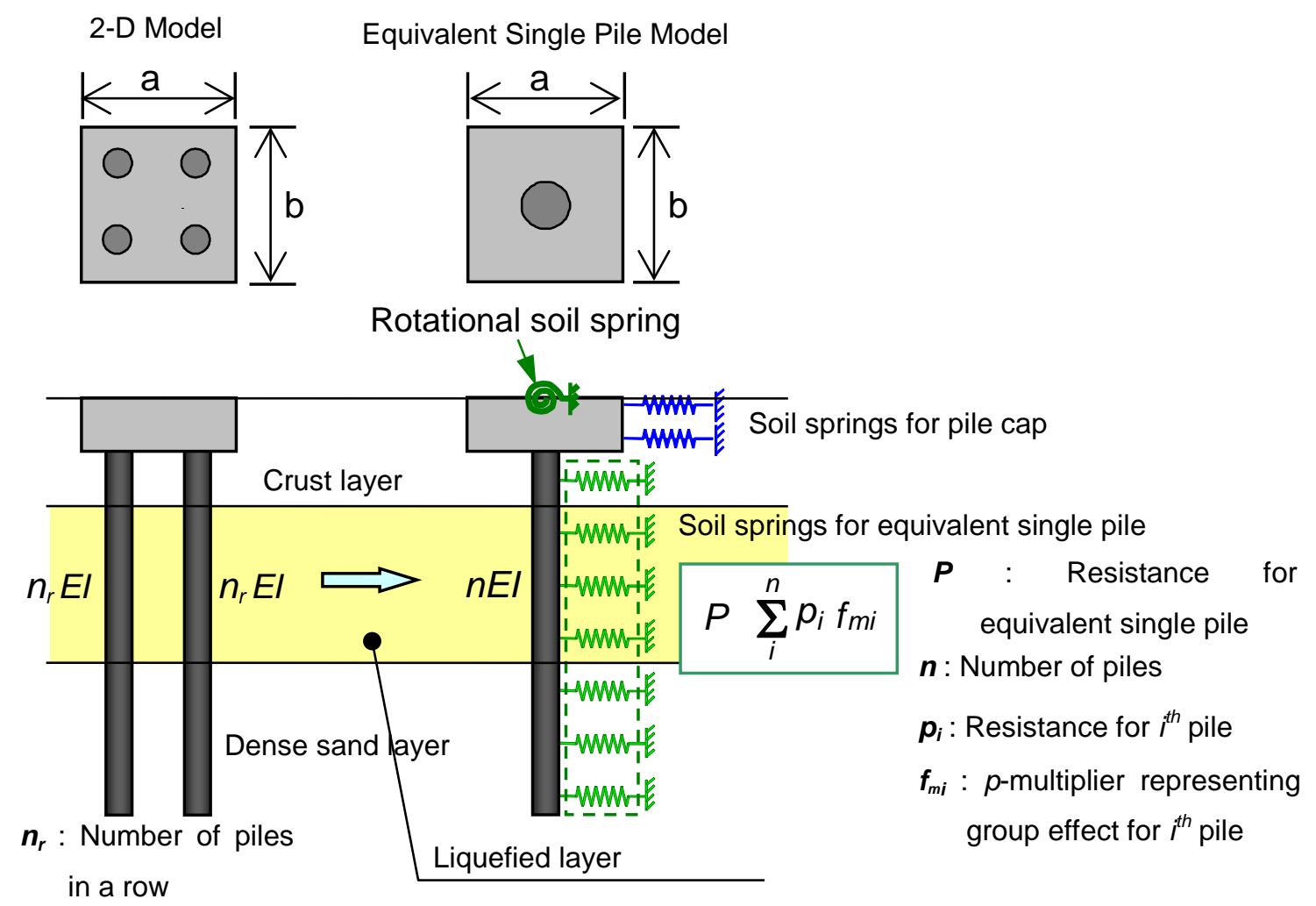

Figure 3.8: Equivalent single pile model illustrations

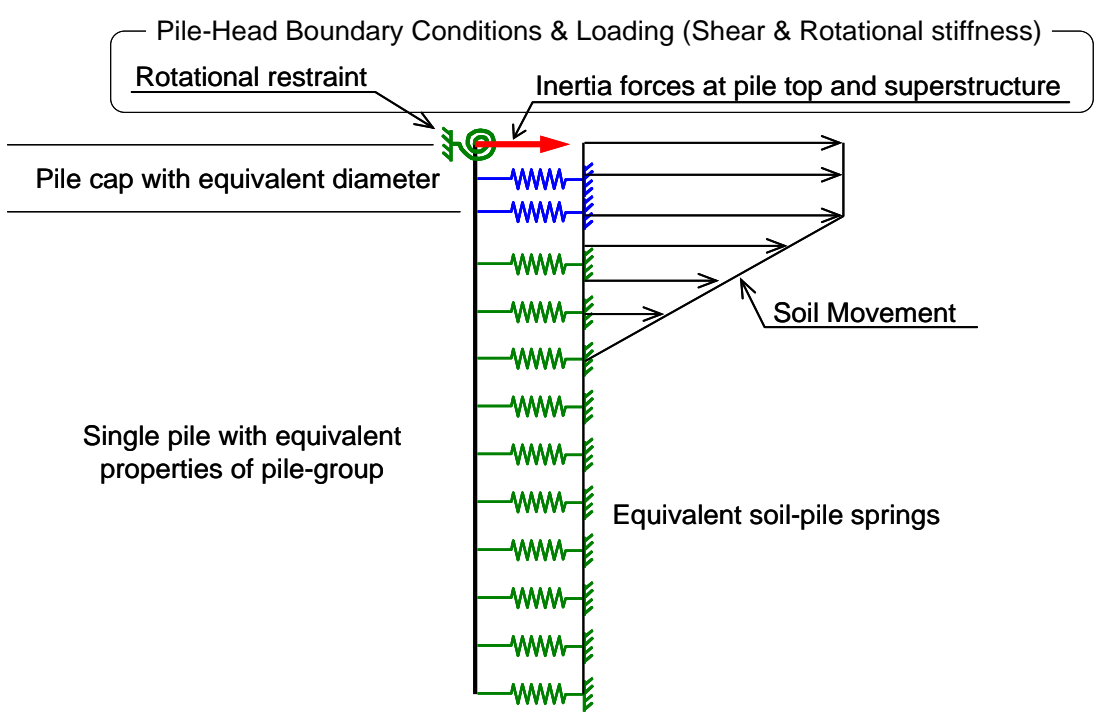

Figure 3.9: Boundary conditions and imposed soil displacement 


\subsubsection{Calculate Moment Curvature Relationship}

The LPILE software is used to calculate the moment-curvature of a single pile. Then, the moment is scaled by the number of group piles (16) while keeping the curvature equal to that of a single pile. The ductility of the equivalent pile is fixed as 12 and the ultimate moment capacity is computed as 1.1 times the maximum moment obtained from single pile times number of piles in the group. The moment-curvature and moment-stiffness relationship for the single pile is shown in Figure 3.10 (a) and the moment-curvature relationship for the equivalent pile in Figure 3.10 (b). The moment capacity and stiffness of a single pile and equivalent pile are shown in Table 3.5.
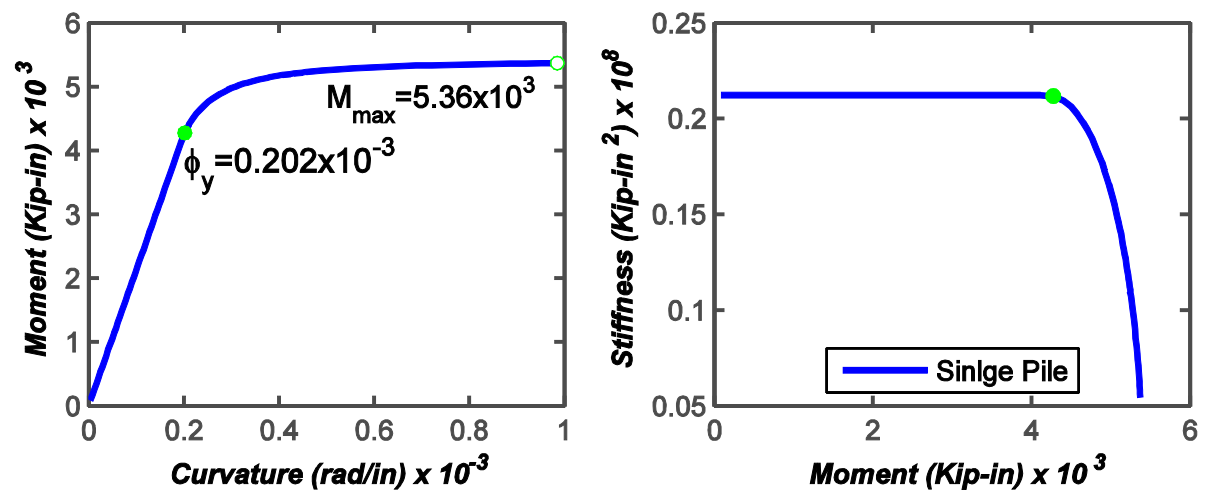

a) Single pile

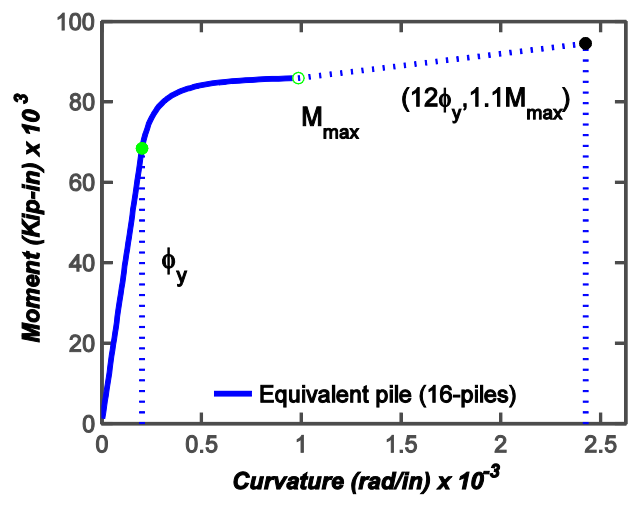

b) Equivalent pile

Figure 3.10: Section analysis: a) Moment-curvature and stiffness-moment relations for a single pile; b) moment-curvature relationship for equivalent pile 
Table 3.5: Moment and stiffness properties of a single pile and equivalent pile

\begin{tabular}{ccc}
\hline Property & Single pile & Equivalent pile \\
\hline Yield moment $\left(M_{y}\right)($ kip-in) & $4.23 \times 10^{3}$ & $6.77 \times 10^{4}$ \\
Maximum moment $\left(M_{\max }\right)($ kip-in) & $5.38 \times 10^{3}$ & $8.61 \times 10^{4}$ \\
Ultimate moment $\left(M_{u l t}\right)($ kip-in) & $5.92 \times 10^{3}$ & $9.47 \times 10^{4}$ \\
Elastic $E I\left(\right.$ kip-in $\left.{ }^{2}\right)$ & $2.11 \times 10^{7}$ & $3.38 \times 10^{8}$ \\
Plastic EI $\left(\mathrm{kip}^{2} \mathrm{in}^{2}\right)$ & $2.42 \times 10^{5}$ & $3.87 \times 10^{6}$ \\
\hline
\end{tabular}

\subsection{3. p-y Curves for Non-liquefied Crust Layer}

The $p-y$ curve for the pile cap is computed following the guidelines provided by CALTRANS (2011). The procedures to compute the $p-y$ curve are shown in Appendix D. A sample calculation to compute the controlling passive failure mechanism is shown below.

\section{Case A}

Depth of pile cap from surface $(D)=1 \mathrm{ft}$

Thickness of pile cap $(T)=4 \mathrm{ft}$

Cohesion $(c)=850$ psf

Adhesion factor $(\alpha)=0.5$

Passive pressure force $\left(F_{\text {passive-A }}\right)$

$$
\begin{aligned}
& =\left(4+\frac{\gamma(D+T)}{c}+\frac{D+T}{4 W_{T}}+2 \alpha\right) c W_{T} \frac{(D+T)}{2} \\
& =\left(4+\frac{42.6(1+4)}{850}+\frac{1+4}{4 \cdot 19}+2 \cdot 0.5\right) \cdot 850 \cdot 19 \frac{(1+4)}{2} \frac{1}{1000}=214 \mathrm{kip}
\end{aligned}
$$

Force of piles $\left(F_{\text {piles-A }}\right)$

$$
F_{\text {piles-A }}=n \cdot G R F \cdot P_{u l t-p i l e} \cdot L_{c}
$$

where $n$ is the numebr of piles in group, GRF is group reduction factor, $L_{c}$ is the pile length 
For clay layer, $p_{\text {ult-pile }}$ is calculated using API (1993) procedure (Appendix-D)

$$
X_{R}=\frac{6 B}{\frac{\gamma^{\prime} B}{c}+J}=\frac{6 \cdot 16}{\frac{42.6 \cdot 16}{850} \cdot \frac{1}{12}+0.5} \cdot \frac{1}{12}=14 \mathrm{ft}
$$

Since, $\mathrm{X}<\mathrm{X}_{\mathrm{R}}$

$$
\begin{aligned}
& \text { ultimate pressure on clay }\left(p_{\text {ult }- \text { pile }}\right)=\left(3 c+\gamma^{\prime} X+J c \frac{X}{B}\right) B \\
& =\left(3 \cdot 850+42.6 \cdot 7.5+0.5 \cdot 850 \frac{7.5}{16} \cdot 12\right) 16 \cdot \frac{1}{12}=7.0 \mathrm{kip} / \mathrm{ft}
\end{aligned}
$$

The GRF for the pile group is calculated using Mokwa and Duncan (2001) chart as shown in Figure 1.22. The spacing-to-diameter ratio for the pile group $(\mathrm{s} / \mathrm{D})=$ $60 / 16=3.75$. For the s/D ratio of 3.75 , the $p$-multipliers for the leading row, $1^{\text {st }}$ trailing row, $2^{\text {nd }}$ trailing row, and $3^{\text {rd }}$ trailing row are estimated as $0.86,0.78,0.67$, and 0.62 , respectively.

$$
\begin{aligned}
& \text { Average GRF }=(0.86+0.78+0.67+0.62) / 4=0.73 \\
& \boldsymbol{F}_{\text {piles-A }}=16 \cdot 0.73 \cdot 7 \cdot 5=409 \mathrm{kip}
\end{aligned}
$$

\section{Pile cap side force $\left(F_{\text {sides-A }}\right)$}

$$
\begin{aligned}
& \boldsymbol{F}_{\text {sides-A }}=2 \alpha c(T) W_{L} \\
& \boldsymbol{F}_{\text {sides }-A}=2 \cdot 0.5 \cdot 850 \cdot 19 \cdot \frac{4}{1000}=65 \mathrm{kip}
\end{aligned}
$$

\section{The ultimate forces from mechanism $A$ is}

$$
\boldsymbol{F}_{\text {ult }-\boldsymbol{A}}=214+409+65=688 \mathrm{kip}
$$

\section{Case B}

for $D=1 \mathrm{ft}, T=9 \mathrm{ft}, \alpha=0.5, \mathrm{c}=850 \mathrm{psf}$

Passive pressure force ( $\left.F_{\text {passive-B }}\right)$ 


$$
=\left(4+\frac{42.6(1+9)}{850}+\frac{1+9}{4 \cdot 19}+2 \cdot 0.5\right) \cdot 850 \cdot 19 \frac{(1+9)}{2} \frac{1}{1000}=455 \mathrm{kips}
$$

Pile cap side force $\left(F_{\text {sides-B }}\right)$

$$
\boldsymbol{F}_{\text {sides }-B}=2 \cdot 0.5 \cdot 850 \cdot 19 \cdot \frac{9}{1000}=145 \mathrm{kips}
$$

\section{The ultimate forces from mechanism $B$ is}

$$
\boldsymbol{F}_{\text {ult-B}}=455+145=600 \text { kips }
$$

Since $\mathrm{F}_{\text {ult-B }}<\mathrm{F}_{\text {ult-A}}$, mechasim B control in this example.

The maximum relative displacement $\left(\Delta_{\max }\right)$ to mobilize fully passive resistance against the pile cap is determined as:

$$
\Delta_{\text {MAX }}=(T)\left(0.05+0.45 f_{\text {depth }} f_{\text {width }}\right)
$$

where $f_{\text {depth }}$ and $f_{\text {width }}$ are the factors for the finite width of the pile cap

$$
f_{\text {depth }}=e^{-3\left(\frac{Z_{c}-D}{T}-1\right)} ; f_{\text {width }}=\frac{1}{\left(\frac{10}{\frac{W_{T}}{T}+4}\right)^{4}+1}
$$

where $W_{T}$ is pile cap width, $T$ is pile cap thickness, $Z_{c}$ is the depth of the crustal layer

$$
f_{\text {depth }}=e^{-3\left(\frac{10-1}{4}-1\right)}=0.023 \text { and } f_{\text {width }}=\frac{1}{\left(\frac{10}{\frac{19}{4}+4}\right)^{4}+1}=0.36
$$

$$
\Delta_{\text {MAX }}=(4)(0.05+0.45 \cdot 0.023 \cdot 0.36)=0.214 f t=2.57 \text { in }
$$

The value of $p_{\text {ult }}$ for the $p-y$ curve is calculated as 


$$
p_{u l t}=\frac{F_{u l t}}{Z_{c}-D}=\frac{600}{10-1}=67 \mathrm{kip} / \mathrm{ft}=5555 \mathrm{lb} / \mathrm{in}
$$

The idealized p-y curve for the pile cap is shown in Figure 3.11.

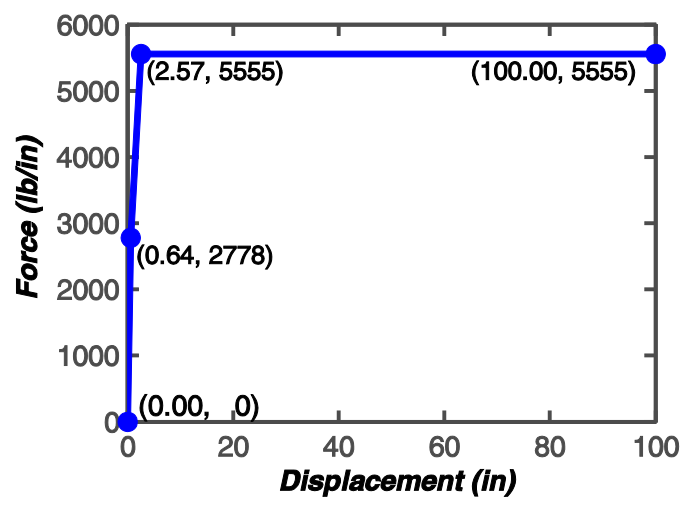

Figure 3.11: Idealized p-y curves for pile cap in crust layer

\subsubsection{Softening in Non- liquefied Layer}

Correction for the effect of a "smeared profile" in liquefied sand to the adjacent boundary soil is carried out using $p$-multiplier. The length of the influenced zone is estimated as described in CALTRANS (2011). For pile diameters between 1 and $3 \mathrm{ft}$, the depth affected by the liquefaction $\left(S_{b}\right)$ is calculated as (shown in Figure 1.28)

$$
S_{b}=2-\frac{\left(\frac{16}{12}-1\right)}{2}=1.83
$$

So the influence zone is extended to 1.83 times the diameter of the pile i.e. $2.4 \mathrm{ft}$. Since case B controls, the failure mechanism behaves as composite block, and application of the smeared profile is not appropriate in the non-liquefied crust. Therefore, the reduction in the $p-y$ strength is only applied to the underlying non-liquefied layer. However, if case A had controlled the smeared profiled would have been appropriate for both the upper and lower non-liquefied layers. The subgrade reaction for the dense sand is calculated using API (1993) method as

$$
p_{u l t}=\left(C_{1} z+C_{2} B\right) \gamma^{\prime} z
$$


where $p_{\text {ult }}$ is the ultimate soil pressure, $B$ is the diameter of pile, $\gamma^{\prime}$ is the effective unit weight , $z$ is the depth of the layer, and $C_{1}$ and $C_{2}$ are the coefficients depending upon the friction angle $(\phi)$, calculated as (from CALTRANS 2011)

$$
\begin{aligned}
& \left.\begin{array}{l}
C_{1}=3.42-0.295 \phi+0.00819 \phi^{2} \\
C_{2}=0.99-0.0294 \phi+0.00289 \phi^{2}
\end{array}\right\} \text { for } 20 \leq \phi \leq 40 \\
& p_{N L}=(4.036 \cdot 22+4.04 \cdot 16 / 12) 62.6 \cdot 22=130 \mathrm{kip} / \mathrm{ft}=10808 \mathrm{lb} / \mathrm{in}
\end{aligned}
$$

The subgrade reactions for liquefiable layers are estimated based on API (1993) for clay using liquefied residual strengths. The required equations are provided in Appendix-D. The adjustment factors are shown in Table 3.6.

for lower loose sand layer with detph $=22 \mathrm{ft}$

$$
\begin{aligned}
& p_{L-\text { lower }}=9 c B \text { since } \mathrm{X}>\mathrm{X}_{R}(8 \mathrm{ft}) \\
& p_{L-\text { lower }}=9 \cdot 119 \cdot \frac{16}{12}=1428 \mathrm{lb} / \mathrm{ft}=119 \mathrm{lb} / \text { in }
\end{aligned}
$$

Table 3.6: Adjustment factors for softening in dense sand layer

\begin{tabular}{cc}
\hline Distance from interface (ft) & $\boldsymbol{P}_{\boldsymbol{u}}$ adjustment factor $\left(\boldsymbol{m}_{\boldsymbol{p}}\right)$ \\
\hline 1 & $\frac{P_{L}}{P_{N L}}+\left(1-\frac{P_{L}}{P_{N L}}\right)\left(\frac{1}{S_{b} \cdot B}\right)=\frac{119}{10808}+\left(1-\frac{119}{10808}\right)\left(\frac{1}{1.83 \cdot 1.33}\right)=0.42$ \\
2 & $\frac{P_{L}}{P_{N L}}+\left(1-\frac{P_{L}}{P_{N L}}\right)\left(\frac{1}{S_{b} \cdot B}\right)=\frac{119}{10808}+\left(1-\frac{119}{10808}\right)\left(\frac{2}{1.83 \cdot 1.33}\right)=0.82$
\end{tabular}

\subsection{5. p-y Curve Scaling Factors}

For the given s/D ratio of 3.75 , the $p$-multipliers for the leading row, $1^{\text {st }}$ trailing row, $2^{\text {nd }}$ trailing row, and $3^{\text {rd }}$ trailing row are estimated as $0.86,0.78,0.67$, and 0.62 , respectively. The average value of the $p$-multipliers was found to be 0.73 . The $p$-multipliers were obtained from Mokwa and Duncan (2001). The chart for calculating $p$-multipliers is shown in Section 1.3.2.2. Final $p$ multipliers for the equivalent pile along the depth are shown in Table 3.7. 
Table 3.7: Summary of p-multiplier coefficient for equivalent pile

\begin{tabular}{cccc}
\hline Depth & \multicolumn{2}{c}{$\boldsymbol{p}$ multipliers for single pile } & $\begin{array}{c}\text { Combined } \boldsymbol{p} \text { multiplier } \\
\text { interval (ft) }\end{array}$ \\
\cline { 2 - 3 } $0-10$ & Group effect & Smeared profile & 1 \\
$0-10$ & 1 & 1 & 16 \\
$10-22$ & 1 & 1 & 4.9 \\
$22-23$ & 0.73 & 0.42 & 9.6 \\
$23-24$ & 0.73 & 0.82 & 11.68 \\
$24.4-37$ & 0.73 & 1 & - \\
$37-45$ & - & - & \\
\hline
\end{tabular}

\subsubsection{Rotational Stiffness for Pile Cap}

In this example, the axial stiffness $\left(k_{a x}\right)$ of the pile is assumed to be equal in uplift and compression. For relatively small pile group, this assumption is reasonable as found in previous research (Mokwa and Duncan 2003; Juirnarongrit and Ashford 2006). If the moment -rotation relationship for the pile cap is linear up to the ultimate restraining moment of a pile group, the foundation will rotate approximately about its center. According to CALTRANS (2011), 75\% of the ultimate axial resistance of a pile can be mobilized at 0.25 -in axial displacement. Then, the rotational stiffness $\left(k_{m \theta}\right)$ for the pile cap can be estimated using the axial resistance of the pile.

$$
\begin{aligned}
k_{a x} & =\frac{0.75 \cdot 225}{0.25}=675 \mathrm{kips} / \text { in } \\
k_{m \theta} & =k_{a x} \sum n \cdot x^{2}=675 \cdot\left(4 \cdot(7.5 \cdot 12)^{2}+4 \cdot(2.5 \cdot 12)^{2}+4 \cdot(-2.5 \cdot 12)^{2}+4 \cdot(-7.5 \cdot 12)^{2}\right) \\
& =4.86 \times 10^{7} \mathrm{kips}-\text { in }
\end{aligned}
$$

It is noted that the spacing between the rows is 5 - $\mathrm{ft}$ and each row contains four piles. The above calculated value will be used for rotational restraint at the top of the equivalent pile as a boundary condition. 


\subsubsection{Inertial Loads on the Foundation}

The same lateral inertial load as computed in Section 3.2.5 will also be specified in this example. Since, only two boundary conditions can be applied in the LPILE, shear force and rotational spring are specified as boundary conditions.

\subsubsection{Evaluate Seismic Performance}

Using all the data, an LPILE model is developed as shown in Figure 3.9. For the non-liquefiable crustal layer, modified $p$-y curve is used (Section 3.3.3), the liquefiable layers are modeled as soft clay with residual strength (Section 2.4), dense sand layer was modeled as API (1993) sand, and the bedrock is modeled as strong rock using the unconfined compressive strength (available in LPILE). A constant displacement of 60-in is imposed throughout the non-liquefiable crust and linear decreasing value to zero at the interface of the bottom liquefiable layer and non-liquefiable dense sand layer.

Based on the performance criteria, the maximum allowable bending moment and shear force for a single pile are 448 kip-ft and 328 kip, respectively (Table 3.8). The displacement, bending moments, shear force, and soil loading for the pile group foundation are obtained from pushover analysis. The results are shown in Figure 3.12. A summary of the results is presented in Table 3.8, which is obtained from the Figure 3.12. The maximum moment or shear demand for the individual pile is calculated by dividing the total moment or total shear in the equivalent pile by the number of piles in the group. Comparing the results with the performance criteria, only shear demand of the pile group satisfies the performance objective. The moment demand on the piles (455 kip-ft) is larger than the allowable moment (448 kips-ft). Thus, the pile group foundation does not satisfy the performance criteria. Severe yielding of the pile may lead to partial or total collapse of the bridge. Therefore the performance of the pile group foundation has to be improved. Methods to increase the performance are explained in the next section. It is noted that ODOT does not specified any displacement criteria so that no performance has been assessed in terms of pile displacement. 


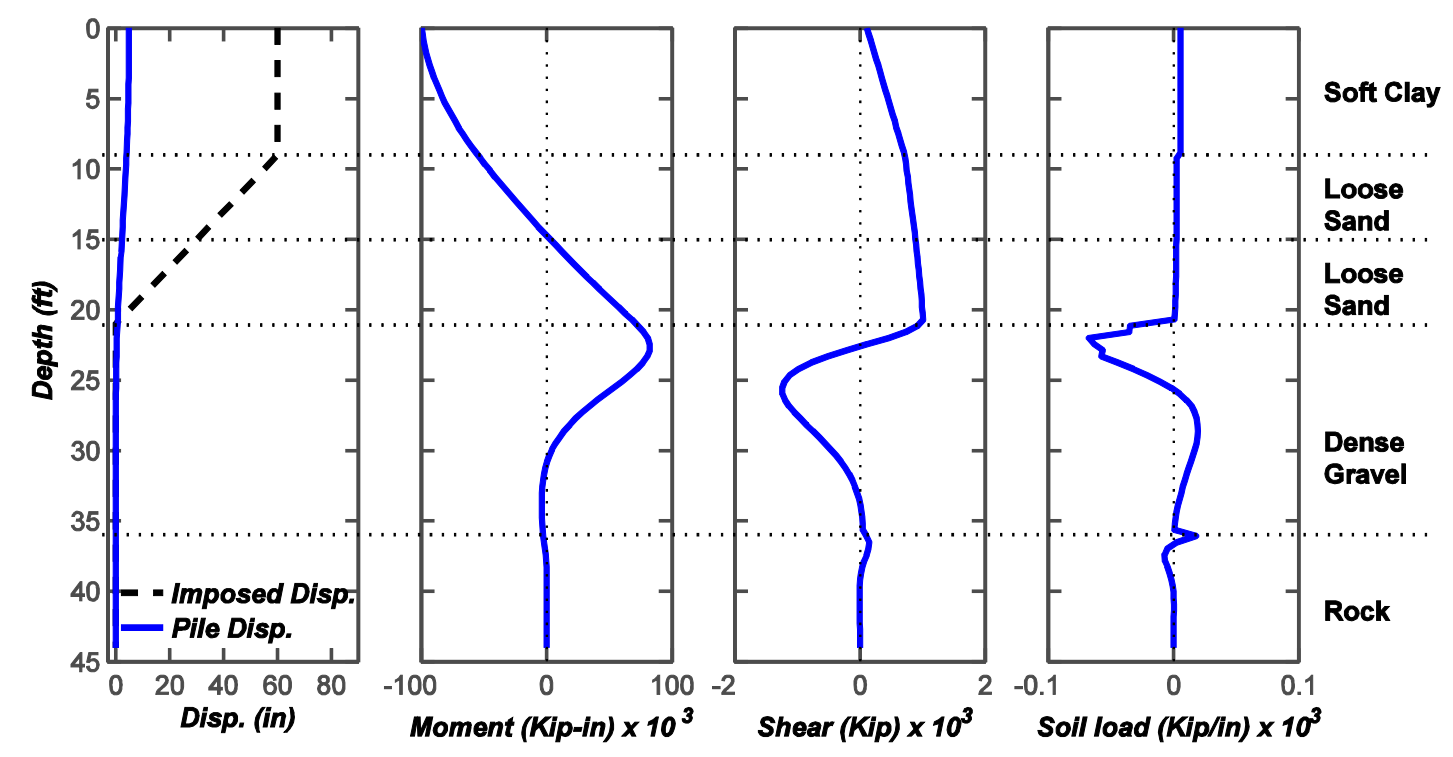

Figure 3.12: Response of pile group foundation to lateral spreading

Table 3.8: Summary of response for pile group foundation

\begin{tabular}{ccc}
\hline Parameter & $\begin{array}{c}\text { Inertia and lateral } \\
\text { spreading demand }\end{array}$ & Allowable limit \\
\hline Disp. of pile cap & $4.78 \mathrm{in}$ & - \\
Max. shear in a single pile & $78 \mathrm{kip}$ & $328 \mathrm{kip} *$ \\
Max. moment in a single pile & $455 \mathrm{kip}-\mathrm{ft}$ & $448 \mathrm{kip}-\mathrm{ft}$ \\
\hline
\end{tabular}

Note: * The shear strength of the pile is computed using AISC (2005) steel manual

The shear strength of the pile

$$
V_{n}=\frac{F_{c r} A_{g}}{2}=\frac{0.6 \cdot 45000 \cdot \pi \cdot\left(16^{2}-(16-2 \cdot 0.5)^{2}\right) / 4}{2} \cdot \frac{1}{1000}=328 \mathrm{kip}
$$

where $F_{c r}$ is the critical stress for buckling (taken as $0.6 f_{y}$ ) and $A_{g}$ is the gross area of the pile section. 


\subsubsection{Enhancing Performance/Retrofitting the Pile Group Foundation}

Although the shear demand in the pile is less than the allowable shear force, yielding of piles occurs for the given design earthquake loading scenario. Therefore, the foundation has to be modified to satisfy the performance criteria and preventing occurrence of yielding in pile groups. Generally, the performance of the foundation can be increased by three methods

1) Increasing the number of piles in a row or increasing the number of rows in the pile group;

2) Increasing the sectional properties (e.g., diameter, thickness) of the pile and using equal (or increasing) number of piles in the group;

3) Using additional piles of relatively large size (e.g., drilled shaft) and tied them to the existing foundation system

In the case of new foundation design, methods 1 and 2 could be the best solutions to improve the performance of the foundation. However, it is noted that if the moment demand is significantly higher than the capacity of the pile, it is possible that method 1 may not give a suitable solution. In method 1, increasing the number of piles not only increases the moment capacity, but also increases the stiffness. The increase in stiffness may lead to a proportional increase in moment demand. Thus, method 1 may require a significantly higher number of piles be added in order to achieve the foundation criteria. On the other hand, using method 2 may give a better solution because increasing the diameter of the pile significantly increases the moment capacity as well as stiffness. As a result, relatively few piles are sufficient to achieve the foundation performance criteria without yielding the piles.

In the case of an existing foundation, method 3 could be a suitable solution as the cost of retrofitting is usually cheaper than replacing the whole foundation. In this method, relatively stiffer piles are combined with the existing foundation and moment demand in the foundation is distributed according to the pile’s relative stiffness. Generally, drilled shafts are suitable for this purpose and a small number of shafts could be sufficient to retrofit the bridge foundation.

Though this example is for existing bridge foundation, sample calculations were provided for all three methods for enhancing the performance of the pile foundation. The following sub sections describe each of the methods. 


\subsubsection{Performance Enhancement by Increasing Number of Piles}

As described in above section, the performance of the existing pile foundation can be increased by adding more piles. In this example, the existing foundation is retrofitted by adding 4 piles having same size as existing piles. The layout of the retrofitted foundation is shown in Figure 3.13. By following the same procedure from section 3.3.1 to section 3.3.7, LPILE model was developed and analysis was carried out. The response of the retrofitted foundation is shown in Figure 3.14 and the summary of the results is presented in Table 3.9. The retrofitted foundation has satisfied both bending moment and shear force performance criteria

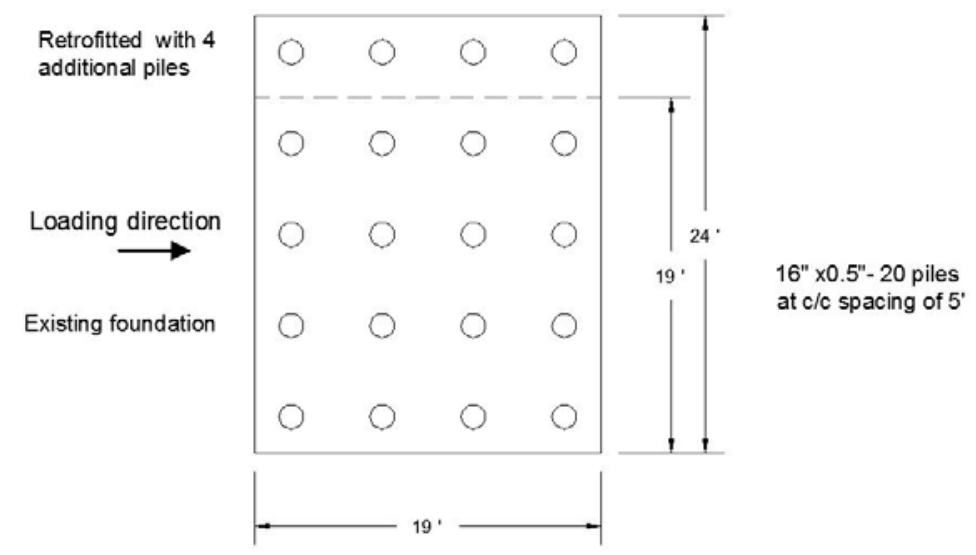

Figure 3.13: Retrofitted foundation layout

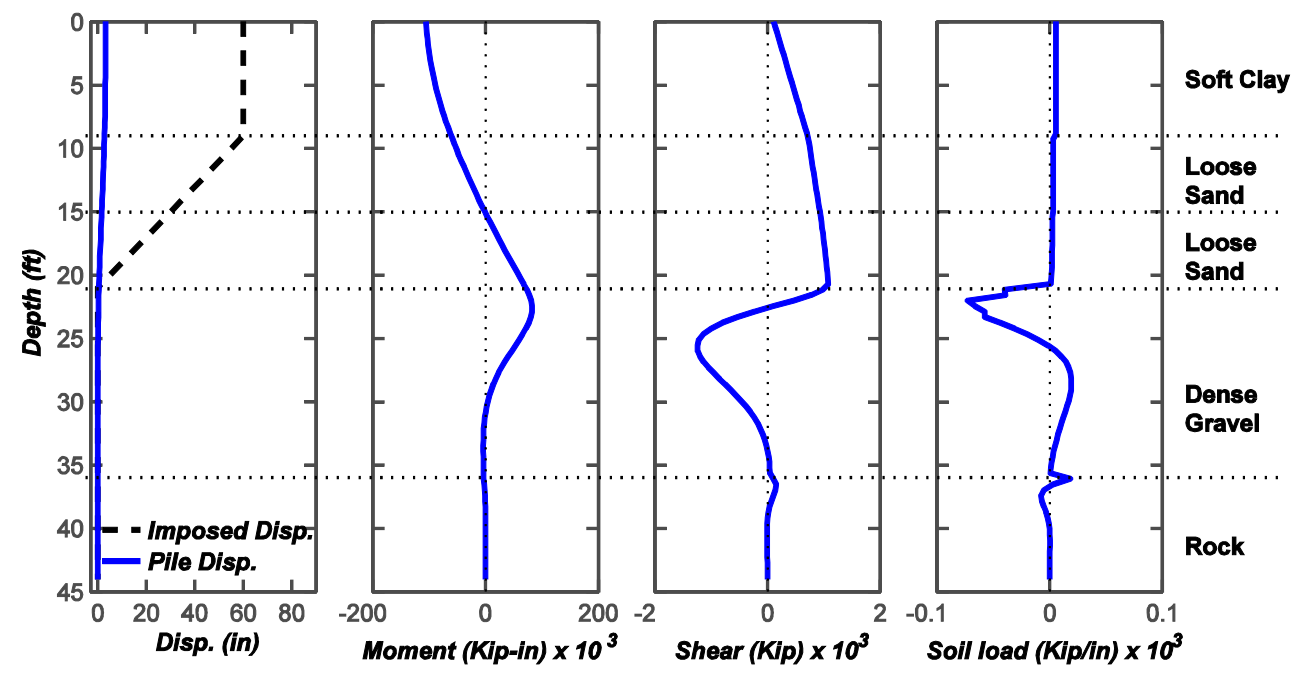

Figure 3.14: Response of pile group foundation to lateral spreading 
Table 3.9: Summary of response for pile group foundation

\begin{tabular}{ccc}
\hline Parameter & $\begin{array}{c}\text { Inertia and lateral } \\
\text { spreading demand }\end{array}$ & Allowable limit \\
\hline Disp. of pile cap & $3.22 \mathrm{in}$ & - \\
Max. shear in a single pile & $62 \mathrm{kip}$ & $328 \mathrm{kip} *$ \\
Max. moment in a single pile & $393 \mathrm{kip}-\mathrm{ft}$ & $448 \mathrm{kip}-\mathrm{ft}$ \\
\hline
\end{tabular}

\subsubsection{Performance Enhancement by Using Larger Pile}

This method is only suitable for the design of new foundations, where the size of the pile can be changed during the design phase. For this example, 9 piles are used with each pile having $2 \mathrm{ft}$ diameter and 0.5-in thickness. The center to center spacing between the piles was provided with 5 - $\mathrm{ft}$ and the corresponding size of the pile cap is $16 \mathrm{ft} \times 16 \mathrm{ft} \times 4 \mathrm{ft}$. It is noted that size is progressively increased until the optimal design can be achieved. However, in this example a larger diameter is selected to show that the new pile configuration can satisfy the foundation performance criteria. The moment -curvature and moment-stiffness behavior for the new pile are shown in Figure 3.15. The sectional properties of the single pile and corresponding equivalent pile are shown in Table 3.10. The modified $p-y$ curve for the pile cap is shown in Figure 3.16.

Results of the pushover analysis are shown in Figure 3.17. A summary of the results is shown in Table 3.11, which is obtained from Figure 3.17. The maximum moment demand and shear demand in an individual pile are 810 kip-ft and 96 kip respectively. These demands are less than the maximum allowable limits for moment 1025 kip-ft and shear force 498 kip. Thus, the new foundation satisfies the performance criteria. From these results, it can be seen that appropriate pile size can reduce the number of piles and pile cap size to satisfy the performance criteria. As mentioned before, ODOT does not specify criteria for pile cap displacement; therefore no assessment has been carried out. 

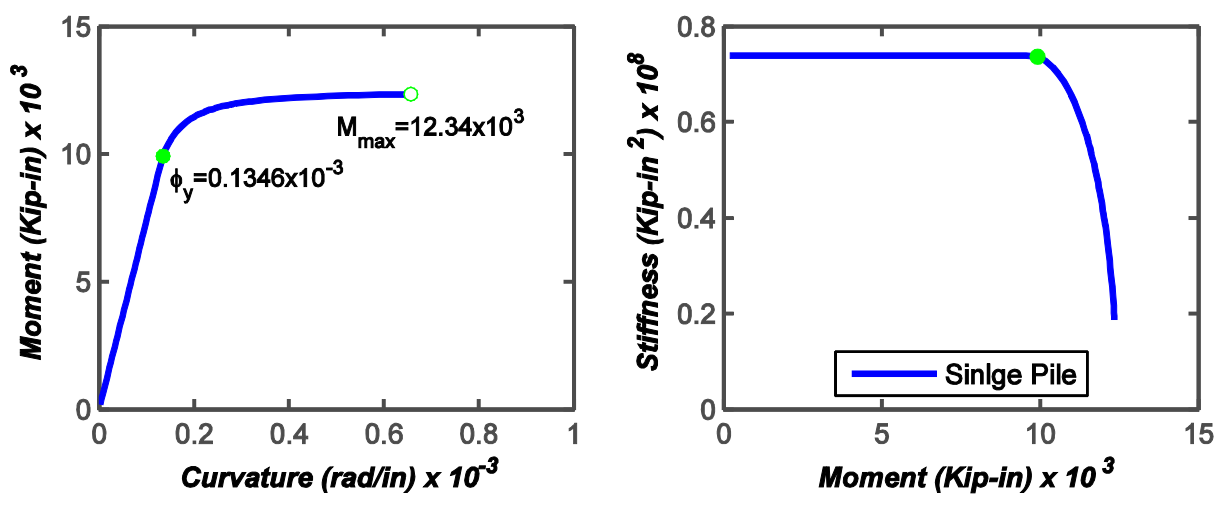

a) Single pile

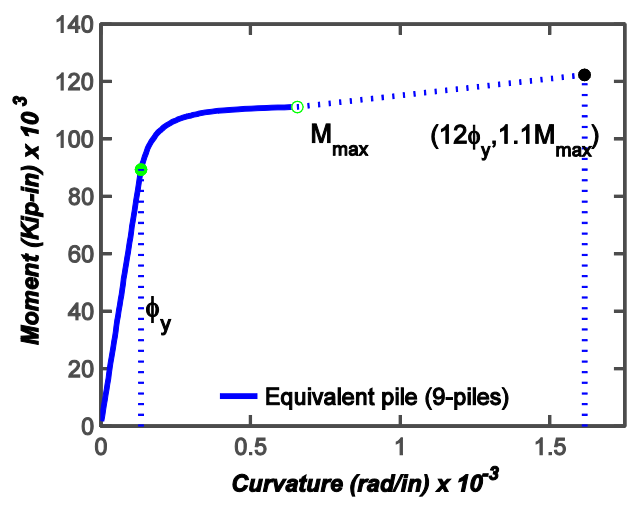

b) Equivalent pile

Figure 3.15: Section analysis: a) Moment-curvature and stiffness-moment relations for a single pile; b) moment-curvature relationship for equivalent pile

Table 3.10: Moment and stiffness properties of a single pile and equivalent pile

\begin{tabular}{ccc}
\hline Property & Single pile & Equivalent pile \\
\hline Yield moment $\left(M_{y}\right)($ kip-in) & $9.91 \times 10^{3}$ & $8.92 \times 10^{4}$ \\
Maximum moment $\left(M_{\max }\right)(\mathrm{kip}-\mathrm{in})$ & $1.23 \times 10^{4}$ & $1.11 \times 10^{5}$ \\
Ultimate moment $\left(M_{u l t}\right)(\mathrm{kip}-\mathrm{in})$ & $1.35 \times 10^{4}$ & $1.22 \times 10^{5}$ \\
Elastic $E I\left(\mathrm{kip}-\mathrm{in}^{2}\right)$ & $7.39 \times 10^{7}$ & $6.65 \times 10^{8}$ \\
Plastic $E I\left(\mathrm{kip}-\mathrm{in}^{2}\right)$ & $9.11 \times 10^{5}$ & $8.21 \times 10^{6}$ \\
\hline
\end{tabular}




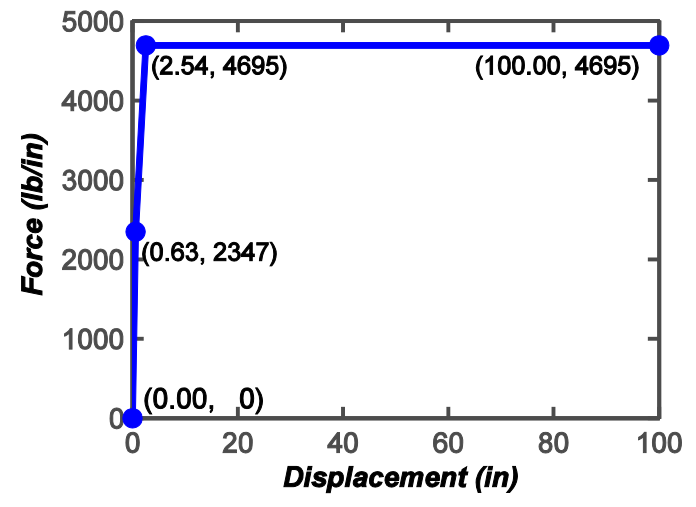

Figure 3.16: Idealized p-y curve for non-liquefied crust layer

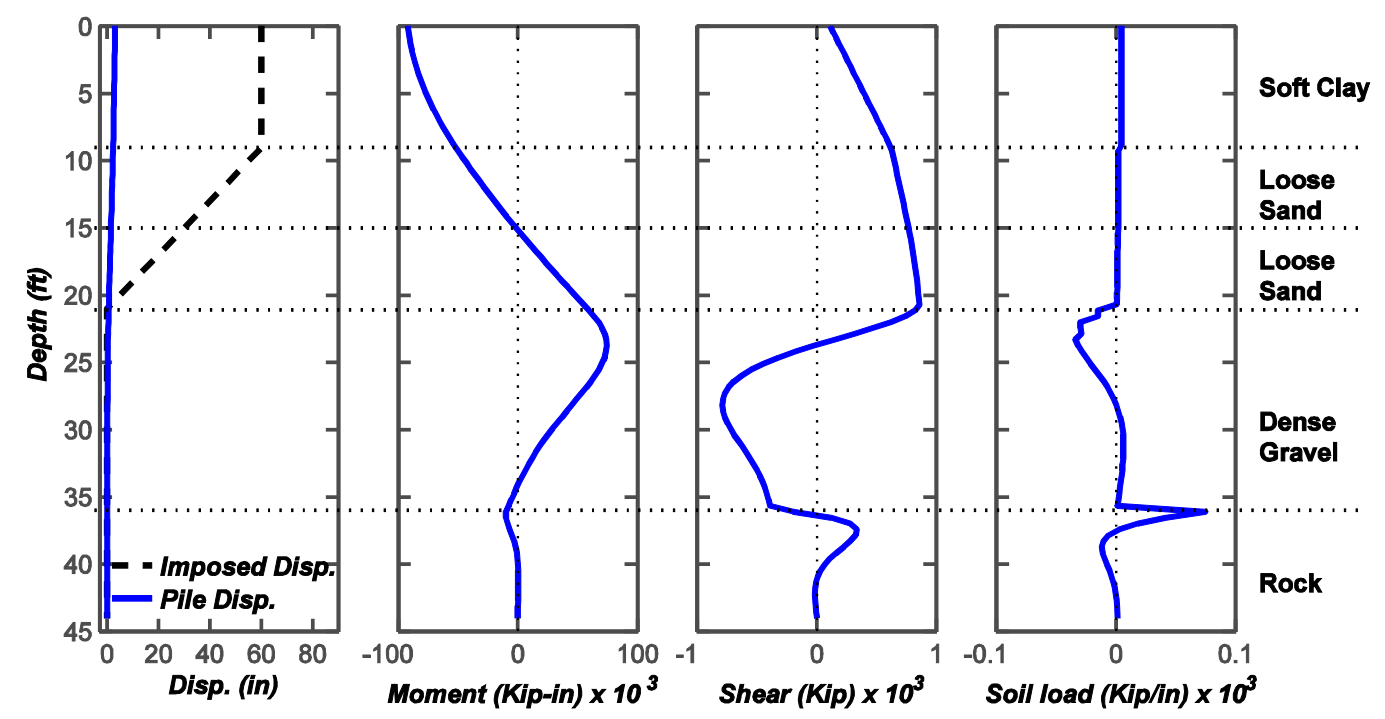

Figure 3.17: Response of pile group foundation with 2-ft diameter pile

Table 3.11: Summary of response of bridge foundation with 2-ft diameter piles

\begin{tabular}{ccc} 
Parameter & $\begin{array}{c}\text { Inertia and lateral } \\
\text { spreading demand }\end{array}$ & Allowable limit \\
\hline Disp. of pile cap & 2.86 in & - \\
Max. shear in a single pile & $96 \mathrm{kip}$ & $498 \mathrm{kip} *$ \\
Max. moment in a single pile & $810 \mathrm{kip}-\mathrm{ft}$ & $1025 \mathrm{kip}-\mathrm{ft}$ \\
\hline
\end{tabular}

Note: * Shear capacity is calculated based on AISC (2005). 


\subsubsection{Performance Enhancement by Connecting with Additional Drilled Shafts}

In this method, trial and error can be used to estimate the number and size of drilled shafts to be used to retrofit an existing bridge. Then the combined stiffness is computed for the equivalent pile. In this example, two drilled shafts having 42-in diameter are selected as a starting point. The layout of the retrofitted pile group foundation and the cross-section of the new drilled shafts are shown in Figure 3.18. The moment-curvature and moment-stiffness of the drilled shaft are shown in Figure 3.19 together with the moment-curvature relationships for equivalent pile. The combined moment-curvature relationships is obtained by adding the moment curvature for the existing single pile times number of pile and moment curvature for the new drilled shaft times number of drilled shafts. The sectional properties for the single pile and single drilled shafts are shown in Table 3.13

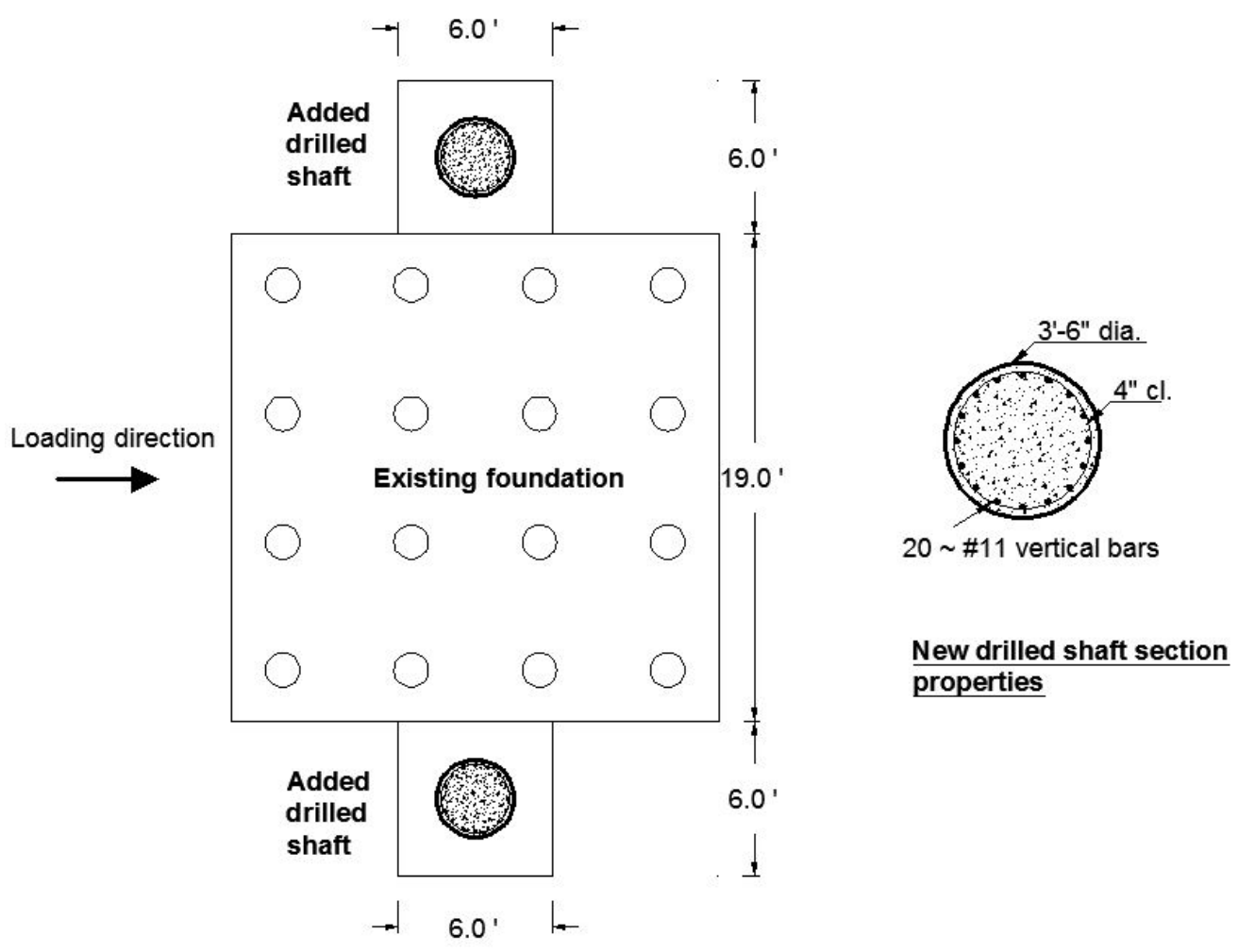

Retrofitting configuration

Figure 3.18: Size of the drilled shaft used for retrofitting 

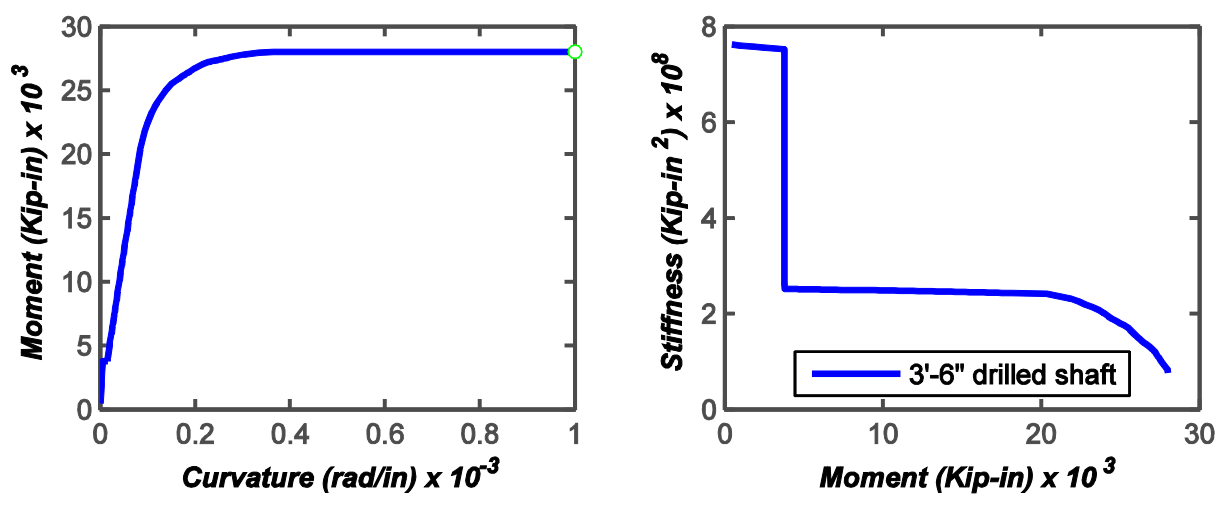

a) New drilled shaft

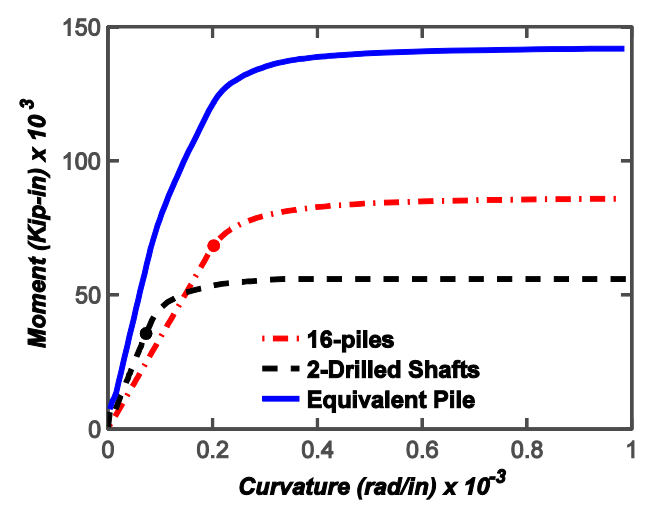

b) Equivalent pile

Figure 3.19: Section analysis: a) Moment-curvature and stiffness-moment relations for a new drilled shaft; b) moment-curvature relationship for equivalent pile

Table 3.12: Moment and stiffness properties of a single pile and drilled shaft

\begin{tabular}{lcc}
\hline Property & $\begin{array}{c}\text { Single existing } \\
\text { pile }\end{array}$ & $\begin{array}{c}\text { Single drilled } \\
\text { shaft }\end{array}$ \\
\hline Yield moment $\left(M_{y}\right)($ kip-in) & $4.23 \times 10^{3}$ & $1.78 \times 10^{4}$ \\
Maximum moment $\left(M_{\text {max }}\right)($ kip-in) & $5.38 \times 10^{3}$ & $2.80 \times 10^{4}$ \\
Ultimate moment $\left(M_{\text {ult }}\right)($ kip-in) & $5.92 \times 10^{3}$ & $3.08 \times 10^{4}$ \\
Elastic EI $\left(\right.$ kip-in $\left.{ }^{2}\right)$ & $2.11 \times 10^{7}$ & $2.44 \times 10^{8}$ \\
Plastic EI $\left(\right.$ kip-in $\left.{ }^{2}\right)$ & $2.42 \times 10^{5}$ & $1.89 \times 10^{6}$ \\
\hline
\end{tabular}


The calculation for the combined and relative stiffness of the pile group and drilled shafts is as follows

1) Bending stiffness of 16 piles $=3.3 \times 10^{8} \mathrm{kip}^{-\mathrm{in}^{2}}$ (from Section 3.3.2)

2) Bending stiffness of new drilled shaft $=2.4 \times 10^{8}$ kip-in ${ }^{2}$ (from Figure 3.19)

3) Thus, total stiffness of new super-pile $=3.3 \times 10^{8}+2 \times 2.4 \times 10^{8}=8.3 \times 10^{8}$ kip-in $^{2}$

4) Relative stiffness of 16 piles combined $=3.3 \times 10^{8} / 8.3 \times 10^{8}=0.40$

With these equivalent pile properties, analysis is conducted again. In this example, the $p$ $y$ curve for the pile cap is assumed to be similar to that of the original pile cap (Figure 3.11). Furthermore, the rotational stiffness for the pile cap is also considered equal to that of the original pile cap (Section 3.3.6). The analysis results are shown in Figure 3.20 and a summary of the results is shown in Table 3.13 .

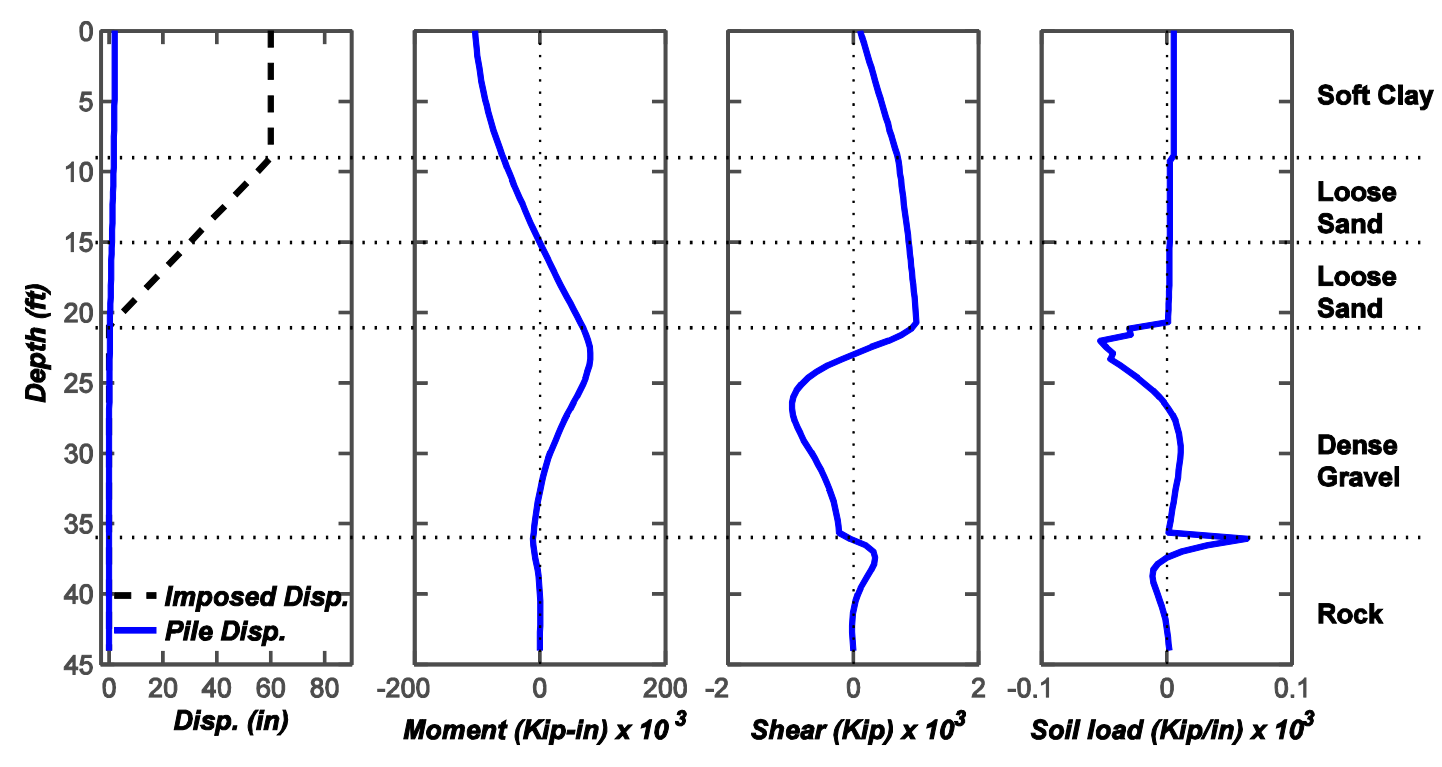

Figure 3.20: Response of pile group foundation retrofitted with 3-ft diameter drilled shaft

The maximum moments demand on the single pile and new drilled shaft are computed as

5) The maximum moment in the super pile $=92000$ kip-in (obtained from Figure 3.20)

6) The moment in the 16 piles $=92000 \times 0.40$ (calculated in step 4)

7) $=36800$ kip-in $=3067$ kip-ft 
8) Therefore, moment in single pile $=3067 / 16=192$ kip-ft $<448$ kip-ft OK

9) Moment in the two drilled shafts $=92000 \times(1-0.4)=54000 \mathrm{kip}-\mathrm{in}=4500 \mathrm{kip}-\mathrm{ft}$.

10) Moment in a single drilled shaft $=4500 / 2=2250$ kip-ft $<2566$ kip-ft OK

Table 3.13: Summary of response for retrofitted 16” PP pile

\begin{tabular}{ccc}
\hline Parameter & $\begin{array}{c}\text { Inertia and lateral } \\
\text { spreading demand }\end{array}$ & Allowable limit \\
\hline Disp. of pile cap & 2.1 in & - \\
Max. shear in a single pile & $25 \mathrm{kip}$ & $328 \mathrm{kip} *$ \\
Max. moment in a single pile & $192 \mathrm{kip}-\mathrm{ft}$ & $448 \mathrm{kip}-\mathrm{ft}$ \\
\hline
\end{tabular}

As can be seen from the Table 3.13, the retrofitted foundation satisfies the performance criteria for both moment and shear force in the pile. This example is only focused on the procedure to retrofit the pile foundation, so the proposed drilled shaft size may not be an optimal size. Additional analysis can be carried out with different drilled shaft sectional properties. Furthermore, the design example had shown here only serves as a simplified method to analyze bridge pile foundations in liquefaction induced laterally spreading ground. This design example is only intended to be a quick check for a routine job. In an important or large project, a detailed analysis would be required, which might involve 3D finite element methods with nonlinear constitutive models for soils and piles. 


\section{Chapter 4: Design Example for Foundation at Bridge Abutment}

\subsection{Introduction}

This chapter presents an example for the seismic performance evaluation of a pile supported foundation at a bridge abutment using the "pinning" method. The seismic performance of the abutment is evaluated by following the procedure for the "foundation restrained crustal displacement case” in CALTRANS (2011) guidelines. In this method, it is assumed that the abutment provides lateral resistance to the displacement of the soil, which helps to reduce the foundation displacement and increase the overall performance of the foundation, leading to an economical design.

The bridge has a single row pile group foundation and integral abutment at both ends of the bridge, so the performance evaluation is carried out for the single row pile foundation case. The procedure for single and multiple rows is similar. Therefore, rather than providing another example for a multiple row pile foundation, additional comments are provided in the subsequent section of the single row procedure, which will be sufficient to evaluate the performance for multiple row pile foundations. Finally, examples are presented for seismic retrofitting of the integral abutment foundation. The liquefaction assessment of the soil profile at bridge abutment locations was already carried out in Chapter 2 and the residual strength of the liquefied soil computed in Chapter 3 will be used in slope stability analysis of the embankment.

\subsection{Numerical Analysis for Pile Group Foundation at Bridge Abutment}

Dimensions of the bridge abutment and foundation along with the soil profile are shown in Figure 4.1. The abutment rests on a pile group with a single row of 10 piles of size 16 ” x 0.5 ”PP. These piles are exactly the same as the piles used in Section 3.3. The dimensions and layout for the pile group are shown in Figure 4.2. The properties of the pile cap are shown in Table 4.1. Descriptions of the variables used for the calculation are shown in Figure 3.7 (identical to the variables used by CALTRANS 2011). 


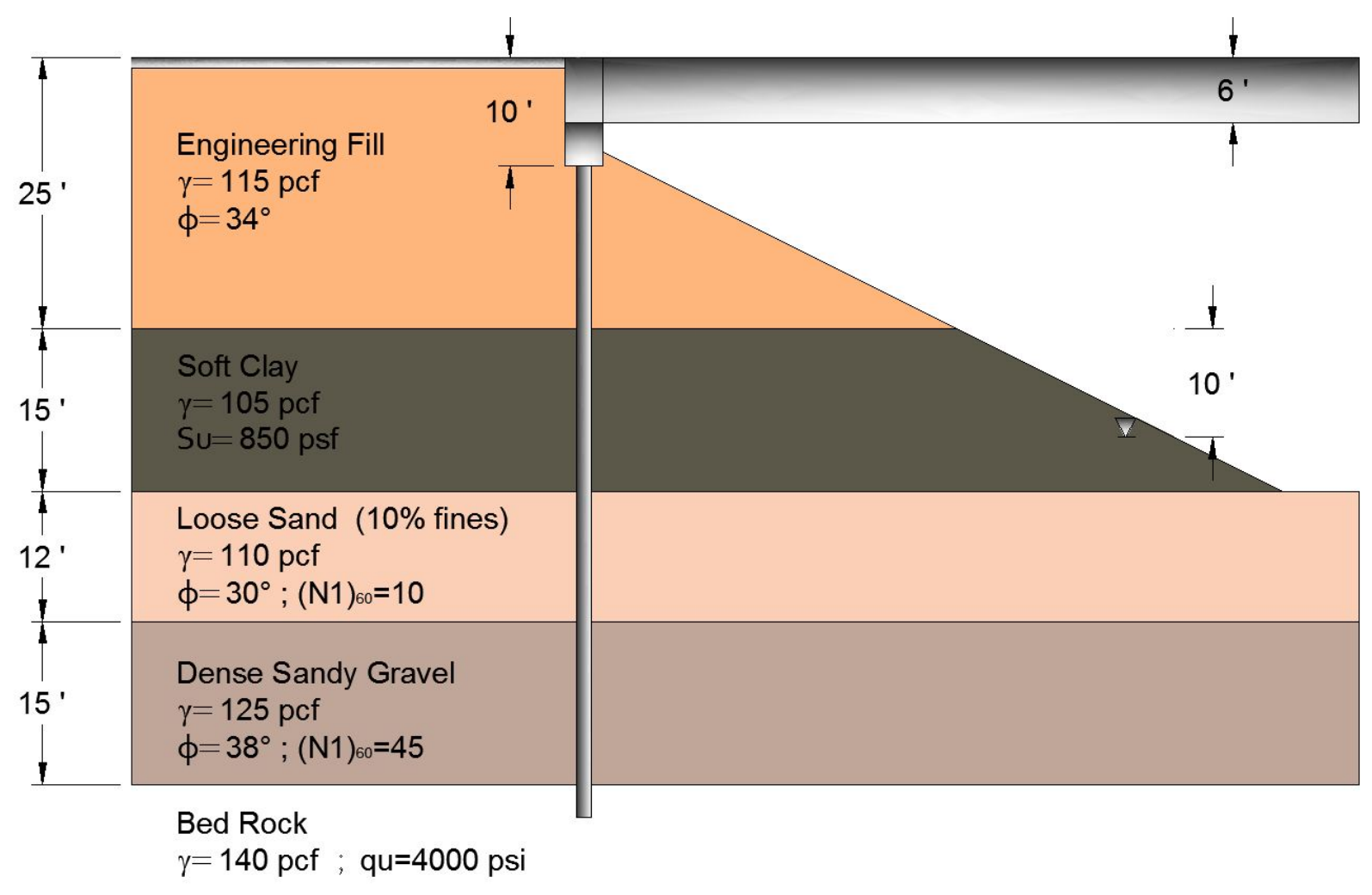

Figure 4.1: Soil profile and abutment layout (left section) with dimensions

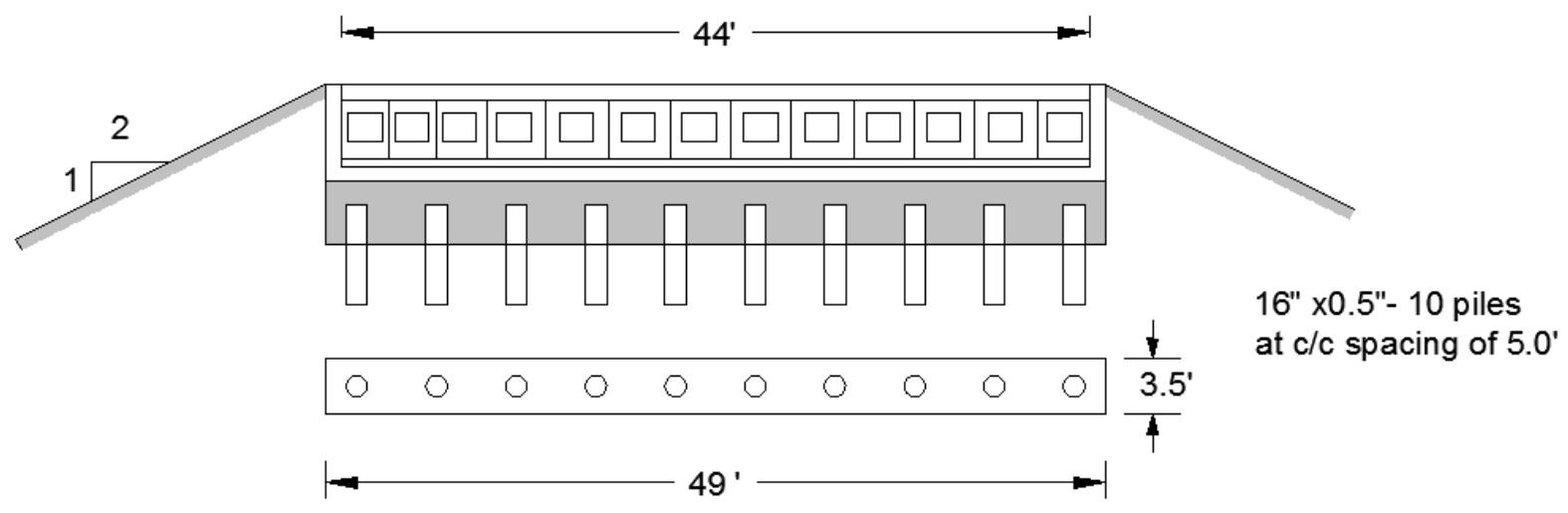

Figure 4.2: Pile group layout with pile cap dimensions 
Table 4.1: Pile cap structural properties

\begin{tabular}{cc}
\hline$W_{T}$ & $49 \mathrm{ft}$ \\
$W_{L}$ & $3.5 \mathrm{ft}$ \\
$T$ & $4 \mathrm{ft}$ \\
$I$ & $175 \mathrm{ft}^{4}$ \\
$E$ & $3.61 \times 10^{3} \mathrm{ksi}$ \\
\hline
\end{tabular}

\subsubsection{Modeling Methodology}

The pile group modeling technique and analysis using an equivalent pile, as described in Section 3.3.1, will be used. Since the foundation restraint (or pile pinning) condition is considered, the lateral spreading displacement is not known at the beginning of the analysis. Therefore, analyses are carried out by using a series of incremental lateral spreading displacement profiles (as described in Section 4.2.8).

\subsubsection{Calculate Moment-curvature Relationship}

The moment-curvature and stiffness-moment relationship for 16” x 0.5”PP (ASTM A252, Grade 3) is shown in Figure 3.10. The properties of the equivalent pile are shown in Table 4.2.

Table 4.2: Moment and stiffness properties of a single pile and equivalent pile

\begin{tabular}{ccc}
\hline Property & Single pile & Equivalent pile \\
\hline Yield moment $\left(M_{y}\right)($ kip-in) & $4.23 \times 10^{3}$ & $4.23 \times 10^{4}$ \\
Maximum moment $\left(M_{\max }\right)(\mathrm{kip}-\mathrm{in})$ & $5.38 \times 10^{3}$ & $5.38 \times 10^{4}$ \\
Ultimate moment $\left(M_{u l t}\right)(\mathrm{kip}-\mathrm{in})$ & $5.92 \times 10^{3}$ & $5.92 \times 10^{4}$ \\
Elastic EI $\left(\mathrm{kip}-\mathrm{in}^{2}\right)$ & $2.11 \times 10^{7}$ & $2.11 \times 10^{8}$ \\
Plastic EI $\left(\mathrm{kip}-\mathrm{in}^{2}\right)$ & $2.42 \times 10^{5}$ & $2.42 \times 10^{6}$ \\
\hline
\end{tabular}

\subsection{3. p-y Curves for Non-liquefied Crust Layer}

The $p$-y curve for the pile cap is computed following the guidelines provided by CALTRANS (2011). The procedures to compute the $p-y$ curve are shown in Appendix D. A sample calculation to compute the controlling passive failure mechanism is shown below. 


\section{Case A}

Depth of pile cap from surface $(D)=0 \mathrm{ft}$

Thickness of Pile Cap $(T)=10 \mathrm{ft}$

Cohesion (c') $=0$ psf

Passive pressure force $\left(F_{\text {passive-A }}\right)$

$$
\begin{aligned}
\boldsymbol{F}_{\text {passive-A }} & =\left(\overline{\sigma_{v}^{\prime}} K_{p}+2 c^{\prime} \sqrt{K_{p}}\right)(T)\left(W_{T}\right)\left(k_{w}\right) \\
& \sigma_{v}^{\prime}=(D+T / 2) \cdot 115=(0+10 / 2) \cdot 115=575 p s f \text { (Mean stress is computed) } \\
& \text { for friction angle }(\phi)=34^{\circ} \text { and } \delta=\phi / 3=11.33
\end{aligned}
$$

Passive earth pressure coefficient $\left(K_{P}\right)=4.66$ (from log spiral method)

Active earth pressure coefficient $\left(K_{a}\right)=\operatorname{Tan}^{2}(45-34 / 2)=0.28$

for $D=0 \mathrm{ft} ; T=10 \mathrm{ft}$; Pile Cap Length $\left(W_{T}\right)=49 \mathrm{ft}$

From Appendix D, the coefficient $k_{w}$ is estimated as

$$
\begin{aligned}
& k_{w}=1+\left(K_{p}-K_{a}\right)^{\frac{2}{3}}\left(1.1\left(1-\frac{T}{D+T}\right)^{4}+\frac{1.6}{1+\frac{5 W_{T}}{T}}+\frac{0.4\left(K_{p}-K_{a}\right)\left(1-\frac{T}{D+T}\right)^{3}}{1+\frac{0.05 W_{T}}{T}}\right) \\
& k_{w}=1.17
\end{aligned}
$$

Accounting 3D wedge effect and finite width and height of the pile cap, $k_{w}$ is reduced by $20 \%$.

$$
\begin{aligned}
& k_{w}=1+0.17 \cdot 0.8=1.13 \\
& \boldsymbol{F}_{\text {passive }-A}=575 \cdot 4.66 \cdot 10 \cdot 49 \cdot 1.13 / 1000=1483 \mathrm{kips}
\end{aligned}
$$




\section{Force of piles $\left(F_{\text {piles-A }}\right)$}

For cohesionless fill,

$$
P_{u l t-\text { fill }}=\left(C_{1} \stackrel{-}{H}+C_{2} B\right) \gamma \stackrel{-}{H}
$$

for $\phi=34, C_{1}=2.85 ; C_{2}=3.33$ (API 1993 , Appendix D)

ultimate pressure on fill $\left(P_{u l t-\text { fill }}\right)$

$$
\begin{aligned}
& =(2.85 \cdot 17.5+3.33 \cdot 16 / 12) \cdot 115 \cdot 17.5 / 1000 \\
& =109 \mathrm{kip} / \mathrm{ft}
\end{aligned}
$$

For cohesive soil

$$
X_{R}=\frac{6 B}{\frac{\gamma^{\prime} B}{c}+J}=\frac{6 \cdot 16}{\frac{42.6 \cdot 16}{850} \cdot \frac{1}{12}+0.5} \cdot \frac{1}{12}=14 \mathrm{ft}
$$

Since $X>X_{R}$

ultimate pressure on clay layer $\left(p_{\text {ult-pile }}\right)=9 c B$

cohesion for $\operatorname{clay}(\mathrm{c})=850 \mathrm{psf}$

ultimate pressure on clay $\left(P_{\text {ult-clay }}\right)=9 \cdot 850 \cdot 16 / 12=10.2 \mathrm{kip} / \mathrm{ft}$

$$
\boldsymbol{F}_{\text {piles-A }}=n \cdot G R F \cdot P_{\text {ult-pile }} \cdot L_{c}
$$

where $n$ is the number of piles in group, $G R F$ is group reduction factor, $L_{c}$ is the pile length. Here $n=10$, and $G R F=1.0$.

$$
\boldsymbol{F}_{\text {piles-A }}=(109 \cdot 15+10.2 \cdot 15) \cdot 1 \cdot 10=17880 \text { kips }
$$

\section{Pile cap side force (Fsides-A)}

$$
\begin{aligned}
\boldsymbol{F}_{\text {sides }-A} & =2\left(\overline{\sigma_{v}^{\prime}} \operatorname{Tan}(\delta)+\alpha c^{\prime}\right)(T) W_{L} \\
\boldsymbol{F}_{\text {sides }-A} & =2 \cdot(575 \cdot \operatorname{Tan}(11.33)) \cdot 3.5 \cdot 10 / 1000 \\
& =8.06 \mathrm{kips}
\end{aligned}
$$


The ultimate forces from mechanism $A$ is

$$
\boldsymbol{F}_{u l t-A}=1483+17880+8=19371 \text { kips }
$$

\section{Case B}

Passive pressure force $\left(F_{\text {passive-B }}\right)$

$$
\begin{aligned}
& \text { for } \phi=34^{\circ} \\
& K_{a}=\operatorname{Tan}^{2}(45-34 / 2)=0.28 \\
& K_{p}=\operatorname{Tan}^{2}(45+34 / 2)=3.53
\end{aligned}
$$

It is noted that the mean stress is used to estimate the passive earth pressure in the crust layer. The mean stress is obtained from dividing total effective stress by 2 .

$$
\begin{aligned}
& \sigma_{v}^{\prime}=\frac{25 \cdot 115+10 \cdot 105+5 \cdot(105-62.4)}{2}=2069 p s f \\
& \text { for } D=0 \mathrm{ft} ; T=40 \mathrm{ft} ; W_{T}=49 \mathrm{ft} \\
& k_{w}=1.49
\end{aligned}
$$

Accounting 3D wedge effect and finite width and height of pile cap, $k_{w}$ is reduced by $20 \%$.

$$
\begin{aligned}
& k_{w}=1+0.49 \cdot 0.8=1.39 \\
& \boldsymbol{F}_{\text {passive }-\boldsymbol{B}}=(2069 \cdot 3.53 \cdot 25+2 \cdot 850 \cdot \sqrt{1.0} \cdot 15) \cdot 49 \cdot 1.39 / 1000=14173 \mathrm{kip}
\end{aligned}
$$

Pile cap side force $\left(F_{\text {sides-B }}\right)$

$$
\boldsymbol{F}_{\text {sides }-B}=2 \cdot(2069 \cdot \operatorname{Tan}(11.33) \cdot 25+0.5 \cdot 850 \cdot 15) \cdot \frac{3.5}{1000}=117 \mathrm{kip}
$$

\section{The ultimate forces from mechanism $B$ is}

$$
\boldsymbol{F}_{\text {ult }-\mathbf{B}}=14173+117=14290 \text { kip }
$$


Since, $\mathrm{F}_{\text {ult-B }}<\mathrm{F}_{\text {ult-A }}$, mechanism B controls the failure mechanism.

The maximum relative displacement $\left(\Delta_{\max }\right)$ to fully mobilize passive resistance against pile cap is determined as

$$
\Delta_{\text {MAX }}=(T)\left(0.05+0.45 f_{\text {depth }} f_{\text {width }}\right)
$$

where $f_{\text {depth }}$ and $f_{\text {width }}$ are the factors for the finite width of the pile cap calculated as

$$
f_{\text {depth }}=e^{-3\left(\frac{40-0}{40}-1\right)}=1 \text { and } f_{\text {width }}=\frac{1}{\left(\frac{10}{\frac{49}{40}+4}\right)^{4}+1}=0.069
$$

$$
\Delta_{\text {MAX }}=(40)(0.05+0.45 \cdot 1 \cdot 0.069)=3.24 f t=38.9 \mathrm{in}
$$

The value of $p_{u l t}$ for the $p-y$ curve is calculated as

$$
p_{u l t}=\frac{F_{u l t}}{Z c-D}=\frac{14290}{40-0}=333 \mathrm{kip} / \mathrm{ft}=29770 \mathrm{lb} / \mathrm{in}
$$

The idealized $p$ - $y$ curve for the pile cap is shown in Figure 4.3

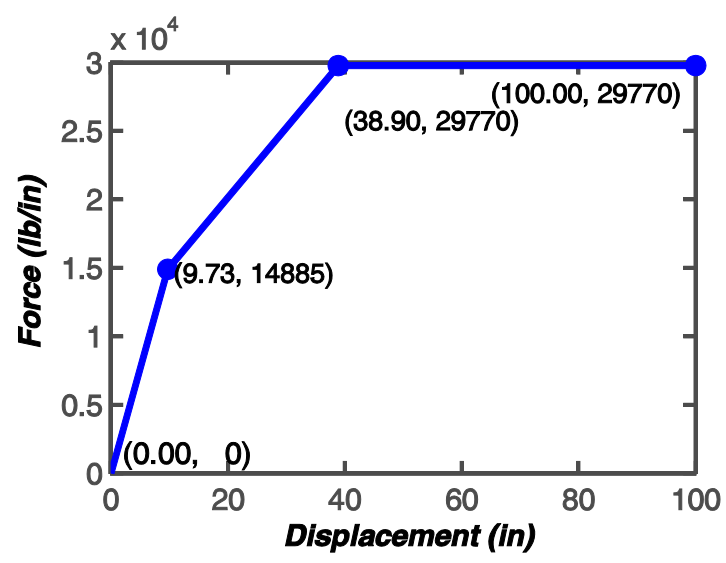

Figure 4.3: Idealized p-y curves for pile cap in crust layer 


\subsubsection{Softening in Non- liquefied Layer}

The correction factor for the soil strength reduction (softening) in the non-liquefied lower soil layer is computed as described in Section 3.3.4. Since, the case B controls the failure mechanism and the soil above the liquefiable soil is considered as a composite cap-soil-block, no adjustments were made in upper layer. The correction factors are shown in Table 4.3.

The subgrade reaction for the dense sand is calculated using API (1993) method

$$
p_{N L}=(4.036 \cdot 52+4.04 \cdot 16 / 12) 62.6 \cdot 52=700 \mathrm{kip} / \mathrm{ft}=58392 \mathrm{lb} / \mathrm{in}
$$

The subgrade reactions for liquefiable layers are estimated based on API (1993) for clay using liquefied residual strengths. The required equations are provided in Appendix-D.

For the liquefied sand layer depth=40+12/2=46 ft

The residual strength $=443$ psf (Section 2.4)

$$
\begin{aligned}
& p_{L}=9 c B \text { since } \mathrm{X}>\mathrm{X}_{R}(8 \mathrm{ft}) \\
& p_{L}=9 \cdot 443 \cdot \frac{16}{12}=5316 \mathrm{lb} / \mathrm{ft}=443 \mathrm{lb} / \mathrm{in}
\end{aligned}
$$

Table 4.3: Adjustment factors for softening near the liquefaction interface

\begin{tabular}{cc}
\hline Distance from interface (ft) & $\boldsymbol{P}_{\boldsymbol{u}}$ adjustment factor $\left(\boldsymbol{m}_{\boldsymbol{p}}\right)$ \\
\hline 1 & $\frac{P_{L}}{P_{N L}}+\left(1-\frac{P_{L}}{P_{N L}}\right)\left(\frac{1}{S_{b} \cdot B}\right)=\frac{443}{58392}+\left(1-\frac{443}{58392}\right)\left(\frac{1}{1.83 \cdot 1.33}\right)=0.42$ \\
2 & $\frac{P_{L}}{P_{N L}}+\left(1-\frac{P_{L}}{P_{N L}}\right)\left(\frac{1}{S_{b} \cdot B}\right)=\frac{443}{58392}+\left(1-\frac{443}{58392}\right)\left(\frac{2}{1.83 \cdot 1.33}\right)=0.82$ \\
& \\
\hline
\end{tabular}




\subsection{5. $p$-y Curve Scaling Factors}

In this example, there is only one row so there is no group effect. The final $p$-multipliers for the equivalent pile along the depth are shown in Table 4.4. If the pile group has multiple rows, the group effect has to be considered as described in Section 3.3.5.

Table 4.4: Summary of p-multiplier coefficient

\begin{tabular}{cccc}
\hline $\begin{array}{c}\text { Depth } \\
\text { interval (ft) }\end{array}$ & \multicolumn{2}{c}{$\boldsymbol{p}$ multipliers for single pile } & $\begin{array}{c}\text { Combined } \boldsymbol{p} \text { multiplier } \\
\text { for all 10 piles }\end{array}$ \\
0 Group effect & Smeared profile & 1 \\
$40-52$ & 1 & 1 & 10 \\
$52-53$ & 1 & 1 & 4.2 \\
$53-54$ & 1 & 0.42 & 8.2 \\
$54.4-67$ & 1 & 0.82 & 10 \\
$67-70$ & - & 1 & - \\
\hline
\end{tabular}

\subsubsection{Rotational Stiffness for Pile Cap}

As the current example only contains a single row, there would be no restraint at the cap. Since the abutment is integral no rotation is allowed at the pile cap. In LPILE the boundary condition is applied by prescribing zero rotation at the pile head. If the foundation has multiple rows, the rotational stiffness can be computed using the procedure described in Section 3.3.6.

\subsubsection{Inertial Loads on the Foundation}

In an integral abutment, the inertial loads from the superstructure and pile cap have to be considered. The inertial force at the superstructure can be roughly estimated as a function of pseudo-spectral acceleration (PSA) at its natural period, its weight $(W)$, and some modification factors (i.e. $C_{c c}$ and $C_{\text {liq }}$ ) as

$$
\begin{aligned}
& \text { Inertial force }(V)=P S A(\text { or } P G A) C_{c c} C_{l i q} W \\
& \mathrm{~W}_{\text {super-structure }}=1180 \text { kips (structural weight based on tributary area) }
\end{aligned}
$$


The $C_{c c}$ and $C_{l i q}$ parameters are used to calculate the equivalent inertial force in superstructure and pile cap for liquefaction conditions. These parameters are obtained from Ashford et al. (2011) as shown in Table 4.5. Since no particular ground motion is selected in this example, the inertial load from the superstructure is computed using PGA. However, in routine practice, response spectrum analysis should be carried out to obtain the PSA.

Inertial force from superstrucutre $\left(V_{\text {Super-structure }}\right)=0.4 \mathrm{~g} \cdot 0.55 \cdot 0.65 \cdot \frac{1180}{\mathrm{~g}}=169 \mathrm{kips}$

Also, weight of pile cap $\left(W_{\text {pilecap }}\right)=3.5 \mathrm{ft} \cdot 49 \mathrm{ft} \cdot 10 \mathrm{ft} \cdot 150 \mathrm{lb} / \mathrm{ft}^{3}=257 \mathrm{kips}$ (including abutment)

Intertial force for pile cap $\left(V_{\text {pile-cap }}\right)=0.4 \mathrm{~g} \cdot 0.75 \cdot 0.85 \cdot \frac{257}{\mathrm{~g}}=66 \mathrm{kips}$

Total inertial load $V=169+66=235$ kips

Fifty percent of this inertial force (118 kips) is applied to the foundation model.

Table 4.5: Inertia coefficients for BNWF analysis of pile foundations in liquefied ground (Ashford et al. 2011)

\begin{tabular}{ccccc}
\hline $\begin{array}{c}\text { Design spectra for non-liquefied } \\
\text { condition } \mathbf{S}_{\mathrm{aT}=1 \mathbf{s}} / \mathbf{S}_{\mathrm{aT}=\mathbf{0 s}}\end{array}$ & \multicolumn{2}{c}{ Pile Cap } & \multicolumn{2}{c}{ Superstructure } \\
\cline { 2 - 5 } & $C_{\text {liq }}$ & $C_{c c}$ & $C_{\text {liq }}$ & $C_{c c}$ \\
\hline $1.7-2.4$ & 1.4 & 0.85 & 0.75 & 0.65 \\
$0.5-1.6$ & 0.75 & 0.85 & 0.55 & 0.65 \\
$\leq 0.4$ & 0.35 & 0.85 & 0.45 & 0.65 \\
\hline
\end{tabular}

\subsubsection{Lateral Spreading Displacement and Shear Stress in the Foundation}

Incremental crust displacement is imposed in the equivalent pile and the shear force in the pile at the middle of the liquefiable sand is obtained. The shape of the imposed displacement can be seen in Figure 4.4. 


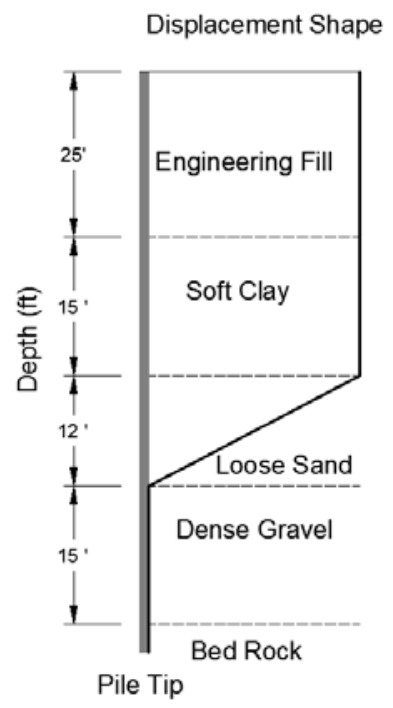

Figure 4.4: Imposed soil displacement into the analysis induced by lateral spreading

Using all the data defined earlier, pushover analyses are conducted with a series of incremental lateral spreading displacement profiles. The shear forces at the midpoint of the liquefied layer (the assumed location of discrete slip surface) are obtained and plotted against the lateral displacement at the top of the equivalent pile. The pushover analysis results are shown in Figure 4.5. The equivalent constant restraining, which is obtained by taking the running average of the shear forces obtained from pushover analysis, are also plotted. This curve will be used for the compatibility analysis in the next section.

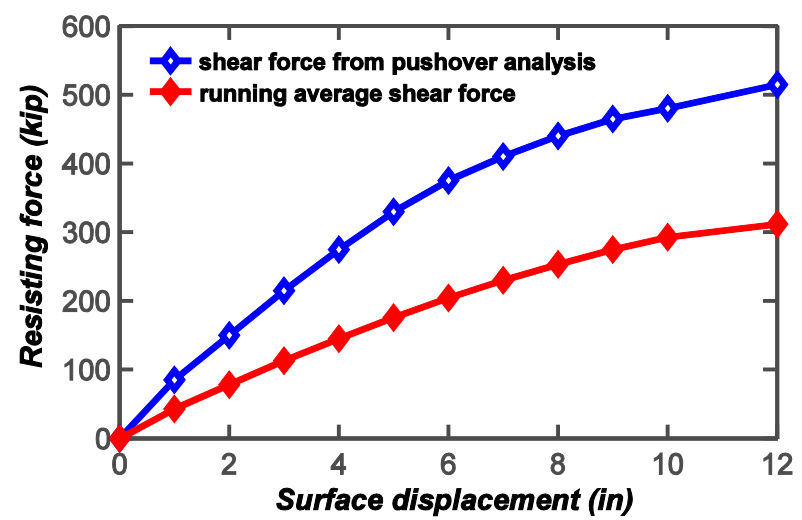

Figure 4.5: Pushover analysis of the super pile and abutment wall from L-pile 


\subsection{Estimating Lateral Spreading displacements}

The lateral spreading displacement for the embankment slope is determined using the Newmark sliding block method. Slope stability analyses were carried out to determine the force required to move the soil mass. In the bridge abutment location, the bridge deck can provide longitudinal resistance to movement of the abutment wall and provides a "pinning" effect for the moving soil mass. The abutment is assumed to be fully restrained from the bridge deck and has enough capacity to resist the lateral earth pressures generated due to the sliding soil mass. In this case, the lateral earth pressure will be equal to the ultimate passive resistance of the soil behind the abutment back wall. The passive resistance force can be calculated as

$$
F_{D E C K}=\left(\overline{\sigma_{v}^{\prime}} K_{p}+2 S_{u} \sqrt{K_{p}}\right)\left(T_{D E C K}\right) W_{T}
$$

where $W_{T}$ is the equivalent width accounting for the non-rectangular embankment shape as shown in Figure 4.6. The value is computed as

$$
\begin{aligned}
& W_{T}=44+\frac{m}{2} \cdot H=44+\frac{2}{2} \cdot 10=54 \mathrm{ft} \\
& F_{D E C K}=\left(\overline{\sigma_{v}^{\prime}} K_{p}+2 S_{u} \sqrt{K_{p}}\right)\left(T_{D E C K}\right) W_{T}==3 \cdot 115 \cdot 3.53 \cdot 6 \cdot 54=395 \mathrm{kips}
\end{aligned}
$$

This force is used in the slope stability analyses as force per unit abutment width. Assuming the equivalent width of the embankment is $54 \mathrm{ft}$, the restrained force is 395/54= $7.31 \mathrm{kips} / \mathrm{ft}$.

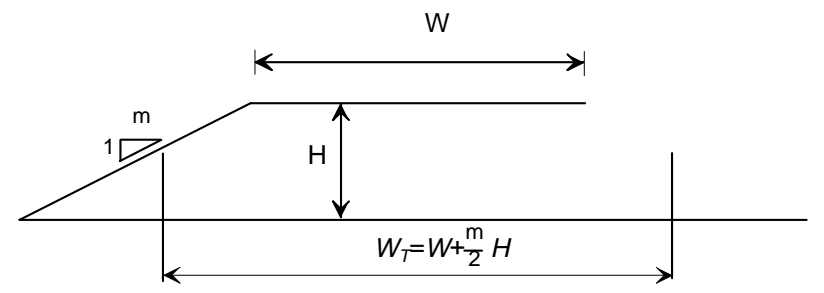

Figure 4.6: Estimation of tributary width of the embankment

The slope stability analysis was carried out in Slope-w program using Spencer's method. $F_{D E C K}$ computed above is applied at the deck location. Then, the seismic yield coefficients $\left(k_{y}\right)$ were determined for different resisting forces located at the middle of the liquefied layer, for 
which the factor of safety is one. The slip surface was block type and forced to pass through the middle of the liquefied layer. The typical slip surface for the slope stability analysis of the embankment is shown in Figure 4.7. The embankment displacement is estimated using the Bray and Travasarou (2007) expression (Appendix C). The plot for $k_{y}$ and laterally spreading displacement is shown in Figure 4.8. Finally, using the pushover and slope stability analysis results, the compatibility force-displacement plot is developed as shown in Figure 4.9. The compatible displacement is found to be 9.4-in. The performance of the abutment foundation for 9.4-in lateral spreading displacement is evaluated and presented in the next section.

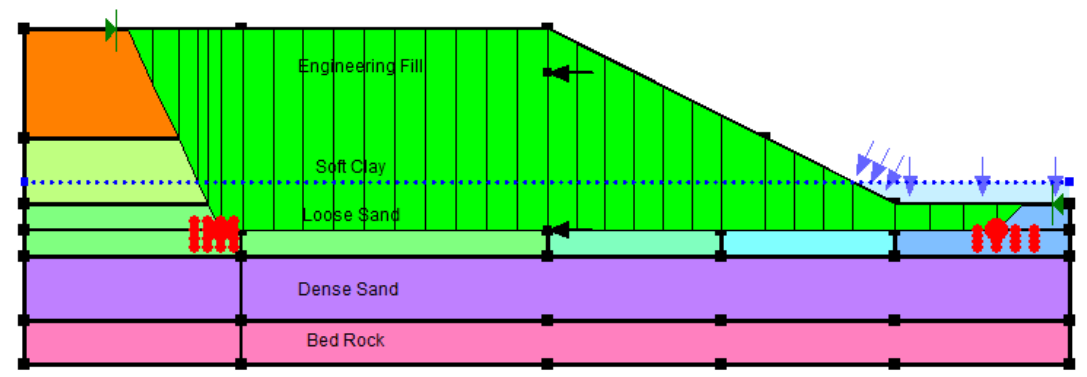

Figure 4.7: Slope stability analysis to computer $k_{y}$ for set of resisting forces.
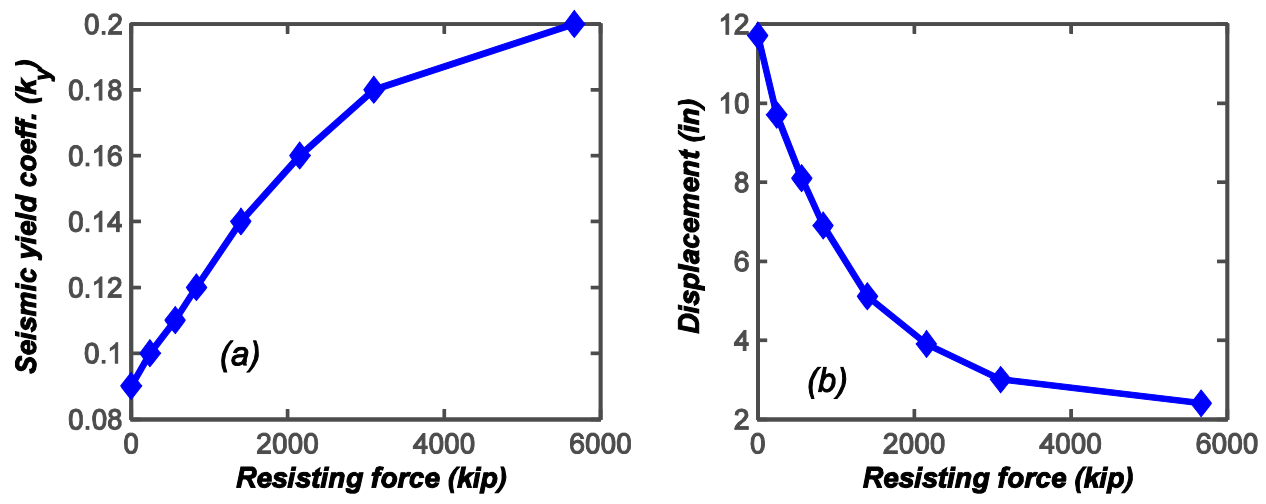

Figure 4.8: Results of embankment displacement analyses for different restraining forces: (a) yield acceleration from slope stability analysis using Spencer's method and (b) embankment slide mass displacements estimated 


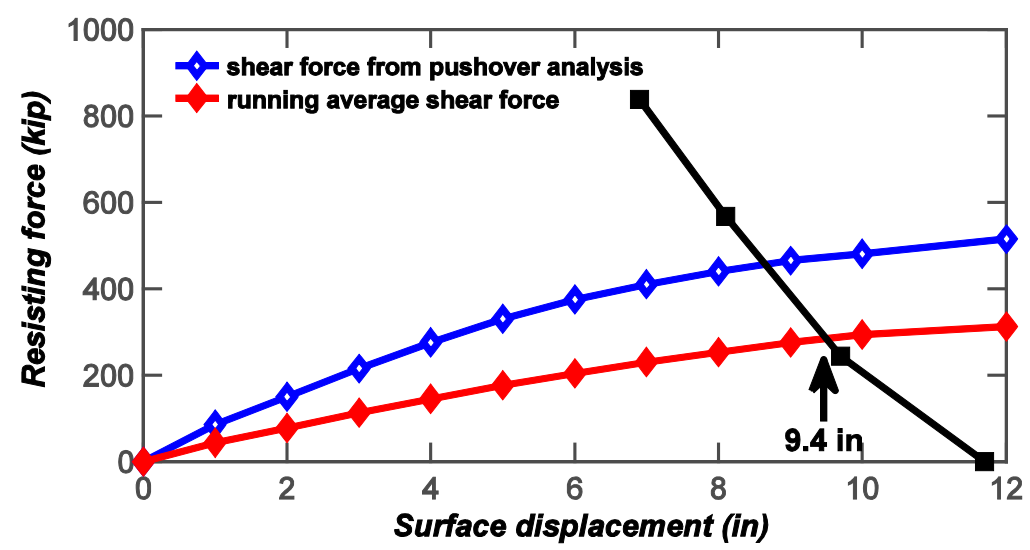

Figure 4.9: Compatibility force-displacements plot

\subsection{Evaluate results against foundation performance criteria}

Based on the displacement obtained from the compatibility curve, the analysis is carried out to determine the demands on the foundation. The displacement is imposed on the pile foundation model obtained from Section 4.2. The results of the imposed displacement of 9.4-in are shown in Figure 4.10 and the summary of the results are presented in Table 4.6.

Based on the results, the maximum bending moment in a pile is more than the allowable moment, which suggests yielding of the piles. Severe yielding of the pile may lead to partial or total collapse of the bridge. Therefore, the performance of the pile foundations at abutment needs to be improved. The shear demand on the pile is less than maximum allowable limits. No performance has been evaluated in terms of pile cap displacement demand. 


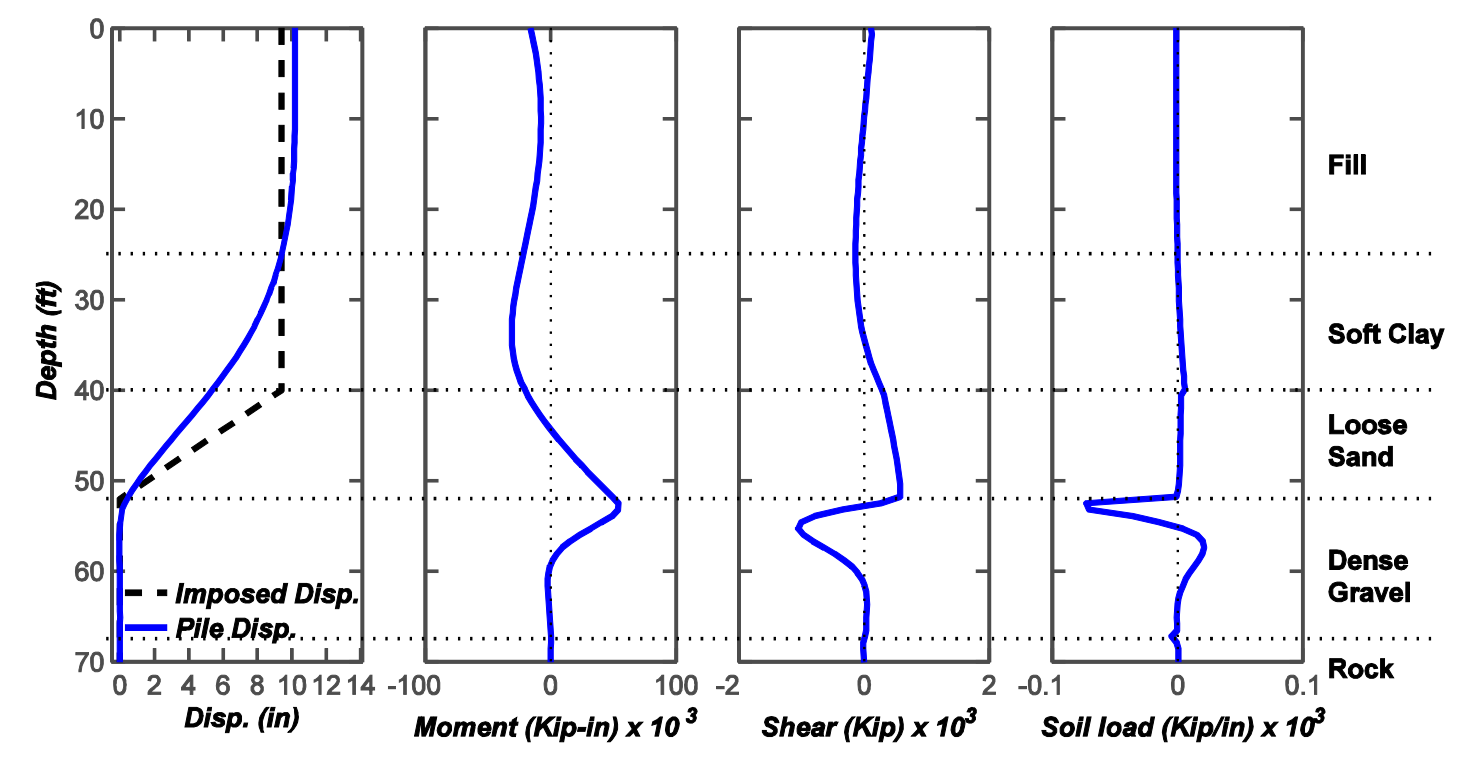

Figure 4.10: Pushover analysis results for compatible displacement of 9.3 in

Table 4.6: Summary response for pile group foundation at abutment

\begin{tabular}{ccc}
\hline Parameter & $\begin{array}{c}\text { Inertia and lateral } \\
\text { spreading demand }\end{array}$ & Allowable limit \\
\hline Disp. of pile cap & $10.18 \mathrm{in}$ & - \\
Max. shear in a single pile & $105 \mathrm{kip}$ & $328 \mathrm{kip} *$ \\
Max. moment in a single pile & $453 \mathrm{kip}-\mathrm{ft}$ & $448 \mathrm{kip}-\mathrm{ft}$ \\
\hline
\end{tabular}

\subsection{Enhancing Performance/Retrofitting the Foundation}

As discussed in Section 3.3.9, seismic performance of the foundation can be improved by using different methods. For new foundations, the number of piles can be increased or the size of the pile can be increased or both. For existing foundations, additional piles can be added to reduce the seismic demand on the piles. In this example, the performance of the foundation is increased by increasing number of piles and connecting the pile foundation with additional drilled shafts.

\subsubsection{Performance Enhancement by Increasing Number of Piles}

In this example, trial and error method is used to determine the number of piles to be added in the existing foundation in order to satisfy the performance criteria. The layout of the retrofitted foundation is shown in Figure 4.11. In the existing foundation, additional 20 piles are added so 
that the size of pile cap is also increase to $11 \mathrm{ft}$ x $49 \mathrm{ft}$ x $4 \mathrm{ft}$. By following the same procedure from Section 4.2.1 to Section 4.2.8, LPILE model was developed and analysis was carried out to determine new pushover curves. Then the compatible displacement of 8 in is determined as shown in Figure 4.12. The response of the retrofitted foundation is shown in Figure 4.13 and the summary of the results is presented in Table 4.7. The retrofitted foundation has satisfied both bending moment and shear force performance criteria.

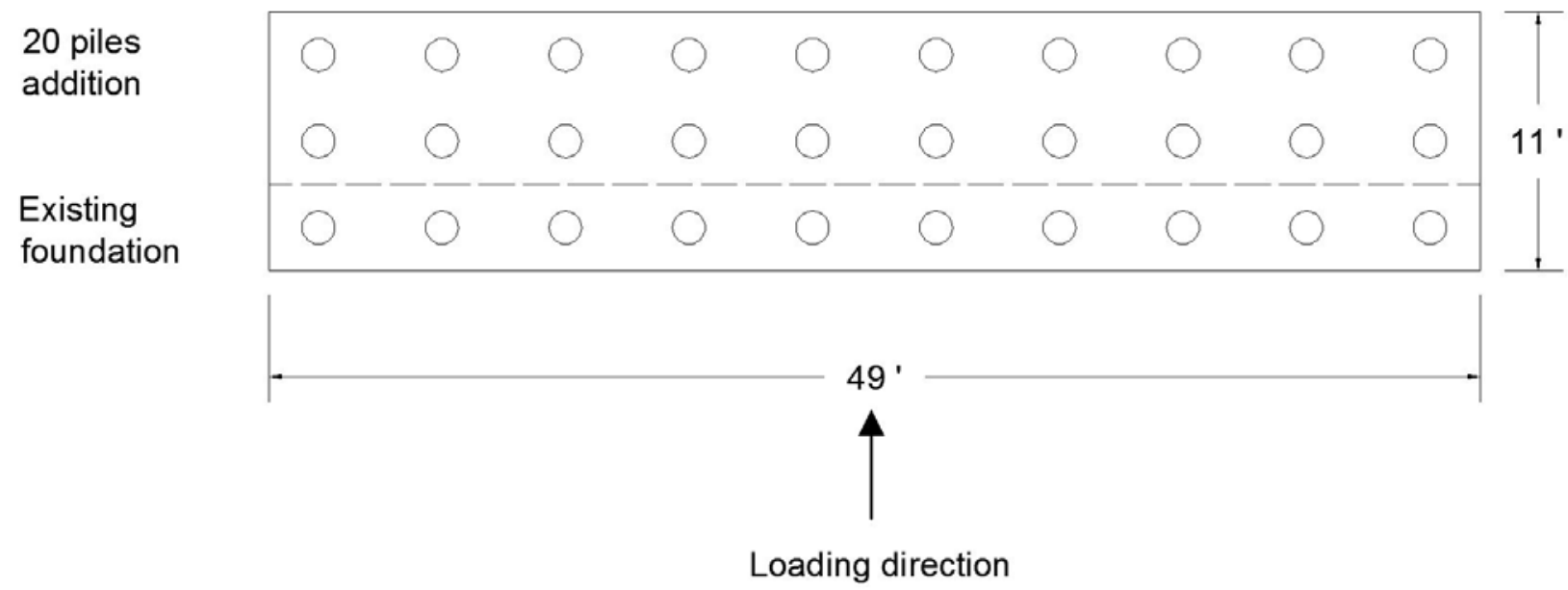

Figure 4.11: Foundation layout for retrofitting foundation by the addition of piles

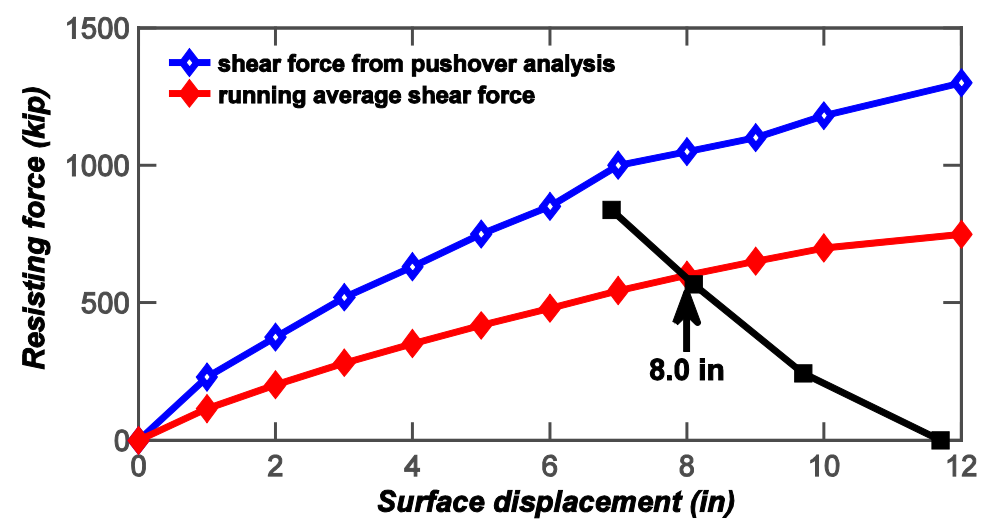

Figure 4.12: Compatibility force displacement plot for retrofitted foundation 


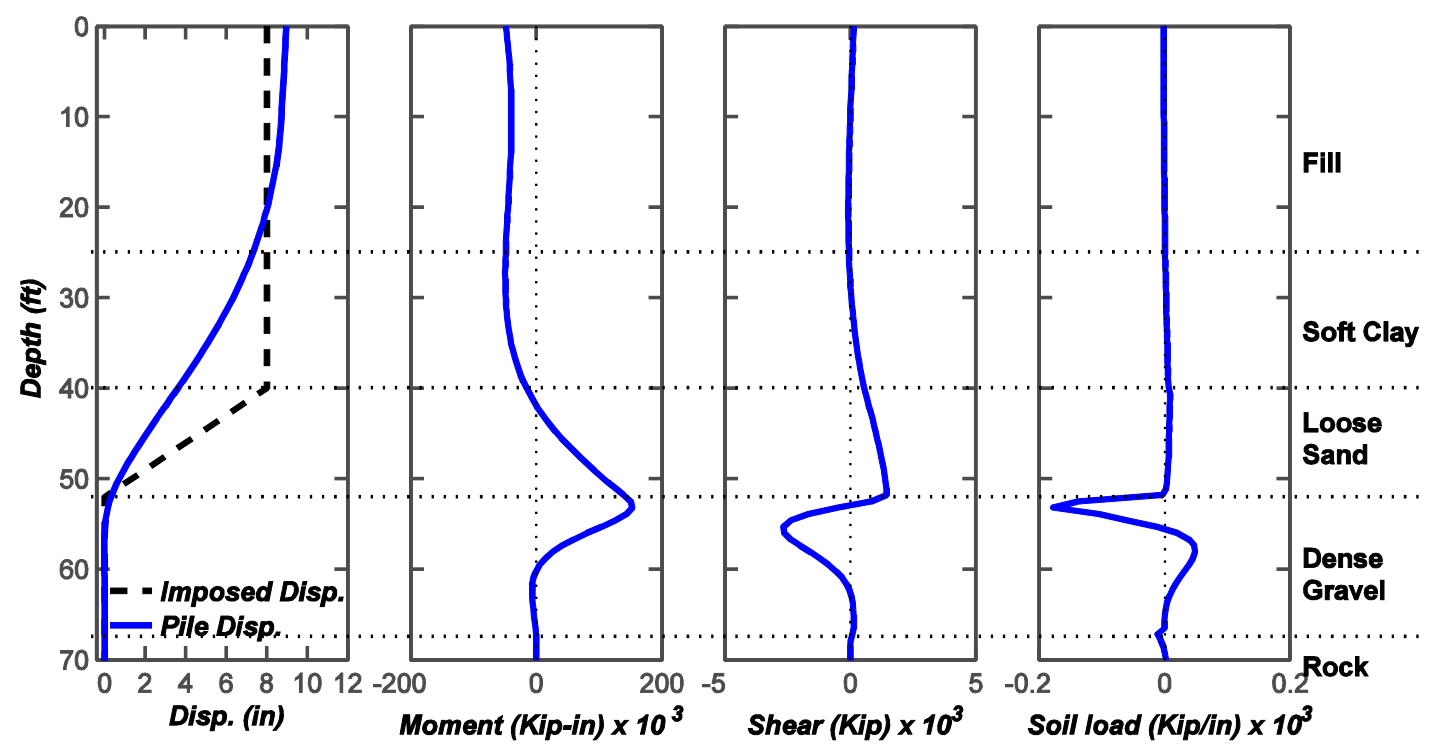

Figure 4.13: Pushover analysis results for compatible displacement of 8 in

Table 4.7: Summary response for pile group foundation at abutment

\begin{tabular}{ccc}
\hline Parameter & $\begin{array}{c}\text { Inertia and lateral } \\
\text { spreading demand }\end{array}$ & Allowable limit \\
\hline Disp. of pile cap & $8.96 \mathrm{in}$ & - \\
Max. shear in a single pile & $89 \mathrm{kip}$ & $328 \mathrm{kip} *$ \\
Max. moment in a single pile & $417 \mathrm{kip}-\mathrm{ft}$ & $448 \mathrm{kip}-\mathrm{ft}$ \\
\hline
\end{tabular}

\subsubsection{Performance Enhancement by Connecting with Additional Drilled Shafts}

The trial and error method can be used to estimate the size of the drilled shaft. Similar to Section 3.3.11.1, three 3-ft diameter drilled shafts are selected as a starting point. The layout of the retrofitted pile group foundation and the cross-section of new drilled shafts are shown in Figure 4.14.The moment-curvature and moment-stiffness relationships for the new drilled shaft are shown in Figure 4.15 together with the moment-curvature relationships for equivalent pile. The combined moment-curvature relationships is obtained by adding the moment curvature for the existing single pile times number of pile and moment curvature for the new drilled shaft times number of drilled shafts. The sectional properties for the single existing pile and single new drilled shafts are shown in Table 4.8. 


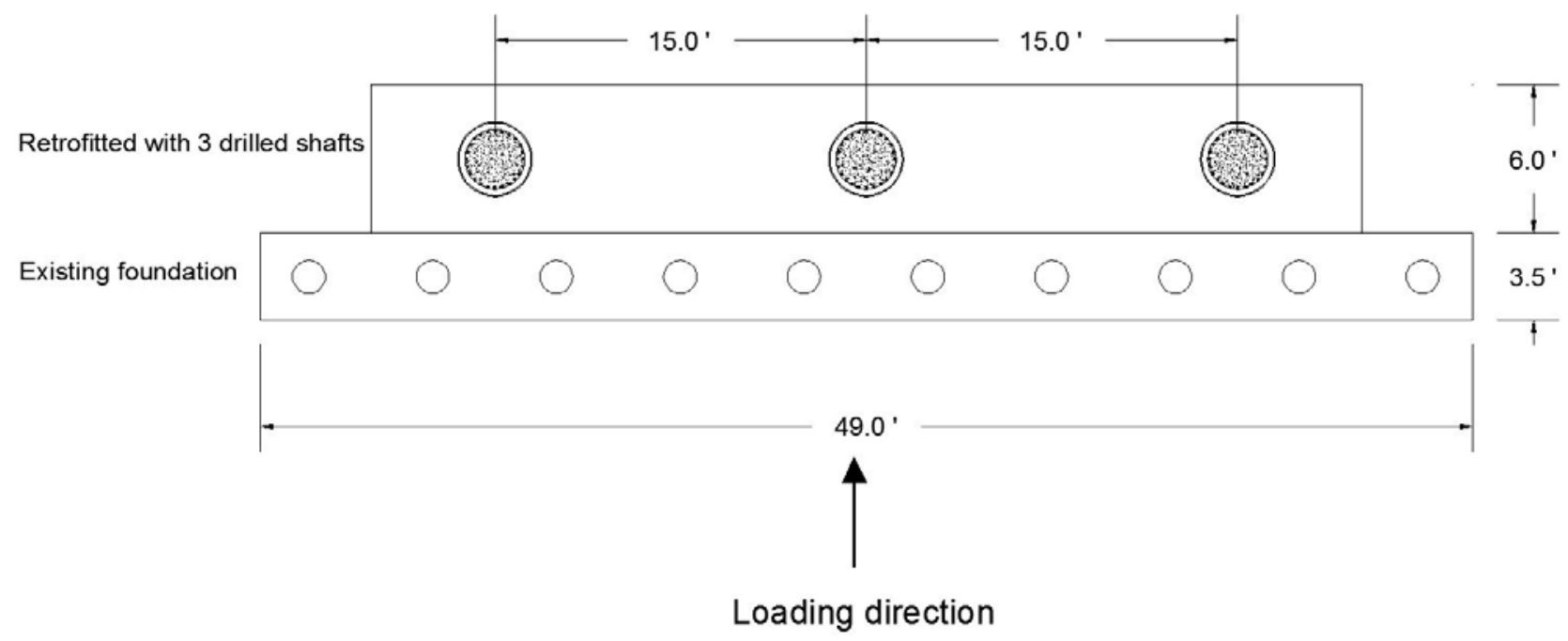

a) Foundation layout

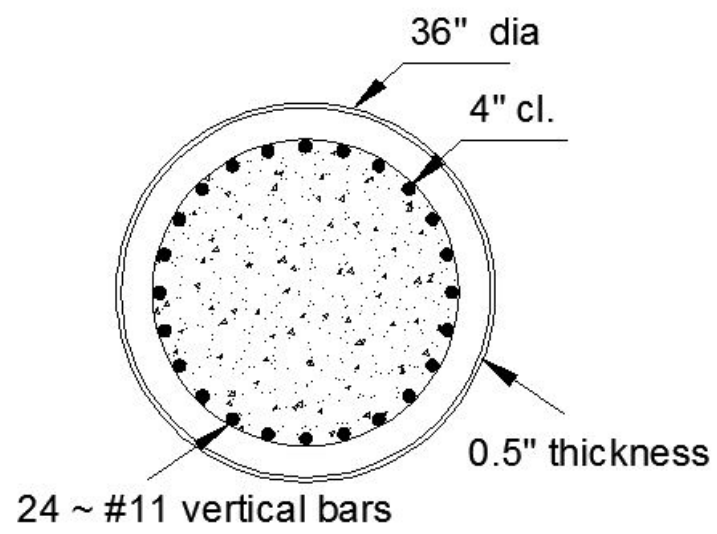

b) New drilled shaft cross section

Figure 4.14: Foundation retrofitting by additions of new drilled shaft a) Layout plan view; b) crosssection property of drilled shaft 

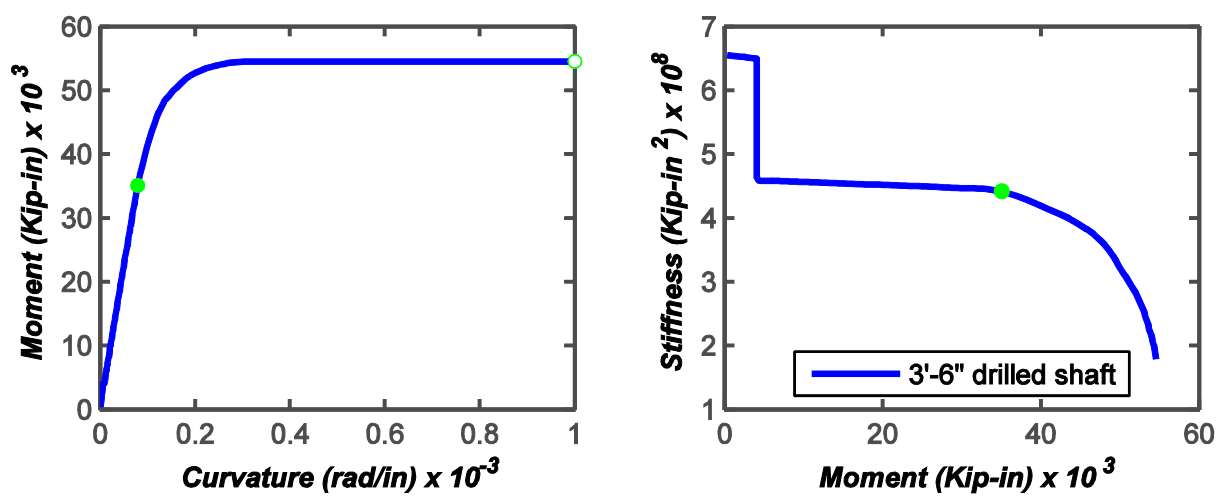

a) Section properties for drilled shaft

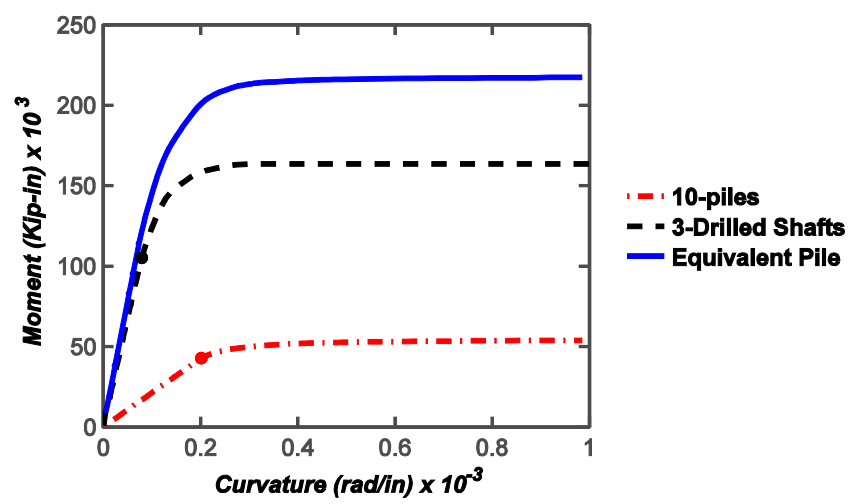

b) Moment curvature relationships for equivalent pile

Figure 4.15: Moment and stiffness properties of a single pile and equivalent pile: a) moment curvature and stiffness moment relationships for new drilled shaft ; b) Combined moment curvature relationship for equivalent pile

Table 4.8: Moment and stiffness properties of a single pile and drilled shaft

\begin{tabular}{ccc}
\hline Property & Single existing pile & Single drilled shaft \\
\hline Yield moment $\left(M_{y}\right)($ kip-in) & $4.23 \times 10^{3}$ & $3.51 \times 10^{4}$ \\
Maximum moment $\left(M_{\max }\right)($ kip-in) & $5.38 \times 10^{3}$ & $5.45 \times 10^{4}$ \\
Ultimate moment $\left(M_{u l t}\right)($ kip-in) & $5.92 \times 10^{3}$ & $6.00 \times 10^{4}$ \\
Elastic EI $\left(\right.$ kip-in $\left.{ }^{2}\right)$ & $2.11 \times 10^{7}$ & $4.45 \times 10^{8}$ \\
Plastic EI $\left(\right.$ kip-in $\left.{ }^{2}\right)$ & $2.42 \times 10^{5}$ & $6.24 \times 10^{6}$ \\
\hline
\end{tabular}

The combined stiffness of the pile group and the drilled shaft can be computed as 
1) Bending stiffness of 10 piles $=2.12 \times 10^{8} \mathrm{kip}^{-i n^{2}}$ (Section 4.2.2)

2) Bending stiffness of new drill shaft= $4.45 \times 108$ kip-in2 (Table 4.8)

3) Thus, total stiffness of equivalent pile $=2.12 \times 10^{8}+3 \times 4.45 \times 10^{8}=1.54 \times 10^{9} \mathrm{kip}-\mathrm{in}^{2}$

4) Relative stiffness of 10 piles combined $=2.12 \times 10^{8} / 1.54 \times 10^{9}=0.14$

With these properties of the new equivalent pile, pushover analyses are carried out once again and compatibility displacements are determined, as shown in Figure 4.16. The compatible lateral displacement was found to be 7.8-in. This displacement is again imposed on the LPILE model and the performance is evaluated. The results of the pushover analysis for 7.8-in laterally spreading displacement are shown in Figure 4.17 and a summary of the pushover analysis results is shown in Table 4.9. The moment for a single pile in the retrofitted pile group is computed as

5) The maximum moment in the equivalent pile in the LPILE model $=200000$ kip-in

6) The moment in the 10 piles $=200000 \times 0.14=28000 \mathrm{kip}-\mathrm{in}=2333 \mathrm{kip}-\mathrm{ft}$

7) Therefore, moment in 1 pile $=2333 / 10=233$ kip-ft $<448$ kip-ft OK

8) Moment in 1 drilled shaft $=(200000 \times(1-0.14)) /(3 \times 12)=4777$ kip-ft $<5000$ kip-ft OK

From the results, it can be seen that retrofitted foundation satisfies both displacement and moment performance criteria. In this example, only the procedure to retrofit the bridge foundation is shown and the proposed drilled shaft size may not be an optimal. Additional analysis can be carried out with different sectional properties of drilled shaft.

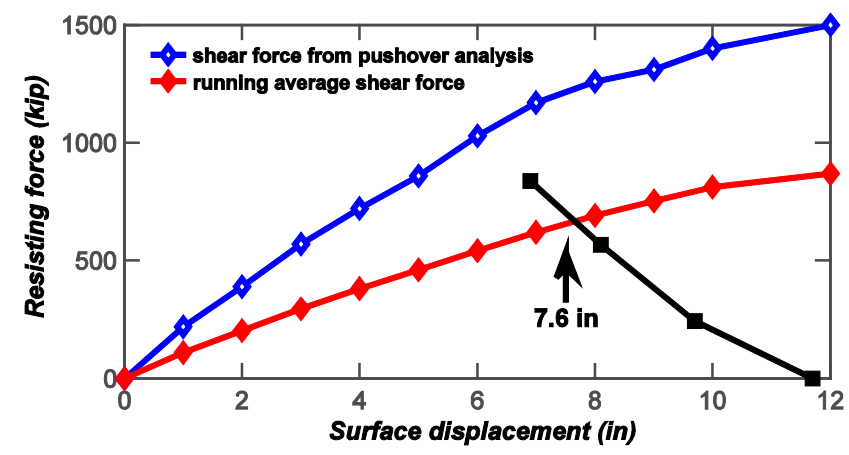

Figure 4.16: Compatibility of forces and displacements for new super pile 


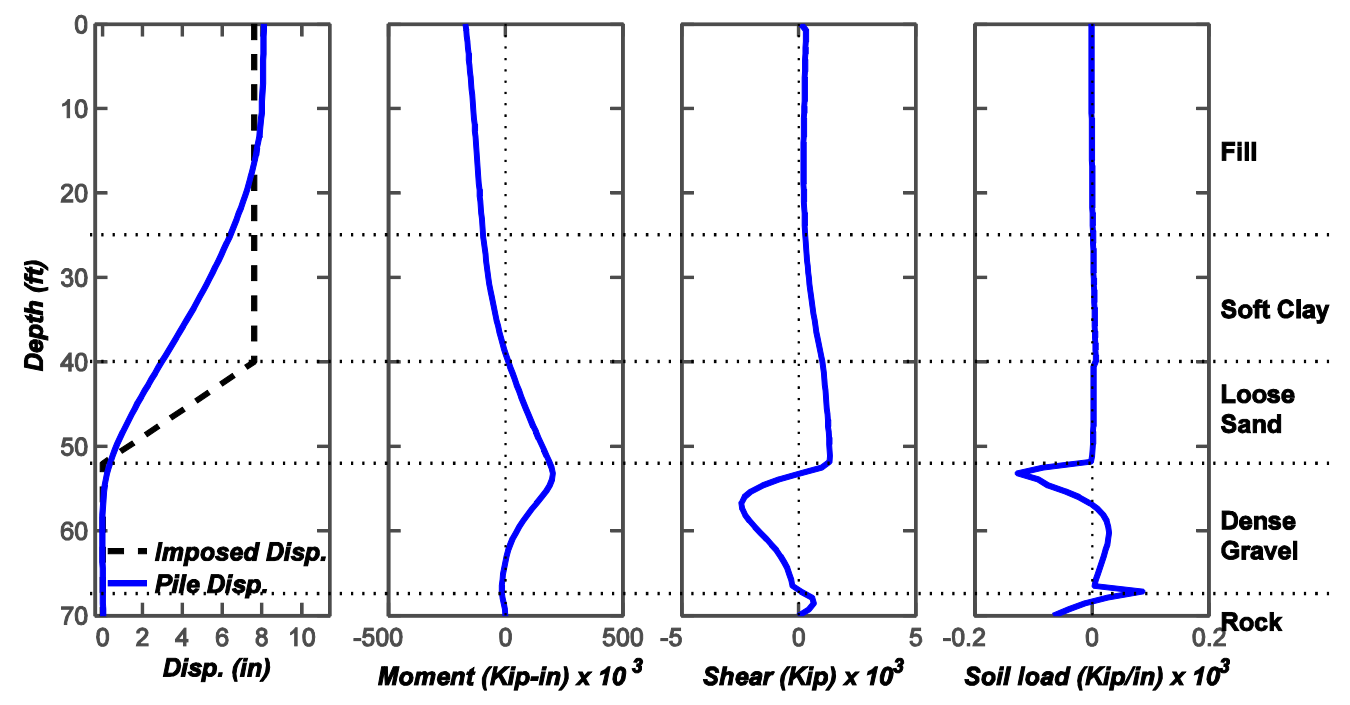

Figure 4.17: Response of pile foundation to lateral spreading at 8.0-in imposed soil displacement

Table 4.9: Summary response of retrofitted bridge foundation

\begin{tabular}{ccc}
\hline Parameter & $\begin{array}{c}\text { Inertia and lateral } \\
\text { spreading demand }\end{array}$ & Allowable limit \\
\hline Disp. of pile cap & $8.0 \mathrm{in}$ & - \\
Max. shear in a single pile & $35 \mathrm{kip}$ & $328 \mathrm{kip} *$ \\
Max. moment in a single pile & $233 \mathrm{kip}-\mathrm{ft}$ & $448 \mathrm{kip}-\mathrm{ft}$ \\
Max. moment in a single drilled shaft & $4780 \mathrm{kip}-\mathrm{ft}$ & $5000 \mathrm{kip}-\mathrm{ft}$ \\
\hline
\end{tabular}




\section{Chapter 5: Design Example for Ground Improvements}

\subsection{Introduction}

As discussed in previous sections, performance of the bridge foundation can be improved under earthquake loading if liquefaction is prevented at the site. The most common method to mitigate liquefaction is by ground improvement using discrete elements such as stone column or deep soil mixing column (DSM). In particular, stone columns are effective to mitigate liquefaction by densifying the surrounding loose soil during installation. Thus, stone columns are effective for loose sand with nominal fine contents. On the other hand, DSM grids are effective in mitigating liquefaction based on the shear stress distribution mechanism. Since densification or drainage is difficult to achieve in silty soils, reducing the seismic shear stress in the soil is effective mechanism to mitigate risk of liquefaction. The DSM grids are effective for this purpose.

This chapter is focused on ground improvement using stone columns. Since ODOT is interested in the design of DSM grids in silty soil, design examples are also presented for DSM grids. The main working principle for the DSM grid is exactly same as the shear reinforcement mechanism of stone columns as presented in Section 1.2.1.3. As a result, no additional literature review is presented; however, necessary information (and references) required to design the DSM grids are presented in the subsequent sections. Designs for stone columns are carried out based on densification mechanisms, while shear reinforcement mechanism is used for DSM. It is noted that the stone columns can also be designed for shear reinforcement purpose following the procedures for DSM grids that is provided herein.

\subsection{Example problem}

Assuming the bridge foundation site has easy access the ground improvement can be carried out. From chapter 3, it is found that the liquefiable loose sand layers at bridge interior bent are potentially liquefiable. Thus, the same soil profile is used to demonstrate design examples for ground improvement. To follow easily and for completeness, the soil profile is shown in Figure 5.1. The same earthquake scenario is used as described in chapter 3. ODOT provided the design earthquake scenario from the CSZ event with $M_{\mathrm{w}}=8.7$. The designed peak ground acceleration (PGA) given by the ODOT is $0.40 \mathrm{~g}$. Since, the examples provided in this report serve as a guideline rather than specific answer for a particular site, the data provided by ODOT is used for 
all calculations. However, for the actual performance evaluation of a bridge site, characterization of the seismic hazard using appropriate techniques is highly recommended.

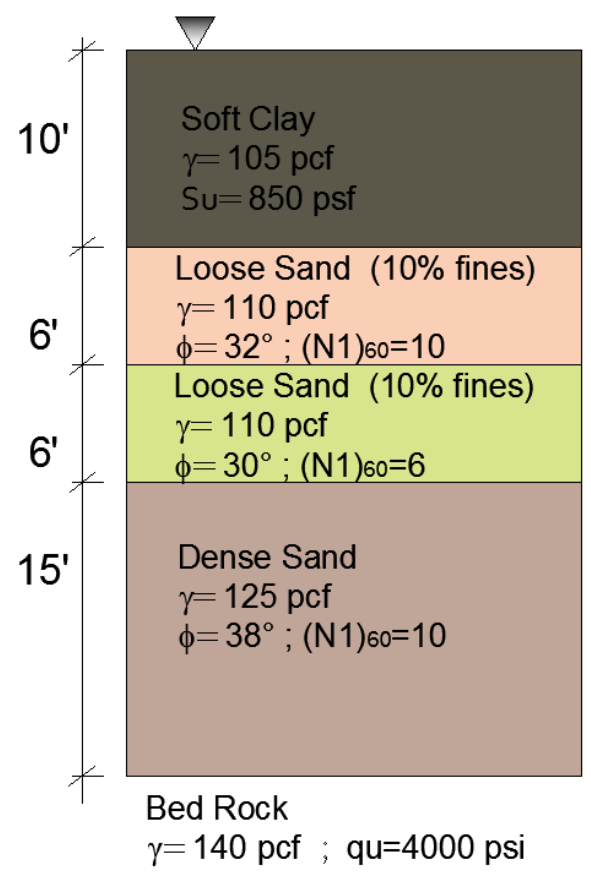

Figure 5.1: Design example soil profile for ground improvement

\subsection{Design Calculations for Stone Column}

Based on the literature review, stone columns are mainly effective as densification mechanisms rather than drainage and reinforcement mechanisms. Therefore, the design calculation is only based on the densification method only. It is noted that all the stresses are calculated at the middle of the liquefiable layers.

For the upper sand layer

Total Stress $=1380 \mathrm{psf}$

Effective stress $=568.8 \mathrm{psf}$

SPT value $\left(\mathrm{N}_{1}\right)_{60}=10$

Relative Density $=\sqrt{\frac{\left(N_{1}\right)_{60}}{46}}=\sqrt{\frac{10}{46}}=47 \%$ 
CSR is calculated using Youd et al. (2001) (Appendix A) as

$$
\text { CSR }=0.65 \frac{1380 p s f}{568 p s f} \cdot 0.4 \cdot 0.97=0.61
$$

From Figure 5.2, the equivalent clean sand SPT value for CSR of 0.61 with $10 \%$ fine contents is 30. Since, the SPT value for the given layer is 10, which is less than the required SPT value of 30, ground improvement is necessary. From the Figure 5.3, the required area replacement ratio for the SPT value of 30 and $10 \%$ fines is obtained as $22 \%$.

\section{For lower sand layer}

Total Stress $=2040 \mathrm{psf}$

Effective stress $=854.4 \mathrm{psf}$

SPT value $=6$

Relative Density $=\sqrt{\frac{\left(N_{1}\right)_{60}}{46}}=\sqrt{\frac{6}{46}}=36 \%$

The cyclic stress ratio is then calculated as

$$
\text { CSR }=0.65 \frac{\sigma_{v}}{\sigma_{v}{ }^{\prime}} \frac{a_{\max }}{g} r_{d}=0.65 \frac{2040}{854.4} \cdot 0.4 \cdot 0.96=0.60
$$

From Figure 5.2, the equivalent clean sand SPT value for CSR of 0.60 with $10 \%$ fine contents is 30. Since, the SPT value for the given layer is 6, which is less than the required SPT value of 30 , ground improvement is necessary.

From Figure 5.3, the required area replacement ratio for the SPT value of 30 and $10 \%$ fines is obtained as $22.0 \%$. Applying 1.1 as a safety margin, the area replacement ratio for liquefaction mitigation is 24.2 .

Thus, the required area replacement ratio to mitigate the liquefaction $=24.2 \%$. Assuming 3-ft diameter columns triangular grid pattern, the required spacing would be

$$
A_{r}=\frac{A_{s c}}{A}=\frac{\pi d^{2}}{4 \cdot 0.87 \cdot s^{2}}=\frac{\pi \cdot 3^{2}}{4 \cdot 0.87 \cdot s^{2}}=0.242
$$


The factor of 0.87 is to account the triangular grid pattern for calculating the tributary area, as shown in Figure 5.3 (Barksdale and Bachus 1983).

$$
\begin{aligned}
& s^{2}=\frac{\pi \cdot 3^{2}}{4 \cdot 0.87 \cdot 0.242} \\
& s=5.79 \mathrm{ft}
\end{aligned}
$$

The horizontal spacing of the stone column (s) is 5.8- $\mathrm{ft}$ measured from center to center of the stone columns. The stone columns are designed for triangular grid pattern with 3 - $\mathrm{ft}$ diameter. Generally the horizontal extent of treatment is carried out to $2 / 3$ of the liquefiable depth. In this example, the depth of liquefiable soil is $22 \mathrm{ft}$ so the horizontal extend for stone column installation is $15 \mathrm{ft}(2 / 3 \times 22=14.66 \cong 15 \mathrm{ft})$ measured from the side of the bridge foundation.

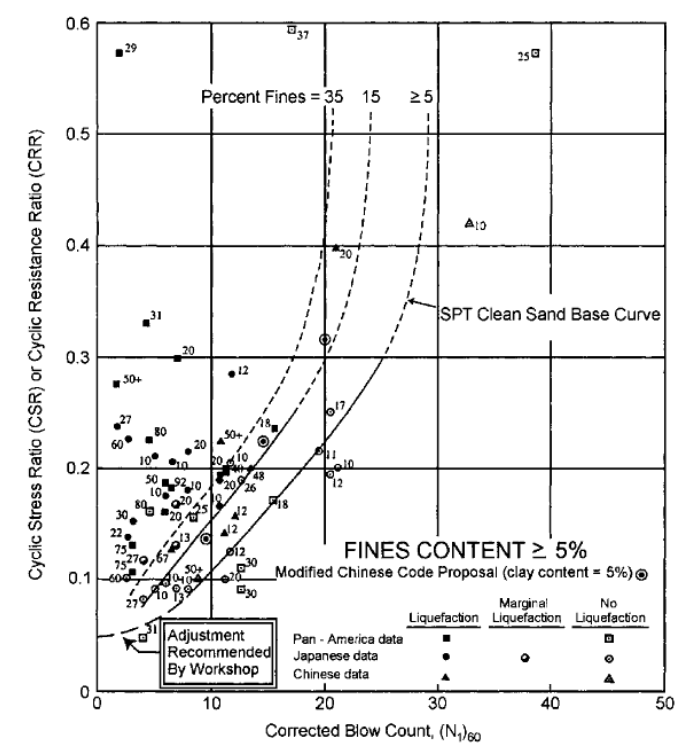

Figure 5.2: SPT clean-sand base curve for magnitude 7.5 earthquakes with data from liquefaction case histories (Youd et al. 2001) 

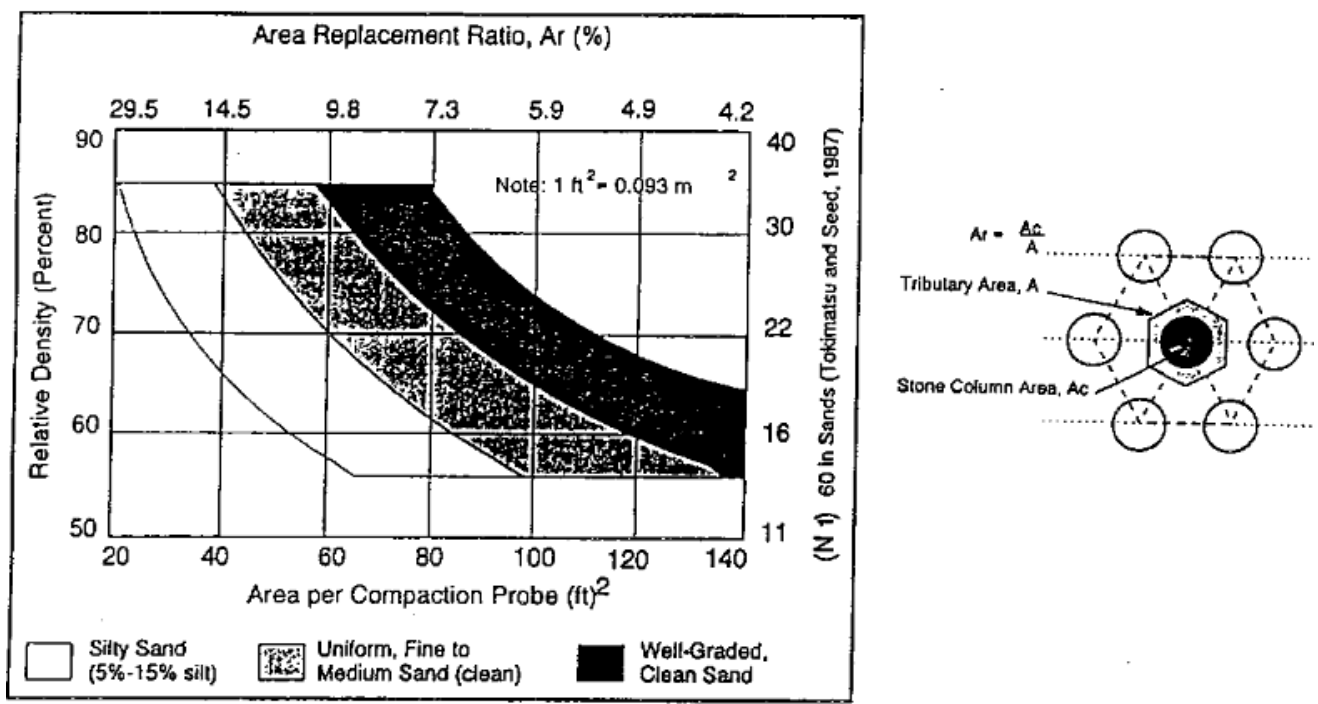

Figure 5.3: Approximate variation of relative density based on tributary area (Barksdale and Bachus, 1983; Baez and Martin 1993)

\subsection{Design Calculations for DSM Grids}

As explained before, the design of DSM grids is based on the shear reinforcing mechanism rather than the densification and drainage mechanisms. In this design method, the cyclic stress ratio is calculated based on the seed and Idriss (1971) framework. The ratio of CSR for improved (CSR,I) ground and CSR for unimproved (CSR,U) ground is calculated as

$$
K_{G}=\frac{\tau_{s}}{\tau}=\frac{C S R, I}{C S R, U}
$$

The DSM grids are mainly designed using shear reinforcement mechanism assuming shear strain compatibility between the DSM grid and enclosed soil. Based on shear strain compatibility, the shear stress reduction factor, $K_{\mathrm{G}}$, is calculated as (Baez 1995; Baez and Martin 1993)

$$
K_{G}=\frac{\tau S}{\tau}=\frac{1}{G_{r}\left[A_{r}+\frac{1}{G_{r}}\left(1-A_{r}\right)\right]}
$$


where $\tau_{s}$ is the shear stress in improved ground surface and $\tau$ is the average shear stress in unimproved ground, $A_{r}$ is area replacement ratio, $G_{r}$ is the shear modulus ratio.

Recent research shows that the strain compatibility assumption is not valid and the level of shear stress by the above equation may be unconservative. Ngyugen et al. (2012) has conducted numerical investigations on these assumptions and provides new methods for calculating $K_{\mathrm{G}}$ factor by incorporating shear strain incompatibility in the DSM and surrounding soil as

$$
R_{r d}=\min \left(\frac{1}{G_{r} \cdot\left[A_{r} \cdot C_{G} \cdot \gamma_{r}+\frac{1}{G_{r}} \cdot\left(1-A_{r}\right)\right]}, 1\right)
$$

where $C_{G}$ is a factor for accounting for flexural deformation in the DSM grid, $\gamma_{r}$ is the shear strain ratio between the DSM grid and the surrounding soil. It is noted that for static loading, $K_{G}$ and $R_{r d}$ are equivalent. Detailed information about the computation of $R_{r d}$ can be found in Nyugen et al. (2012) and the paper is presented in Appendix E for ODOT review. Based on Nyugen et al. (2012), the $C_{G}$ and $\gamma_{r}$ factors are computed as

$$
\begin{gathered}
C_{G}=1-0.5 \sqrt{1-A_{r}} \\
\left.\gamma_{r}=\left[1-\left(1-A_{r}\right)^{1.3} \cdot\left(\frac{G_{r}-1}{185}\right)^{0.4}\right] \cdot \min \left(\frac{H}{S}, 1\right)\right)
\end{gathered}
$$

where $H$ is the height of the DSM grid and $S$ is the spacing of the grid.

Using this framework, the DSM grid can be designed for liquefaction mitigation. All the stresses are calculated at the middle of the liquefiable layers

For upper sand layer

Total Stress $=1380 \mathrm{psf}$

Effective stress $=568.8 \mathrm{psf}$

SPT value $\left(\mathrm{N}_{1}\right)_{60}=12$ 
Shear wave velocity $=85\left[\left(\mathrm{~N}_{1}\right)_{60}+2.5\right]^{0.25}=165.8 \mathrm{~m} / \mathrm{s}$ [modified fit of Andrus and Stokoe (2000) at $\left.p_{\mathrm{r}}=1 \mathrm{~atm}\right]$

Unit weight of soil $(\rho)=110 \mathrm{pcf}=1762 \mathrm{~kg} / \mathrm{m}^{3}$

Shear modulus $=\rho V^{2}=1762 \cdot 165.8^{2}=4.84 \times 10^{7} \mathrm{kPa}=1.01 \times 10^{9} \mathrm{ps} f$

The cyclic stress ratio is then calculated as

$$
\text { CSR }=0.65 \frac{\sigma_{v}}{\sigma_{v}{ }^{\prime}} \frac{a_{\max }}{g} r_{d}=0.65 \frac{1380}{568.8} \cdot 0.4 \cdot 0.97=0.61
$$

Then, for an earthquake $M_{w}=8.7$, the modified CSR $=0.61 / 0.68=0.89$.

From Figure 5.2, the CSR value for an SPT value of 10 and $10 \%$ of fines is 0.12

The shear stress ratio is,

$$
K_{G}=\frac{0.12}{0.89}=0.14
$$

For a 3-ft thick DSM grid and shear modulus ratio $\left(G_{r}\right)$ of 50 , the required area replacement ratio $A_{r}$ is $35 \%$ from Figure 5.4. It is noted that the $R_{r d}$ and $K_{G}$ are equivalent as both are the shear stress reduction ratio in the soil.

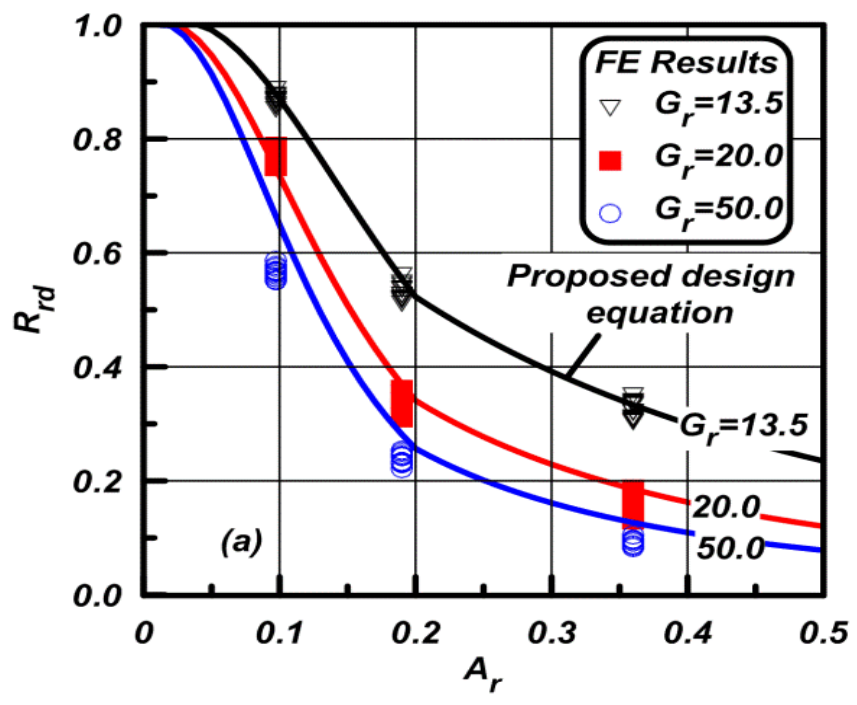

Figure 5.4: Design chart for DSM grid (Nyugen et al. 2012)

Since the DSM grids are installed in a square pattern as shown in Figure 5.5, the spacing of the grid can be calculated as 


$$
A_{r}=\frac{\frac{t}{2} \cdot S \cdot 4-4 \cdot \frac{t}{2} \cdot \frac{t}{2}}{S \cdot S}=\frac{2 t S-t^{2}}{S^{2}}
$$

Solving this quadratic equation,

$$
S=\frac{2 t \pm \sqrt{4 t^{2}-4 A_{r} t^{2}}}{2 A_{r}}
$$

Thus, for $A_{r}=35 \%$ and $\mathrm{t}=3 \mathrm{ft}, S=1.66 \mathrm{ft}$ and $15.48 \mathrm{ft}$.

Since, $1.66-\mathrm{ft}$ is unrealistic, the spacing of the grid is rounded to $15 \mathrm{ft}$.

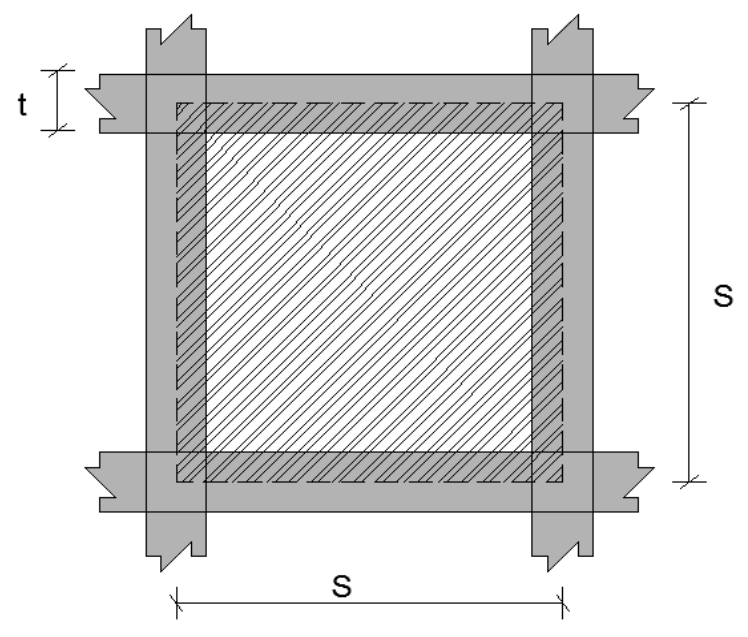

Figure 5.5: DSM grid unit cell and dimensions

For lower sand layer

Total Stress $=2040 \mathrm{psf}$

Effective stress $=854.4 \mathrm{psf}$

SPT value $\left(\mathrm{N}_{1}\right)_{60}=6$

Shear wave velocity $=85\left[\left(\mathrm{~N}_{1}\right)_{60}+2.5\right]^{0.25}=144.1 \mathrm{~m} / \mathrm{s}$ [modified fit of Andrus and Stokoe (2000) at $\left.p_{\mathrm{r}}=1 \mathrm{~atm}\right]$

Unit weight of soil $(\rho)=110 \mathrm{pcf}=1762 \mathrm{~kg} / \mathrm{m}^{3}$

Shear modulus $=\rho V^{2}=1762 \cdot 144.1^{2}=3.66 \times 10^{7} \mathrm{kPa}=7.64 \times 10^{8} \mathrm{ps} f$

The cyclic stress ratio is then calculated as

$$
C S R=0.65 \frac{\sigma_{v}}{\sigma_{v}{ }^{\prime}} \frac{a_{\max }}{g} r_{d}=0.65 \frac{2040}{854.4} \cdot 0.4 \cdot 0.96=0.60
$$

Then, for an earthquake $M_{w}=8.7$, the modified CSR $=0.60 / 0.68=0.88$ 
Now, from Figure 5.2, the CSR value for SPT value of 6 and 10\% of fines is 0.08 . In this case, using a factor of safety of 1.1 , the CSR value is $=0.08 / 1.1=0.07$.

The shear stress ratio is,

$$
K_{G}=\frac{0.07}{0.82}=0.08
$$

For a 3-ft thick DSM grid and shear modulus ratio of 50, the required area replacement ratio $A_{r}$ is $50 \%$ from Figure 5.4. For $A_{r}=50 \%$ and $t=3 \mathrm{ft}$, the spacing $S=1.76 \mathrm{ft}$ and $10.24 \mathrm{ft}$. Since, 1.76-ft is unrealistic; the spacing of the grid is $10.24 \mathrm{ft}$ rounded to $10 \mathrm{ft}$. Thus, based on two layers the DSM grid spacing is designed as 10-ft with 3-ft thick of DSM grid and stiffness of the DSM grid material is 50 times higher than the stiffness of the lower sand layer $\left(5.0 \times 10^{10} \mathrm{psf}\right)$. Similar to stone column design, the DSM grids are horizontally extended to at least of $15-\mathrm{ft}$ measured from the bridge foundation.

It is also noted that rather than using the chart, the calculation can be carried out using equations provided above. A trial and error method can be used by changing the thickness of grid, area replacement ratio, and shear modulus ratio.

For example, assume thickness of DSM grid is3ft and $A_{r}$ is $20 \%$ for the upper sand layer as an initial trial. Then the following steps can be carried out to check the design conditions:

1) calculate $C_{G}$ factor to account flexure in DSM grid

$$
C_{G}=1-0.5 \sqrt{1-A_{r}}=1-0.5 \sqrt{1-0.20}=0.552
$$

2) calculate shear strain ratio $\gamma_{\mathrm{r}}$

$$
\begin{aligned}
\gamma_{r} & =\left[1-\left(1-A_{r}\right)^{1.3} \cdot\left(\frac{G_{r}-1}{185}\right)^{0.4}\right] \cdot \min \left(\frac{H}{S}, 1\right) \\
& =\left[1-(1-0.20)^{1.3} \cdot\left(\frac{50-1}{185}\right)^{0.4}\right] \cdot \min \left(\frac{16}{28}, 1\right)=0.56 \cdot 57=0.32
\end{aligned}
$$

The spacing is determined from the quadratic equation presented above using $t$ and $A_{r}$.

3) calculate shear stress reduction factor $R_{r d}$ 


$$
\begin{aligned}
& R_{r d}=\min \left(\frac{1}{G_{r} \cdot\left[A_{r} \cdot C_{G} \cdot \gamma_{r}+\frac{1}{G_{r}} \cdot\left(1-A_{r}\right)\right]}, 1\right) \\
& =\min \left(\frac{1}{50 \cdot\left[0.20 \cdot 0.552 \cdot 0.32+\frac{1}{50} \cdot(1-0.20)\right]}, 1\right)=\min (0.39,1) \\
& =0.39>K_{G}=0.14 \text { for upper sand layer. NOT OK }
\end{aligned}
$$

Thus, the chosen initial trial for DSM grids does not satisfy the required $K_{G}$ of 0.14 for upper sand layer. Now, provide second trial conditions, with $\mathrm{t}=3-\mathrm{ft}$ and $A_{r}=35 \%$.

4) calculate $C_{G}$ factor

$$
C_{G}=1-0.5 \sqrt{1-A_{r}}=1-0.5 \sqrt{1-0.35}=0.596
$$

5) calculate $\gamma_{r}$

$$
\gamma_{r}=\left[1-(1-0.35)^{1.3} \cdot\left(\frac{50-1}{185}\right)^{0.4}\right] \cdot \min \left(\frac{16}{15}, 1\right)=0.664 \cdot 1=0.664
$$

6) calculate $R_{r d}$

$$
\begin{aligned}
R_{r d} & =\min \left(\frac{1}{50 \cdot\left[0.35 \cdot 0.596 \cdot 0.664+\frac{1}{50} \cdot(1-0.35)\right]}, 1\right)=\min (0.13,1) \\
& =0.13<K_{G}=0.14 \mathrm{OK}
\end{aligned}
$$

Thus, the chosen design parameters for DSM grids satisfy the required shear stress reduction ratio $\left(K_{G}=0.14\right)$ for upper sand layer. Similarly, other parameters for DSM grids for lower sand layer can be determined as well. 


\section{REFERENCES}

Abdoun, T. (1997). Modeling of Seismically Induced Lateral Spreading of Multi-layered Soil and its Effect on Pile Foundations, PhD. Thesis, Rensselaer Polytechnic Institute, Troy, New York.

Abdoun, T., Dobry, R., O’Rourke, T. D., and Goh, S. H. (2003). "Pile Response to Lateral Spreads: Centrifuge Modeling.” Journal of Geotechnical and Environmental Engineering, 129(10), 869-878.

ACI 318 (2008). Building Code Requirements for Structural Concrete and Commentary, American Concrete Institute.

Adalier, K., and Elgamal, A. (2004). "Mitigation of Liquefaction and Associated Ground Deformations by Stone Columns." Journal of Engineering Geology, 72(3-4), 275-291.

Adalier, K., Elgamal, A., Meneses, J., Baez, I.J. (2003). "Stone Columns as Liquefaction Counter-measure in Non-plastic Silty Soils." Journal of Soil Dynamics and Earthquake Engineering 23 (7), 571- 584.

American Institute of Steel Construction (AISC) (2005). Steel Construction Manual,13th Edition

American Petroleum Institute (API) (1987). Recommended Practice for Planning, Designing and Constructing Fixed Offshore Platforms. API Recommended Practice 2A(RP-2A), 17th edition ,Washington D.C.

American Petroleum Institute (API) (1993) "Recommended Practice for Planning, Designing and Constructing Fixed Offshore Platforms - Working Stress Design”, RP 2A-WSD, 20th Edition, Washington, DC.

Andrews, D. C. A. (1997). "Liquefaction of Silty Soils: Susceptibility, Deformation, and Remediation.” PhD Thesis, University of Southern California, Los Angeles, CA.

Ansal, A., Bardet, J.P., Barka, A., Baturay, M.B., Berilgen, M., Bray, J., Cetin, O., Clu, L., Durgunoglu, T., Erten, D., Erdik, M., Idriss, I.M., Karadayilar, T., Kaya, A., Lettis, W., 
Olgun, G., Paige, W., Rathje, E., Roblee, C., Stewart, J., and Ural, D. (1999). Initial Geotechnical Observations of the November 12, 1999, Duzce Earthquake. A Report of the Turkey-US Geotechnical Earthquake Engineering Reconnaissance Team.

Ashford, S.A., Boulanger, R.W., and Brandenberg, S.J. (2011). Recommended Design Practice for Pile Foundations in Laterally Spreading Ground, Report No. PEER2011/04, Pacific Earthquake Engineering Research Center, Univ. of California, Berkeley, CA, 68 pages.

Ashford, S. and Juirnarongrit, T.,(2004), “Evaluation of Force Based and Displacement Based Analysis for Response of Single Piles to Lateral Spreading”, Proc. of 11th International Conference on Soil Dynamics and Earthquake Engineering and 3rd International Conference Earthquake Geotechnical Engineering, University of California, Berkeley, Vol. 1, pp. 752759.

Ashford, S. A., Juirnarongrit, T., Sugano, T., and Hamada, M. (2006). "Soil-pile Response to Blast-induced Lateral Spreading. I: Field test.” Journal of Geotechnical and Environmental Engineering, 132(2), 152-162.

Ashford, S. A., Rollins, K. M., and Baez, J. I. (2000a). "Comparison of Deep Foundation Performance in Improved and Nonimproved Ground using Blast Induced Liquefaction.” Proc., Geo-Denver 2000, Soil Dynamics and Liquefaction, ASCE Geotech. Special Publ., $107,20-34$.

Ashford, S.A., and Rollins, K.M. (2002). “TILT: Treasure Island Liquefaction Test Final Report,” Structural Systems Research Report No. SSRP-2001/17, Department of Structural Engineering, UCSD, 498p.

Ashford, S. A., Rollins, K. M., Bradford, S. C., Weaver, T. J., and Baez, J. I. (2000b). "Liquefaction Mitigation using Stone Columns around Deep Foundations: Full Scale Test Results.” Proc., Transportation Research Board Meeting, Transportation Research Board, Washington, D.C., p. 110-118.

Atwater, B.F., Nelson, A.R., Clague, J.J., Carver, G.A., Yamaguchi, D.K., Bobrowsky, P.T., Bourgeois, J., Darienzo, M.E., Grant, W.C., Hemphill-Haley, E., Kelsey, H.M. Jacoby, G.C., 
Nishenko, S.P., Palmer, S.P., Peterson, C.D., and Reinhart, M.A., 1995, Summary of coastal geologic evidence for past great earthquakes at the Cascadia subduction zone: Earthquake Spectra, Vol. 11, no. 1, p. 1-18.

Atwater, B.F., and Hemphill-Halley, E., 1997, Recurrence intervals for great earthquakes of the past 3,500 years at northeastern Willapa Bay: U.S. Geological Survey Professional Paper, 108.

Baez, J.I. and Martin, G.R. (1992). “Quantitative Evaluation of Stone Column Techniques for Earthquake Liquefaction Mitigation." Proc., 10th World Conference on Earthquake Engineering, Madrid, Spain.

Baez, J. I., and Martin, G. R. (1995). "Permeability and Shear Wave Velocity of VibroReplacement Stone Columns.” Soil Improvement for Earthquake Hazard Mitigation. ASCE Geotech. Special Publ., 49, 66-81.

Baez, J.I. (1997). “Vibro-stone Columns, Soil Improvement-a 20 Year Update.” Proc., Ground Improvement, Ground Reinforcement, Ground Treatment 1987 - 1997, Logan, UT. ASCE Geotechnical Special Publication, vol. 69.

Barksdale, R. D. and Bachus, R. C. (1983). "Design and Construction of Stone Columns Volume I. Report No: FHWA/RD-83/026.” Federal Highway Administration, Office of Engineering and Highway Operations, Research and Development, Washington D.C.

Bartlett, S.F. and T.L. Youd. (1992). Case Histories of Lateral Spreads Caused by the 1964 Alaska Earthquake, Case Studies of Liquefaction and Lifeline Performance During Past Earthquake, Technical Report NCEER-92-0002, National Center for Earthquake Engineering Research, State University of New York, Buffalo. pp. 2.1-2.127.

Benuzka, L.E.(1990). “ Loma Prieta Earthquake Reconnaissance Report.” Report by EERI and NRC, Supplement to Vol. 6 of Earthquake Spectra.

Boulanger, R.W. and Hayden, R.F. (1995). “Aspects of Compaction Grouting of Liquefiable Soil.” Journal of Geotechnical Engineering 121(12):844-855. 
Boulanger, R., Idriss, I., Steward, D., Hashash, Y., and Schmidt, B. (1998). "Drainage Capacity of Stone Columns or Gravel Drains for Mitigating Liquefaction.” Proc., Geotechnical Earthquake Engineering and Soil Dynamics III, ASCE Geotech Special Publ., No. 75, 678690.

Boulanger, R. W., Kutter, B. L., Brandenberg, S. J., Singh, P., and Chang, D. (2003). “Pile Foundations in Liquefied and Laterally Spreading Ground during Earthquakes: Centrifuge Experiments and Analyses.” Report UCD/CGM-03/01, Center for Geotechnical Modeling, Univ. of California, Davis, CA.

Bourgeois, E., Rakotonindriana, M.H.J., Kouby, A.L., Mestat, P., and Serratrice, J.F. (2010). “Three-dimensional Numerical Modelling of the Behaviour of a Pile Subjected to Cyclic Loading”. Computers and Geotechnics,37, 999-1007.

Brandenberg, S. J., Boulanger, R. W., Kutter, B. L., and Chang, D. (2005). "Behavior of Pile Foundations in Laterally Spreading Ground during Centrifuge Tests.” Journal of Geotechnical and Environmental Engineering, 131(11), 1378-1391.

Brandenberg, S. J., Boulanger, R. W., Kutter, B. L., and Chang, D. (2007). "Static Pushover Analysis of Pile Groups in Liquefied and Laterally Spreading Ground in Centrifuge Tests.” Journal of Geotechnical and Environmental Engineering, 133 (9), 1055-1066.

Bray, J.D., and Travasarou, T. (2007). "Simplified procedure for estimating earthquake-induced deviatoric slope displacements.” Journal of Geotechnical and Environmental Engineering, 133(4): 381-392.

Brown, D. A., Morrison, C., and Reese, L. C. (1988). “Lateral Load Behavior of a Pile Group in Sand.” Journal of Geotechnical and Environmental Engineering, 114(11), 1261- 1276.

Brown, D.A. and Shie, C.F(1990). “Three Dimensional Finite Element Model of Laterally Loaded Piles”. Computers and Geotechnics, 10, 59-79.

Bruce, D.A. (2000). “An Introduction to the Deep Soil Mixing Methods as Used in Geotechnical Applications”, Volume I. FHWA-RD-99-138. 
California Department of Transportation (CALTRANS) (2011). Guidelines on Foundation Loading and Deformation Due to Liquefaction Induced Lateral Spreading. Internal Policy Proposal, February 2011.

Canadian Geotechnical Society (1992). Canadian Foundation Engineering Manual, 3rd. Ed., Canadian Geotechnical Society, BiTech,Vancouver, B.C., Canada.

Chang, D., Boulanger, R.W., Kutter, B.L., and Brandenberg, S. J. (2005). "Experimental Observations of Inertial and Lateral Spreading Loads on Pile Groups during Earthquakes.” Earthquake Engineering and Soil Dynamics, ASCE, GSP 133.

Chu, B. L., Hsu, S. C., Lay, S. Y., and Chang, Y. M. (2000). "Failures Associated with Liquefaction at Wufeng during Chi-Chi Earthquake.” Proc., Int. Workshop on Annual Commemoration of Chi-Chi Earthquake, 3, 46-57.

Cubrinovski, M. and Ishihara, K. (2007). "Simplified Analysis of Piles Subjected to Lateral Spreading: Parameters and Uncertainties", $4^{\text {th }}$ International Conference on Earthquake Geotechnical Engineering, June, Greece.

Curras, C. J., Boulanger, R. W., Kutter, B. L., and Wilson, D. W. (2001).“Dynamic Experiments and Analyses of a Pile-group-supported Structure.” Journal of Geotechincal. Geoenviront Engineering, 127(7), 585-596.

Dickenson, S.E., McCullough, N.J., Barkau, M.G., and Wavra, B.J. (2002). “Assessment and Mitigation of Liquefaction Hazards to Bridge Approach Embankments in Oregon - Final Report”. SPR 361. Oregon Department of Transportation. November 2002.

Earthquake Engineering Research Institute (EERI). Special Earthquake Report- November 2010.

Earthquake Engineering Research Institute (EERI). Special Earthquake Report- May 2011.

Elgamal, A., Yang, Z., Parra, E., and Ragheb, A. (2003). "Modeling of cyclic mobility in saturated cohesionless soils.” International Journal of Plasticity, 19, 883-905. 
Elgamal, A., Yan, L., Yang, Z., and Conte, J. P. (2008). “Three-dimensional seismic response of Humbolt Bay bridge-foundation-ground system.” Journal of Structural Engineering, ASCE, 134(7), 1165-1176.

Elgamal, A., Lu, J., and Forcellini, D. (2009). "Mitigation of Liquefaction-Induced Lateral Deformation in a Sloping Stratum: Three-dimensional Numerical Simulation.” Journal of Geotechnical and Geoenvironmental Engineering, ASCE 135(11), 1672-1682.

Faris, A.T., Seed, R.B., Kayen, R.E., and Wu, J., (2006). “A semi-empirical model for the estimation of maximum horizontal displacement due to liquefaction-induced lateral spreading," $8^{\text {th }}$ National Conference on Earthquake Engineering, EERI, San Francisco, CA.

Ferritto, J. (1997). .Seismic Design Criteria for Soil Liquefaction,. Technical Report TR-2077-SHR, U.S. Naval Facilities Engineering Services Center, Port Hueneme, CA. 58 p.

Francis, M.A. and Gorski, G.A. (1998). "In Situ Soil Mixing for the Mitigation of Seismic Lateral Spreading: A Case History,” Proc. of the Deep Foundation Institute Annual Meeting, Seattle, Washington.

Fujii, S., Isemoto, N., Satou, Y., Kaneko, O., Funahara, H., Arai, T., and Tokimatsu, K. (1998). "Investigation and analysis of a pile foundation damaged by liquefaction during the 1995 Hyogoken-Nambu earthquake." Special Issue of Soils and Foundations, Japanese Geotechnical Society, 179-192.

Geo-Engineering Extreme Events Reconnaissance (GEER) Association (2010a). Geoengineering Reconnaissance of the 2010 Maule, Chile Earthquake. J. Bray and D. Frost, eds., Report No. GEER-022.

Geo-Engineering Extreme Events Reconnaissance (GEER) Association (2010b). Geotechnical Reconnaissance of the 2010 Darfield (New Zealand) Earthquake. R. A. Green and M. Cubrinovski, eds., Report No. GEER-024.

Geo-Engineering Extreme Events Reconnaissance (GEER) Association (2011). Geotechnical Reconnaissance of the 2011 Christchurch, New Zealand Earthquake. M. Cubrinovski, R. A. Green, and L. Wotherspoon, eds., Report No. GEER-027. 
Goughnour, R.R. and Pastena, J.M. (1998). "Mechanical Behavior of Stone Columns Under Seismic Loading.” Proc., 2nd Int. Conf. on Ground Improvement Techniques, Singapore, $157-162$.

Green R.A., Olgun, C.G, and Wissmann, K.J. (2008). "Shear Stress Redistribution as a Mechanism to Mitigate the Risk of Liquefaction.” Journal of Geotechnical Earthquake Engineering and Soil Dynamics IV, ASCE, GSP 181.

He, L., Elgamal, A., Hamada, M., and Meneses, J. (2008). "Shadowing and Group Effects for Piles during Earthquake-Induced Lateral Spreading," The 14th World Conference on Earthquake Engineering, October 12-17, Beijing, China.

Iai, S., Matsunaga, Y., Morita, T., Sakurai, H., Oishi, H., Ogura, H., Ando, Y., Tanaka, Y., and Kato, M. (1994). "Effects of Remedial Measures against Liquefaction at 1993 Kushiro-Oki Earthquake.” Proceedings of the Fifth US-Japan Workshop on Earthquake Resistant Design of Lifeline Facilities and Countermeasures against Site Liquefaction. T.D. O.Rourke and M. Hamada (eds.). National Center for Earthquake Engineering Research. NCEER-94-0026. State University of New York, Buffalo, 135-152.

Iai, S., Morita, T., Kameoka, T., Matsunaga, Y., Abiko, K. (1995). “Response of a Dense Sand Deposit during 1993 Kushiro-Oki Earthquake.” Soils and Foundations, 35 (1), 115- 131.

Juirnarongrit, T., and Ashford, S.A. (2006). "Soil-Pile Response to Blast-Induced Lateral Spreading. II: Analysis and Assessment of the p-y Method,” Journal of Geotechnical and Geoenvironmental Engineering, ASCE, 132(2), pp. 163-172.

JRA (2002). Specifications for highway bridges. Japan Road Association, Preliminary English Version, prepared by Public Works Research Institute (PWRI) and Civil Engineering Research Laboratory (CRL), Japan.

Kimura, M., Adachi, T., Kamei, H., and Zhang F (1995). “3-D Finite Element Analyses of the Ultimate Behavior of Laterally Loaded Cast-in-place Concrete Piles,” Proceeding of the Fifth International Symposium on Numerical Models in Geomechanics, 589-594. 
Kramer, S. L. (2008). Evaluation of Liquefaction Hazards in Washington State. Washington State Department of Transportation (WSDOT), WA-RD 668.1.

Lam, I. P., Arduino, P., and Mackenzie-Helnwein, P. (2009). “Opensees soil-pile interaction study under lateral spread loading." International Foundation Congress and Equipment Expo, Orlando, FL.

Li, X. S., and Dafalias, Y. F. (2000). "Dilatancy for cohesionless soils.” Geotechnique, 50(4), 449-460.

Liu, L. and Dobry, R. (1995). “ Effect of Liquefaction on Lateral Response of Piles by Centrifuge Model Tests.” NCER Bulletin, SUNY-Buffalo, NY.

Luehring, R.,Snorteland, N., Mejia, L., and Stevens, M. (2001). "Liquefaction Mitigation of a Silty Dam Foundation using Vibro-stone Columns and drainage Wicks: a Case History at Salmon Lake Dam.” Proc. 21st USSD annual meeting and lecture, Denver, Colorado.

Matlock, H. (1970). "Correlations of design of laterally loaded piles in soft clay." Proc. Offshore Technology Conference, Houston, TX, Vol. 1, No. 1204, 577-594.

McGann, R. C., Arduino P., and Mackenzie-Helnwein P. (2011), Applicability of Conventional p-y Relations to the Analysis of Piles in Laterally Spreading Soils, ASCE Journal of Geotechnical and Geoenvironmental Engineering, 137(6), 557-567.

McVay, M., Bloomquist, D., Vanderlinde, D., and Clausen, J. (1994). "Centrifuge modeling of laterally loaded pile groups in sands.” ASTM Geotechnical Testing Journal, 17, 129-137.

McVay, M., Casper, R., and Shang, T. (1995). "Lateral Response of Three Row Groups in Loose to Dense Sands at 3D and 5D Pile Spacing." Journal of Geotechnical and Environmental Engineering, 121(5), 436-441.

McVay, M., Zhang, L., Molnit, T., and Lai, P. (1998). "Centrifuge Testing of Large Laterally Loaded Pile Groups in Sands.” Journal of Geotechnical and Environmental Engineering , 124(10), 1016-1026. 
Millea, M. T. (1990). “Liquefaction mitigation technology.” Final report, February 1988-June 1989.

Mitchell, J.K. (2008). "Mitigation of Liquefaction Potential of Silty Sands.” From Research to Practice in Geotechnical Engineering Congress 2008, 453-451.

Mitchell, J. K. and Wentz, F.L. (1991). "Performance of Improved Ground during the Loma Preita Earthquake, Report No. UCB/EERC-91/12.” E. E. R. Center, University of California, Berkeley.

Mitchell, J. K., Baxter, C.D.P, and Munson, T.C. (1995). "Performance of Improved Ground During Earthquakes." ASCE Geotechnical Special Publ. No. 49 - Soil Improvement for Earthquake Hazard Mitigation: 1-36.

Mitchell, J.K., Cooke, H.G., and Schaeffer, J.A. (1998). "Design Considerations in Ground Improvement for Seismic Risk Mitigation,” Proc. of the Geotechnical Earthquake Engineering and Soil Dynamics III, ASCE Geotechnical Special Publication 75(1):580-613.

Mokwa, R. L. (1999). “Investigation of the Resistance of Pile Caps to Lateral Spreading.” PhD thesis, Dept. of Civil Engineering, Virginia Polytechnic Institute and State Univ., Blacksburg, VA.

Mokwa, R.L., and Duncan, J.M. (2001a). "Experimental evaluation of lateral-load resistance of pile caps." Journal of Geotechnical and Environmental Engineering, ASCE. 127(2). 185-192.

Mokwa, R. L. and Duncan, J. M. (2001b). "Laterally Loaded Pile Groups and p-y Multipliers,” ASCE Geotechnical Special Publication Number 113, Foundations and Ground Improvement, 2001: A Geo-Odyssey, Virginia Tech, Blacksburg, VA, 728-742.

Mokwa, R. L. and Duncan, J. M. (2003). "Rotational restraint of pile caps during lateral loading.” Journal of Geotechnical and Geoenvironmental Engineering, 129 (9), 829-837.

Motamed, R. and Towhata, I. (2010). "Shaking Table Model Tests on Pile Groups behind Quay Walls Subjected to Lateral Spreading." Journal of Geotechnical and Environmental Engineering, 136(3), 477-489. 
Muqtadir, A, and Desai C.S. (1986). “Three Dimensional Analysis of a Pile-Group Foundation”. International Journal of Numerical and Analysis Methods in Geomechanics, 10, 41-58.

National Cooperative Highway Research Program (NCHRP) (2002). Comprehensive Specification for the Seismic Design of Bridges. NCHRP Report 472, National Academy Press, Washington, D.C.

Nguyen, T.V., Rayamajhi, D., Ashford, S.A., Boulanger, R.W., Lu, J., Elgamal, A., and Shao, L. (2012). "Effect of DSM grids on shear stress distribution in liquefiable soil." ASCE GeoCongress Conference,Oakland, California, March 25-29.

Oh-Oka, H., Onishi, K., Nanba, S., Mori, T., Ishikawa, K., and Shimazu, S. (1997). "Liquefaction-induced Failure of Piles in 1995 Kobe Earthquake.” Geotechnical Engineering in Recovery from Urban Earthquake Disaster, 3rd Kansai International Geotechnical Forum on Comparative Geotechnical Engineering (KIG - Forum 97), Kansai Branch, Japanese Geotechnical Society, Osaka, Japan.

Olgun, C. G. and Martin, J.R. (2008). "Numerical Modeling of the Seismic Response of Columnar Reinforced Ground.” Journal of Geotechnical Earthquake Engineering and Soil Dynamics IV, ASCE, GSP 181.

Onoue, A. (1988). "Diagrams Considering Well Resistance for Designing Spacing Ratio of Gravel Drains.” Soils and Foundations, 28 (3), 160-168.

Oregon Department of Transportation (ODOT) (2009). Seismic Vulnerability of Oregon State Highway Bridges, Mitigation Strategies to Reduce Major Mobility Risks, A report prepared by ODOT Bridge Engineering Section, November 2009, 60p.

Petek, K. A. (2006). "Development and application of mixed beam-solid models for analysis of soil-pile interaction problems.” Ph.D. thesis, Univ. of Washington.

Pressley, J.S. and Poulos, H.G(1986). "Finite Element Analysis of Mechanisms of Pile Group Behavior”. International Journal for Numerical and Analytical Methods in Geomechanics, 10, 213-221. 
Reese, L. C., Cox, W. R., and Koop, F. D. (1974). “Analysis of Laterally Loaded Piles in Sand.” Offshore Technology Conference, Vol. II, Paper No. 2080, Houston, Texas, 473-484.

Reese, L. C. and Welch, R. C. (1975). "Lateral loading of deep foundations in stiff clay." Journal of the Geotechnical Engineering Division, ASCE, 101(7), 633-649.

Remaud, D., Garnier, J., Frank, R. (1998). "Laterally loaded Piles in Dense Sand: Group Effects,” Proceedings, 1998 International Conference on Centrifuge, Netherlands, 533-538.

Rollins, K.M., Lane, D.J., and Gerber, T.M. (2005a). "Measured and Computed Lateral Response of a Pile Group in Sand.” Journal of Geotechnical and Environmental Engineering, 131(1), 103-114.

Rollins, K.M.,Gerber, T.M.,Lane, D.J., and Ashford, S.A. (2005b). "Lateral Resistance of a FullScale Pile Group in Liquefied Sand.” Journal of Geotechnical and Environmental Engineering, 131(1), 115-125.

Rollins, K.M. and Sparks, A.E. (2002) "Lateral Load Capacity of a Full-Scale Fixed-Head Pile Group.” Journal of Geotechnical and Geoenvironment, Engineering, 128 (9), 711-723.

Salgado, R. (2008). The Engineering of Foundations. The McGraw-Hill Companies, Inc.

Sasaki, Y., and Taniguchi, E. (1982). "Shaking Table Tests on Gravel Drains to Prevent Liquefaction of Sand Deposits.” Soils and Foundations, 22 (3), 1-14.

Seed, H.B. and Booker, J.R. (1977). "Stabilization of Potentially Liquefiable Sand Deposits Using Gravel Drains." Journal of Geotechnical Engineering Division, 103(7), 757 - 768.

Seed, H.B and Idriss, I.M. (1971). "Simplified Procedure for Evaluating Soil Liquefaction Potential." Journal of Soil Mechanics and Foundation Division, 97(9), 1249-1273.

Seed, R.B., Dickenson, S.E., Riemer, M.F., Bray, J.D., Sitar, N., Mitchell, J.K., Idriss, I.M., Kayen, R.E., Kropp, A., Hander Jr., L.F., and Power, M.S.(1990). Preliminary Report on the Principal Geotechnical Aspects of the October 17, 1989, Loma Prieta Earthquake. Report No. UCB/EERC-90/05, Earthquake Engineering Research Center, University of California, Berkeley. 
Shenthan, T. (2005). "Liquefaction Mitigation in Silty Soils Using Stone Columns Supplemented with Wick Drains.” PhD Thesis, Civil Engineering. Buffalo, New York, State University of New York at Buffalo.

Shenthan, T., Nashed, R., Thevanayagam, S., and Martin, G. R. (2004a). "Liquefaction. Mitigation in Silty soils using Composite Stone Columns and Dynamic Compaction.” Journal of Earthquake Engineering and Vibrations, 3(1).

Shenthan, T., Thevanayagam, S., and Martin, G.R. (2004b). "Densification of Saturated Silty Soils using Composite Stone Columns for Liquefaction Mitigation. Proc., 13th WCEE, Vancouver, BC, Canada.

Sonu, C.J., Ito, K., Oishi, H., (1993). Harry Seed, liquefaction and gravel drain. Civil Engineering ASCE 63 (12), 58-60.

Stewart, D.P., Boulanger, R.W., Idriss, I.M., Hashash, Y. , and Schmidt, B. (1997). "Ground Improvement Issues for Posey \& Webster St. Tubes Seismic Retrofit Project: Lessons from Physical Modeling Studies,” Report No. UCD/CGM-97/04, Center for Geotechnical Modeling, Dept. of Civil \& Environmental Engineering, Univ. of California, Davis.

Tobita, T., Iai, S., Sugaya,M.,and Kaneko, H. (2006). “Analysis of Group Pile Behavior under Lateral Spreading," Seismic Performance and Simulation of Pile Foundations, ASCE.

Tokimatsu, K., and Asaka, Y. (1998). "Effects of Liquefaction-induced Ground Displacements on Pile Performance in the 1995 Hyogoken-Nambu Earthquake.” Special Issue of Soils and Foundations, Japanese Geotechnical Society, 163-177.

Tokimatsu, K., Mizuno, H., and Kakurai, M. (1996). "Building Damage Associated with Geotechnical Problems.” Special Issue of Soils and Foundations, Japanese Geotechnical Society, 219-234.

Trochanis, A.M., Bielak, J., and Christiano P(1991). "Three-dimensional Nonlinear Study of Piles”. Journal of Geotechnical Engineering, 117(3), 429-447.

Wakai, A., Gose, S., and Ugai, K(1999). “3-D Elasto-plastic Finite Element Analysis of Pile Foundations Subjected to Lateral Loading. Soil and Foundations, 39(1), 97-111. 
Wang, C.-H. (2003). Prediction of the Residual Strength of Liquefied Soils. Ph.D. Dissertation, University of Washington, WA.

Wang, S.-T., and Reese, L. C. (1998). "Design of Pile Foundations in Liquefied Soils." Geotechnical Earthquake Engineering and Soil Dynamic III, GSP No. 75, P. Dakoulas and M. Yegian, eds., Vol. 2, ASCE, Reston, Va., 1331-1343.

Weaver, T.S., Ashford, S.A., Rollins, K.M. (2005). Response of liquefied sand to a 0.6-m CISS pile under lateral loading, Journal of Geotechnical and Environmental Engineering, 131(1), 94-102.

Wilson, D. W. (1998). “Soil-pile-superstructure Interaction at Soft and Liquefying Soil Sites.” $\mathrm{PhD}$ dissertation, Univ. of California, Davis, Calif.

Wilson, D. W., Boulanger, R. W., and Kutter, B. L. (2000). "Observed Seismic Lateral Resistance of Liquefying Sand.” Journal of Geotechnical and Environmental Engineering, 126(10), 898-906.

Yang, Z., Elgamal, A., and Parra, E. (2003). “Computational Model for Cyclic Mobility and Associated Shear Deformation.” Journal of Geotechnical and Environmental Engineering, 129(12), 1119-1127.

Yang, Z. and Jeremic, B. (2003). "Numerical Study of Group Effects for Pile Groups in Sands”. International Journal for Numerical and Analytical Methods in Geomechanics, 27, 12551276.

Yang, Z. and Jeremic, B. (2005). "Study of soil layering effects on lateral loading behavior of piles.” Journal of Geotechnical and Geoenvironmental Engineering, ASCE, 131(6), 762-770.

Yasuda, S., Ishihara, K., Harada, K., and Shinkawa, N. (1996). "Effect of Soil Improvement on Ground Subsidence Due to Liquefaction,” Soils and Foundations . Special Issue on Geotechnical Aspects of the January 17, 1995 Hyogoken-Nambu Earthquake, Japanese Geotechnical Society. pp. 99-107.

Yen, W.-H. P., Chen, G., Buckle, I., Allen, T., Alzamora, D., Ger, J., and Arias, J. G. (2011). Post-Earthquake Reconnaissance Report on Transportation Infrastructure: Impact of the 134 
February 27, 2010, Offshore Maule Earthquake in Chile. Publication No. FHWA-HRT-11030, U.S. Department of Transportation, Federal Highway Administration, McLean, VA.

Youd, T.L. (1993). .Liquefaction-Induced Damage to Bridges,. Transportation Research Record 1411, Transportation Research Board, National Research Council, Washington, D.C. 35-41.

Youd, T.L., Idriss, I.M. Andrus, R.D. Arango, I., Castro, G., Christian, J.T., Dobry, R., Liam Finn, W.D.L., Harder, L.F., Jr., Hynes, M.E., Ishihara, K., Koester, J.P., Liao, S.S.C., Marcuson, W.F., III, Martin, G.R., Mitchell, J.K., Moriwaki, Y., Power, M.S., Robertson, P.K., Seed, R.B., Stokoe, K.H., II, (2001). "Liquefaction Resistance of Soils: Summary Report from the 1996 NCEER and 1998 NCEER/NSF Workshops on Evaluation of Liquefaction Resistance of Soils", Journal of Geotechnical and Geoenvironmental Engineering. 127(10), 817-833. 


\section{APPENDIX-A Assessing Liquefaction Potential}

In the past four decades, several frameworks have been proposed for liquefaction assessment of soils. The most common framework is semi-empirical field based procedures. In this method, earthquake induced cyclic stresses are compared with cyclic shear resistance of the soils. The earthquake induced dynamic stresses, also known as cyclic stress ratio (CSR), are estimated based on the "simplified procedure" proposed by Seed and Idriss (1971). Over the years, the simplified procedure of estimating CSR has been modified by several researchers (e.g., Seed et al. 1985; Youd et al. 2001; Cetin et al. 2004; and Idriss and Boulanger 2008). The soil resistance, also known as cyclic resistance ratio $(C R R)$, is based on in-situ index tests such as Standard Penetration Test (SPT), Cone Penetration Test (CPT) or shear wave velocity $\left(V_{s}\right)$, typically obtained from empirical correlations (Youd et al. 2001; Idriss and Boulanger 2008). These correlations are based on documentation of liquefaction and non-liquefaction case histories in past earthquakes.

Liquefaction in the soil is likely to happen when the CSR exceeds the $C R R$. Thus, a factor of safety against liquefaction $\left(F S_{L}\right)$ can be calculated as the ratio of $C R R$ divided by the $C S R$ as

$$
F S_{L}(\mathrm{z})=\operatorname{CRR}(\mathrm{z}) / \operatorname{CSR}(\mathrm{z})
$$

From this equation, the liquefaction potential of the soils can be assessed at any depth $z$. Liquefaction is likely to occur when the $F S_{L}$ is less than unity $(<1.0)$, whereas liquefaction is not likely to occur when the $F S_{L}$ exceeds unity (>1.0). However, the parameters used in the above equation are developed from semi-empirical relationships, and therefore the value of $F S_{L}$ is not an exact value to evaluate the liquefaction potential. Furthermore, several researchers have proposed different relationships to estimate the CSR and CRR of the soils, and thus $F S_{L}$ obtained from different methods will results in different values. Therefore, careful engineering judgment would be required to properly assess the liquefaction potential of soils. 


\section{Determination of the Earthquake Induced Cyclic Stress Ratio (CSR)}

The basic relationship proposed by Seed and Idriss (1971) is as follows

$$
C S R=\frac{\tau_{a v}}{\sigma_{v o}^{\prime}}=0.65\left(\frac{a_{\max }}{g}\right)\left(\frac{\sigma_{v o}}{\sigma_{v o}^{\prime}}\right) r_{d}
$$

where $\tau_{a v}$ is the average, or uniform, earthquake-induced cyclic shear stress, $\sigma^{\prime}{ }_{v c}$ is the preearthquake effective overburden stress, $\sigma_{v o}$ is the vertical total stress in the soil at the depth in question, $a_{\max }$ is the peak horizontal acceleration at the ground surface modified for site specific soil conditions, $g$ is the acceleration due to gravity, and $r_{d}$ is a stress reduction factor which takes into account the flexibility of the soil column.

In the above equation, the $a_{\max }$ can be estimated by using site specific response analysis. The site specific response analysis provides detailed modeling of the site conditions and provides better conversion of bed rock peak acceleration to the peak ground surface acceleration. However, the site response analyses can directly predict the CSR; they are not used with a simplified procedure. By using the indirect method, the maximum surface acceleration can be obtained by multiplying the bedrock maximum acceleration values by amplification factors $(F)$. Stewart et al. (2003) provided the amplification factors for different soil formation, which account for nonlinear response at higher levels of shaking. The factor can be obtained as

$$
\ln F=\alpha+\beta\left(a_{\max }\right)_{\text {rock }}
$$

where $\alpha$ and $\beta$ are shown in Table A.1.

Table A.1 Coefficients for estimation of $F$ (after Stewart et al. 2003)

\begin{tabular}{|l|r|r|}
\hline Surface Geology Category & \multicolumn{1}{|l|}{$\boldsymbol{\alpha}$} & \multicolumn{1}{l|}{$\boldsymbol{\beta}$} \\
\hline Quaternary alluvium & -0.15 & -0.13 \\
\hline Holocene lacustrine/marine & -0.59 & -0.39 \\
\hline Holocene coarse & -0.11 & -0.1 \\
\hline Holocene fine/mixed & -0.5 & -0.33 \\
\hline Pleistocene & 0.14 & 0.02 \\
\hline Tertiary & 0.23 & -0.02 \\
\hline Mesozoic+ Igneous & -0.13 & -0.08 \\
\hline
\end{tabular}


Over the past four decades, many researchers have proposed different semi-empirical correlations to estimate the $r_{d}$ factor (e.g., i.e. Ishihara 1977, Iwasaki et al. 1978, Golesorkhi 1989, Idriss 1999, Seed et al. 2001, and Cetin et al. 2004). From previous research, it was shown that the $r_{d}$ factor is mainly dependent on the earthquake ground motion characteristics (e.g., intensity and frequency content), earthquake magnitude, nonlinear dynamic soil properties, soil depth, and thickness of the soil layer. Thus, different correlations have been proposed by incorporating different parameters.

For routine practice and non-critical projects, Youd et al. (2001) proposed a correlation to determine the $r_{d}$ factor, which is shown in equation A.4. The correlation is modified from the recommendation given by Seed and Idriss (1971) (Figure A.1).

$$
r_{d}=\frac{1.000-0.4113 \mathrm{z}^{0.5}+0.04052 \mathrm{z}+0.001753 \mathrm{z}^{1.5}}{1.000-0.4177 \mathrm{z}^{0.5}+0.05729 \mathrm{z}-0.006205 \mathrm{z}^{1.5} 10.001210 \mathrm{z}^{2}}
$$

where $z$ is the depth below the ground surface in meters. Even though the equation provides the $r_{d}$ factor to a depth of 23-m, the simplified procedure was only verified to depth of 15-m by Youd et al. (2001). Thus, the equation is only applicable to the maximum depth of 15-m and is not recommended for use at greater depths.

Based on several parametric site response analyses, and extending the work of Golesorkhi (1989), Idriss (1999) developed a correlation for $r_{d}$ as a function of depth and earthquake magnitude (M). The expression is shown in equation A.5.

$$
r_{d}=\exp \left[\alpha(z)+\beta(z) M_{w}\right]
$$

where

$$
\begin{aligned}
& \alpha(z)=-1.012-1.126 \sin \left(\frac{z}{11.73}+5.133\right) \\
& \beta(z)=0.106+0.118 \sin \left(\frac{z}{11.28}+5.142\right)
\end{aligned}
$$

and $z$ is depth in meters, $M$ is moment magnitude, and the arguments inside the sine terms are in radians. The above equation is mathematically applicable to a depth of 34-m; however, Idriss and 
Boulanger (2008) recommended applying the equation to a maximum depth of $20-\mathrm{m}$. At higher depths, site specific response analysis is recommended.

\section{Determination of the Cyclic Resistance Ratio (CRR)}

As mentioned earlier, only SPT based correlations are summarized for the estimation of CRR. The $C R R$ for any earthquake magnitude $(M)$ and effective stress $\left(\sigma^{\prime}{ }_{v c}\right)$ is estimated as

$$
C R R_{M, \sigma_{v o}^{\prime}}=C R R_{M=7.5, \sigma_{v o}^{\prime}=1 a t m} \cdot M S F \cdot K_{\sigma}
$$

where $\mathrm{CRR}_{M=7.5, \sigma^{\prime} v c=1}$ is the reference cyclic stress ratio adjusted for the earthquake magnitude of $7.5\left(M_{w}\right)$ and effective vertical consolidation pressure of 1 atmosphere, MSF is the earthquake magnitude scaling factor to account for the earthquake magnitude under consideration, and $K_{\sigma}$ is the overburden correction factors to account for the overburden stresses at the depth of interest. To be consistent in determining the $C R R$, all the simplified procedure evaluate the $\mathrm{CRR}_{M=7.5, \sigma^{\prime} v c=1}$ first and then additional factors $\left(M S F, K_{\sigma}\right)$ are applied to account for the site specific conditions.

\section{Estimation $C R R_{7.5,1 \mathrm{~atm}}$}

Youd et al. (2001) recommended a correlation for CRR modified from Seed et al. (1985) and shown in the equation below

$$
\mathrm{CRR}_{7.5,1 \mathrm{~atm}}=\frac{1}{34-\left(N_{1}\right)_{60 c s}}+\frac{\left(N_{1}\right)_{60 c s}}{135}+\frac{50}{\left[10 \cdot\left(N_{1}\right)_{60 c s}+45\right]^{2}}-\frac{1}{20}
$$

where (N1) 60cs $_{\text {c }}$ is the equivalent clean sand SPT values corrected for the percentage of fine contents (FC). A chart developed based on the above equation is shown in Figure A.2. For the case of sand with fines, Youd et al. (2001) proposed the correlation to compute equivalent clean sand $\left(N_{1}\right)_{60 c s}$ based on $\left(N_{1}\right)_{60}$ for clean sand. The correction factors are as follows

$$
\left(N_{1}\right)_{60 c s}=\alpha+\beta\left(N_{1}\right)_{60}
$$

where $\alpha$ and $\beta$ are calculated as 


$$
\begin{gathered}
\alpha=\left\{\begin{array}{cc}
0 & \text { for } F C \leq 5 \% \\
\exp \left[1.76-\left(190 / F C^{2}\right)\right] & \text { for } 5<F C<35 \% \\
5.0 & \text { for } F C \geq 35 \%
\end{array}\right. \\
\beta=\left\{\begin{array}{cc}
1.0 & \text { for } F C \leq 5 \% \\
{\left[0.99+\left(\mathrm{FC}^{1.5} / 1000\right)\right]} & \text { for } 5<F C<35 \% \\
1.2 & \text { for } F C \geq 35 \%
\end{array}\right.
\end{gathered}
$$

The above equation of CRR is only applicable for $\left(\mathrm{N}_{1}\right)_{60 \mathrm{cs}}<30$, as recommended by Youd et al. (2001) because soils with $\left(\mathrm{N}_{1}\right)_{60 \mathrm{cs}} \geq 30$ are considered to be non-liquefiable.

Idriss and Boulanger (2008) presented the CRR relationship from work initially proposed by Idriss and Boulanger (2004) for clean sand and shown in the equation below. The graph of the equation is shown in Figure A.3

$$
C R R_{7.5,1 \text { atm }}=\exp \left[\frac{\left(N_{1}\right)_{60 c s}}{14.1}+\left(\frac{\left(N_{1}\right)_{60 c s}}{126}\right)^{2}-\left(\frac{\left(N_{1}\right)_{60 c s}}{126}\right)^{3}+\left(\frac{\left(N_{1}\right)_{60 c s}}{126}\right)^{4}-2.8\right]
$$

The fine content correction factor to compute the equivalent clean sand is given as

$$
\begin{aligned}
\left(N_{1}\right)_{60 c s} & =\left(N_{1}\right)_{60}+\Delta\left(N_{1}\right)_{60} \\
\Delta\left(N_{1}\right)_{60} & =\exp \left(1.63+\frac{9.7}{F C}-\left(\frac{15.7}{F C}\right)^{2}\right)
\end{aligned}
$$

\section{Estimation of Magnitude Scaling Factor(MSF)}

CRR depends on the number of loading cycles, which strongly correlates with earthquake magnitude (Seed et al. 1975). The $M S F$ is used to adjust the $C R R_{7.5,1}$ atm to account for different magnitude earthquakes that can occur at a specific site Different researchers have proposed different relationships for MSF.

Youd et al. (2001) recommended the lower bound of MSF as

$$
M S F=\frac{10^{2.24}}{M_{w}^{2.56}}
$$


Idriss and Boulanger (2008) recommended the relationship originally developed by Idriss (1999) with the following relationship;

$$
M S F=6.9 \exp \left(\frac{-M}{4}\right)-0.058 \leq 1.8
$$

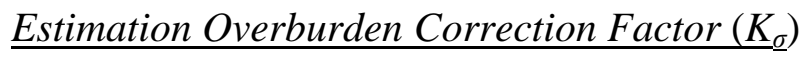

The overburden correction factor $\left(K_{\sigma}\right)$ is used to adjust the $C R R$ for effective overburden stress at different depths. Effective stress in the soil is a function of depth and CRR of sand depends on the effective stress. Thus, the liquefaction resistance of the same sand would be different at different depths. To be consistent the CRR values are corrected for the overburden stress.

Youd et al. (2001) recommended the $K_{\sigma}$ for engineering practice based on the work of Hynes and Olsen (1999). The proposed relationship is

$$
K_{\sigma}=\left(\sigma_{v o}^{\prime} / P_{a}\right)^{(f-1)} \leq 1.0
$$

where $f$ is an exponent that is a function of site conditions including relative density $\left(D_{r}\right)$, stress history, aging, and overconsolidation ratio $\left(f=0.7-0.8\right.$ for $D_{r}=40-60 \%$ and $f=0.6-0.7$ for $D_{r}=60-80 \%$ ), and $P_{a}$ is the atmospheric pressure measured in the same units as $\sigma^{\prime}{ }_{v o .}$

Idriss and Boulanger (2008) adopted the procedure to compute $K_{\sigma}$ from Idriss and Boulanger (2004) with the following relationships;

$$
\begin{aligned}
& K_{\sigma}=1-C_{\sigma} \ln \left(\frac{\sigma_{v o}^{\prime}}{P_{a}}\right) \leq 1.1 \\
& C_{\sigma}=\frac{1}{18.9-2.55 \sqrt{\left(N_{1}\right)_{60}}} \leq 0.3
\end{aligned}
$$

where $(N 1)_{60 c s}$ is the equivalent clean sand SPT values corrected for the percentage of fine contents (FC), $\sigma^{\prime}{ }_{v o}$ is the effective stress at given depth, and $P_{a}$ is the atmospheric pressure measured in the same units as $\sigma^{\prime}{ }_{v o}$. 


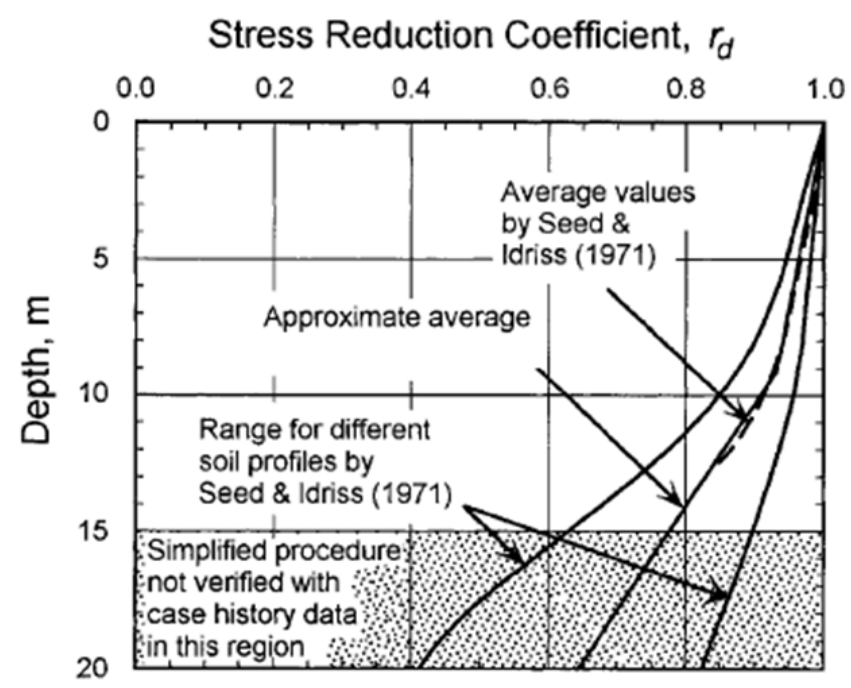

Figure A.1: Range of $r_{d}$ values for different soil profiles by Seed and Idriss (1971) together with the approximate average value predicted by equation A.3 (Youd et al. 2001)

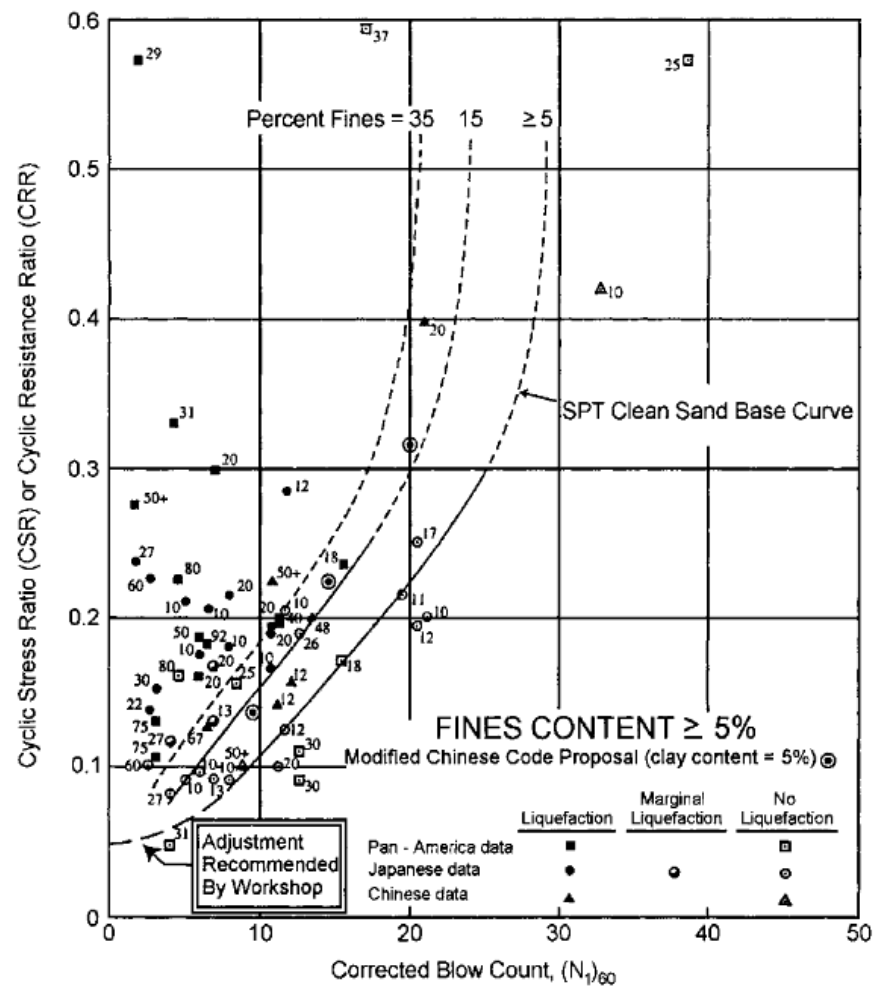

Figure A.2: SPT Clean-Sand Base Curve for Magnitude 7.5 Earthquakes (Youd et al. 2001; Seed et al. 1985) 


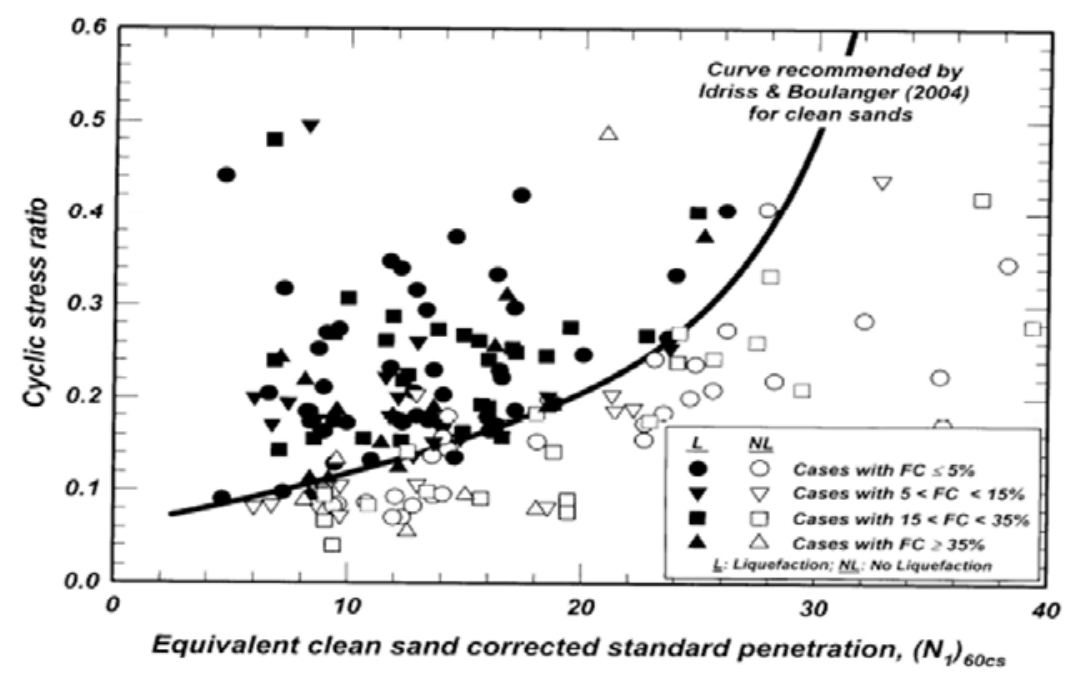

Figure A.3: CRR for $M=7.5$ and $\sigma_{v c}^{\prime}=1$ atm proposed by Idriss and Boulanger (2008)

\section{$\underline{\text { References }}$}

Cetin, K.O., Seed, R.B., Kiureghain, A.D., Tokimatsu, K., Harder, L.F., Kayen, R.E., Moss, R.E.S. (2004). “Standard Penetration Test-Based Probabilistic and Deterministic Assesment of Seismic Soil Liquefaction Potential.” Journal of Geotechnical and Geoenvironmental Engineering, ASCE, Vol. 130, No. 12, Dec. pp. 1314-1340.

Golesorkhi, R. (1989). "Factors Influencing the Computational Determination of EarthquakeInduced Shear Stresses in Sandy Soils, Ph.D. thesis, University of California at Berkeley, 395 pp.

Hynes, M.E., and Olsen, R.S. (1999). “Influence of Confining Stress on Liquefaction Resistance.” Proc., International Workshop on Phys. And Mech. of Soil Liquefaction, Balkema, Rotterdam, Netherlands, pp. 145-152.

Idriss, I.M. (1999). “An Update of the Seed-Idriss Simplified Procedure for Evaluating Liquefaction Potential.” Proc., TRB Workshop on New Approaches to Liquefaction, Publication No. FHWA-RD-99-165, Federal Highway Administration, January.

Idriss, I.M., and Boulanger, R.W. (2004). "Semi-empirical Procedures for Evaluating Liquefaction Potential During Earthquakes.” Proc. 11th International Conference on Soil 
Dynamics and Earthquake Engineering, and 3rd International Conference on Earthquake Engineering, Vol 1, pp. 32-56.

Idriss, I.M., and Boulanger, R.W. (2008). “Soil Liquefaction During Earthquakes”, Earthquake Engineering Research Institute, Oakland, CA.

Seed, H.B., Idriss, I.M., Makdisi, F., and Banerjee, N. (1975). "Representation of Irregular Stress Time Histories by Equivalent Uniform Stress Series in Liquefaction Analyses.” Report No. EERC 75-29, Earthquake Engineering Research Center, University of California at Berkeley, CA, October.

Seed, H.B., Tokimatsu, K., Harder, L.F., and Chung, R.M. (1985). "The Influence of SPT procedures in soil liquefaction resistance evaluations.” Journal of Geotechnical and Geoenvironmental Engineering, ASCE, Vol. 111, No. 12, pp. 1425-1445.

Stewart, J.P., Liu, A.H., and Choi, Y. (2003). Amplification factors for spectral acceleration in tectonically active regions,” Bulletin of the Seismological Society of America, 93(1), 332352. 


\section{APPENDIX-B \\ Residual Strength of Liquefied Soil}

One of the most severe effects of liquefaction is the loss of soil shear strength, which ultimately causes instability in the ground deformation under static loading alone (i.e., after the earthquake shaking). When the shear strength of liquefied soil is not sufficient to maintain stability, flow slide occurs, which can involve a large volume of soil and produce very large soil deformation. Bridges foundations resting on soils involved in flow slides can lead to complete damage of entire superstructure. Therefore, estimating the residual shear strength $\left(S_{r}\right)$ of liquefied soil should be considered when assessing the post-liquefaction performance of a bridge foundation.

Over the past three decades, several researchers have proposed empirical relationships for estimating the in-situ $S_{r}$ of liquefied sand by back-analyses of liquefaction flow slides. The pioneering work of back-analysis of liquefaction flow slides to estimate the $S_{\mathrm{r}}$ was first carried out by Seed (1987). Since then, several researchers have modified the method (e.g., Seed and Harder 1990, Stark and Mesri 1992, Olsen and Stark 2002, Idriss and Boulanger 2008). Seed and Harder (1990) provides an estimation of $S_{r}$ in residual strength, as shown in Figure B.1 whereas Olsen and Stark (2002) [Figure B.2], Idriss and Boulanger (2008) [Figure B.3], provide the estimation of $S_{r}$ in terms of overburden stress normalized by residual strength. Recently, Kramer (2008) proposed a new hybrid model based on the work of Kramer and Wang (2007) to estimate the $S_{r}$ in terms of strength normalized by atmospheric pressure.

The Kramer (2008) method to compute the residual strength is

$$
S_{r}=\exp \left(-8.444+0.109\left(N_{1}\right)_{60}+5.379\left(\frac{\sigma_{v}^{\prime}}{1 a t m}\right)^{0.1}\right)
$$

where $S_{r}$ is in terms of atmospheric pressure. In this model, fine corrections are not performed.

In literature, no consensus has been met for estimating the residual strength of the liquefied soil. Different procedures available in literature (e.g., Seed and Harder 1990, Stark and Mesri 1992, Olsen and Stark 2002, Idriss and Boulanger 2008) estimate the residual strength of liquefied soil with significant uncertainty (as shown in Figures B.1-B.3). Therefore, in practice 
all procedures are recommended to use in estimating the residual strength of the liquefied soil and based on engineering judgment appropriate weightage factor should be applied different methods.

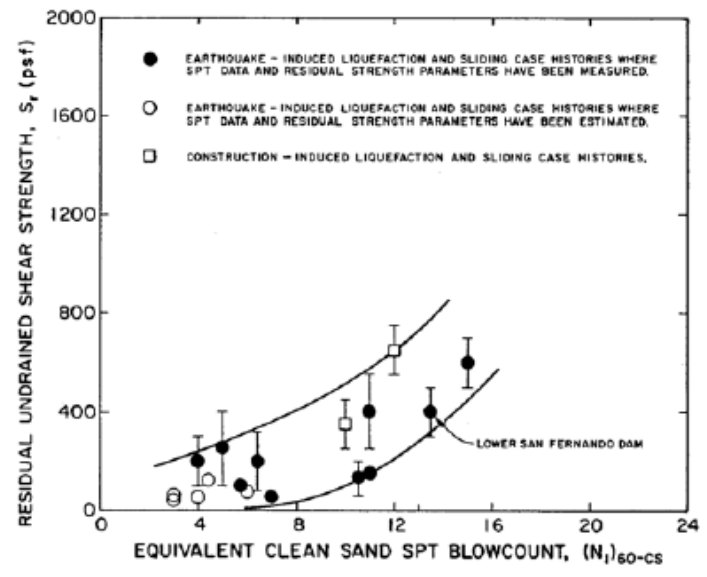

Figure B.1: Estimation of residual strength from SPT resistance (Seed and Harder, 1990)

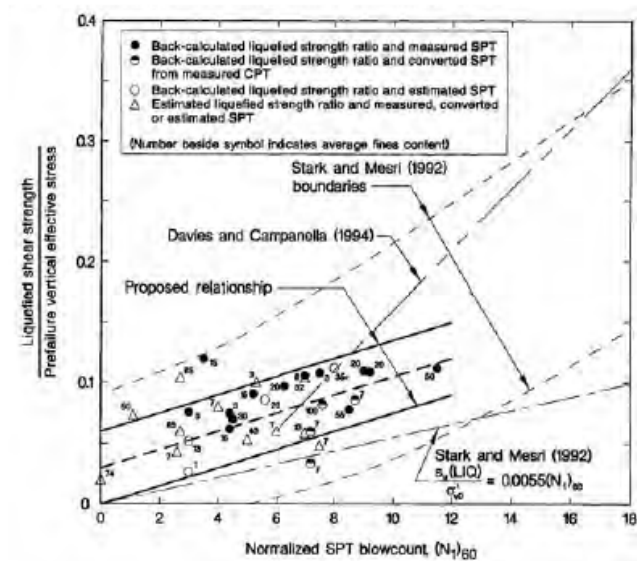

Figure B.2: Estimation of normalized residual strength from SPT resistance (Olson and Stark 2002) 


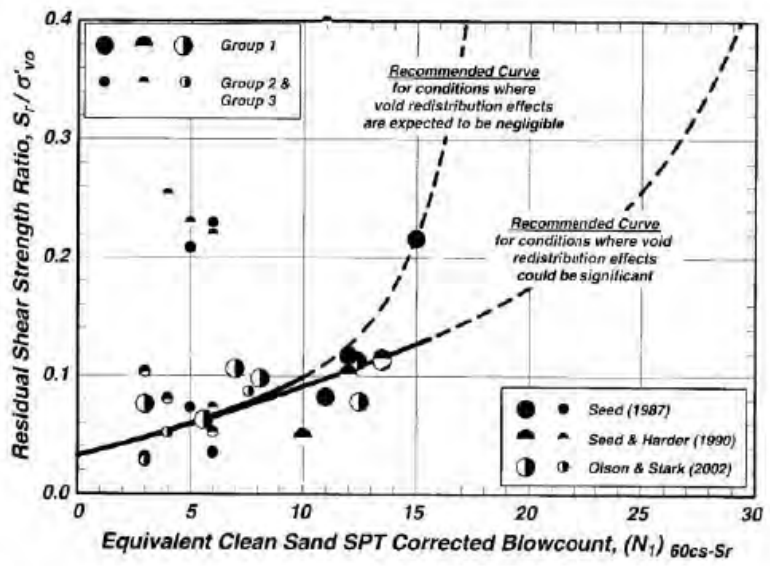

Figure B.3: Estimation of normalized residual strength from SPT resistance (Idriss and Boulanger 2008)

\section{$\underline{\text { References }}$}

Idriss, I.M., and Boulanger, R.W. (2008). “Soil Liquefaction During Earthquakes”, Earthquake Engineering Research Institute, Oakland, CA.

Kramer. S.L. and Wang, C.-H. (2007). "Estimation of the residual strength of liquefied soil, in preparation.

Olsen, S.M. and Stark, T.D. (2002). "Liquefied strength ratio from liquefaction flow failure case histories.” Canadian Geotechnical Journal, Vol. 39, pp. 629-647.

Seed, H.B. (1987). “Design Problems in Soil Liquefaction.” Journal of Geotechnical Engineering. 113(8), 827-845.

Seed, R.B., and Harder, L.F. (1990). “SPT- Bases Analysis of Cyclic Pore Pressure Generation and Undrained Residual Strength.” Proc., of the H.B. Seed Memorial Symposium, Vol. 2, 351-376.

Stark, T.D., and Mesri, G. (1992). "Undrained shear strength of liquefied sands for stability analysis.” Journal of Geotechnical Engineering Division, ASCE, Vol. 118, No. 11, pp. 17271747 


\section{APPENDIX-C \\ Estimating Lateral Spreading Displacement}

Liquefaction induced-lateral spreading can occur in gently sloping ground and in the vicinity of natural and cut slopes. It is crucial to determine the amount of lateral spreading, particularly for the design of bridge foundations. However, predicting the level of ground movement due to liquefaction is very complex and difficult. The magnitude of the displacement within lateral spreads depends upon local topography, soil stratigraphy, material properties, and ground motion. A number of different procedures are proposed in the past by several researchers, ranging from empirical correlation to nonlinear site response analyses. For routine engineering practice, simplified displacement procedures are commonly used.

The most common procedures to estimate the lateral spreading are based on estimated shear strain potential (e.g., Shamoto et al. 1998, Zhang et al. 2004, Faris et al. 2006, Idriss and Boulanger 2008) and Newmark sliding block (e.g., Lin and Whitman 1983, Kramer and Smith 1997, Bray and Travasarou 2007). The shear strain potential approach is most applicable to conditions where the ground surface is a gentle slope and the ground displacement is typically the result of distributed shear. On the other hand, the Newmark sliding block based procedure is applicable to the conditions where the failure surface is reasonably predictable. It is noted that all the procedures predict different values of lateral spread with quite large uncertainty. Therefore, cautions and engineering judgment are required in using the methods available in the literature.

\section{Estimated Shear Strain Potentials}

The Idriss and Boulanger (2008) procedure is used to estimate the lateral displacement due to liquefaction. In this method, the lateral spreading displacement or lateral displacement index $(L D I)$ is calculated by integrating maximum shear strain within a liquefiable layer over the thickness of the liquefaction layers as 


$$
L D I=\int_{0}^{Z_{\max }} \gamma_{\max } d z
$$

where $Z_{\max }$ is the depth of the liquefiable layer, $\gamma_{\max }$ is the maximum shear strain during undrained cyclic loading, which can be computed as

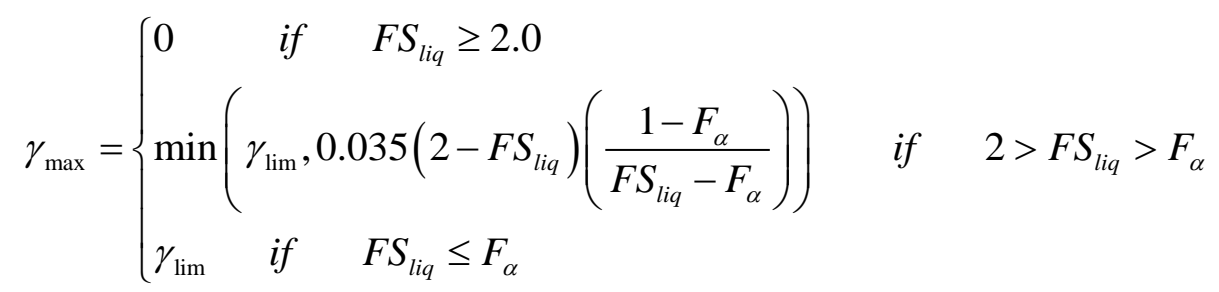

where

$$
\begin{aligned}
& \gamma_{\lim }=1.859\left(1.1-\sqrt{\frac{(N 1) 60 c s}{46}}\right)^{3} \geq 0 \\
& F_{\alpha}=0.032+0.69 \sqrt{\left(N_{1}\right)_{60 c s}}-0.13\left(N_{1}\right)_{60 c s}
\end{aligned}
$$

$\gamma_{\max }$ is the limiting shear strain for the lateral spreading, $F S_{\text {liq }}$ is the factor of safety against liquefaction, and (N1) 60 cs is SPT values for corrected fine contents.

\section{Newmark Sliding Block}

In the Newmark sliding block method, the soil mass is assumed to slide incrementally when the shaking-induced inertial forces cause the total shear stress to exceed the available shear resistance. The inertial force causing the yielding (onset of the sliding) of the mass is described by the yield acceleration coefficient $\left(k_{y}\right)$, which is given by the inertial force at yield divided by the slide mass. In routine engineering work, $k_{y}$ can be obtained by conducting slope stability analysis of the ground profile by which entails incrementally increasing the horizontal acceleration until the factor of safety becomes unity. For slope stability analysis, the strength of the liquefiable soil is replaced with its liquefied residual strength $\left(S_{r}\right)$. 
Bray and Travasarou (2007) developed an empirical relationship to estimate the ground deformation, which was based on a very large set of ground motion records and nonlinear deformable sliding block model. The model proposed by Bray and Travasarou incorporated different parameters such as design earthquake magnitude $\left(M_{w}\right), k_{y}$, and pseudo-spectral acceleration (PSA) at the fundamental period of the sliding mass as a ground motion input parameter If the sliding mass is assumed to be Newmark rigid block, peak ground acceleration (PGA) can be used in estimating the lateral displacement by replacing the PSA. The correlation provided by Bray and Travasarou (2007) for the Newmark rigid block case can be written as

$$
\begin{aligned}
\boldsymbol{D}(\mathrm{cm}) & =\operatorname{Exp}\left[-0.22-2.83 \ln \left(k_{y}\right)-0.333\left(\ln \left(k_{y}\right)\right)^{2}+0.566 \ln \left(k_{y}\right) \ln (P G A)\right. \\
& \left.+3.04 \ln (P G A)-0.244(\ln (P G A))^{2}+0.278\left(M_{w}-7\right)\right]
\end{aligned}
$$

\section{$\underline{\text { References }}$}

Bray, J.D., and Travasarou, T. (2007). "Simplified procedure for estimating earthquake-induced deviatoric slope displacements." Journal of Geotechnical and Environmental Engineering, 133(4): 381-392.

Idriss, I.M., and Boulanger, R.W. (2008). “Soil Liquefaction During Earthquakes”, Earthquake Engineering Research Institute, Oakland, CA.

Shamoto Y., Zhang J. and Tokimatsu K. (1998), "New charts for predicting large residual postliquefaction ground deformation," Soil Dynamics and Earthquake Engineering, Vol. 17, February 18, pp 427-438.

Zhang G., Robertson K. P. and Brachman I. W. R. (2004), "Estimating liquefaction-induced lateral displacements using the standard penetration test or cone penetration test," Journal of Geotechnical and Geoenvironmental Engineering, Vol 130, No. 8, August 1, pp 861-871

Lin, J.S., Whitman, R.V.(1983). "Decoupling approximation to the evaluation of earthquakeinduced plastic slip in earth dams.” Earthquake Engineering and Structural Dynamics 11, 667-678. 


\section{APPENDIX-D \\ Estimating p-y Curve for Pile Cap}

As recommended in CALTRANS (2011) guidelines, different passive failure scenarios have to be considered for non-liquefied crust layer. There are two possible scenarios for the failure of the crust layer as shown in Figure D.1. The ultimate crustal load, $P_{u l t}$, is then calculated from both cases and the minimum value between these two is taken as the controlling condition. In Case A, a log-spiral based passive pressure is applied to the face of the pile cap. This passive pressure is combined with the lateral resistance provided by the portion of the pile length that extends through the crust. A side force on the pile cap is added to the passive resistance. On the other hand, case B assumes that the pile cap, soil crust beneath the pile cap, and piles within the crust act as a composite block. This block is loaded by a Rankine passive pressure and the side force is developed over the full height of the block. Rankine passive pressure is assumed in this case because the weak liquefied layer directly beneath the composite block cannot transfer the stresses required to develop the deeper log-spiral failure surface that is generated by wall face friction. More detailed information can be found in CALTRANS (2011).
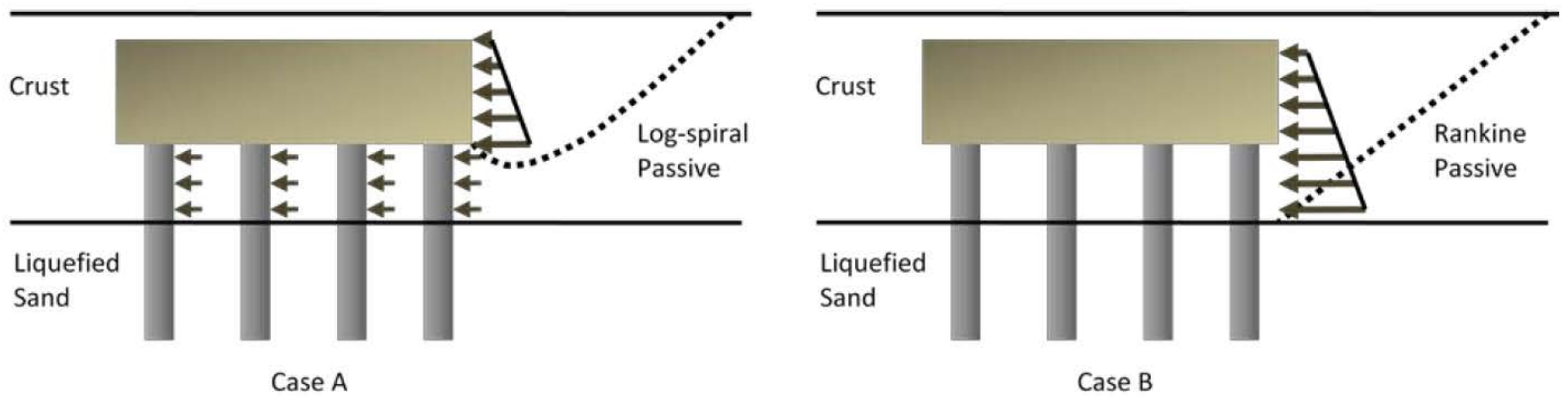

Figure D.1: Possible failure wedges for crust overlain in liquefiable soil under group piles (CALTRANS 2011)

The $p-y$ curves for the pile cap are developed using the same procedure recommended in the CALTRANS (2011). For convenience, all the expressions available in CALTRANS (2011) 
guidelines for computing $p$-y curves for pile caps are listed in this Appendix. The variables used in the expression are defined in Figure D.2.

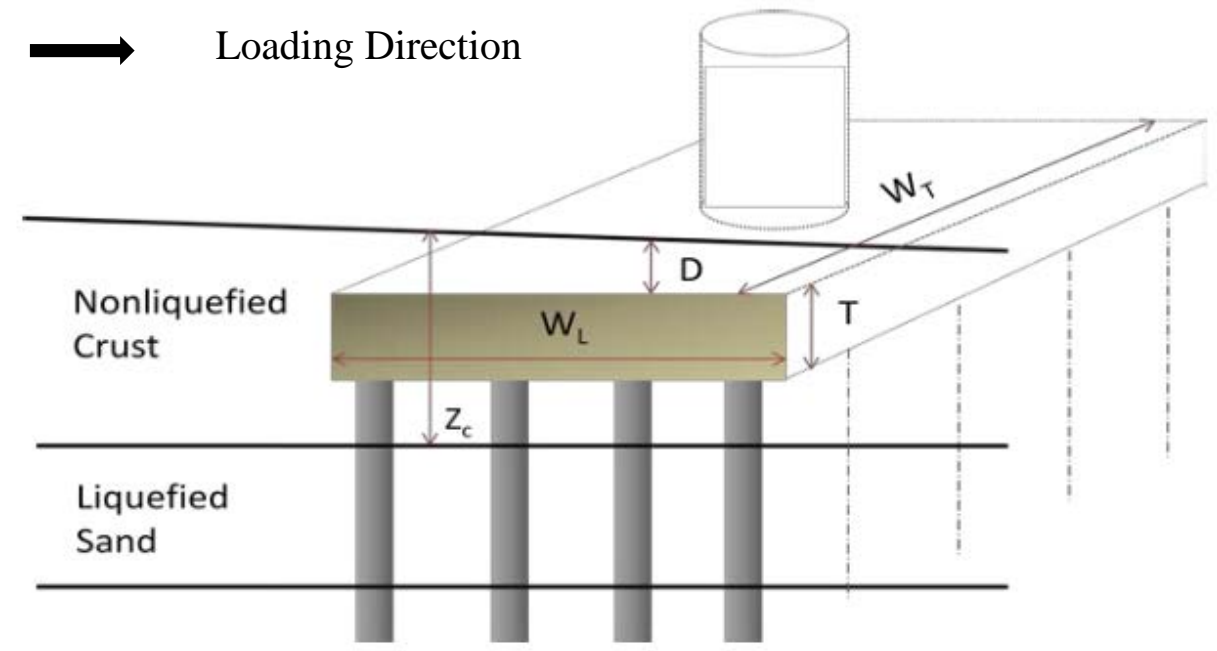

Figure D.2: Description of the variables used in calculation (CALTRANS 2011)

\section{Case A}

For case A, the ultimate load can be calculated as

$$
F_{U L T-A}=F_{P A S S I V E-A}+F_{P I L E S-A}+F_{\text {SIDES-A }}
$$

\section{$\underline{\text { FASSIVE-A }}$}

where, $\mathrm{F}_{\text {PASSIVE-A }}$ is computed depending upon the type of soil in the crust layer given below. The passive force of the cohesive soil is estimated using the expression provided by CALTRANS (2011)

$$
F_{\text {PASSIVE }}=\left\{\begin{array}{l}
\left(\overline{\sigma_{v}^{\prime}} K_{p}+2 c^{\prime} \sqrt{K_{p}}\right)(T)\left(W_{T}\right)\left(k_{w}\right) \quad \text { for cohesion-friction (c- } \phi \text { ) soil } \\
\left(4+\frac{\gamma(D+T)}{c}+\frac{D+T}{4 W_{T}}+2 \alpha\right) c W_{T} \frac{(D+T)}{2} \text { for cohesive (c) soil only }
\end{array}\right.
$$


where, $\sigma^{\prime}{ }_{v}$ is the vertical effective stress, $c$ is the undrained shear strength, $D$ is the depth of pile cap from ground surface, $W_{T}$ is the width of the pile cap, $Z_{c}$ is the depth of the crust layer from ground surface, $k_{w}$ is an adjustment factor for a wedge shape failure surface obtained from Ovesen (1964) and Brinch Hansen (1966), $\alpha$ is the adhesive factor, and $K_{p}$ is coefficient of passive earth pressure. For cohesive clay, CALTRANS (2011) adopted the expression for passive resistance developed by Mokwa and Duncan (2000). The factors $k_{w}$ and $K_{p}$ are computed as

$$
\begin{aligned}
& k_{w}=1+\left(K_{p}-K_{a}\right)^{\frac{2}{3}}\left(1.1\left(1-\frac{T}{D+T}\right)^{4}+\frac{1.6 B}{1+\frac{5 W_{T}}{T}}+\frac{0.4\left(K_{p}-K_{a}\right)\left(1-\frac{T}{D+T}\right)^{3} B^{2}}{1+\frac{0.05 W_{T}}{T}}\right) \\
& K_{p-\text { (log spiral })}= \begin{cases}\operatorname{Tan}^{2}\left(45+\frac{\phi}{2}\right)\left(1+\left(0.8152-0.0545 \phi+0.001771 \phi^{2}\right) \frac{\delta}{\phi}-0.15\left(\frac{\delta}{\phi}\right)^{2}\right) \phi>0 \\
1 \quad \text { for } \phi=0\end{cases}
\end{aligned}
$$

where $\mathrm{B}$ is based on spacing of multiple anchor block ( $B=1$ for a single pile cap) $K_{a}$ is the active earth pressure coefficient and computed as

$$
K_{a}=\operatorname{Tan}^{2}\left(45-\frac{\phi}{2}\right)
$$

\section{$\underline{F_{P I L E S-A}}$}

The ultimate lateral resistance of the pile can be estimated using API (1993) as

For sand material

$$
p_{\text {ult-Pile }}=\left(C_{1} \bar{H}+C_{2} B\right) \gamma \bar{H} \quad \text { for sand }
$$


where $H$ is the average pile depth in the crust, $B$ is the pile diameter, $\gamma$ is the effect unit weight of the soil, and $C_{1}$ and $C_{2}$ are coefficients computed as

$$
\left.\begin{array}{l}
C_{1}=3.42-0.295 \phi+0.00819 \phi^{2} \\
C_{2}=0.99-0.0294 \phi+0.00289 \phi^{2}
\end{array}\right\} \text { for } 20 \leq \phi \leq 40
$$

The expressions for $C_{1}$ and $C_{2}$ are developed by the CALTRANS (2011) based on the chart provided in API (1993).

For the clay material, the ultimate resistance of soil per unit length varies from 3c to 9c depending upon depth of the clay layer.

$$
p_{\text {ult-Pile }}=\left\{\begin{array}{lr}
\left(3 c+\gamma^{\prime} X+J c \frac{X}{B}\right) B & \text { for } \mathrm{X}<\mathrm{X}_{\mathrm{R}} \\
9 c B & \text { for } X \geq X_{R}
\end{array}\right.
$$

where $\mathrm{X}$ is depth below ground surface, $\mathrm{J}$ is the empirical constant varies from 0.25 to 0.5 , c is the cohesion, B is the diameter of pile, $\gamma$ is the effect unit weight of the soil, and $\mathrm{X}_{\mathrm{R}}$ is the depth below the ground surface and estimated as

$$
X_{R}=\frac{6 B}{\frac{\gamma^{\prime} B}{c}+J}
$$

Then, using the $p_{\text {ult-pile }}$ of a single pile, the total force can be calculated as

$$
F_{\text {PILES }-A}=n \cdot G R F \cdot p_{\text {ult-pile }} \cdot L_{c}
$$

where $n$ is the number of piles in the group, GRF is the group reduction factor, and $L_{c}$ is the length of the pile extended through the crust.

\section{$\underline{\text { FIDES-A }_{\text {SI }}}$}

Based on the centrifuge tests, Boulanger et al. (2003) found that the interface friction along the side and base of the pile cap are significant and recommended to considered in the design. The base friction force in the pile cap can be ignored when a gap between the 
pile cap base and underlain soil layer is likely to occur (Boulanger et al. 2003). Therefore, engineering judgment would be required whether to consider the base friction force or not. In this report, the base friction is ignored assuming that the sufficient gap will be developed during liquefaction and only side friction force is considered. The load on the side of the pile cap can be estimated as

$$
F_{\text {SIDES }}= \begin{cases}2\left(\sigma_{v}^{\prime} \operatorname{Tan}(\delta)+\alpha c^{\prime}\right)(T) W_{L} & \text { for } c-\phi \text { soil } \\ 2 \alpha c(T) W_{L} & \text { for } c \text { soil }\end{cases}
$$

All the variables are described earlier in the above sections.

\section{Case B}

For the case B, the ultimate load can be calculated as

$$
F_{U L T-B}=F_{P A S S I V E-B}+F_{S I D E S-B}
$$

In this case, the piles and the cap act as a composite block. The calculation of $F_{\text {PASSIVE-B }}$ is similar to that of case A except the $K_{p}$ is calculated from Rankine earth pressure theory as

$$
K_{p}=\operatorname{Tan}^{2}\left(45+\frac{\phi}{2}\right)
$$

Also, $F_{S I D E S-B}$ can be calculated from the above equation by replacing pile cap thickness, $T$, by the thickness of the composite block (pile cap-pile-soil) (i.e., $Z_{c}-D$ ).

Once the passive pressure is computed from above two methods, the lower passive earth pressure force controls failure of the non-liquefied crust layer.

\section{$\underline{\text { Determination of } \Delta_{M A X}}$}

To develop the $p-y$ curves for the cap, the maximum relative displacement to fully mobilize passive resistance against the bent-wall needs to be determined. As described in the CALTRANS (2011) design example, $\Delta_{M A X}$ is determined with following relationship 


$$
\Delta_{\text {MAX }}=(T)\left(0.05+0.45 f_{\text {depth }} f_{\text {width }}\right)
$$

where $f_{\text {depth }}$ and $f_{\text {width }}$ are adjustment factors to account the effect of finite thickness and width of pile cap and calculated as

$$
\begin{aligned}
& f_{\text {depth }}=e^{-3\left(\frac{Z_{c}-D}{T}-1\right)} \\
& f_{\text {width }}=\frac{1}{\left(\frac{10}{\frac{W_{T}}{T}+4}\right)^{4}+1}
\end{aligned}
$$

Finally, the lateral force $(p)$ for the $p-y$ curve of the pile cap can be computed by distributing the passive force (computed above) along the depth of the non-liquefied crust layer. Then, the idealized $p$ - $y$ curve for the pile cap can be computed as shown in Figure D.3.

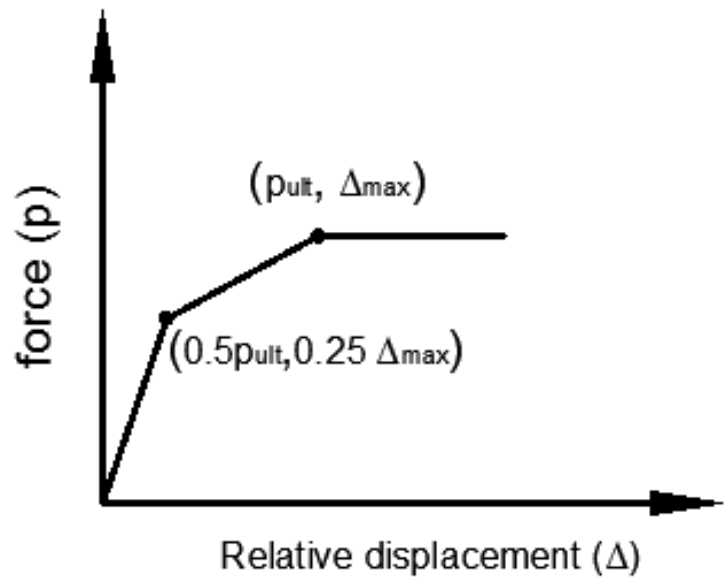

Figure D.3: Idealized $p$-y curve for pile cap)

\section{$\underline{\text { References }}$}

American Petroleum Institute (API) (1993) "Recommended Practice for Planning, Designing and Constructing Fixed Offshore Platforms - Working Stress Design”, RP 2A-WSD, 20th Edition, Washington, DC. 
Boulanger, R. W., Kutter, B. L., Brandenberg, S. J., Singh, P., and Chang, D. (2003). "Pile Foundations in Liquefied and Laterally Spreading Ground during Earthquakes: Centrifuge Experiments and Analyses.” Report UCD/CGM-03/01, Center for Geotechnical Modeling, Univ. of California, Davis, CA.

Mokwa, R.L., and Duncan, J.M., (2002). "Investigation of the Resistance of Pile Caps and Integral Abutments to Lateral Loading”, Final Contract Report, Virginia Transportation Research Council, Charlottesville, VA

Ovesen, N. K. (1964). “Anchor slabs, calculation methods and model tests.” Bulletin No. 16, The Danish Geotechnical Institute, Copenhagen.

Hansen, J. B. (1966). “ Resistance of a Rectangular Anchor Slab.” Bulletin No. 21, The Danish Geotechnical Institute, Copenhagen. 


\section{APPENDIX-E Research Work Publications}

The following are the publications from the research on stone columns and DSM grids funded jointly by ODOT, OTREC, PEER, and Hayward-Baker Inc. Copies of these publications have been submitted to ODOT under separate cover.

Rayamajhi, D., Nguyen, T.V., Ashford, S.A., Boulanger, R.W., Lu, J., Elgamal, A., and Shao, L. (2013). "Simplified Design Method for Discrete Columns in Liquefiable Soils Based on Numerical Analyses," ASCE, Journal of Geotechnical and Geoenvironmental Engineering, 10 pages. (In press)

Nguyen, T.V., Rayamajhi, D., Ashford, S.A., Boulanger, R.W., Lu, J., Elgamal, A., and Shao, L. (2013). "Design of DSM Grids for Liquefaction Remediation." ASCE, Journal of Geotechnical and Geoenvironmental Engineering, 10 pages (In press)

Rayamajhi, D., Nguyen, T.V., Ashford, S.A., Boulanger, R.W., Lu, J., Elgamal, A., and Shao, L. (2012). "Effect of discrete columns on shear stress distribution in liquefiable soil," Geocongress 2012: State of the Art and Practice of Geotechnical Engineering, ASCE, Reston, VA. pp. 1908-1917.

Nguyen, T.V., Rayamajhi, D., Ashford, S.A., Boulanger, R.W., Lu, J., Elgamal, A., and Shao, L. (2012). "Effect of DSM grids on shear stress distribution in liquefiable soil," Geocongress 2012: State of the Art and Practice of Geotechnical Engineering, ASCE, Reston, VA. pp. 1948-1957. 



\section{GOTREC \\ AND EDUCATION CONSORTIUM}

P.O. Box 751

Portland, OR 97207

OTREC is dedicated to stimulating and conducting collaborative multi-disciplinary research on multi-modal surface transportation issues, educating a diverse array of current practitioners and future leaders in the transportation field, and encouraging implementation of relevant research results. 